


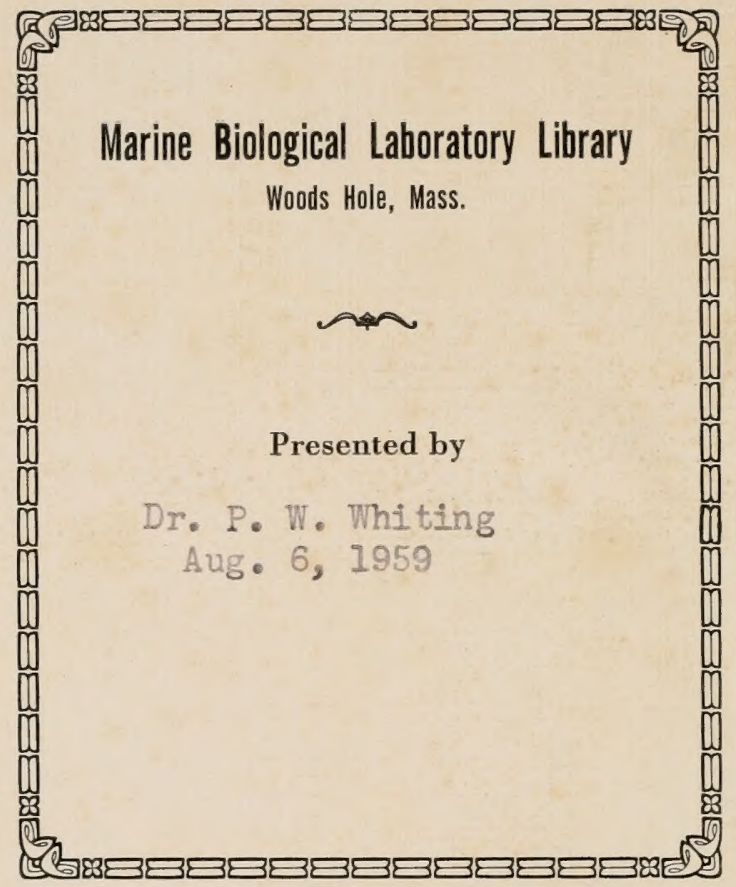


4.50

P. W. Whiting Univ. of Perm. 



\section{THE ANTHOCYANIN PIGMENTS OF PLANTS}




\section{CAMBRIDGE UNIVERSITY PRESS}

C. F. CLAY, Manager

ILañon: FETTER LANE, E.C.

造ointurgh: Io० PRINCES STREET

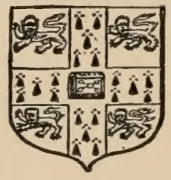

Petor Zgork: G. P. PUTNAM'S SONS

Bombay, Calcutta and fftadras: MACMILLAN AND CO., Ltd

Toronto: J. M. DENT AND SONS, LTD.

$\tau$ okno: THE MARUZEN-KABUSHIKI-KAISHA 


\section{THE}

\section{ANTHOCYANIN PIGMENTS OF PLANTS}

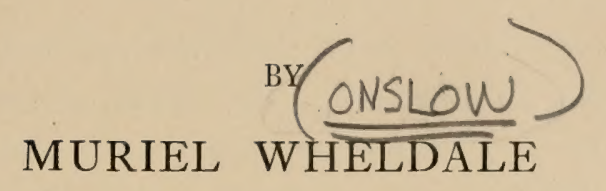

Fellow of Newnham College, Cambridge, and formerly Research Student at the John Innes Horticultural Institution, Merton, Surrey

Cambridge :

at the University Press

I 9 I 6 



\section{PREFACE}

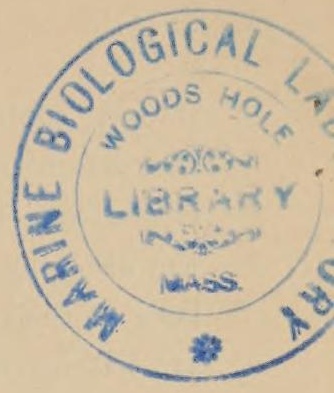

$\mathrm{O}^{\mathrm{F}}$ the various investigations which have been made upon the anthocyanin pigments along botanical, chemical and genetical lines, no complete account has yet been written. It is the object of this book to provide such an account of the work which has been done. Although it is only within recent years that any very notable researches have been made upon these pigments, I feel that consideration is due to the many workers who, in the course of the last century, have paved the way for their successors. This I offer as my excuse for dwelling in the following pages upon some researches which are now almost entirely superseded.

I do not pretend to claim that anthocyanins will ever have a great significance from the strictly botanical point of view. Even when the obscurity which surrounds their physiological functions is elucidated, it can scarcely be expected that they will have a significance in the least comparable, for instance, to that of chlorophyll. From the strictly chemical standpoint, as chemical compounds, they have a certain interest. But I believe it to be in connection with problems of inheritance that they will provide a great and interesting field for research.

We have now ample evidence that the development in plants of many and various anthocyanin pigments affords an almost unlimited supply of material for the study of inheritance. It must also be patent to those who have been working on the subject of Genetics that a proper conception of the inter-relationships and inheritance of the manifold characters of animals and plants will be greatly facilitated by a knowledge of the chemical substances and reactions of which these characters are largely the outward expression. Herein lies the 
interest connected with anthocyanin pigments. For we have now, on the one hand, satisfactory methods for the isolation, analyses and determination of the constitutional formulae of these pigments. On the other hand, we have the Mendelian methods for determining the laws of their inheritance. By a combination of the two methods, we are within reasonable distance of being able to express some of the phenomena of inheritance in terms of chemical composition and structure. There can be little doubt that exact information of this kind must be at least helpful for the true understanding of the vital and important subject of Heredity.

In the preparation of this book I gratefully acknowledge the help afforded to me by many of my friends, and I am especially indebted to Mrs E. A. Newell Arber for kindly correcting my proofs.

To Professor Bateson, F.R.S., my sincerest thanks are due for the great interest he has taken in much of my work which is included in this volume, and for his many valuable suggestions and criticisms. I wish also to record my thanks to Dr F. F. Blackman, F.R.S., for criticisms and assistance with the manuscript.

I regret that some of the most recent and important work on the subject has not been altogether successfully incorporated in the book, owing to the difficulty I have experienced in learning, at the earliest opportunity, of the results obtained by scientists in other countries during this and the preceding year.

M. W.

CAMbridge,

May, 1916. 


\title{
CONTENTS
}

\author{
PART I
}

\section{GENERAL ACCOUNT}

\section{Chapter I. Introductory}

Definition of Anthocyanin Pigments-Early Observations of Boyle and Nehemiah Grew-Main Lines of Investigation-DistributionInfluence of Outside Factors-Functions-Chemical Nature-Connection with Genetics-Factors for Anthocyanin Formation in Antirrhinum, Lathyrus and Matthiola-Origin of Anthocyanins from Flavones-Hypothesis as to Mode of Formation-Formation by OxidationFormation by Reduction-Chemical Interpretation of Mendelian Factors.

Chapter II. The Morphological Distribution of Antho-

CYANINS . . . . . . . . .

Wideness of Distribution in Higher Plants-Presence in Lower Plants-Distribution in Leaves-In Stems and Petioles-In Young Leaves and Shoots-In Young Leaves in Tropics-Autumnal Coloration-Development in Injured Organs-Formation in Winter-In Drought-In 'High Alpine Plants-In Halophytes-In Red-leaved Varieties-In Petals, Perianths and Inflorescences-In Fruits-In Seeds-In Roots-In Parasites and Saprophytes.

Chapter III. The Histological Distribution of AnthoCYANIVS

Condition of Pigment in Cell-sap-In Crystalline and Solid Form in Cells--List of Species in which Solid and Crystalline Anthocyanin has been noted-Artificial Formation of Anthocyanin Bodies-Various Deposits Coloured with Anthocyanin-Classification of Distribution of Anthocyanin in Leaf-tissues-In Petals-Combination of Pigments in Petals-Localisation of Anthocyanin in Various Natural Orders. 
Chapter IV. The Properties and Reactions of Antho-

Question as to Number of Pigments Included in the Group-Crystalline Form-Solubilities-Qualitative Reactions-With Alkalies-With Acids-With Lead Acetate-Reactions of Accompanying SubstancesWeigert's Classification-Wilstätter's Interpretation of Colour Reactions -Reactions with Iron Salts-With Sodium Bisulphite-Action of Nascent Hydrogen-Compounds with Acids-Spectroscopic Examination-Willstätter's Groups of Anthocyanins.

\section{Chapter V. The Isolation and Constitution of Antho- CYANINS}

General Views-Special Cases of Isolation and Analyses-Flower-pigment of Centaurea by Morot-Pigment of Wine by Glénard-Pigment of Coleus Leaves by Church-Flower-pigment of Rosa by Senier-Pigment of Wine by Gautier-Pigment of Grapes by Heise-Pigment of Red Vine Leaves by Gautier-Flower-pigment of Althaea by GlanFruit-pigment of Pilberry by Heise-Flower-pigment of Pelargonium by Griffiths-Flower-pigment of Althaea and Pelargonium by GrafeFlower-pigment of Antirrhinum by Wheldale-Flower-pigment of Cen taurea, Delphinium, Malva, Pelargonium and Rosa and Fruit-pigment of Vaccinium by Willstätter-Constitution of Anthocyanins.

Chapter VI. Physiological Conditions and Factors InFLUENCING THE FORMATION OF ANTHOCYANINS

Connection with Photosynthesis-Connection with Accumulation of Synthetic Products-Formation as Result of Mechanical Injury and Injury by Insects and Fungi-As Result of Decortication-Formation in Alpine Plants-In Parasites-Connection with Nutrition-Effect of Temperature - Effect of Light-Varying Results in Flowers, Stems, Leaves and Roots-Connection with Presence of Oxygen-Analyses of Gaseous Exchange in Red Leaves-Effect of Drought-Effect of Sugarfeeding-Experiments of Overton, Katić and Gertz-Summary of Results.

Chapter VII. Reactions involved in the Formation of AnTHOCYanins

Early Views as to Origin of Anthocyanin from Chlorophyll and Tannins -Palladin's Respiration Pigments-Oxidase Reactions in Plants-Hypothesis as to Origin from Flavones-Criticism of Hypothesis-Evidence for Hypothesis from Results of Cross-breeding-From Analogous Reactions - From Connection with Photosynthesis - From Gaseous Exchange in Red Leaves-Work of Keeble, Armstrong and Jones on Oxidases and Anthocyanins-Formation of Artificial AnthocyaninResults of Combes and Willstätter. 


\section{Chapter VIII. The Significance of Anthocyanins}

Biological Significance-Physiological Significance-Light-screen Hypothesis-Pringshein's and Reinke's Results on Bleaching of Chlorophyll-Kerner's Suggestions as to Uses of Anthocyanin-Evidence of Engelmann and Reinke against Light-screen Hypothesis-Pick's Hypothesis of Protection of Diastase-Stahl's Hypothesis of Conversion of Light Rays into Heat-Ewart's Criticism of Stahl-Investigation of Internal Temperature of Red Leaves by Smith.

\section{PART II}

\section{ANTHOCYANINS AND GENETICS}

Classes of Variation

Kinds of Colour-variation-Different Series in Different GeneraVariation to Albinism-Red Varieties-Soluble- and Plastid-Yellow Varieties-The Cream Variety-The Blue Variety-Deep and Pale Varieties-Coloured Varieties from Inbibited Types-Variation in Nature.

Details of Cases of Mendelian Inheritance in ColourVARIETIES

Details of Colour-inheritance in more Important Cases-In Antirrhinum, Lathyrus, Matthiola, Mirabilis, Phaseolus, Pisum, Primula, Solanum, Zea, and many others.

Connection of Flower-colour with the Presence of Anthocyanin in Vegetative Organs, Fruits and Seeds

Examples from Cases Investigated.

Heterozygous Forms . . . . . . .

Examples from Cases Investigated.

Colour Factors in Reduplication Series . . . .

Phenomenon of Coupling and Repulsion in Lathyrus and PrimulaColour-factors involved.

Pattern in Colour Variation . . . . . .

Examples from Cases Investigated-Differentiation of Kinds of Pattern. 
Striped Varieties and Bud-vartation

Occurrence of Striping in Various Genera-De Vries' Fversporting Varieties-Inheritance of Striping in Antirrhinum and Zea-Emerson's Explanation of Results-Comection between Striping and Bud-variation -Bud-variation due either to Mendelian Segregation or Somatic Mutation.

The Effect of Outside Factors on Colour-variation

Experiments of Molisch on Hydrangea-Cultures with Iron and Aluminium salts-Effect of Insolation on Flower-colour.

Connection Between Colour and other Plant Characters

Colour and Vigour-Colour and Flavour-Colour and Hoariness in Matthiola-Colour and Hooded Structure in Lathyrus.

The Chemical In'terpretation of Factors for FlowerCOLOUR . . . . . . . . . .

Chemical Interpretation of Factors in Antirrhinum-Reversible Reactions-Chemistry of Different Kinds of Factors-Interpretation of Reddening, Blueing, Diluting and Deepening Factors.

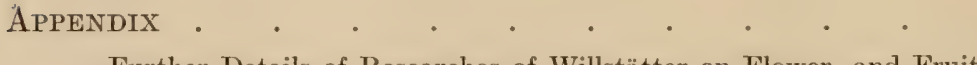

Further Details of Researches of Willstätter on Flower- and Fruitpigments-Analyses of Pigments of Colour-varieties-Bearing on Mendelian Problems.

BiBLIOGRAPHY

INDEX 


\section{PART I}

\section{GENERAL ACCOUNT}


Idea 27. And first, their Colours; where, with respect to several Plants and Parts, they are more Changeable; as Red, in Flowers; or Constant, as Green in Leaves. Which, with respect to several Ages of one Part, are more fading, as Green in Fruits; or durable, as Yellow in Flowers. In what Parts more Single, as always in the Seed; or more Compounded, as in the Flower; and in what Plants more especially, as in Pancy. Which proper to Plants that have such a Taste or Smell, as both, in White Flowers, are usually less strong. To Plants that flower in such a Season, as a Yellow Flower, I think, chiefly, to Spring Plants. And to Plants that are natural to such a Soil or Seat, as to Water-plants, more usually, a white Flower. What, amongst all Colours, more Common to Plants, as Green; or more Rare, as Black. And what all these Varieties of Colours are upon Cullivation, but chiefly, in their natural Soil. To observe also with their superficial Colours, those within: so the Roots of Docks, are Yellow; of Bistort, Red; of Avens, Purple; but of most, White. Where the Inward, and Superficial Colours agree; as in Leaves; or vary, as in the other Parts frequently. And in what manner they are Situated; some universally spreading, others running only along with the Vessels, as in the Leaves of Red Dock, and the Flowers of Wood-Sorrel.

From Nehemiah Grew's Anatomy of Plants, with an Idea of a Philosophical History of Plants. 1682. 


\section{PART I \\ GENERAL ACCOUNT}

\section{CHAPTER I}

\section{INTRODUCTORY}

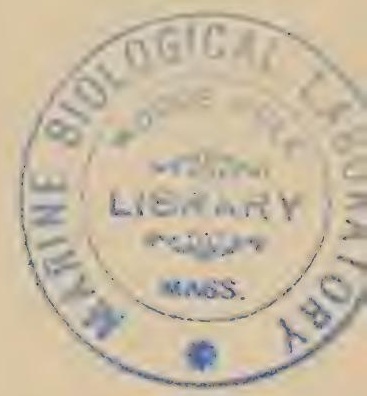

The subject of the anthocyanin pigments of plants has received considerable attention, yet the results are comparatively slight. Such colouring matters have sometimes been spoken of as soluble pigments, since they are in a state of solution in the cell-sap, as contrasted with those which are in some way bound up with the structure of organised protoplasmic bodies known as plastids. The innumerable shades of blue, purple, violet, mauve and magenta, and nearly all the reds, which appear in flowers, fruits, leaves and stems are due to anthocyanin pigments. On the other hand, green, and the large majority of orange and yellow colours, are in the form of plastid pigments. Other colours. again, notably some scarlets and orange-reds, browns and even black, are produced by the presence of both plastid and anthocyanin pigments together in the tissues.

For almost a hundred years botanists have employed one term to

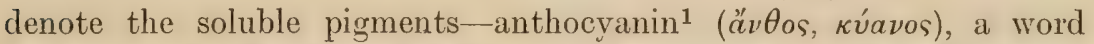
first coined by Marquart $(5)^{2}$ for these substances in 1835 and retained in the same sense to the present day; other rival terms, now obsolete, such as erythrophyll, cyanophyll and cyanin have also been used from time to time.

Vegetable pigments served as matter for investigation at a very early date, and the property which first attracted attention was their behaviour towards acids and bases, that is, the reddening by acids and the formation of green coloured products with a base. Thus, in 1664, in the Experiments and Considerations touching Colours of Roberi

1 In the present volume anthocyanin is largely used in the collective sense, that is as a term which we know to include a number of substances; sometimes however, when the context demands it, the plural form is used.

${ }^{2}$ Numbers in brackets refer to papers, etc., in the Bibliography at the end of the book, and such references are either entirely concerned with anthocyanins, or have some direct bearing upon them. References, on the contrary, in the foot-notes are not directly concerned with anthocyanins. 
Boyle (107), we find the following directions: "Take good Syrrup of Violets, Imprægnated with the Tincture of the flowers, drop a little of it upon a White Paper... and on this Liquor let fall two or three drops of Spirit either of Salt or Vinegar, or almost any other eminently Acid Liquor, \& upon the Mixture of these you shall find the Syrrup immediately turn'd Red,...But to improve the Experiment, let me add what has not...been hitherto observ'd,...namely, that if instead of Spirit of Salt, or that of Vinegar, you drop upon the Syrrup of Violets a little Oyl of Tartar per Deliquium, or the like quantity of Solution of Potashes, \& rubb them together with your finger, you shall find the Blew Colour of the Syrrup turn'd in a moment into a perfect Green."

And again in The Anatomy of Plants of 1682, Nehemiah Grew (1) tells us that "...Spirit of Harts Horn droped upon a Tincture of the Flower of Lark-heel \& Borage turn them to a verdegreese Green."

"Spirit of Sulphur on a Tincture of Violets turns it from Blew to a true Lacke, or midle Crimson."

"Spirit of Sulphur upon a Tinclure of Clove-July-Flowers makes a bright blood Red. Into the like Colour, it hightens a Tincture of Red Roses."

It is not clear from the writings of Boyle and Nehemiah Grew whether these authors considered the great variety of shades to be the expression of one or of many substances, though it is clear that Nehemiah Grew differentiated between red, blue and green pigments as regards their solubilities. For he says, "...The Liquors I made use of for this purpose, were three, sc. Oyl of Olives, Water, \& Spirit of Wine. The Water I used was from the Thames, because I could not procure any clear Rain Water, \& had not leasure at present to distill any. But next to this, that yields as little Salt, as any." The oil he found dissolved the green colour, "...But there is no Vegetable yet known which gives a true Red to Oyl, except Alkanet Root." This root "which immediately tinctures $O y l$ with a deeper Red, will not colour Water in the least. Next it is observable, That Wuter will take all the Colours of Plants in Infusion except a Green. So that as no Plant will by Infusion give a perfect Blew to $O y l$; so their is none, that I know of, which, by Infusion will give a perfect Green to Water ${ }^{1}$." Boyle, on the other hand, was evidently impressed by the uniformity of the acid

1 This is entirely in accordance with our present-day knowledge of the pigments. Chlorophyll, like all plastid pigments, is insoluble in water, but soluble in oil. The red, blue and purple anthocyanin pigments are soluble in water, but insoluble in oil. The red pigment of Alkanet root is not an anthocyanin and has quite different solubilities. 
and alkali reactions: "...it is somewhat surprizing to see,...how Differingly-colour'd Flowers, or Blossoms,...how remote soever their Colours be from Green, would in a moment pass into a deep Degree of that Colour, upon the Touch of an Alcalizate Liquor." The gradual evolution of the idea of the multiplicity of pigments included under anthocyanin can only be realised in a comprehensive survey of the subject.

After the preliminary and somewhat diffuse observations of the earliest scientists, there follows a period during which certain definite lines of investigation emerge, and it is practically to these lines that the chapters in this book correspond. It may not be out of place, however, to give a general account of the different phases and kinds of investigation showing how they have developed, and how they are related to each other in the complete history.

The above lines of investigation may be enumerated thus: the morphological and histological distribution of the pigments, the factors controlling their formation, their function, their chemical composition, their mode of origin, and lastly, the part they have played in heredity.

First let us consider their distribution. Contributions to this portion of the subject naturally formed a great part, though by no means the whole, of the earlier work on pigments, since it merely involved general observation and microscopical examination of petals and leaves. Various writers published full accounts of the pigments of flowers, fruits, leaves, etc., showing how some colours are due to plastid, others to soluble pigments, and others again are the result of the combination of both in the cells. As would be expected, this form of investigation has tended to diminish in later years for, the histological basis once laid down, the physiological, chemical and biochemical aspects have come to the front. Mention must be made, however, of the publications of Buscalioni \& Pollacci (17) in 1903 on the histological distribution of anthocyanin, and of a paper on similar lines read by Parkin (77) at the meeting of the British Association of the same year. Still later work of this kind is that of Gertz (19) which appeared in 1906; this author made a most thorough and systematic investigation of the occurrence of anthocyanin in representative genera of all natural orders, but the publication of his work in Swedish unfortunately restricts the circulation of his results.

The question of factors controlling anthocyanin formation is the next line of enquiry most convenient for consideration. The main factors concerned are light, temperature and nutrition. 
The matter of fundamental significance in all questions of factor control, and one which it will be well to understand before turning to the factors in detail, is the dependence of anthocyanin formation upon the supply of an initial product or chromogen, as it is called, from which the pigment arises. This substance, like all others in plant metabolism, ultimately depends for its existence on a supply of carbohydrates (sugars), the first products of synthesis in the plant. The relationship between anthocyanin formation and the presence of sugars in the tissues has provided an important subject for research. Overton $(333,334)$, in 1899 , first drew attention to its significance ${ }^{1}$; this botanist had noticed, while carrying out some experiments on osmosis, that culture of Hydrocharis Morsus-ranae in sugar solutions leads to greater production of anthocyanin in the leaves. Further experiments showed the phenomenon to be constant for quite a number of species when isolated leaves and twigs were fed on solutions of cane sugar, dextrose, laevulose and maltose. Repetition of experiments on these lines at later dates by Katić (354), Gertz (386) and others gave full confirmation to Overton's results. This discovery led Overton to the fairly obvious inference that possibly, in the normal plant, reddening of leaves, etc., is correlated with excess of sugar in the tissues, and he states that by tests upon red autumnal leaves he could detect more sugar in red than in green leaves.

More elaborate and conclusive work in this direction was commenced by Combes in 1909 and carried on in the following years. Combes $(374,385)$ had noted that decortication in some plants brings about a considerable development of anthocyanin in the leaves above the point of decortication. Analyses were made by him, not only of leaves reddened through this cause, but also of autumnal and other red leaves. In all cases he (207) claims to have shown that the red leaves contain greater quantities of sugars and glucosides than green ones from the same plant. From other, more general, phenomena, in addition to Combes's results, it may be safely inferred that an accumulation of such synthetic products as are manufactured in the leaves leads to production of anthocyanin. For example, we frequently find abnormal reddening of a single leaf on a plant otherwise in full vigour, and investigation almost invariably shows the reddening to be accompanied by injury, and the injury, whether it be due to mechanical cutting or breaking, or to the attacks of insects, will be found to

1 The connection between pigmentation and the presence of sugars was also pointed out in 1899 by Mirande (332) as a result of his investigations on the genus Cuscuta. 
affect those tissues which conduct away the synthetic products of the leaf.

There is little doubt that the chromogen of anthocyanin, in the form of a glucoside, is also manufactured in the leaves, and the whole trend of results goes to show that an enforced accumulation of this chromogen, together with sugars, by stoppage of the translocation current, leads to formation of anthocyanin in the leaf; and a similar result may arise from artificial feeding with sugars. To the more precise relationships between chromogen, anthocyanin and sugars attention will be given in a later chapter.

Thus it will be seen that in all problems connected with effects of temperature, light, etc., on anthocyanin formation, we are confronted with two distinct questions, i.e. the direct effect of light and temperature on the actual production of pigment, and the indirect effect of these factors on the supply of organic compounds from which the chromogen of anthocyanin is synthesised.

The relationship between pigment formation and light constitutes a problem to which there is no very satisfactory solution. Sachs $(269,271)$, Askenasy (282) and others have tried the obvious methods of growing plants in the dark with controls in the light, of darkening leaves while leaving inflorescences uncovered and so forth. The outcome of these researches, as weil as of several others, has been to show that in many cases, for example, in flowers of Tulipa, Hyacinthus, Iris and Crocus, anthocyanin develops equally well in the dark; in other cases, such as Pulmonaria, Antirrtinum, and Prunella, the development is feeble or absent. A general survey of anthocyanin distribution leaves us in no doubt that, as far as organs where anthocyanin may be expected to develop are concerned, the greatest production takes place in the most illuminated parts. But we have on the other hand not a few examples, of which the root of Beta is a good illustration, of development of pigment in total darkness. In the absence of fuller evidence, the most reasonable point of view is that the actual process of pigment formation may in itself be entirely independent of light, should the tissues contain sufficient reserve materials to supply the chromogen. But if there is a shortage of reserve materials, such as would arise from diminished photosynthesis, the anthocyanin may fail to appear from lack of chromogen.

The problem of the effect of temperature offers similar difficulties. Does the temperature influence the actual formation of pigment, or is it again an indirect cause, making itself felt only through its effects 
upon the supply of materials from which the pigment is synthesised? That low temperature favours pigment formation would seem to be demonstrated by autumnal coloration, and the winter reddening of leaves of Hedera, Ligustrum, Mahonia and other evergreens. Conversely, Overton (333) found in Hydrocharis, the higher the temperature, the less anthocyanin. Klebs (360) also notes that flowers of Campanula and Primula may be almost white in a hot-house, but the same individuals kept in the cold will bear coloured flowers. The consideration of temperature is perhaps more difficult than that of light; for low temperature, on the one hand, retards photosynthesis by which sugars are formed, but, on the other hand, it also retards growth, starch formation and probably translocation, thereby tending to raise the sugar contents of the tissues. High temperature, on the contrary, accelerates growth and respiration, and consequently prevents the accumulation of any excess of synthetic products.

An interesting application of these views upon light and temperature effects can be made in the case of Alpine flower coloration. The subject has been extensively studied by Gaston Bonnier (288, 289, $294,307,328)$, Flahault $(288,289,290,292)$ and others, and has had a great vogue with the writers on flower coloration in connection with insect pollination. The special features of the case are intensity of flower-colour and the formation of anthocyanin in the vegetative parts. Gaston Bonnier \& Flahault have compared individuals grown at heights of 2300 metres with individuals grown in the plains, and have found that the latter produce paler flowers and less anthocvanin in the leaves and stems. It seems most reasonable to suppose that these phenomena form a natural demonstration of some of the relationships which we have just been considering between colour and factors. High Alpine plants are stunted in growth, i.e. little material is expended vegetatively ; they are exposed by day to intense insolation while the night temperature is low. One may therefore suppose photosvnthesis to be very active, whereas translocation and growth are retarded, these being conditions which favour high sugar and chromogen concentrations in the tissues and resultant abundance of pigment.

The so-called functions of anthocyanin have provided material for another main line of research. Two essentially different types of function are readily distinguished, the biological and the physiological. The biological function is a subject which, in itself, needs extensive treatment, and does not lie within the scope of this book. It is solely connected with the attractive value of the coloured floral organs for 
pollination by insects, and the subsidiary question of the attractive value of ripe pigmented fruits for dispersal by birds. The relationship between flower-colour and entomophily has received great attention from botanists, and the whole matter is dealt with most thoroughly in Knuth's Handbook of Flower Pollination (426), which includes an excellent bibliography.

The physiological function is a very difficult and far less satisfactory matter. Several different functions of a physiological nature have been attributed to anthocyanin. One of the most famous is the screen theory, the idea of which was first based on work published in 1880 by Pringsheim, who showed that chlorophyll was bleached by intense light, but not if protected artificially by a red screen. Thus the view arose that anthocyanin might be protective in function, but experimental evidence does not altogether favour this hypothesis. For, in 1885, Reinke pointed out that it is those rays absorbed by chlorophyll which have the greatest destructive effect on chlorophyll, and Engelmann (394), in 1887, demonstrated that the absorption spectrum of anthocyanin is on the whole complementary to that of chlorophyll. Hence anthocyanin absorbs those rays which are least harmful to chlorophyll, and cannot therefore be said to provide an effective screen. A second suggestion, brought forward by Stahl (405) in 1896, and largely supported by him, is that anthocyanin absorbs certain of the sun's rays, and by converting them into heat, raises the temperature of the leaf, and this may serve to accelerate transpiration in difficult circumstances, as in damp regions of the tropics, or may protect leaves from low temperature as in Alpine regions. The chief points in favour of this hypothesis are the distribution of anthocyanin in leaves of shade-loving plants, and the fact, observed also by Stahl, and confirmed in 1909 by Smith (420), that the internal temperature of red leaves is greater than that of green.

The next line of investigation, the chemical composition of the pigments, is also difficult, and though spasmodically attacked from time to time, met with no very serious consideration till 1906. So intimately connected with its chemical composition that it can scarcely be considered separately, is the question of the mode of formation of anthocyanin, that is, the chemical reactions involved in the process. Closely connected also, though in a lesser degree, is the part played by anthocyanin pigments in heredity. It is proposed therefore to deal with these three lines of research more or less together.

As already pointed out, the reactions with acids and alkalies are the most obvious and striking chemical properties of anthocyanins, 
and they have helped to draw the attention of chemists to the subject; for much of the earlier chemical work on anthocyanin, notably of a group of French chemists (1800-1825), Braconnot (110), Payen \& Chevallier $(113,114,115)$ and Roux (116), centred round these reactions, especially in some cases round their rôle as indicators. But the idea of anthocyanin as an indicator was fuliy conceived long before 1807 by Robert Boyle (107). "When," he says, "we have a mind to examine, whether or no the Salt predominant in a Liquor or other Body, wherein 'tis Loose and Abundant, belong to the Tribe of Acid Salts or not... if such a Body turn the Syrrup of a Red or Reddish Purple Colour, it does for the most part argue the Body (especially if it be a distill'd Liquor) to abound with Acid Salt. But if the Syrrup be made Green, that argues the Predominant Salt to be of a Nature repugnant to that of the Tribe of Acids." After the reactions of anthocyanin with acids and alkalies, other reactions were noticed with iron salts and various reagents, many of which modify the colour as it is modified in nature. These reactions gave rise to views among some chemists, Fremy \& Cloëz (126) and Wigand (136), that natural blue, purple and red pigments are modifications of the same substance, brought about by the presence of other compounds in the cell-sap. But as analyses and investigations proceeded, the view of a certain multiplicity of pigments gained the ascendency.

One of the first actual analyses of anthocyanin was carried out in 1849 by Morot (122) who isolated the blue pigment of the Cornflower, and found it to contain carbon, hydrogen and oxygen, with nitrogen as impurity. Ten years later Glénard $(129,130)$ isolated the pigment of wine, found it also to contain carbon, hydrogen and oxygen, and gave it a percentage formula.

An early suggestion as to the chemical nature of anthocyanin and its mode of formation was that of Wigand (136) in 1862. This author suggested that anthocyanin arises by the oxidation of a colourless tannin-like chromogen, a substance widely distributed in plants and giving a green reaction with iron salts and a yellow reaction with alkalies. The same substance obviously had been noted at an earlier date by Filhol $(125,132)$ who observed it to be widely distributed, and maintained that the green coloration of anthocyanin with alkalies was due to a mixture of a blue anthocyanin reaction plus the yellow reaction of these accompanying substances; a view also held by Wiesner (135). The idea of the formation of anthocyanin from a tannin-like chromogen by oxidation was, from this time onward, generally accepted by botanists 
and chemists. It was, for instance, again (1878) suggested by Gautier (149) on the strength of isolation and analyses of the pigments of various wines. Later, further analyses of Vine pigments were made by Gautier (175) and other investigators, notably Heise (167), but their results were in no way concordant except in so far as they agreed that the pigment contained carbon, hydrogen and oxygen only. These were followed again by analyses of the pigment of Bilberry fruits by Heise (178).

In 1895 Weigert (179) made the first attempt at a classification of anthocyanins based upon their chemical reactions, and he differentiated two groups, the 'Weinroth' and the 'Ruibenroth,' according to the behaviour of the pigment to acids, alkalies and lead acetate solution. The Riibenroth group is however a small group of anthocyanin pigments of the orders Phytolaccaceae, Amarantaceae and Portulacaceae of the Centrospermae; the Weinroth group, including the greater number of anthocyanins, still remained undifferentiated.

In 1906 Grafe (197) published the results of some careful analyses of the pigment of the Hollyhock (Althaea rosea), followed by further analyses (222) of the pigment of scarlet Pelargonium flowers in 1911. In this publication Grafe clearly expresses the view that anthocyanin must be regarded as a general term for a number of substances, having similar properties and reactions, but differing somewhat from each other in chemical constitution.

Meanwhile from the year 1900 and onwards, the study of anthocyanin pigments gained a new impetus through their connection with the inheritance of colour in plants. For many experiments on the crossbreeding of colour-varieties were commenced about this time by Bateson, Punnett, Saunders $(475,487)$ and others working on the lines of Mendelian inheritance. Two of the first plants to be used for this purpose were the Stock (Matthiola) and the Sweet Pea (Lathyrus). Both these plants have a number of varieties, and although it is doubtful whether we know the character of the original type in Matthiola, it is fairly certain that the original wild Sweet Pea resembled the form known as 'Purple Invincible' which has a chocolate standard and purplish-blue alae. We now know from the teachings of heredity that all the coloured varieties of Sweet Pea, and probably many of those of Stocks, have arisen through the loss of certain factors from the type, and by recrossing selected varieties, the type can be obtained again, the process being known as the phenomenon of 'reversion to type.' One of the most striking results (496) of the experiments on Sweet Peas and Stocks 
was the phenomenon of the production of a plant bearing purple flowers (in the Sweet Pea the original type) by crossing two white-flowered strains. From such results the hypothesis arose, that red colour (anthocyanin) is due to the presence of two factors, $C$ and $R$, in the plant, the loss of either factor resulting in an albino. A third factor, $B$, by its presence modifies the red colour to a blue or purple, but unless $C$ and $R$ are also both present in the plant, $B$ is without effect. Hence white plants of known parentage can be selected which are carrying $C, R$, or $B$ only, or $C B$, or $R B$.

Such a discovery is not only highly important in its connection with heredity, but it also provides us with well-defined material for the solution of the problem as to what chemical processes are involved in anthocyanin formation. Conversely, these processes once discovered, we should also be provided with a chemical interpretation of the Mendelian factors for flower-colour.

The problem was first attacked by the author in 1909. The plant selected for investigation was Antirrhinum majus, since the inheritance of the flower-colour of this species had already been worked out (514, 535) during the years 1903-9, and confirmed independently by Baur (536). Antirrtinum majus presents a case of singular interest. In this species (as in Matthiola and Lathyrus) two white varieties, or more strictly two varieties which are albinos as regards anthocyanin, when crossed together, produce the magenta pigment (anthocyanin) characteristic of the type; but, whereas in Lathyrus and Matthiola the two whites producing a purple are identical in appearance, the two albinos in Antirrhinum can be distinguished at sight. One, which is known as ivory, is ivory-white in colour, the other, the true white, is dead white. These two varieties must obviously, between them, contain the chemical substances, or the power to produce the chemical substances, essential to the formation of anthocyanin.

The first clue to the solution was provided by the difference in the action of ammonia vapour on the two flowers. The ivory exposed to ammonia turns bright yellow whereas the white is practically unaltered. It has been mentioned previously that Filhol (125), and in fact several of the earlier workers on plant pigments, had noted the occurrence of colourless substances in the plant which gave a bright yellow reaction with alkalies. Moreover, a tentative suggestion was made by Bidgood (18) some years ago (1905) in the Journal of the Royal Horticultural Society, that these substances were the colouring matters known as flavones. Reference to the work of A. G. Perkin on the flavones provided the 
information that these substances have a general distribution in nature, and had attracted the notice of chemists on account of their value as vegetable dyes. Some flavones have been found in many species, others in but one, or a few, though this appearance of restriction may be due to lack of information. All members of the group are yellow substances differing slightly from each other in their chemical composition. In the plant they frequently occur as glucosides, in which condition their colour is much paler, and their solubility greater, than in the free state. All give intense yellow or orange-yellow coloration with alkalies, and green or brown coloration with iron salts. This information led the author to conclude that the widely distributed substances, occurring in all plant tissues which give the yellow reaction to ammonia vapour, are flavones, and that the pigment of the ivory variety of Antirrhinum is of the same nature. The white variety of Antirrhinum is without the flavone, and must contain some substance capable of action on the flavone to form anthocyanin.

At about this period a series of papers were published by Palladin $(203,210)$ setting forth what is known as the theory of 'Atmungspigmente.' Broadly speaking, Palladin supposes plants to contain chromogens which are capable of being oxidised by enzymes to pigments which in turn pass on oxygen to respirable substances in the plant. Among the 'Atmungspigmente' Palladin includes anthocyanin.

Palladin's conception, together with the evidence provided by Antirrhinum, led the author $(212,217,226)$ to bring forward the hypothesis that anthocyanin is formed from a flavone by the action of an oxidising enzyme or oxidase. Thus the formation of magenta pigment in Antirrtinum would be brought about by the action of an oxidase produced by the white variety upon the flavone present in the ivory. Likewise in every plant anthocyanin would be formed by the action of an oxidase upon a flavone, and just as the flavones are a class of substances having similar properties, though showing some variety in structure, the anthocyanins also would have properties in common as a class but would, many of them, differ somewhat in chemical structure.

The oxidase hypothesis of anthocyanin formation has been taken up by Keeble \& Armstrong $(230,231)$. These authors invented a microchemical method for testing for oxidases in plant tissues, and applied the method chiefly to colour varieties of the Chinese Primrose (Primula sinensis), a plant largely used for Mendelian experiments. By means of their test they discovered that oxidases in Primula are chiefly confined to the epidermis and the bundle sheaths, both regions where 
anthocyanin also is localised. A further point of interest was discovered in connection with certain varieties of Primula known as dominant whites. These varieties have pigment (anthocyanin) in stems and leaves, though the flowers are white, and they are regarded, from their behaviour in crossing, as coloured forms in which the flower-colour is inhibited by some factor present in the plant. Keeble \& Armstrong were able to show that flowers of these varieties gave ordinarily no oxidase reaction, but after treatment with certain reagents, the inhibitor was removed, and the oxidase reaction appeared in the petals. On the other hand, they found that the true albinos in Primula gave the oxidase reactions as well as the coloured varieties. Hence to make the hypothesis fit the case of Primula, they were obliged to assume the lack of colour in the true albino to be due to lack of chromogen, an assumption which has never been verified.

Meanwhile the author's investigations on Antirrhinum proceeded on the lines of isolation and analysis (244) of the pigments of the colourvarieties. These pigments were prepared on as large a scale as possible by making water extracts of the flowers, precipitating the pigment as a lead salt by lead acetate, and again decomposing the salt with sulphuric acid. Fiitered from lead sulphate, the pigment was obtained in dilute acid solution. It had been previously ascertained that anthocyanins are largely present in the plant in combination with sugar as glucosides. On boiling with acid, the glucoside is hydrolysed and the pigment, which is less soluble than the glucoside, separates out. This method was adopted for obtaining the pigment from the acid solution. The pigment of the ivory variety of Antirrhinum was identified by Bassett and the author with apigenin, a flavone of known constitution occurring in Parsley (Apium Petroselinum). Of the anthocyanin-containing varieties of Antirrhinum there are two, red and magenta, analogous to the red and purple varieties of Lathyrus and Matthiola. Analyses were made (254) of the red and magenta pigments prepared separately from several different varieties, and the results were concordant. In the case of both pigments the percentage of oxygen was greater than that in the flavone apigenin. Determination of the molecular weights of the red and magenta pigments, though not obtained to a high degree of accuracy, indicated that the molecules of anthocyanin are considerably larger than those of apigenin.

The conclusions drawn by Bassett and the author (25.) were that in Antirrhinum the anthocyanins are derived from the flavone apigenin by oxidation, accompanied by condensation, possibly of two flavone 
molecules, or possibly of a flavone molecule with other aromatic substances present in the plant.

The problem of anthocyanin formation has quite recently received a most important series of contributions by Willstätter and a number of his co-workers. In 1913 Willstätter $(245)$ first published some results on anthocyanins in general and the anthocyanin of the Cornflower (Centaurea Cyanus) in particular. Willstätter states that all natural anthocyanins are present in the plant in the condition of glucosides, and that many of them, moreover, including the anthocyanin of Centaurea, are very unstable in water solution, and readily change in these circumstances to a colourless isomer. The change can be prevented by adding certain neutral salts, and also acids, to the pigment solution. The explanation, according to Willstätter, of these phenomena lies in the fact that anthocyanin is an oxonium compound having a quinonoid structure and containing tetravalent oxygen. The quinonoid structure is rendered stable by the formation of oxonium salts with acids or with neutral salts, such as sodium nitrate and sodium chloride. The pigment itself, in the neutral state, is purple in colour, and has the structure of an inner oxonium salt. With acids it forms red oxonium salts, and with alkalies blue salts, the position of the metal being undetermined. More recently Willstätter $(256,257)$ has published the results of the isolation and analyses of a number of other anthocyanins in addition to that of Centaurea, i.e. from the flowers of Delphinium, scarlet Pelargonium, Mallow and Hollyhock; from Grapes also, and the fruits of the Bilberry and Cranberry. In every case crystalline salts were obtained with hydrochloric acid, and from the analyses of these salts Willstätter obtained a series of percentage formulae for his anthocyanins. Compared with the percentage formulae of the known flavones, he found that each anthocyanin could be derived theoretically from a flavone by loss of an atom of oxygen, i.e. by reduction.

The view of anthocyanin formation by reduction from a flavone has received support from a series of phenomena of a very curious and interesting nature, which were first observed by Keeble \& Armstrong (240), and of which an account was published in June, 1913. These observations were concerned with the effect of reducing plant extracts with nascent hydrogen. A number of flowers, among which were the yellow Wallflower, Daffodil, Crocus and Polyanthus, were extracted with alcohol, and the extracts acidified and treated with zinc dust. Filtered from the zinc, and exposed to air, the solution develops a red colour which changes to green on addition of alkali. 
Thus Keeble \& Armstrong were led to believe that they had made artificial anthocyanin, and that preliminary reduction and subsequent oxidation are the essential processes of anthocyanin formation. In November of the same year, a note was published by Combes (234) in the Comptes Rendus, giving a record of practically the same observation though in a much more complete form. By treating with sodium amalgam the acid alcohol solution of a yellowish crystalline substance which he had extracted from Ampelopsis leaves, he obtained a fine purple pigment which crystallised in needles. This pigment, he claims, on the basis of chemical and physical properties, to be identical with crystals of natural anthocyanin from the same plant; but no analyses are included. In addition, he found (235) that natural anthocyanin, after treatment with hydrogen peroxide, gives a yellow product identical with the natural yellow substance from which he started.

Combes believes that these results entirely revolutionise our ideas on anthocyanin formation. Thus he says: "La production expérimentale d'une anthocyane peut donc être considérée comme réalisée. Ce résultat permet d'entrevoir comme très proche la solution du problème de la formation des pigments anthocyaniques posé depuis p̉lus de 120 ans et qui fut abordé par de nombreux physiologistes. On sait que dans toutes les hypothèses relatives à cette question, formulées depuis 1825 , la pigmentation a toujours été considérée comme un phénomène d'oxydation; cette opinion ne peut plus être soutenue, puisqu'il apparaît que l'anthocyane des feuilles rouges prend naissance lorsque le composé correspondant contenu dans les feuilles vertes est soumis à l'hydrogène naissant, c'est-ì-dire dans un milieu qui est au contraire réducteur."

The essential difference between Keeble \& Armstrong's results and those of Combes can be explained in the following way. The purple pigment, as indeed the natural anthocyanin, will become colourless on powerful reduction, though it regains its colour in air. Thus Kecble \& Armstrong's reduction was carried beyond the preliminary formation of pigment to the colourless stage, the colour returning again on exposure to air, whereas Combes's product was not reduced so far.

The production of a purple colour on reduction of flavone with sodium amalgam had been known to chemists some time before the work of Keeble \& Armstrong. The almost universal distribution of flavones naturally explains the appearance of the colour on reduction of many plant extracts. The crystalline yellow product used by Combes is undoubtedly a flavone also, as will be seen on referring to 
his original communications. The question at issue is whether these purple pigments are anthocyanins.

The problem of the artificial formation of anthocyanin has been attacked by Willstätter (257) also in 191t. By treating quercetin, according to Combes's method, Willstätter in the same way obtains a purple pigment, the bulk of which he finds is unstable in acid solution on boiling, though a certain amount of colour remains after this process. The product unstable to heat is, in Willstätter's opinion, not a true anthocyanin, but he maintains that the small amount of stable product left after heating is, when isolated, identical with the anthocyanin (cyanidin) of the Cornflower. Thus Willstätter regards this reaction as giving further confirmation to his views of the reduction hypothesis of pigment formation, which we have seen to be based upon analyses of the anthocyanins he has isolated, and to be practically a proof of his suggested constitution of anthocyanin. To quote from his latest paper: "Die Bildung von Cyanidin aus Quercetin hat zweifache Bedeutung. Es ist dadurch eine Synthese von Cyanidin ausgeführt, da das Quercetin selbst vor zehn Jahren von St. von Kostanecki... synthetisch dargestellt worden ist. Ferner wird durch diese Umwandlung die Konstitutionsformel des Cyanidins bewiesen."

The author has been so far unable to bring the results provided by the case of Antirrlinum into line with Willstätter's views. In Antirrhinum the chromogen is, without doubt, apigenin; when treated with nascent hydrogen this flavone produces a purple pigment, yet the latter does not resemble the natural anthocyanin of Antirrhinum, either in composition or properties (255).

Thus we have arrived at the last stage in the subject as far as investigation has gone. There is little doubt that anthocyanins are derived from flavones, but further evidence is needed of the actual chemical connection between these two classes of substances. Neither of Willstätter's two lines of proof is beyond criticism. Actual comparison of the percentage formula of any anthocyanin with any flavone, though significant, does not prove their relationship in nature, by reduction or otherwise, unless we know that they occur together. For since the known flavones can be arranged in a series, each member of which differs from the others by an atom of oxygen, any anthocyanin might be either an oxidation or a reduction product of a flavone. What is really necessary is to know which flavone accompanies the anthocyanin in a number of plants. At present Antirrhinum alone supplies us with information, for as far as it is possible to judge, 
Willstätter did not in any case extract the flavone accompanying the anthocyanin he isolated. The second line of evidence, i.e. the formation of a very small quantity of a purple pigment, as a by-product, during the reduction of a large quantity of quercetin, might quite well involve reactions other than reduction.

Willstätter's views ${ }^{1}$ provide a very different interpretation of Mendelian factors for coloration from that of Keeble \& Armstrong and the author. For we must suppose, should Willstätter be correct, that the factors for colour are the chromogen (flavone) and the power to reduce the chromogen with a complete change of structure from the pyrone grouping of the flavone to the quinonoid structure of anthocyanin. A purple flower would contain the pigment in its neutral form; a reddening factor would be the power to produce acid cell-sap; conversely, a blue variety must have alkaline sap. Thus we have a reversion to the ideas of the earliest writers, and it is less easy to correlate such a view with the results of cross-breeding. But there is no doubt that Willstätter's researches, whether his interpretation prove to be the right one or not, have brought the whole problem of soluble pigments within measurable distance of explanation. Such a solution, moreover, will provide what is perhaps of greater importance, namely, a chemical basis for one series, at any rate, of Mendelian phenomena.

1 Sce also Appendix. 


\section{CHAPTER II}

\section{THE MORPHOLOGICAL DISTRIBUTION OF ANTHOCYANINS'}

It is a striking fact that anthocyanins are almost universally distributed. This is not fully realised until a systematic investigation is made, and then-it is seen how few plants are entirely without these pigments. Many plants may appear to the casual observer to be free from anthocyanin, but a closer examination generally reveals its presence, often only in minute quantity, in such places as the base of the stem, the petioles, bud-scales, bracts or even in some unexpected organ, as for instance, the anthers and stigma. Again, an abnormal condition of drought, or fungal attack, may cause its appearance when otherwise the healthy plant is green. A number of plants, moreover, only form anthocyanin in their young leaves at the beginning, or in their old leaves at the close, of the vegetative season, or pigment may develop shortly before the death of the whole plant. Reviewing the flowering plants as a whole, two orders present an anomaly with respect to the distribution of anthocyanin. The power to form anthocyanin seems to be absent, first, from the Cucurbitaceae, as far as it has been possible to ascertain, and secondly, from certain genera of the Amaryllidaceae (Leucojum, Galanthus, Ornithogalum and Narcissus). This observation is confirmed by Certz (19), who also adds to the list, Herniaria (Caryophyllaceae) and Chrysosplenium (Saxifragaceae), some species of Potamogeton, Eleocharis (Cyperaceae), Kniphofia, Aloe, Reseda, i.e. R. odorata and $R$. lutea, and Buxus. To the statement as regards $R$. odorata and $R$. lutea exception must be taken, since both these species form anthocyanin in their leaves under adverse conditions, such as are brought about by drought or injury.

The distribution of anthocyanin in the lower groups of plants has been investigated by Gertz (19). It appears in the young fronds of Osmunda regatis, of many species of Adiantum, of species of Doodia, Pellace and Davallia. Gertz also notes it in Blechnum and Azolla, and among the Gymnosperms, in the cones of Picea, Pinus and Larix. 
As regards the Angiosperms, the present chapter contains an enumeration of the organs in which anthocyanin is formed in the varying circumstances of plant life. Some authors have attempted to classify the appearance of anthocyanin into permanent and transitory or periodical, normal and abnormal, etc., ete., but the variety and complexity of the underlying physiological causes in each case render such classifications of little value. No distinctions of this kind are attempted in the following classification.

1. The leaves of the majority of plants are green; nevertheless, in many genera and species, anthocyanin is always present as a normal decelopment, and a complete series might be found ranging from plants whose leaves show a faint trace of anthocyanin to those whose leaves are more or less heavily pigmented. Some writers, notably Kerner (398), have pointed out that plants in which there is a considerable development of anthocyanin have often a special habitat. It would seem on the whole that this view is justified, though in many instances red pigmentation appears to be a specific character bearing no special relation to environment, as for example in Geranium Robertiunum.

Kerner's views can be best expressed in his own words: "...antho. cyanin frequently occurs only on the under side of foliage-leaves. This is observed especially among plants in the depths of shady forests, which, although belonging to widely-differing families, agree in a remarkable manner in this one point. One group of these plants has thick, almost leathery, evergreen leaves lying on the ground, which arise from subterranean tubers, or root-stocks, or from procumbent stems. The widely-distributed Cyclamen europaum may serve as a type of this group....Amongst other species belonging to this group may be mentioned C'yclamen repandum and C. hederifolium, Cardamine trifolia, Soldanella montana, Hepatica tritoba and Saxifraga Geum and cuneifolia. Growing in habitats similar to these are to be met biennial, occasionally perennial, plants which in autumn form a rosette of leaves on their erect stems which survive the winter; these are always coloured violet on the side turned towards the ground, while the leaves which develop in the following warm summer on the elongated flower-stalks usually appear green below. To this group belong, especially, numerous Cruciferac (e.g. Peltaria alliacea, Turritis glabra, Arabis brassicaformis); species of spurge (e.g. Euphorbia amygdaloides), bell-flowers (e.g. Campanula persicifolia), and hawkweeds (e.g. Hieracium tenuifolium). Finally, deciduous shrubs are to be found in the depths and on the margins of forests whose leaves do not survive the winter, but which produce 
on the stems developing in the summer flat leaves whose under side contains abundant anthocyanin, as, for example, Senecio nemorensis and nebrodensis, Valeriana montana and tripteris, Epilobium montanum, Lactuce muralis, and many others." And again, "That which occurs in plants of the forest shade occurs similarly in those marsh plants whose leaf-like stems or flat, disc-like leaves float on the surface of the water. The green discs of duckweeds (e.g. Lemna polyrrtiza), of the Frogbit (Hydrocharis morsus-rance), of the Villarsia (Villarsia nymphoides), of water lilies (Nymphoce Lotus and thermalis), and of the magnificent Victoria regia, are strikingly bi-coloured, being light-green above and deep violet below." Occasionally anthocyanin is limited to definite areas in the leaf, and in this form is the cause of the dark brown or black spots on leaves (Orchis maculata, Arum maculatum ${ }^{1}$, Medicago maculata, Polygonum Persicaria ${ }^{2}$ ), the dark colour being the result of the mixture of purple pigment and green chloroplastids.

Most of the above examples have been taken from flora of the temperate regions, but when we consider the tropical and sub-tropical regions, cases of red pigmentation are not only more numerous but are also much more striking. It is almost impossible to enumerate the specie which have wonderfully variegated leaves, and constitute the class of 'beautiful-leaved plants' of cultivation. Examples are quoted by Hassack (393) in a paper on variegated leaves, and good plates -have been published in a book by Lowe \& Howard (29). A few of the most remarkable are as follows: Calathea, Marania (Marantaceae), Alocasia, Caladium, Xanthosoma violaceum (Araceae), Tradescantia discolor (Commelinaceae), many Bromeliaceae (Vriesia splendens, Nidularium spp., Billbergia gigantea, Tillandsia), Dracaena spp. (Liliaceae), species of C'roton, Acalyphu and Codiceum (Euphorbiaceae), many Gesneriaceae (Sinningia atropurpurea, Episcia sp., Aeschynanthus sp. and Gesneria cinaberina), Coleus Verschaffeltii (Labiatae), Iresine sp., Alternanthera versicolor (Amarantaceae), Fittonia sp. (Acanthaceae) and numerous Begonias. Hassack points out in a most interesting way how the colour in such leaves may vary from purple or crimson, through brown-reds

1 In the case of Arum maculatum the leaves are not always spotted; in fact, according to the evidence of Colgan (73) and of Pethybridge (78), the spotted form is much less common, both in Great Britain and Ireland, than the unspotted. These two authors give some interesting data with regard to the distribution of both forms, as well as observations upon the structure and inheritance of the spot.

2 Garjeanne (74) mentions the discovery in Polygonum Persicaria of a variegated form in which the chlorophyll is absent from large areas of the leaf, and when this is the case, the anthocyanin patch shows bright red. 
to browns and bronze-greens, according to the amount of anthocyanin present, and its situation in the leaf, whether epidermal or deep-seated.

Stahl (405) lays great emphasis on the fact that many of these variegated-leaved plants, and those with purple and red under-surfaces, inhabit in the tropics, as in the temperate zones, the damp and shady forest regions; he quotes examples of such in support of his views upon the physiological significance of anthocyanin, to which we shall return in Chapter viII. He notes that the orders specially represented are Araceae, Marantaceae, Piperaceae, Begoniaceae, Melastomaceae, Orchidaceae (Pogonic crispa) and Vitaceae (Cissus discolor); these probably include many of the plants already mentioned above. Some of these shade-loving plants are, in addition, characterised by a velvety surface due to epidermal papillae, which emphasises the richness of the variegation colour. Spotting and flecking with anthocyanin are also common in tropical plants, and occur on a much larger scale than in the temperate zones; instances are given by Hassack (393) and Stahl (405), such as Gesneria cinaberina, Tradescantia zebrina, Musa zebrina Van Houtte and Costus zebrinus.

Although the observations, which led Stahl to conclude that anthocyanin development is a characteristic of many shade-loving plants, are undoubtedly correct, yet it is also true that when a plant is capable of forming anthocyanin, those individuals which inhabit dry and sumny situations develop more anthocyanin than other individuals in moist and shady positions. That is, a plant may be green-leaved in the shade, and more or less red-leaved when exposed to the sun. This fact is at once patent to any one who gives attention to the matter, as the observations of F. Grace Smith (412) have shown. This author examined plants from regions in Massachusetts and Maine, and of 285 plants showing anthocyanin, 150 were from dry sunny places, 61 from dry shady places, 40 from wet sunny places and 34 from wet shady places. It seems likely that the phenomenon of pigmentation in shade, especially in the tropics, is a special adaptation, and of a different nature from the more general reddening of vegetation in sunny situations, and that some explanation may be found for the apparent contradiction between the two phenomena. Though F. G. Smith's observations do not give sufficient information to be conclusive, there is one significant fact among them, namely, that in wet shady places, the percentage of cases of red colour in the leaves is higher than that in the stems, whereas among the plants as a whole, anthocyanin was more frequently found in stems and petioles than in leaves. This may indicate that reddening 
in the shade is a peculiar function of the lamina, and is not connected with general reddening of the plant.

In petioles, anthocyanin is more frequent than in leaves, and in stems one might say that it is almost universal; the stem may be entirely red, or only red at the basal internodes: or the nodes may be red and the internodes green, or vice versa. A spotted effect produced by the local distribution of anthocyanin is seen in some stems, for example in Chaerophyllum temulum and Conium maculatum (Umbelliferae).

Red pigment is also very characteristic of the bud-scales of trees and shrubs; in some cases these scales represent leaf-bases (Aesculus Hippocastanum, Acer pseudoplatanus, A. campestris), in other cases, stipules (Ulmus campestris, Tilia europaea). In addition the stipules of herbaceous plants are often red, and the same statement holds good for enlarged leaf-bases (Umbelliferae).

2. Anthocyanin is characteristic, though by no means universally so, of young developing leaves and shoots. It is interesting to note how in some species one finds both reddening of young leaves and autumnal colouring, whereas in others this is not the case. There are, in fact, four possibilities:

(a) Both anthocyanin in young leaves and autumnal reddening. Species of Acer, Rosa, Crataegus and Rubus.

(b) Anthocyanin in young leaves but no autumnal reddening. Corylus Avellana, Juglans regia, Fraxinus excelsior and Quercus Robur.

(c) No anthocyanin in young leaves but some autumnal reddening. Aesculus Hippocastanum. This is a much rarer combination than (a) or $(b)$.

(d) No anthocyanin in either young or old leaves. Fagus sylratica ${ }^{1}$.

Anthocyanin is especially abundant in the leaves of certain tropical trees (Cinnamomum, Haematoxylon, ete.); in addition to being coloured red, the young leaves often hang vertically downwards and straighten up again when mature (Bauhinia, Dryobalanops, Cinnamomum)2. In other species, especially among the Caesalpineae group of the Leguminosae, the whole young shoot has a vertical position, and in this respect, together with its intense red colour, forms a striking contrast to the older parts of the tree with green leaves in the normal horizontal position. As instances, certain species are mentioned by Stahl (405) and Keeble (403): Amherstia nobilis with young leaves of

1 Pick (391) reports the presence of anthocyanin in young Beech leaves.

2 Willis, J. C., The Flowering Plants and Ferns, Cambridge, 1904, p. 157 
a bright red tint; a variety of Cynometra cauliflora, bright rose-colour; Jonesia reclinata, golden-green to bright red; Brownea hybrida and $B$. grandiceps, green spotted with red. Keeble further remarks that the coloration of young foliage in low latitudes is of such general occurrence that at the time of leaf-renewal, a tropiçal forest rivals in its tints the autumnal forests of the temperate regions; he also quotes in confirmation the following extract from a paper by Johow (392), writing of the Lesser Antilles: "...all at once a red tint, due to the young foliage of the trees, appears in the landscape." Further details of such cases are given by Stahl $(62,405)$, Ewart (406), Keeble (403), Smith (420) and Weevers (421), and the physiological significance of anthocyanin formation in young leaves is discussed in Chapter virr.

3. The older leaves of many herbaceous plants often acquire a considerable formation of anthocyanin by the end of the vegetative (not necessarily autumnal) season (Litium candidum, Digitalis purpurea). Sometimes the whole plant becomes red in a striking way (Chaerophyllum. sylvestre, C. temulum, Galium Aparine).

4. The autumnal coloration characteristic of temperate climates is one of the most pronounced cases of anthocyanin development. With the onset of the cooler weather of autumn, anthocyanin appears in quantity in the leaves of a number of trees, shrubs and climbing plants (species of Acer, Rhus, Euonymus, Crataegus, Viburnum, Cornus, Vitis, Ampelopsis). In the Pfanzenleben, descriptions are given by Kerner (398) of the beauty of the autumnal foliage in the forests along the Rhine and the Danube, on the shores of the Canadian lakes of North America and among the vegetation of the Alpine slopes. Kerner's descriptions give such vivid pictures of autumnal colouring that this opportunity is taken of quoting one of the passages from his account. "The heights along the middle course of the Danube, for example, the region known as the Wachan, below the town of Melk, shows wide expanses of forest, in which beeches, hornbeams, evergreen oaks, common and Norway maples, birches, wild cherries and pears, mountain ashes and wild service-trees, aspens, limes, spruces, pines and firs take a share in the greatest variety. Bushes of Barberry (Berberis vulgaris), Dogwood (Cornus sanguinea), Cornel (Comus mas), Spindle Tree (Euonymus Europceus and vermcosus), Dwarf cherry (Prumus Chamcecer(sus), Sloe (Prunus spinosa), Juniper (Juniperus communis), and many other low shrubs arise as undergrowth, and spring up on the margins of the forests. The mountain slopes abutting on the valleys are planted with vines, and near by grow peach and apricot trees in great abundance. In 
the meadows on the shore, and on the islands of the Danube, rise huge abeles and black poplars, elms, willows, alders, and also an abundant sprinkling of trees of the bird cherry (Prumus Padus).... The first frosts are the signal for the beginning of the vintage: all is busy in the vineplanted districts, and the call of the vine-dresser resounds from hill to hill. But it is also the signal for the forests on the mountain slopes and in the meadows to change their hues. What an abundance of colour is then unfolded! The crowns of the pines bluish-green, the slender summits of the firs dark green, the foliage of hornbeams, maples, and white-stemmed birches pale yellow, the oaks brownish-yellow, the broad tracts of forest stocked with beeches in all gradations from yellowish to brownish-red, the mountain ashes, cherries and barberry bushes scarlet, the bird cherry and wild service trees purple, the cornel and spindle-tree violet, aspens orange, abeles and silver willows white and grey, and alders a dull brownish-green. And all these colours are distributed in the most varied and charming manner. Here are dark patches traversed by broad light bands and narrow twisted stripes; there the forest is symmetrically patterned; there again the Chinese fire of an isolated cherry-tree or the summit of a single birch, with its lustrous gold springing up among the pines, illuminates the green background. To be sure this splendour of colour lasts but a short time. At the end of October the first frosts set in, and when the north wind rages over the mountain tops, all the red, violet, yellow, and brown foliage is shaken from the branches, tossed in a gay whirl to the ground, and drifted together along the banks and hedges. After a few days the mantle of foliage on the ground takes on a uniform brown tint, and in a few more days is buried under the winter coat of snow." The extreme beauty of the Alpine vegetation in autumn is also described by Overton (333), and led him to investigate the cause of the coloration.

Detailed accounts of the physiological processes producing autumnal coloration will be given in Chapter vi.

As in the case of reddening of young dereloping leaves, autumnal coloration is by no means universal, since, as we have seen, there are many trees and shrubs of which the leaves turn either yellow or brown and show no trace of pigment (Fagus syleatica, Carpinus Betulus, Quercus Robur, Betula alba, Alnus glutinosa, Populus riba, P. nigra, $P$. tremula). There is some indication of a general tendency among genera of certain orders to develop red autumnal coloration, whereas genera of other orders are without it. Thus, for instance, the trees and shrubs of the Rosaceae (species of Pyrus, Prumus, Rost, Crataegus) 
very readily produce anthocyanin. On the other hand, the majority of the trees in the Amentales do not form red pigment in the autumn (species of Salix, Populus, Betula, Alnus, Juglans, Morus, Carpinus, Corylus, Castanea, Fagus and Quercus). To the above, Quercus rubra and $Q$. coccinea form an exception. On the whole, however, little emphasis can be laid on the connection between autumnal coloration and relationship, as is illustrated by the Viburnums-V. Opulus and $V$. Lantana; the former rapidly reddens in autumn whereas the latter forms little or no anthocyanin under similar conditions.

5. In a number of species, mechanical injury frequently leads to formation of anthocyanin in the portion of leaf, stem, or shoot, distal to the point of injury. Partial severing of a portion of the leaf blade may induce reddening in the severed portion. Crushing, or partial breaking of a stem or petiole, leads to the same result, as was shown by Gautier (175) in the Vine, or ringing of a stem will cause the leaves above to turn red, as Combes $(374,385)$ has demonstrated in Spiraca. The same kind of injury, with similar results, may be brought about by the attacks of insects. Under this heading must be included, as a result of injury, the copious formation of anthocyanin in galls, such as those which occur on species of Rosa, Salix, Quercus and many other plants. Also the local appearance of pigment in tissues infected with Fungi: as an example one may quote the purple blotches produced on leaves of Tussilago Farfara and the purple streaks on Wheat stems when these plants are infected with Puccinia. The physiological causes involved in the production of pigment on injury are dealt with in Chapter vi. Some plants show a greater tendency to redden on injury than others (Oenolhera, Rumex, Rheum); also the reddening on injury is more rapid and frequent in autumn when the vegetative season is about at an end.

6. Low temperature may induce anthocyanin formation apart from autumnal coloration, for, in the development of the latter, factors other than temperature play an important part. Many evergreen shrubs show a reddening ${ }^{1}$ in their leaves during winter (Ligustrum vulgare, Mahonia spp.). The same statement holds good for certain herbaceous plants which retain their leaves in winter (Saxifraga umbrosa).

7. Plants exposed to drought often develop anthocyanin. This may be seen sometimes in individuals in pots (Pelargonium) which have

1 This is of course quite different from the reddening shown by some evergreens in winter, notably species of the Gymnosperms, and which is due to the formation of a red product from chlorophyll in the chloroplastids. 
been insufficiently watered. Miyoshi (375) has observed that leaves of trees in the East Indies, Ceylon and Java redden during the dry period in the same way as autumnal leaves in the temperate regions.

8. In High Alpine plants there is undoubtedly, on the whole, a much stronger development of anthocyanin in all the parts-stem, leaves, bracts and flowers, than in plants growing in lowland regions. Gaston Bonnier $(294,307)$ has made observations upon this point, and has found that the flowers of many species are more highly coloured, the greater the altitude. Kerner (398) also remarks: "The leaflets and stem of the Alpine Sedum atratum, those of Bartsia alpina, and, above all, numerous species of Pedicularis (e.g. Pedicularis incarnata, rostrata, recutita) are coloured wholly purple or dark violet....It is also a very striking phenomenon that widely-distributed grasses (e.g. Aira ccespitosa, Brizu media, Festuca nigrescens, Mitium effusum, Poa annua and nemoralis), which in the valley possess pale-green glumes, develop anthocyanin in them on lofty mountains, so that there the spikes and panicles exhibit a deep violet tint, and on this account the regions in which grasses of this kind grow in great quantities receive a peculiar dark colouring....The same occurs in the numerous sedges and rushes growing in the Alps, which have dark-violet, almost black, scales covering the flowers (e.g. Carex nigra, atrata, aterrima, Juncus Jacquinii, trifidus, castaneus)....It is known that the floral-leaves of many plants growing on lofty mountains, and in the far north, are coloured blue or red by anthocyanin, whilst in the same species, growing in warm lowlands and in southern districts, they appear white. Particularly noticeable in this respect are the Gypsophyllas (Gypsophylla repens), the Carline Thistle (Carlina acaulis), the large-flowered Bitter-cress (Cardamine amara), the Milfoil (Achillea Millefolium), and many of those Umbelliferæ which have a very wide distribution, and occur all the way from the lowlands up to a height of 2500 metres in the Alps, such as Pimpinella magna, Libanotis montana, Chorophyllum Cicutaria, and Laserpitium latifolium." And again: "The flowers of species grown in the Alpine garden on the Blaser at a height of 2195 metres above the sea exhibited, as a rule, brilliant floral tints, and some were decidedly darker than the flowers grown in the Vienna Botanic Garden. Agrostemma Githago, Campanula pusilla, Dianthus inodorus (sylvestris), Gypsophila repens, Lotus corniculatus, Saponaria ocymoides, Satureja hortensis, Taraxacum officinale, Viciu Cracca, and Vicia sepium are good examples of this. Several species, which produced pure white 
petals in the Vienna gardens, e.g. Libanotis montana, had petals coloured reddish-violet by anthocyanin on their under sides in the Alpine garden. The glumes of all the Grasses which were green, or only just tinged with violet at a low level became a dark brownish-violet in the Alpine garden. The abundant formation of anthocyanin in the green tissue of the foliageleaves and sepals, and in the stem, was particularly apparent. The leaves of the Stonecrops, Sedum acre, album, and sexangulare became purple-red, those of Dracocephalum Ruyschianum and Leucanthemum vulgare violet, those of Lychnis Viscaria and Satureja hortensis a brownishred, and the foliage-leaves of Bergenia crassifolia and Potentilla Tiroliensis, even in August, had the scarlet-red colour which they usually assume in sunny spots in the valley in late autumn."

As regards Arctic vegetation, Gertz (19), on the authority of Wulff (71), maintains that abundant production of anthocyanin is a distinguishing feature; and so much so, that the periodicity of antumnal coloration is very little marked. The causes of the intense colour in Alpine and Arctic vegetation are dealt with in Chapter vi.

9. Production of anthocyanin in vegetative organs is characteristic of certain halophytes (Salicornia, Suaeda, Atriplex).

10. The red-leaved varieties of green-leaved types are due to the production of anthocyanin, which is either absent from the type, or present to only a slight extent (red-leaved varieties of Fagus, Berberis, Brassica and Prunus).

11. The petals and perianth are essentially the organs producing anthocyanin. To these must be added the perianth-like calyx (Anemone, Delphinium, Aconitum, Begonia and others). Also the bracts of the inflorescence may develop anthocyanin to a large extent, and may either assist (Salvia), or even take the place of, the corolla as organs of attraction (Bougainvillaea, Euphorbia, Poinsettia, spathes of Araceae). In general, we may say that the stems and pedicels of most inflorescences show an abundant formation of anthocyanin which no doubt increases the conspicuousness of these parts; yet, at the same time, the underlying cause is probably that the physiological conditions in all tissues of reproductive organs enhance the formation of pigment.

Anthocyanin is not confined to the perianth, but is frequently present in the carpels and style: of its occurrence in the stigma we have many examples among the Amentales (Myrica, Alnus, Betula, Corylus, Carpinus, Salix, Populus), as well as in Rumex and Ricinus.

In the stamens, too, it is found, especially in many anemophilous plants (Populus, Fraxinus) and in the Graminaceae (Molinia, Phleum, 
Alopecurus, Cynosurus, Dactylis). Pollen grains may also be coloured with anthocyanin (Campanula).

12. Many fruits form abundant anthocyanin. The pigment may be temporary in some stages of development of capsules which eventually become dry and dead (many of the Leguminosae, Hypericum, Sedum) and schizocarps (Umbelliferae). The more obvious cases are the drupes and berries, and of these, two types stand out, i.e. those in which the pigment is limited to the epicarp (Prunus, Vitis), and those in which it is present in both epicarp and mesocarp (Rubus, Ribes, Ligustrum, Taccinium, Atropa, Solanum, Sambucus, Viburnum, Lonicera). It may be formed also in the tissues of 'false fruits' (Fragaria, Pyrus). From other fruits (Cucurbita, Solanum, Lycopersicum, Citrus ${ }^{1}$ ) it is entirely absent.

13. Anthocyanin is sometimes developed in the cells of the testa of seeds (Abrus, Phaseolus, Pisum). Further instances are the seeds of Adenanthera, Erythrina, Lepeirosia (Potonié, 56), Trifolium pratense (Preyer, 66) and many Podalyrieae (Iindinger, 76). More frequently pigmentation in the seed-coat is due to impregnation of the cell-wall by pigments which cannot be classified as anthocyanins, and of which very little is known.

14. Roots and underground stems often form anthocyanin in considerable quantity. Three cases of this type of pigmentation may be differentiated:

(a) The pigment develops under ground apart from the influence of any outside factors. Well-known examples for roots are Beta vulgaris and Raphanus sativus, and for underground stems, Solanum. tuberosum; in the latter species the pigment may be confined to the epidermal layers or may be present in the inner tissues (Salaman, 544). To the above may be added other cases such as:

Root-tips of species of Saxifragaceae and Crassulaceae (Irmisch, 27). Roots of Parietaria diffusa and Gesneria sp. (Zopf, 48).

Roots of species of Pontederiaceae, Haemodoraceae and Cyperaceae in the ground (Ascherson, 43).

Roots of Wachendorfia in the ground (Hildebrand, 44).

(b) The pigment develops in roots normally exposed.

Aerial roots of Ficus indica (Möbius, 68).

Floating roots of Pontederiaceae (Hildebrand, 44; Ascherson, 43).

Aerial roots of Aroideae (van Tieghem, 33; Lierau, 51).

Aerial roots of Orchidaceae (Leitgeb) ${ }^{2}$.

1 Except in the red-fleshed variety, the so-called 'Blood Orange.'

2 Leitgeb, H., 'Die Luftwurzeln der Orchideen,' Denkschr. Ak. Wiss., Wien, 1865, xxrv, p. 179 (р. 204). 
(c) The pigment develops in roots abnormally exposed.

Exposed roots of Alnus (Möbius, 68).

Roots of Salix grown in water in glasses (Schell, 287).

Adventitious roots of Echeveria metallica (Pirotta, 42).

Roots of Zea Mays growing in water or in moss and exposed to light (Dufour, 305; Devaux, 308).

Exposed roots of Saccharum officinarum (Benecke, 312).

Adventitious roots above ground of Poa nemoralis (Beyerinck, 303).

To Kerner (398) we owe the observation that rhizomes of Dentaria bulbifera, Lathraea Squamaria and of species of Cardamine and Viola become violet when exposed in water to sunlight.

Gertz (19) lays stress upon the fact that numbers of roots and underground stems form anthocyanin when, for some reason, they have been exposed, as for instance when they grow out from banks of streams, or in shallow water, or when exposed during autumnal ploughing. He appends the following list of such cases including Tradescantia zebrina, Eriophorum angustifolium, Phragmites communis, Rumex Acetosella, Geranium molle, Potentilla anserina, Gunnera scabra, Stachys palustris, Plantago major, Anthemis ariensis and Artemisia vulgaris.

15. A development of anthocyanin appears to be characteristic of many parasites and saprophytes, though possibly the absence of chlorophyll has the effect of making the red pigment more conspicuous (species of Cuscuta, Orobanche, Lathraea). Mirande (332) gives an interesting account of the development of anthocyanin in the genus Cuscuta. 


\section{CHAPTER III}

\section{THE HISTOLOGICAL DISTRIBUTION OF ANTHOCYANINS}

When tissues containing anthocyanin are examined microscopically, in the majority of cases the pigment is found to be in solution in the cell-sap, which, of course, occupies the vacuole or vacuoles of the cell. We know, as Gertz (19) points out, from the researches of de Vries (141) and Pfeffer ${ }^{1}$ that in living cells the protoplasm is impermeable to anthocyanin in the cell-sap. But when the protoplasm is dead and semipermeability ceases, anthocyanin exosmoses out of the cell, and at the same time it is often taken up, like a stain, by the protoplasm and nucleus ${ }^{2}$.

From the condition of solution in the cell-sap, two deviations are possible: first, in tissues which gradually die or become woody, the anthocyanin may be absorbed into the substance of the cell-wall, thereby causing the latter structure to become coloured; secondly, the concentration of anthocyanin in living cells may become so great that the

1 Pfeffer, W., Osmolische Untersuchungen, Leipzig, 1877 (pp. 134, 135).

2 Staining of the nucleus under these conditions has been noted by Hartig, de Vries and Molisch.

Hartig, Th., 'Chlorogen,' Bot. Ztg., Berlin, 1854, xII, pp. 553-556 (p. 555).

Hartig, Th., 'Ueber das Verfahren bei Behandlung des Zellenkerns mit Farbstoffen,' Bot. Ztg., Berlin, 1854, xп, pp. 877-881 (p. 879).

Hartig, Th., 'Ueber die Bewegung des Saftes in den Holzpflanzen;' Bot. Ztg., Leipzig, 1862, xx, pp. 89-94 (p. 93).

Vries, H. de, 'Plasmolytische Studien über die Wand der Vacuolen,' Jahrb. wiss. Bot., Berlin, 1885, xvI, pp. 465-593.

Molisch, H., Untersuchungen über das Erfrieren der Pflanzen, Jena, 1897 (pp. 28, 29).

On account of this property, anthocyanin has been used as a stain for histological purposes. The red anthocyanin of Cabbage has been employed in this way by Tait, Gierke, Flesch (159), and Claudius (184); Lavdowsky (160) also recommends anthocyanin from Myrtillus berries.

Tait, L., 'On the Freezing Process for Section-Cutting,' J. Anat. Physiol., London, 1875, ser. 2, vII, pp. 249-258.

Gierke, H., 'Färberei zu mikroskopischen 'Zwecken,' Zs. wiss. Milirosk., Braunschweig, 1884, I, pp. 62-100, 372-408, 497-557 (p. 99). 
pigment separates out either in crystalline or amorphous form. In this solid state, anthocyanin may be pure, or may merely be absorbed by substances in the cell, such as proteins, tannins.

The following account is taken from Gertz (19) who has particularly investigated this portion of the subject. Several cases of pigmented cell-walls are recorded by Gertz among Monocotyledons, but no very definite statements are made as to whether the colour is actually due to anthocyanin. The cases quoted are in Phormium tenax (Engelmann), Eriophorum angustifolium (Wulff), Sorghum (Kraus), Tillandsia diantoidea (Tassi), Pontederia crassipes (Hildebrand), Angraecum superbum and Macroplectrum sesquipedule (Hering); Gertz also includes examples which he has observed himself. Among Dicotyledons coloured cellwalls are more rare. Red bast (Oxalis Ortgiesii) and red epidermis (Epilobium montanum) are quoted; in Jacquinia smaragdina (Vesque ${ }^{1}$ ) the cuticle is crimson. According to Gertz, the coloured cell-walls described in Homalomena rubrum (Nägeli \& Schwendener ${ }^{2}$ ) and in Geranium Robertianum, Begonia maculata, Quercus palustris, and Rumex Acetosella (Wigand, 12) are artificially produced; such artifacts can be brought about by putting anthocyanin-containing cells in a medium absorbing water, but in which anthocyanin is insoluble, such as ether. The phenomenon can be demonstrated in leaves of Begonic spp. In addition to the above cases, red pigment is found in walls of testa cells in Abrus precatorius (Nägeli \& Schwendener ${ }^{2}$ ) though Möbius (68) found cell-sap too. Sclerotic cells of testa of Erythrinc and Goodia have blue, violet and red cell-walls $\left(\mathrm{Tschirch}^{3}\right)$; also in seeds of Trifolium pratense (Preyer, 66).

As regards the presence of solid and crystalline anthocyanin in cells the following list of cases compiled by.Gertz (19) is extremely useful :

Tillandsia amoena, Hildebrand (30).

Aechmea sp., Dennert (14).

Allium Schoenoprasum, Courchet (97).

Lilium Martagon, Overton (333).

Dracaena Jonghi, Hassack (393).

Convallaria majalis, Weiss (91).

Iris pumila, Dennert (14).

1 Vesque, J., 'Mémoire sur l'anatomie comparée de l'écorce,'Ann. sci. nat. (Bot.), Paris, 1875, sér. 6, II, p. 82.

2 Nägeli, C. L., und Schwendener, S., Das Mikroskop, Theorie und Anwendung desselben. Leipzig, 1877.

${ }^{3}$ Tschirch, A., Angewandte Pflanzenanatomie, Wien und Leipzig, 1889, Bd. I, pp. 62, 66. 
Strelitzia Reginae, Mohl (84), Hildebrand (30).

Orchis mascula, Nägeli (85).

Epidendrum cochleatum, Schlockow ${ }^{1}$.

Cattleya quadricolor, Malte².

Laelia Perrinii, Malte?

Oncidium sphacelatum, Schlockow ${ }^{1}$.

Dianthus Caryophyllus, Molisch (104).

Aquilegia atrata, Molisch (104).

Delphinium elatum, Weiss (91), Molisch (104).

D. formosum, Zimmermann ${ }^{3}$.

D. tricolor, Fritsch (94).

D. sp., Molisch (104).

Glaucium fulvum, Schimper (93).

Papaver sp., Hildebrand (30).

Brassica oleracea, Molisch (104).

Hydrangea hortensis, Ichimura (192).

Rubus caesius,

$R$. corylifolius,

R. glandulosus,

Trécul (89).

$R$. laciniatus,

R. lasiocarpus,

Geum sp., Weiss (91).

Rosa sp., Molisch (104).

Pyrus communis, Sorauer (304).

Neptunia oleracea, Rosanoff (92).

Lathyrus heterophyllus,

L. silvestris,

Cytisus Laburnum,

C. Alschingeri,

C. scoparius,

Molisch (104).

Medicago sativa,

Hedysarum coronarium,

Ononis natrix,

Baptisia australis,

Amorpha fruticosa, Hildebrand (30).

Erodium Manescari, Molisch (104).

Pelargonium zonale, Molisch (104).

$P$. Odier hortorum, Molisch (104).

Vitis sp., Molisch (104).

Ampelopsis quinquefolia, Mer (284).

1 Schlockow, A., Zur Anatomie der braunen Blüten, Inaugural-Dissertation zu Heidelberg, Berlin, 1903.

2 Malte, M. O., 'Untersuchungen über eigenartige Inhaltskörper bei den Orchideen,' Bihang till K. Svenska Vet.-Akademiens Handlingar, Bd. xxvir, No. 15, p. 32.

${ }^{3}$ Zimmermann, A., 'Die Morphologie und Physiologie der Pflanzenzelle' (Schenck's Handbuch der Botanik, Breslau, 1887, Bd. III (2), pp. 104, 105). 
Ampelopsis humulifolia,
A. muralis,

Viola tricolor, Nägeli (85).

Passiflora acerifolia, Böhm (88), Weiss (91).

P. alata, Weiss (91).

$P$. laciniata, Unger (86).

P. limbata, Böhm (88).

P. suberosa, Unger (86), Böhm (88), Weiss (91).

Begonia discolor, Unger (86).

B. maculata, Molisch (104).

Centradenia floribunda, Buscalioni \& Pollacci (17).

Primula sinensis, Bokorny (99).

Anagallis arvensis, Courchet (97).

$\left.\begin{array}{l}\text { A. arvensis var ciliata, } \\ \text { A. arvensis var coerulea, }\end{array}\right\}$ Molisch (104).

Acantholimon sp.,

Swertia perennis,

Amsonia salicifolia,

Hoya carnosa,

Müller (61).

Gilia tricolor, Hildebrand (30).

Nemophila sp., Molisch (104).

Salvia splendens, Mohl (84).

Atropa Belladonna, Trécul (89).

Hyoscyamus niger, Müller (61).

Solanum americanum, Nägeli (90).

S. guineense, Trécul (89).

S. Melongena, Weiss (91).

S. nigrum, Hartig (83), Trécul (89), Weiss (91).

Antirrhinum majus, Molisch (104).

Gesneria caracasana, Dennert (14).

Columnea Schiedeana, Weiss (91).

Thunbergia alata, Fritsch (94).

Justicia speciosa, Pim (95).

Coffea arabica, Tschirch (100), Kroemer (102).

Viburnum Tinus, Fritsch (94).

To the above list Gertz adds a number of plants in which he himself has observed solid anthocyanin as well as anthocyanin in solution:

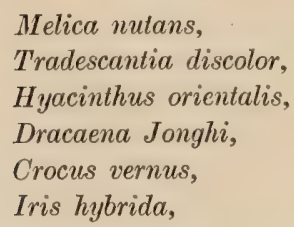

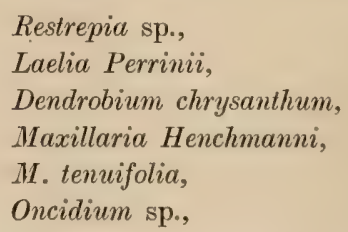

1 Lengerken, A. von, 'Die Bildung der Haftballen an den Ranken einiger Arten der Gattung Ampelopsis,' Bot. Ztg., Leipzig, 1885, xLII, pp. 376, 378. 
Oncidium sphacelatum,

Myrica Gale,

Juglans macrocarpa,

J. regia,

Carya glabra,

Corylus tubulosa,

Castanea vesca,

Quercus macrocarpa,

Q. rubra,

Ulmus montana,

Rumex crispus,

$R$. domesticus,

Rheum rugosum,

Polygonum Persicaria,

Silene tunetana,

Dianthus sp.,

Helleborus multifidus,

Epimedium alpinum,

Drosera rotundifolia,

Saxifraga granulata,

S. tridactylites,

Ribes petraeum,

Rubus Idaeus,

Potentilla thuringiaca,

Baptisia minor,

Robinia viscosa,

Geranium sanguineum,

Pelargonium zonale,

Ailanthus glandulosa,

Rhus typhina,

Serjania grammatophora,
Impatiens glanduligera,

Ceanothus azureus,

Malva rotundifolia,

Garcinia Mangostana,

Trapa bicornis,

$T$. natans,

Fuchsia triphylla,

Primula sinensis,

Androsace lactiflora,

Gentiana Oliveri,

G. acaulis,

Amsonia latifolia,

Hoya carnosa,

Calystegia sepium,

Cobaea scandens,

Collomia grandiflora,

Scopolia orientalis,

Solanum Dulcamara,

Paulownia imperialis,

Scrophularia nodosa,

Columnea picta,

Episcia cupreata,

Alloplectus speciosus,

A. vittatus,

Isoloma hirsuta,

Sciadocalyx Luciani,

Dircaea macrantha,

Gesneria fulgens,

Sambucus racemosa,

Viburnum Tinus.

In the above plants with a few exceptions, according to Gertz, the solid form of anthocyanin could not be obtained by chemical reagents, but in the following plants he was able to obtain 'anthocyanin bodies ' in the cells by treatment with chemical reagents such as alcohol, allaalies, sulphuric and hydrochloric acids.

Adiantum macrophyllum-alcohol.

Nidularium Cervantesi-alkalies, alcohol.

Tradescantia discolor-sulphuric acid.

Phrynium cylindricum-caustic potash.

Rheum rugosum-hydrochloric acid.

Viscaria viscosa-sulphuric acid.

Nepenthes Hookeriana-alkalies?

Sempervivum dichotomum - caustic potash, Eau de Javelle.

Baptisia minor-sulphuric acid.

IV. $\mathbf{P}$. 


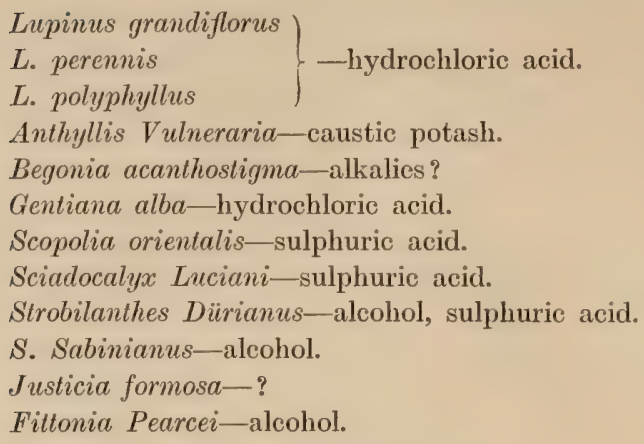

There has been much doubt in some cases as to whether the coloured deposits are of pigment only, or of other substances such as proteins, tannins, etc., impregnated with pigment. Very beautiful crystals are figured by Molisch (104) from cells of red Cabbage leaves and leaves of Begonia maculata. Molisch notes that a low temperature induces the formation of the crystals which may disappear at higher temperatures. In Brassica and Begonia, appearances are certainly in favour of the crystals being pigment. In other plants where the solid deposit is in the form of coloured spheroids or globules, the latter often being viscous in consistency, it seems more probable that the matrix of the bodies is of a tannin or protein nature, and has become impregnated with pigment.

Gertz maintains several possibilities for the natural occurrence of anthocyanin in cells. (1) In crystals as mentioned above either of pure anthocyanin or of colourless substances infiltrated with anthocyanin. (2) In very young cells containing several vacuoles, anthocyanin in the vacuoles may appear as red or blue globules having a superficial likeness to anthocyanin bodies. (3) Anthocyanin may occur in amorphous or globular form, or bound up with amorphous or globular bodies which are of a different nature from the pigment.

To demonstrate how solid anthocyanin bodies may arise, Gertz describes two examples of what may happen artificially in the cell. If tissues of Strobilanthes Dürianus be placed in alcohol, coloured drops appear which afterwards disappear again. The explanation offered is that the alcohol first causes the cells to plasmolyse, and substances in the cell may be precipitated and take up anthocyanin. Later, when semipermeability ceases, the alcohol redissolves out the pigment. Secondly, in Scopolia orientalis, on addition of sulphuric acid, there is a precipitation of coloured bodies which does not disappear. In this 
case Gertz supposes that the precipitated substances are changed by the reagent, or are insoluble in the new medium, and so remain. As already stated, the above examples are artificial, but Gertz suggests that in a similar way in the normal cell, substances may be precipitated and absorb anthocyanin. This precipitation may be brought about by increased concentration, or by lowering of temperature. The latter was found by Molisch to be the cause of crystallisation of anthocyanin in Brassica.

As to the chemical nature of the substances which absorb anthocyanin in the cell, according to Gertz, little can be said. Often they appear to be tannin-like compounds, impregnated with anthocyanin, in the form of solid bodies (in young leaves of Juglans, Quercus, Rubus, Ribes and others), or globules as described in the Bromeliaceae (Wallin, 101), Cissus (D'Arbaumont ${ }^{1}$ ), Euphorbia (Gaucher ${ }^{2}$ ) and Dicentra (Zopf, 48). Possibly in some other cases the ground substance is protein; coloured aleurone grains have been recorded by Hartig (87), which are red in Laurus nobilis and blue in C'heiranthus annurs, and blue grains have been noted by Spiess (103) in Zea. There is also the possibility, even when the anthocyanin deposits are crystalline, of the stroma being of some other substance. Nägeli (90) has suggested that coloured protein crystalloids occur in Solanum americanum.

We may next consider the distribution of anthocyanins in the tissues of leaves, stems, flowers, fruits and seeds.

As regards leaves, reference may be made to the work of Morren (26), Pick (391), Hassack (393), Engelmann (394), Stahl (62, 405), Berthold (64), Griffon (331), and Buscalioni \& Pollacci (17). No very general statement can be made about the histological distribution in leaves beyond that the pigment is often present in the epidermis, quite frequently in the subepidermal tissues also, and in many cases in the more internal tissues as well. Neither can it be predicted with certainty for any plant where the localisation will be, and it may vary considerably in the same plant according to whether we select for investigation leaves in the young, autumnal or winter condition, or leaves during the normal vegetative period; or again leaves under the influence of attacks of insects or Fungi. Accounts of the histological distribution in leaves have been made by various authors (Hassack, Engelmann, Pick, Stahl,

1 D'Arbaumont, 'La tige des Ampélidées,' Ann. sci. nat. (Bot.), Paris, 1881, sér. 6, XI, pp. 186-253 (pp. 241, 242).

2 Gaucher, L., 'Recherches anatomiques sur les Euphorbiacées,' Ann. sci. nat. (Bot.), Paris, 1902, sér. 8, xv, pp. 161-309 (p. 179). 
Massart), and a very detailed classification is recorded by Buscalioni \& Pollacci.

A less detailed classification due to Gertz is quoted as follows:

A. Permanent anthocyanin.

1. In the epidermis. Ex. Orchis, Canna, Marania, atropurpureaforms of Fagus, Corylus and Acer, and also of Beta vilgaris, Atriplex hortensis and Croton sp.

2. In peripheral layer of the ground tissue. Ex. Dracaena, Eucomis punctata, Erythronium Dens-Canis, Arum maculatum, Arisarum vulgare, Berberis vulgaris atropurpurea.

3. In both epidermis and ground tissue. Ex. Aerua sanguinolenta, Aeschynanthus atropurpureus, Iresine Herbstii, Coleus sp.

4. In median ground tissue. Ex. Higginsia refulgens, Sinnmgia purpurea, Gesneria Donkelaari, Pellionia Daveauana.

B. Periodic anthocyanin.

(a) In young leaves and spring leaves.

1. In the epidermis. Ex. Rubus, Rosa, Rhus, Silene, Matva. Veronica, Odontites, Ajuga, Salvia.

2. In the ground tissue. Ex. Salix, Populus, Fagus, Acer, Cydonia, Vicia, Stellaria, Cerastium, Campanula, Taraxacum.

3. In hairs. Ex. Quercus rubra, Q. macrocarpa, Castanea vesca, Chenopodium album, Mallotus juponicus, Vitis alexandrina, V. Labrusca.

(b) In older and autumnal leaves.

1. In the epidermis. Ex. Philadelphus, Deutia, Euonymus europaeus, and some Oenotheraceae.

2. In ground parenchyma. Ex. Populus, Salix, Quercus, Rhus, Acer, Vitis, Ampelopsis, Prunus, Cornus, Viburnum.

(c) In winter leaves.

1. In the epidermis. Ex. Silene, Oenothera, Gaura, Veronica, Lamium.

2. In the ground tissue. Ex. Secale, Hedera, Calluna, Empetrum.

One or two further observations of interest are mentioned by Gertz. This author notes that in some leaves there is an indication of division of labour as regara's anthocyanin. When the pigment appears principally in the epidermis, it is often found in addition in isolated mesophyll cells which are poor in chlorophyll (Spircea, Rosa and Rubus).

Although, as we have seen, from the observations of the abovementioned authors, anthocyanin formation is by no means limited to 
any particular tissue of the leaf, yet Parkin (77), in a recent investigation on the localisation of anthocyanin, points out the prevalency of the idea among botanists that anthocyanin is usually formed in the epidermis. Parkin's researches are interesting because they give an indication as to the particular localisation of the pigment when formed under varying circumstances and under the influence of different factors. He examined 400 cases and classified his results as follows:

1. Transitory anthocyanin of young leaves. This is a feature of the young foliage of many plants in the tropics and temperate regions. The number of species examined was 235 , and the distribution was classified as:

$\begin{array}{ccc}\text { Epidermis } & \text { Mesophyll } & \text { Epidermis and mesophyll } \\ 20 \% & 64 \% & 16 \%\end{array}$

2. Autumnal anthocyanin. The number of species examined was 81 and the distribution:

$\begin{array}{ccc}\text { Epidermis } & \text { Mesophyll } & \text { Epidermis and mesophyll } \\ 11 \% & 78 \% & 11 \%\end{array}$

3. The permanent anthocyanin of mature leaves. In this case the pigment appears as the leaf matures, and persists throughout the life of the leaf as a normal character. This class includes $(a)$ leaves with uniformly red lower surfaces; $(b)$ leaves with definite pigmented areas in the form of spots, blotches or zones; and $(c)$ leaves of horticultural varieties with coloured foliage. The number of species examined was 54, and the distribution:

$\begin{array}{ccc}\text { Epidermis } & \text { Mesophyll } & \text { Epidermis and mesophyll } \\ 70 \% & 17 \% & 13 \%\end{array}$

4. The accidental anthocyanin of mature leaves. This is not normally present in mature leaves but arises only under exceptional conditions such as: $(a)$ excessive insolation, followed by cool nights, as seen in Alpine plants, and in evergreens during winter; $(b)$ the result of injury, when a reddish zone often appears round a wound in a leaf; $(c)$ through the accidental exposure of lower surface to the full rays of the sun. The number of cases examined was 30 , and in the majority the anthocyanin was confined to the mesophyll. Parkin sums up by saying that anthocyanin of young and autumnal leaves is usually confined to the mesophyll; of mature leaves, when a normal feature, to the epidermis; and, when exceptional, to the mesophyll. 
The mesophyll, he considers, to be the usual, and, perhaps, more primitive seat for anthocyanin.

As regards the distribution in stems, we have the work of Berthold (64) and Buscalioni \& Pollacci (17). Two types of distribution can be recognised:

1. Anthocyanin in the epidermis. Ex. Gentianu, some Labiatae (Berthold, 64), some Solidago and Aster spp.

2. Anthocyanin in subepidermal assimilating cells. Ex. Alsinaceae, Papilionaceae and Convolvulaceae.

The histological distribution in petals has been investigated by Hildebrand (30), Koschewnikow (40), Müller (61) and Buscalioni \& Pollacci (17), and in anthers by Chatin (34). In the corolla, anthocyanin is chiefly located in the epidermis, either upper or under, or both, though its appearance in the subepidermal and inner tissues is by no means uncommon. The following table, selected from Buscalioni \& Pollacci's (17) records, gives an idea of the relative frequency with which pigments are formed in the various regions of the corolla and perianth.

Name of plant

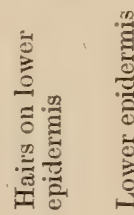

1

.

3 Epacris

4 Erica

5 Cineraria

6

7

8

9

10

\section{1}

\section{1}

Total.

...

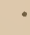$$
\begin{aligned}
& \ldots \\
& \cdots \\
& \cdots \\
& \cdots \\
& \cdots \\
& \cdots \\
& \cdots \\
& \cdots \\
& \cdots \\
& \cdots \\
& \cdots \\
& + \\
& + \\
& + \\
& + \\
& + \\
& \cdots \\
& \cdots
\end{aligned}
$$$$
\begin{array}{ccccc}
\ldots & \ldots & \ldots & \ldots & + \\
\ldots & \ldots & \ldots & \ldots & + \\
\ldots & \ldots & \ldots & \ldots & + \\
\ldots & \ldots & \ldots & \ldots & + \\
\ldots & \ldots & \ldots & \ldots & + \\
\ldots & \ldots & \ldots & \ldots & + \\
\ldots & \ldots & \ldots & \ldots & + \\
\ldots & \ldots & \ldots & \ldots & + \\
\ldots & \ldots & \ldots & \ldots & + \\
\ldots & \ldots & \ldots & \ldots & + \\
+ & \ldots & \ldots & \ldots & + \\
+ & \ldots & + & \ldots & + \\
+ & + & + & \ldots & + \\
& & & & \\
\ldots & \ldots & \ldots & + & \\
\ldots & \ldots & \ldots & + & \\
+ & + & + & + & \\
\ldots & \ldots & + & &
\end{array}
$$ 
Chatin (28) notes that anthocyanin occurs in deep-seated tissues in thicker petals, such as Ulloa and Asclepias, whereas in thinner petals it is usually confined to the epidermis.

The most interesting feature in connection with the histology of coloured petals is the combination of colour effects produced by the simultaneous presence of two, or even more, pigments in the cells. Strictly speaking, the plastid pigments, i.e. the yellow, orange-yellow and orange colouring matters which are bound up with special protoplasmic structures-the plastids, have no place in this account; and the same may be said for the soluble yellow pigments (mostly flavones). But both these classes occur so often with anthocyanin, and so frequently modify its colour, that some mention of them at this point will not be out of place. References can be made, in addition, to other authors; Hildebrand (30) wrote an early account of flower pigmentation, including combinations of plastid and sap colours; there is also an interesting paper by Bidgood (18) on flower colours, and many detailed observations by Dennert (14) and by the author (211).

One of the most frequent combinations of pigments is purple, purplish-red, or red anthocyanin and yellow plastids. The resultant colour may be brown (Cheiranthus Cheiri, Tagetes signata), crimson (Zinnia), scarlet (Geum coccineum), or orange-red (Tropaeolum majus); there are of course a great many other cases of combination of these two pigments, and a correspondingly large number of shades of brown, crimson, or scarlet, as the case may be. A less frequent combination is dark brown, brownish-black, or black resulting from purple anthocyanin and chloroplastids. This effect is produced in some Cypripedium flowers, and we have already noted it in the case of leaves (see p. 19). The brown or black effect is due to the fact that the two pigments are complementary as regards the rays they absorb; those which are not absorbed by chlorophyll are absorbed by anthocyanin, and so the result is negative as regards colour. But black or brown is not always due to this combination; the black spots on Adonis and Papaver flowers owe their appearance to deep blue cell-sap, and in the dark markings on some varieties of Bean (Phaseolus) seeds the cells contain purple anthocyanin. There are, in addition, true brown and black pigments which appear in some flowers as in the spots on the alae of Vicia Faba ${ }^{1}$.

1 Möbius, M., 'Das Anthophaeïn, der braune Blüthenfarbstoff,' Ber. D. bot. Ges., Berlin, 1900, xvII, pp. 341-347. Schlockow, A., Zur Anatomie der braunen Blüten, Inaugural-Dissertation zu Heidelberg, Berlin, 1903. 
Another class of combinations is the outcome of the mixture of anthocyanin and a soluble yellow pigment in the same cell. Such a combination occurs in the crimson flowers of Mirubitis Jalapa, though, on the whole, it is usually found to be characteristic of varieties which have arisen under cultivation, as for instance in the crimson varieties of Antirrhinum majus, Dahlia variabitis and Portulaca grandiflora. In these species the flower of the original wild type had some shade of magenta anthocyanin only. Three variations are then characteristicvariation to ivory-white, to yellow and to crimson, the latter being a mixture of magenta anthocyanin and soluble yellow pigment, such a combination as would not normally occur in nature.

It is interesting to note that colour of type and variation in the anthocyanin-soluble-yellow series is reversed in the anthocyanin-plastid series. In the latter, the original type is either crimson (Zinnia), yellow striped with brown (Cheiranthus), or orangered (Tropaeolum); a variety characteristic of this series is one in which the yellow pigment almost disappears from the plastids, or is replaced by a much paler yellow substance. When anthocyanin is present with these pale yellow pigments, or the yellow pigment is altogether absent, a purple or magenta variety results, as in the purple Cheiranthus and magenta Zinnia. When the anthocyanin is more red, as in the orange-red Tropaeolum majus, a carmine variety arises when these pale plastids only are present. Thus, in the anthocyanin-soluble-yellow series we have a magenta (or purple) type with crimson, ivory-white and yellow varieties, whereas in the anthocyanin-plastid series we have a crimson type, with magenta (or purple), ivory and yellow varieties.

Bidgood (18) mentions one or two unusual colour combinations: the lurid colour of some Delphiniums he attributes to the presence of cells containing red anthocyanin side by side with cells containing blue. Crocus aureus, also, on the outer side of the perianth leaves, shows green stripes which are due to a combination of blue sap colour on the outer side of the perianth leaves and yellow soluble pigment on the inner side. Dennert (11) gives many examples of the different ways in which plastid and sap pigments occur arranged in the tissues, and reference should be marle to his paper if details are required. Generally speaking, the anthocyanin pigments occur in the epidermis of the corolla, and the chromoplastid either in the inner tissues, or in the epidermal, or both, and the great variety of such combinations accounts to a large extent for the numerous shades and tints. Dennert also observed that when both plastid and soluble pigments occur in the same cell, 
especially in the papillae of the epidermis, the plastids tend to occupy the base of the cell, while the soluble pigment is uniformly diffused.

Investigations on the distribution of anthocyanins in fruits have been undertaken by Borbás (38); and in seeds by Sempolowski (36), Preyer (66), Brandza, Lindinger (76) and Coupin (82).

Finally it may be as well to quote the results which Gertz (19) has given of a comparative examination of the localisation of anthocyanin in members of many of the Natural Orders, and from which he finds evidence of a certain amount of agreement between systematic relationship and distribution of pigment. His results are shortly summarised as follows:

Helobiae. In Alisma, Butomus and Hydrocharis subepidermal, in Vallisneria epidermal.

Gramineae. Epidermal in Panicum, Optismenus, Pennisetum, Calamagrostis, Setaria, Holcus, Weingaertneria, Catabrosa, Melica, Briza; subepidermal in Pharus, Phleum, Alopecurus, Baldingera, Bromus, Secale, Triticum, Avena, Aira.

Aroideae. Subepidermal all through and similarly for Lemnaceae.

Bromeliaceae. Chiefly in hypodermis but in some forms also in epidermis.

Commelinaceae. Epidermal.

Juncaceae, Liliaceae and Amaryllidaceae. Subepidermal. In outermost scales of bulb of Allium often epidermal.

Scitamineae. Epidermal.

Orchidaceae. Epidermal in Cypripedium, Orchis, Epipactis, Limodorum, Oncidium; subepidermal in Haemaria, Pogonia, Goodyera, Microstylis, Restrepia, Cattleyu, Laelia, Dendrobium, Phalaenopsis.

Piperaceae. Anthocyanin in subepidermal water tissue or in spongy parenchyma.

Salicaceae. Subepidermal all through.

Betulaceae. Periodic anthocyanin in ground tissue. Permanent in epidermis.

Fagaceae. In general subepidermal. In certain species of Quercus in hairs. In leaves of Copper Beech in epidermis.

Moraceae. Subepidermal in Ficus.

Aristolochiaceae. Epidermal.

Polygonaceae. In young leaves chiefly epidermal. In older, subepidermal, but types somewhat mixed so that localisation rather indefinite, and still more indefinite in Amarantaceae.

Nyctaginaceae, Aizoaceae and Portulacaceae. Epidermal. 
Caryophyllaceae. In Alsinoideae always subepidermal; in Silenoideae usually epidermal, at least as regards origin. Exceptions are species of Dianthus, and, according to Wulff, Sitene acaulis. Also subepidermal in stem of Saponaria.

Ranunculaceae. Subepidermal nearly all through. Epidermal in Paeonia coriacea, Anemone Hepatica, A. japonica and A. Pulsatilla.

Berberidaceae and Papaveraceae. Subepidermal.

Cruciferae. Subepidermal except in Cainelina sitvestris, Braya, Draba verna, Alyssum, Farsetia, Malcomia.

Crassulaceae. Anthocyanin epidermal; in epidermal idioblasts and in parenchymatous sheaths of vascular bundles.

Saxifragaceae. Localisation more indefinite in Saxifraga, but appears to start from the epidermis, at least in young leaves. In spring leaves of Ribes, epidermal; in autumnal, subepidermal.

Rosaceae. In spring leaves in general, anthocyanin in epidermis; in autumnal leaves, anthocyanin in the ground tissue. Subepidermal in spring leaves of Cotoneaster, Cydonia, Pyrus, Photinia, Amelanchier.

Leguminosae. In general subepidermal but found in the epidermis in Acacia, Mimosa, Cercis, Gymnocladus, Gleditschia, Lupinus, Medicago, Trifolium, Indigofera, Glycyrrhiza, Lourea, Onobrychis.

Geraniaceae. In young leaves epidermal, in older, subepidermal. Tropaeolaceae, Linaceae, Polygalaceae. Subepidermal.

Euphorbiaceae. Generally subepidermal, epidermal in Croton, Ricinus and some Euphorbia spp.

Anacardiaceae. In Pistacic and Rhus, anthocyanin epidermal in spring leaves, subepidermal in autumnal leaves.

Aceraceae. Subepidermal in Acer, but epidermal in the red-leaved variety.

Vitaceae. Spring leaves epidermal, autumnal subepidermal.

Tiliaceae. Subepidermal.

Malvaceae. Epidermal.

Theaceae, Hypericaceae and Violaceae. Ground tissue.

Begoniaceae. Epidermal in leaves, and sometimes in certain spongy parenchyma cells.

Lythraceae and Myrtaceae. Subepidermal.

Oenotheraceae. In Oenothera, Epilobium, Godetia, Gaura, Circaca, usually epidermal. Subepidermal in autumnal leaves of Jussiou, Chamaenerium, Fuchsia.

Umbelliferae. Subepidermal, but epidermal in Eryngium amethystinum, and in stem of Chaerophyllum temulum, and Conium maculatum. 
Cornaceae, Ericaceae and Epacridaceae subepidermal. In Primulaceae in ground tissue only except in Androsace and Cyclamen where it is epidermal.

Oleaceae. Usually subepidermal but in spring leaves of Forsythia, Syringa, Chionanthus, Jasminum in epidermis.

Gentianaceae. Epidermal except in Menyanthes.

Apocynaceae, Asclepiadaceae and Convolvulaceae. Subepidermal, but in Cuscuta often epidermal.

Boraginaceae. Altogether in ground tissue except in Symphytum.

Labiatae. Marked epidermal localisation. Subepidermal in certain Coleus varieties, and in autumnal leaves of Prunella vulgaris, Ballota nigra, Betonica officinalis, Lycopus europaeus.

Solanaceae. Subepidermal.

Scrophulariaceae. Subepidermal in Verbascum, Linaria, Nemesia, Limosella, or epidermal in Pentstemon, Veronica, Digitatis, Euphrasia, Odontites, Rhinanthus, Pedicularis, Melampyrum.

Bignoniaceae and Orobanchaceae. Epidermal.

Gesneriaceae. Chiefly epidermal but often also hypudermal and in the spongy parenchyma.

Lentibulariaceae. Epidermal in Pinguicula.

Acanthaceae. Varying localisation, usually epidermal.

Plantaginaceae. Epidermal.

Rubiaceae. Mesophyll in most cases.

Caprifoliaceae. Subepidermal except in Sambucus racemosa and S. Ebulus.

Valerianaceae, Dipsaceae and Campanulaceae. In peripheral ground parenchyma.

Compositae. Both epidermal and subepidermal localisation. In older leaves nearly always the latter. In younger, subepidermal in Solidago, Achillea, Matricaria, Centaurea, Leontodon, Taraxacum, Tragopogon and Scorzonera. Anthocyanin in hairs in Hebeclinium janthinum, Eupatorium atrombens and Gynura aurantiaca. 


\section{CHAPTER IV}

\section{THE PROPERTIES AND REACTIONS OF ANTHOCYANINS}

From time to time the question has been under discussion as to whether all the varieties of red, purple and blue plant pigments are merely one and the same compound, the different shades being due to the presence of other substances in the cell-sap, i.e. acids, alkalies, etc., or whether the term anthocyanin includes many different members of a great group. The earliest expression of opinion on this point is possibly that made by James Smithson (112) in the Proceedings of the Royal Society in 1818; here he remarks, on the slightest experimental basis: "The colouring matter of the violet exists in the petals of red clover, the red tips of those of the common daisy of the fields, of the blue hyacinth, the holly hock, lavender, in the inner leaves of the artichoke, and in numerous other flowers. It likewise, made red by an acid, colours the skin of several plumbs, and, I think, of the scarlet geranium, and of the pomegranate tree. The red cabbage, and the rind of the long radish are also coloured by this principle. It is remarkable that these, on being merely bruised, become blue; and give a blue infusion with water. It is probable that the reddening acid in these cases is the carbonic; and which, on the rupture of the vessels which enclose it, escapes into the atmosphere." In the same way Marquart (5), and Fremy \& Cloëz (126) originally recognised only one blue pigment, from which the red pigments were believed to be derived by action of acids. Of a similar opinion was Wigand (136). who writes: "Die rothe und blaue Farbe der Blithen sind, wie sicl: theils aus den Uebergangserscheinungen, theils aus dem Auftreten beider Farben als homogene Färbung der Zellenflüssigkeit, theils aug dem ïbereinstimmenden Verhalten beider gegen chemische Reagentien ergiebt, unwesentlich verschiedene Zustände eines und desselben Stoffes, des Anthocyans." Hansen (11), also, believed most red flower colours to be due to one substance. 
Later, N. J. C. Muiller (169), on the basis of spectroscopic examination, announced that the red and blue pigments were of various kinds, but it is doubtful whether his materials were pure. Wiesner (135) also appeared to be uncertain as to whether all anthocyanins are alike, whereas Weigert (179) definitely distinguishes two groups of anthocyanin of which more will be said later. From this time onward, as investigations increased, there seemed to be little doubt that a number of substances are responsible for the different colours. Overton (333) held this point of view, and we may quote the words of Molisch (10t) to the same effect: "dass der Begriff Anthokyan, wie er bisher in der Literatur gefasst wurde, kein einheitliches chemisches Individuum darstellt, sondern eine Gruppe von mehreren verschiedenen, wahrscheinlich verwandten Verbindungen." The more recent suggestion of Grafe (209) comes nearer the truth, for he says we must regard anthocyanin as a term to be used for a whole series of pigments, which may have a similar fundamental nucleus, but which differ in the complexes attached to the nucleus. Colour and other chemical reactions would then depend on a particular grouping common to all or most of the pigments. This view has been supported by the recent researches of Willstätter $(245,256,257)$; he has isolated anthocyanin from the flowers or fruits of ten (or more) plants, and has shown that, in all probability, they have the same fundamental structure. Some of the number, though derived from plants quite unrelated, appear to be identical; others differ in the number of their hydroxyl groups; others again, he suggests, have their hydroxyls replaced by different radicals. Thus we may now correctly consider the word anthocyanin to stand, as a collective term, for a class of substances comparable to the sugars, tannins, fats, proteins, etc.

Hence, in giving an account of the reactions of anthocyanin, one is always dealing with a large group of substances of which the properties may differ considerably. Therefore to make any general statement in some cases is difficult, and there is always the further consideration that the substances examined have rarely been obtained pure.

The appearance of anthocyanin as crystals in the living tissues has been discussed in Chapter III. Outside the cell anthocyanin has also been obtained in undoubted crystalline form. Molisch (104) prepared crystals very readily from the petals of the scarlet Geranium, Pelargonium zonale, by placing a petal in distilled water under a coverslip on a slide. The pigment diffuses out, and on slow evaporation deposits groups of beautiful needle-shaped crystals. By a similar 
method, using acetic acid instead of water, Molisch (101) obtained good crystals from petals of garden roses and of Anemone fulgens. Several other investigators have crystallised anthocyanin from extracts; the cases may be mentioned here though the methods of preparation will be given in the next chapter. From the red pigment of Vine leaves, Gautier (175) isolated two substances termed by him $\alpha$ - and $\beta$-ampelochroïc acids. From a solution in hot water, the $\alpha$-acid was obtained on cooling as a red crystalline powder. The $\beta$-acid also was deposited from water in red crystals on slow evaporation. Griffiths (191) prepared crystals from pigment of 'Geranium' (Pelargonium) flowers. From flowers of Althaea rosea, Grafe (197) isolated a deep red pigment which separated out from alcohol in minute crystalline plates. Portheim \& Scholl (204) also succeeded in crystallising the anthocyanin from the testa of seeds of Phaseolus multiflorus. Later, Pelargonium flowers were again employed by Grafe (222) as material for the purification and analysis of anthocyanin, and like Molisch, Grafe found that this pigment very readily crystallised. The facility with which Pelargonium pigment may be made to crystallise, as compared with other anthocyanins, is no doubt due to the difference in its chemical nature. Not only as regards the scarlet colour, but also in its reactions towards reagents, the Pelargonium pigment differs from the more universally distributed purples and purplish reds.

Before describing the solubilities of anthocyanin, it should be mentioned that the pigment usually exists in the plant in the form of a glucoside. In this form it has been isolated from fruits of the Bilberry (Heise, 178), and from flowers of Althaea, Pelargonium (Grafe, 197, 222) and Centaurea (Willstätter, 245). There is little doubt, as will be shown in later chapters, that anthocyanins are aromatic substances containing hydroxyl groups, and, as is well known, hydroxyl groups in plant products are frequently replaced by sugars. As a glucoside, anthocyanin is readily soluble in water, and since it is in this form that the pigments chiefly occur in the cell, they can be extracted with water. After hydrolysis, in the non-glucosidal state, the pigment is far less soluble in water, and in some cases almost or quite insoluble, i.e. Antirhinum (Wheldale \& Bassett, 254) and Bilberry (Heise, 178). To the consideration of these glucosides we shall return again later in the chapter.

In ether, anthocyanin is insoluble, as also in benzene, carbon bisulphide, chloroform and similar solvents in which plastid pigments are soluble. In alcohol, the greater proportion of anthocyanins are soluble; 
there are definite exceptions, such as those of the Amarantaceae, Chenopodiaceae and Phytolaccaceae which are entirely insoluble in this solvent. To these may be added the blue pigment of Centurien (Willstätter, 245), the glucosidal pigment of Allhaea (Grafe, 197) and probably others. In many flowers it is difficult to extract the petals completely with alcohol. This is possibly due in some cases to the presence of several pigments, certain of which are insoluble in alcohol; or there may also be retention of the pigment to some extent by the coagulated cell-contents. A curious phenomenon is comnected with the alcohol solutions of most anthocyanins; such solutions, though at first coloured red or purple as the case may be, somewhat rapidly lose their colour and eventually become quite colourless; the same effect is produced by immersing petals in strong alcohol. The colour returns on evaporation of the alcohol or, in many cases if the solution is sufficiently strong, on adding water. A few drops of acid, also, restore the colour completely; similarly a few drops of alkali produce the green (or yellow) reaction characteristic of anthocyanin. This phenomenon was first remarked upon by Nehemiah Grew (1): "Again though no Blew Flowers, that I know of, will give a Blew Tincture to Spirit of Wine: yet having been for some days infused in the said Spirit, and the Spirit still remaining in a manner Limpid, and void of the least Ray of Blew; if you drop into it a little Spirit of Sulphur, it is somewhat surprizing to see, that it immediately strikes it into a full Red, as if it had been Blew before: and so, if you drop Spirit of Sal Armoniac or other Alkaly upon it, it presently strikes it Green.... It is likewise to be noted, That both Yellow and Red Flowers give a stronger and fuller Tinctuie to Water, than to Spirit of Wine; as in the Tinctures of Cowslip, Poppys, Clove-July-Flowers and Roses, made both in Water and Spirit of Wine. and compared together, is easily seen." Loss of colour in alcohol was also mentioned by Morot (122), Filhol (125) and Fremy \& Cloëz (126). In 1884, Hansen (11) commented on it, and suggested that anthocyanin, in absolute alcohol, forms a colourless anhydride. Keeble \& Armstrong (239) have recently offered another, though unsatisfactory, explanation of this decolorisation (see p. 120). Willstätter (245) considers the loss of colour to be due to the formation of a colourless isomer (see p. 72).

As regards the appearance, colour, melting point, crystalline form, etc., of solid anthocyanin, the accounts of the few workers who have prepared the pigment are so varied that information is best obtained by reference to individual cases quoted in the next chapter. 


\section{Qualitative Reactions.}

With respect to qualitative reactions, the necessity, already mentioned in connection with the properties of anthocyanin, for a guarantee of the purity of the pigment used is of paramount importance. Crude extracts invariably contain other substances which inay modify, or completely alter, the reactions of the pigment itself. In the next chapter, accounts are given of special methods for purification and analyses of anthocyanin, and on studying these, the futility of applying tests to any but pure material will be recognised at once. It is only after careful extraction, and purification by means of analyses, that the reactions of any pigment can be determined with certainty, and qualitative tests on impure extracts are to a large extent worthless. Nevertheless, numbers of observations have been made on more or less impure material, and the following account deals with the more important results.

With alkalies. When an aqueous or alcoholic extract of anthocyanin is treated with alkali, the pigment turns green ${ }^{1}$ and often finally yellow. Sometimes a blue colour precedes the green; with very dilute alkali, or with solutions of salts having a weakly alkaline reaction, a blue colour only may appear. Similarly red, purple and blue flowers placed in ammonia vapour as a rule turn green.

With acids. Anthocyanins almost invariably turn bright red with acids, though the shade may vary in different cases.

With lead acetate. Anthocyanin extracts are generally precipitated by lead acetate, and the colour of the precipitates is usually some shade of green or blue; occasionally it is red.

The reactions of anthocyanins with acids and alkalies have formed a subject for discussion from time to time. The whole matter is so bound up with the views of those who have worked on the pigments that something of the nature of a historical summary must be included.

The question first to be considered is whether the green coloration given when tissues and crude extracts containing anthocyanin are treated with alkalies is a reaction of anthocyanin alone, or is the combined result of reactions with anthocyanin plus reactions with other substances present in the cell or solution, and this can only be determined satisfactorily by testing pure pigments. In most cases, when white flowers are treated with alkalies, or exposed to ammonia vapour, a bright yellow colour is developed, indicating a reaction of alkalies with a class

1 In some cases such solutions are slightly dichroïc, green and red. 
of substances known as flavones which are almost universally distributed in plants. The flavone pigments in bulk are yellow, but exist in the cell-sap in such small quantities as to be inconspicuous except when treated with alkali, when an intense vellow colour is developed; with ferric chloride solution they give a green or brown coloration. They, moreover, occur in the plant largely as glucosides, in which form they are readily soluble in alcohol and water, and hence they are present in all crude aqueous and alcoholic extracts of anthocyanin. Extracts of white flowers, or in fact of any non-anthocyanic parts, give as a rule yellow or orange-yellow precipitates with lead acetate, which are insoluble flavone salts of lead.

That there is some substance in white flowers which turns yellow with animonia was noticed by Boyle (107): "we thought fit to make Trial upon the Flowers of Jasmin, they being both White as to Colour, and esteem'd to be of a more Oyly nature than other Flowers. Whereupon having taken the White parts only of the Flowers, and rubb'd them somewhat hard with my Finger upon a piece of clean Paper,... a strong Alcalizate Solution, did immediately turn the almost Colourless Paper moisten'd by the Juice of the Jasmin,...a Deep, though somewhat Greenish Yellow,... when we try'd the Experiment with the Leaves of those purely White Flowers that appear about the end of Winter, and are commonly call'd Snow drops, the event, was not much unlike that, which, we have been newly mentioning." Later in the Comptes Rendus of 1854 and 1860, Filhol $(125,132)$ published papers of considerable interest in connection with this point. Filhol found that when white flowers of Viburnum Opulus, Philadelphus coronarius and other plants were exposed to ammonia, they turned yellow; as yellow, he says, as the flowers of Laburnum. The same results he observed in leaves in the parts free from chlorophyll. When the flowers, after treatment with alkali, were placed in acidifien water, they became white again. The substance which gives the yellow colour was found to be soluble in water and alcohol and slightly so in ether, and Filhol terms it xunthogène. When coloured, red or purple, flowers were treated with ammonia, they turned green as a rule, but in some cases blue (Paparer, Pelargonium, Salvia splenderis). In one particular experiment when he added aluminium hydroxide to an extract of Vervain flowers, the aluminium hydroxide became yellow but the supernatant liquid retained the purple colour. Thus he comes to the conclusion that the green coloration with alkalies in Tiburnum and other flowers is due to a mixture of a blue colour given by w. P. 
anthocyanin plus a yellow colour given by xanthogene. But in the case of the flowers of Pelargonium, Paparer and Salvia the xanthogène is absent and so the anthocyanin becomes blue or violet with alkalies. In the later paper (132) he remarks on the resemblance of xanthogène to luteolin (which we now know to be a flavone), but he was unable to establish the identity. Thus Filhol's investigations brought him very near to the truth. Similar views were advanced by Wiesner (135) in 1862. From a series of reactions given by various flower pigments he concludes that colourless sap contains, as a rule, a tannin giving a green reaction with iron salts, and a yellow colour with alkalies. Like Filhol he believes that anthocyanin itself gives a blue, never a green, reaction with alkalies, and the green colour is due to admixtmre with rellow given by the tannin. In plants free from tannins giving the yellow reaction, anthocyanin turns blue with alkali. Wiesner's tannins are probably for the most part flavones, since true tannins are rare in flowers. These views on the reactions of anthocyanin gave rise to a certain amount of controversy, for Wigand (136) and Nägeli \& Schwendener (138) held the opinion that the green coloration is given by anthocyanin itself, and may appear when the iron-greening tannins are absent. Some of the arguments involved in the discussion are given by Wiesner in a later paper (142). The alkali reaction of anthocyanin is also mentioned by Overton (333), who considers the blue colour to be due to the formation of an acid salt, the green colour to a neutral salt of the pigment, anthocyanin itself being a dibasic acid. This view is accepted by Grafe (197) as being in accordance with the reactions of Althaea pigment which he prepared in a pure state. Anthocyanin from Antirrhinum (Wheldale \& Bassett, 254), purified from accompanying substances, still gives the green alkali reaction. Willstätter (245), as far as can be determined from his publications, considers the reactions of anthocyanin to be as follows. The pure blue anthocyanin from the Cornflower is not altered by alkali, i.e. pure anthocyanin gives a blue colour with alkalies, but if a solution of the blue pigment has stood for a time, the colour reaction with alkalies is green. This is due to the fact that from the pigment a colourless isomer (see pp. 53, 72, 75, 78) has been formed, and this gives a yellow colour with alkalies; hence the blue plus yellow results in a green reaction. Crude extracts from the flowers, he says, also give a green colour owing to the presence of yellow pigments--ohviously flavones. (Die reine blaue Farbstofflösung zeigt auf Zusatz von wenig Soda zunächst keine Farbänderung, eine gestandene Lösung wird hingegen grünblau oder blaugrün weil 
die Lösung nun auch die farblose Modifikation enthält. Dies ist das Verhalten eines wässrigen Blütenauszugs, worin sich üherdies noch gelbe Farbstoffe befinden, deren Alkalisalze intensiv gelb sind.) The blue colour given by alkalies with the pure anthocyanin pigment will, Willstätter found, become green or yellow by decomposition on standing, or with excess of alkali. Further consideration will be given below (pp. 52-54) to these reactions. With anthocyanins from other plants Willstätter notes various reactions with alkalies (see p. 56). Hence we have at present the following suggestions. Pure anthocyanin from Centurea gives a blue colour with alkalies; the green colour given in solutions and crude extracts is due to mixture with the yellow colour produced by the colourless isomer or accompanying flavones, or both. Pure anthocyanin from Antirhinum gives a green colour with alkalies, and this cannot be due to admixture with flavones, as the latter are removed by purification; nor can we suppose it due to admixture with a colourless isomer, since this is not formed in a strongly acid solution such as that from which the pigment separates out in preparation. Thus, whether the green or blue reaction is given by pure anthocyanin, or whether it is green in some cases, and blue in others, remains undetermined until anthocyanins from many other species have been purified and tested. In many cases the green reaction either rapidly or slowly changes to rellow, and the original colour does not return on neutralisation, so that evidently some anthocyanins are completely destroyed by alkalies.

The same difficulty arises with regard to the precipitates with lead acetate, for the accompanying flavones produce yellow or orangeyellow precipitates with lead acetate, and hence the actual lead salt of anthocyanin is not identifiable except from the pure pigment with which the results are the same as with alkalies. The colour of the lead precipitate varies very considerably in crude solutions. In extracts from white flowers containing little anthocyanin, it is greenish-yellow; from flowers containing much anthocyanin, bright green or blue-green, whereas from red varieties (Wheldale, 211), it is practically red with a greenish tinge. The latter must be distinguished from the red precipitates given by the special pigments of the Amarantaceae and Phytolaccaceae which are mentioned below.

On the basis of qualitative reactions, Weigert (179), in 1895, attempted a classification of anthocyanins into two groups:

The 'Weinroth' group, of which the pigments give blue-grey or blue-green precipitates with basic lead acetate; give the Erdmann 
reaction (see below); are precipitated and give a bright red colour with concentrated hydrochloric acid; and turn green on addition of alkalies. Ex.--Pigments from Vitis, Ampelopsis quinquefolia, Rhus typhina, Cornus sanguinea, etc.

The 'Rübenroth' group, of which the pigments give a red precipitate with basic lead acetate, do not give the Erdmann reaction; turn dark violet with concentrated hydrochloric acid; violet with ammonia, but with other bases yellow. Ex.-Pigments from Beta, Iresine Lindeni, Achyranthes Verschaffeltii, Amaranthus, Atriplex hortensis, Phytolacca decandra. According to Gertz (19), the following should be added to Weigert's 'Rübenroth' group: several Chenopodiaceae (Blitum virgutum, Atriplex litoralis, Corispermum canescens), Amarantaceae (except Mogiphanes brasiliensis), Nyctaginaceae (Oxybaphus nyctagineus), Phytolaccaceae (Phytolacca decandra, leaves), Aizoaceae (Tetragonia crystallina, Mesembryanthemum nodiflorum), Portulacaceae (Portulaca grandiflora) and Basellaceae (Basella rubra). The remaining families of the group Centrospermae, i.e. Polygonaceae and Caryophyllaceae, seem to be distinguished by anthocyanin of the 'Weinroth' group as also the greater number of the Chenopodiaceae.

The reaction of Erdmann (618) was originally employed in order to detect true wine pigment and may be described as follows: The pigment solution (wine) is diluted with four times its volume of water, eight drops of concentrated hydrochloric acid are added, and the mixture shaken up with 16 c.c. of amyl alcohol. The amyl alcohol separates out with a fine violet-red colour, the underlying acid solution being yellow or cherry-red. If the amyl alcohol is separated off, and an equal volume of water added, together with two drops of concentrated ammonia, the amyl alcohol decolorises and the underlying solution becomes bright green. If the original acid solution below the amyl alcohol is placed in a porcelain dish and carefully neutralised with dilute ammonia, at neutralisation point an indigo-blue colour is produced which afterwards becomes green.

The reactions of anthocyanins with acids and alkalies, the Erdmann reaction, etc., have received a new interpretation through the recent researches of Willstätter (245). These views are based upon work devoted in particular to the anthocyanin of Centaurea but also to anthocyanins in general. As far as can be gathered from a preliminary publication, the following represents, in the main, the views of Willstätter (see also Chapter v).

1. Red, purple and blue pigments occur in the plant entirely as 
glucosides (anthocyanins), which can be hydrolysed artificially with the formation of sugar and non-glucosidal pigments (anthocyanidins). From a dilute acid solution anthocyanidins are completely removed by amyl alcohol, whereas anthocyanins are not taken up at all by this solvent. This may be demonstrated experimentally by extracting fresh material containing anthocyanin with dilute sulphuric acid. After filtration and addition of amyl alcohol, no pigment is taken up by the alcohol. But if the solutions are heated for one half to three quarters of an hour on a water-bath, the anthocyanins are hydrolysed, and on addition of amyl alcohol, the anthocyanidins are quantitatively removed.

2. Anthocyanin is itself an acid and in the free state is purple.

3. There is a blue modification which is the potassium salt of the purple.

4. There is a red modification, which is the oxonium salt of anthocyanin; the pigment may be combined with either organic or inorganic acids.

5. In Centaurea, as well as in some other plants, all three forms of anthocyanin readily change to a colourless isomer; with the red form this only occurs in absence of excess of acid. The change to a colourless isomer can be prevented by adding neutral salts to the anthocyanin solution; the anthocyanin forms additive compounds with these substances thereby preventing the isomeric change.

As regards the colour reactions with alkalies, Willstätter, as we have already seen, gives the following explanation. With alkalies a blue salt is formed, which may become green owing to mixture with flavones or the colourless isomer (see pp. 50, 72), if these are present in the extract. The blue salt is also unstable, and with excess of alkali passes to a greenish or even yellow decomposition product. But if a neutral mineral salt is present, the blue salt is rendered stable. This may be brought about by either (1) acidifying the anthocyanin and then neutralising or (2) by adding the neutral salt $\left(\mathrm{NaCl}, \mathrm{NaNO}_{3}\right)$. Thus, for example, if pigment of Bilberries or Grapes (which presumably contain little flavone) are treated with alkali, it gives a greenish colour. But if treated first with some salt, it gives a blue colour, and the same result may be brought about by acidification and subsequent neutralisation.

It is now possible to explain the Erdmann reaction, which, according to Willstätter, has hitherto been misunderstood. The following account is given more or less in Willstätter's words. The Erdmann reaction 
is based on the fact that new, or fairly new, wine gives a green colour on neutralisation with ammonia, but after treatment with hydrochloric acid and neutralisation, a dark greenish-blue colour. This behaviour was incorrectly explained by Erdmann as being due to the splitting of the wine pigment into two pigments by the hydrochloric acid. Erdmann separated the above two pigments by shaking with amyl alcohol; the violet-red amyl alcohol layer gives with dilute ammonia first a bright green, then a brownish-green colour, while the acidified water solution becomes indigo-blue on neutralisation. As a matter of fact no breaking up is brought about by the acid, but during fermentation of the grape juice, a portion of the anthocyanin has been hydrolysed to anthocyanidin. The effect of ammonia on the wine pigment is to give a blue coloration rapidly passing to a green decomposition product. But, as explained by Willstätter, if the anthocyanin is first acidified and then made alkaline, the blue colour is more stable. On shaking up the acidified wine with amyl alcohol, the latter talies up the small portion of anthocyanidin as an oxonium salt. If the wine is heated with hydrochloric acid, or if the hydrochloric layer of the Erdmann reaction is heated, the whole is hydrolysed, and the anthocyanidin can be extracted quantitatively with amyl alcohol. But the hydrolysis does not happen in the cold. Willstätter further points out a source of error in the reaction. Grape juice from fresh berries gives, after acidification with hydrochloric acid, a little pigment in the amyl alcohol. If the amyl alcohol is then washed with dilute sulphuric acid, it is nearly decolorised. The small amount of pigment in the amyl alcohol is not hydrolysed, but is due to the fact that hydrochloricamyl alcohol takes up a little of the anthocyanin oxonium salt, whereas sulphuric-amyl alcohol takes practically none. Hence it is advisable to use sulphuric acid for the test. The statement by Weigert, that the 'Weinroth' group gives the Erdmann reaction, is regarded by Willstätter as erroneous, for the latter maintains that, apart from the small amount of glucoside salt which can be washed out again from the amyl alcohol, the pigment of flowers, berries and leaves remains completely in the water-acid layer.

The sensitiveness of anthocyanin to acids and alkalies has suggested its use as an indicator. In fact these were the first reactions to attract the attention of chemists (see p. 8). Its use in this way has been revived from time to time by Pellagri (146). Sacher (215) and others but without any permanent success.

Reactions with iron sults. Here again the actual colour reaction 
is difficult to estimate unless the pure pigment is tested. The flavones give green or brownish-green colorations with iron salts, the tannins green or blue. Though anthocyanins on the whole appear to give green-blue, green, or sometimes brown reactions, if tannin or flavone be present it is obvious that no reliance can be placed on the results. In a few cases, however, where anthocyanin pigment has been obtained approximately pure, one of the above colour reactions was given. Such a result indicates that anthocyanin has probably hydroxyl groups of the phenol type.

Reactions with sodium bisulphite. An interesting reaction of anthocyanins is that given with sulphur dioxide and bisulphites It was well known at a very early date that flowers containing anthocyanin, or extracts of the pigment, are bleached by sulphur dioxide gas, and that the colour is again restored by stronger acids. Boyle (107) writes: "That Roses held over the Fume of Sulphur, may quickly by it be depriv'd of their Colour, and have as much of their Leaves, as the Fume works upon, burn'd pale, is an Experiment, that divers others have tried, as well as I. But (Pyrophitus) it may seem somewhat strange ...That, whereas the Fume of Sulphur will,... Whiten the Leaves of Roses; That Liquor, which is commonly call'd Oyl of Sulphur...does powerfully heighten the Tincture of Red Roses." Further observations on this bleaching action were made by Kuhlmann (118), Hünefeld (120) and Schönbein (123). Solutions of anthocyanin decolorised by sulphur dioxide have been employed by Kastle to test the relative 'strengths' of acids. Kastle (196) is of the opinion that the decolorisation is not caused by reduction, and the same view is held by Grafe $(197,222)$, who prepared bisulphite derivatives from the anthocyanins of both Althaea and Pelargonium by addition of sodium bisulphite. Both products were colourless, but the red colour returned on addition of a trace of a stronger acid. Grafe concludes that the anthocyanins contain aldehyde colour-producing groups, which form additive compounds with bisulphites, whereby the linkings in the molecule and the resultant colour are changed.

Action of nascent hydrogen. A reaction which would appear to be one of reduction is that produced by treating acid solutions of anthocyanin with zinc dust. The colour rapidly disappears and the solution remains colourless if air be excluded. On exposure to air, if the reducing action is not very violent, the colour returns, the surface of the liquid becoming coloured before the deeper layers. Kastle (196) does not consider the reaction to be of the nature of reduction, since the colour 
did not return on treatment with oxidising enzymes. Grafe (222) holds the view that the loss of colour is due to changes brought about in the aldehyde groups (which he postulates) by the action of nascent hydrogen. The fact that the return of colour in air is not equally great with all acids (Wheldale \& Bassett, 621) may indicate that the reaction is not a simple reduction process.

Compounds with acids. In some cases anthocyanins appear to form definite compounds with acids (Willstätter's oxonium salts), since such compounds occur in crystalline form. Grafe (222) obtained the anthocyanin from Pelargonium in combination with two molecules of acetic acid as a crystalline substance. Willstätter (245) also obtained both anthocyanin, and the corresponding anthocyanidin, in combination with hydrochloric acid as crystalline compounds.

Spectrum of anthocyanin. A considerable amount of attention has been devoted to the spectroscopic examination of flower and leaf pigments. Sorby $(139,144)$, 1lüller (169), Engelmann (394), Jepel (151) and Formánek (186) may be mentioned as workers on these lines; but the results are of little value for identification, or otherwise, on account of the impurity of the products employed, that is the doubt as to the number of pigments present, etc.

Willstätter (245) has distinguished various groups of anthocyanins by their different behaviour to reagents, though the observations do not pretend to include any kind of systematic classification. The following represent some of the classes:

1. Red in acid solution, blue with soda and a blue precipitate with lead acetate; pigment readily isomerises to a colourless modification (Centaurea, Rosa, Lathyrus).

2. Red in acid solution, blue with soda and a blue precipitate with lead acetate; pigment decolorises less readily or not at all (Grapes, Bilberries, flowers of Delphinium).

3. Yellowish-red in acid solution, blue with soda, red precipitate with lead acetate (Radish).

4. Yellowish-red in acid solution (Pelargonium) and blue-red (Papaver); both violet with soda and decolorised by isomerisation.

5. Red in acid solution; with soda red in dense layers, blue-green in thin layers (Pinks) or red-violet to red-brown (Aster).

6. Violet in acid solution, red with soda, red precipitate with lead acetate (Beet-root, Atriplex).

The author $(211,212)$ has also made observations on crude extracts of anthocyanins from a very large number of flowers, using the colour 
reactions given by various chemical reagents, i.e. sulphuric, hydrochloric and oxalic acids, ammonia, caustic potash, lime water, ferric chloride, ferrous sulphate, potassium ferrocyanide, uranium, lear, copper and sodium acetates, stannous chloride and others. Although a certain amount of differentiation was possible on this basis of qualitative reactions, it was soon found that there were too many aberrant and peculiar forms of pigment to arrive at any satisfactory classification.

Before we close the chapter, there is yet another extract which may well be quoted from the writings of Boyle (107), since it dealt two hundred and fifty years ago with some of the phenomena which have formed the basis of Willstätter's constitutional formulae for the cyanidin of the Cornflower, i.e. the reactions of anthocyanin with acids and alkalies, and its instability in water solution.

Boyle writes: "There is a Weed, more known to Plowmen than belov'd by them, whose Flowers from their Colour are commonly call'd Blew-bottles, and Corn-weed from their Growing among Corn. These Flowers some Ladies do, upon the account of their Lovely Colour, think worth the being Candied, which when they are, they will long retain so fair a Colour, as makes them a very fine Sallad in the Winter. But I have try'd, that when they are freshly gather'd, they will afford a Juice, which when newly express'd, (for in some cases 'twill soon enough degenerate) affords a very deep and pleasant Blew. Now, (to draw this to our present Scope) by dropping on this fresh Juice, a little Spirit of Salt, (that being the Acid Spirit I had then at hand) it immediately turn'd (as I predicted) into a Red. And if instead of the Sowr Spirit I mingled with it a little strong Solution of an Alcalizate Salt, it did presently disclose a lovely Green;...And I remember, that finding this Blew Liquor, when freshly made, to be capable of serving in a Pen for an Ink of that Colour, I attempted by moistning one part of a piece of White Paper with the Spirit of Salt I have been mentioning, and another with some Alcalizate or Volatile Liquor, to draw a Line on the leisurely dry'd Paper, that should, e'vn before the Ink was dry. appear partly Blew, partly Red, and partly Green." 


\section{CHAPTER V}

\section{THE ISOLATION AND CONSTITUTION OF ANTHOCYANINS}

Several general and rather vague views have been held as to the constitution of anthocyanin, without any particular experimental evidence. Thus Wigand (136) believed these pigments to arise by oxidation from a colourless tannin-like chromogen; Overton (333) considered them to be tannin-like substances combined with sugar, and Katic (354), too, found that anthocyanin gave the reactions of a tannin. Palladin (203), again recognised in anthocyanin a respiratory pigment, and yet other suggestions have been advanced by Filhol, Mirande and Combes.

But in the following cases, definite isolation of the pigments has been attempted, and analyses have been made; the methods and results, however, are so varied that a separate account is essential in each case. We may enumerate the cases thus:

1849. Morot (122). The flower-pigment of Centaurea Cyanus.

1858. Glénard $(129,130)$. The colouring matter of wine.

1877. Church (147). The pigment from leaves of Coleus.

1877. Senier (148). The flower-pigment of Rosa gallica.

1878. Gautier (149). The colouring matter of wine.

1889. Heise (167). The colouring matter of grapes.

1892. Gautier (175). The pigment from red Vine leaves.

1892. Glan (176). The flower-pigment of Althaea rosea.

1894. Heise (178). The pigment from fruits of the Bilberry.

1903. Griffiths (191). The flower-pigment of Pelargonium.

1906 and 1909. Grafe $(197,209)$. The flower-pigment of Althaea rosea.

1911. Grafe (222). The flower-pigment of Pelargonium.

1913 and 1914. Wheldale $(244,254)$. The flower-pigment of Antirrhinum majus.

1913. Willstätter-(245). The flower-pigment of Centaurea Cyanus.

1914. Willstätter $(256,257)$. The flower-pigment of Delphinium.

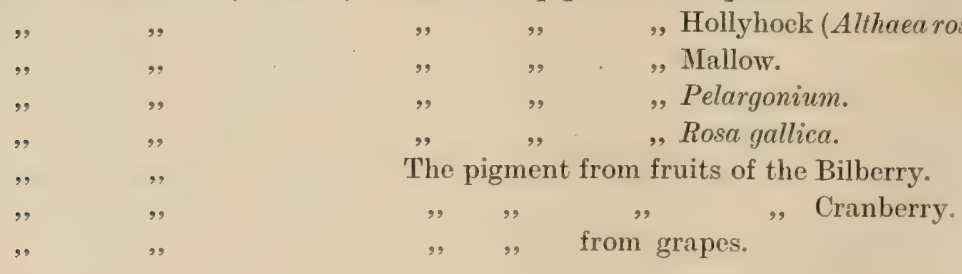


Morot (122), 1849. The flower-pigment of Centaurea Cyanus.

The pigment was prepared by pouring a water extract of the flowers into alcohol. The blue flakes of the precipitate, when collected and dried, formed a blue powder, which, on analysis, gave the following results:

$\mathrm{C} \quad \mathrm{H} \quad \mathrm{O}$

$\begin{array}{rrrr}\text { (i) } & 36.62 \% & 5.04 \% & 58.54 \% \\ \text { (ii) } & 38.76 \% & 5.30 \% & 55.94 \% \\ \text { (iii) } & 37.00 \% & 5.24 \% & 57.76 \% \\ \text { (iv) } & 37.03 \% & 5.26 \% & 57.71 \%\end{array}$

Glénard $(129,130), 1858$. The colouring matter of wine.

The pigment was prepared by first adding lead acetate to wine. The blue precipitate of the lead salt was then treated with ether containing hydrochloric acid gas, which set free the pigment. The latter was then extracted with rectified spirit, the solution evaporated, and water added which precipitated the pigment in red flakes, since it is scarcely soluble in water. The product was not crystalline; on analysis the results were:

\begin{tabular}{lllll} 
& & \multicolumn{1}{c}{$\mathrm{C}$} & \multicolumn{1}{c}{$\mathrm{H}$} & \multicolumn{1}{c}{$\mathrm{O}$} \\
From anthocyanin & $\ldots$ & $57 \cdot 02 \%$ & $4.89 \%$ & $37.89 \%$ \\
Calculated for $\mathrm{C}_{2} \mathrm{HO}$ & $\ldots$ & $57 \cdot 1 \%$ & $4.8 \%$ & $38.1 \%$
\end{tabular}

The pure lead salt was also prepared by adding lead acetate to a dilute alcoholic solution of the pigment. The product, washed and dried at $120^{\circ}$, gave:

$\begin{array}{lcccc} & & \mathrm{C} & \mathrm{H} & \mathrm{O} \\ \text { Lead salt of pigment } & \ldots & 59 \cdot 67 \% & 4 \cdot 49 \% & 35 \cdot 84 \% \\ \text { Calculated for } \mathrm{C}_{20} \mathrm{H}_{9} \mathrm{O}_{9} \ldots & 59 \cdot 71 \% & 4 \cdot 47 \% & 35 \cdot 82 \%\end{array}$

Hence Clénard gave to the pigment, which he termed oenoline, the formula $\mathrm{C}_{20} \mathrm{H}_{9} \mathrm{O}_{9}$. OH, and to its salt, the formula $\mathrm{C}_{20} \mathrm{H}_{8} \mathrm{O}_{9}$. $\mathrm{PbO}$.

Church (147), 1877. Pigment from the leaves of Coleus.

The pigment was extracted with cold alcohol acidified with sulphuric acid; the acid was then precipitated with baryta, and the solution concentrated. The product was further purified by extraction with alcohol and precipitation of the alcohol solution with ether or water. Church termed the pigment colein and gave it the composition $\mathrm{C}_{10} \mathrm{H}_{10} \mathrm{O}_{5}$; its lead salt he expressed as $\mathrm{C}_{20} \mathrm{H}_{18} \mathrm{PbO}_{10}$.

Senier (148), 1877. The flower-pigment of Rosa gallica.

The dried petals were first digested with ether, and the pigment then extracted with alcohol and precipitated with lead acetate. The 
lead salt was decomposed either by sulphuretted hydrogen or sulphuric acid. Microscopic crystals of the sodium, potassium, and ammoniosodium and potassium salts were obtained by evaporating the pigment with alkali in a drop of alcohol. Senier gave to the lead salt, as a result of several analyses, the composition $\mathrm{Pb}_{2} \mathrm{C}_{21} \mathrm{H}_{29} \mathrm{O}_{30}$.

\section{Gautier (149), 1878. The colouring matter of wine.}

Gautier was of the opinion that the colouring matters are formed from tannins which become red on oxidation. He also suggested that homologous series of colouring matters exist, such as $\mathrm{C}_{20} \mathrm{H}_{20} \mathrm{O}_{10}, \mathrm{C}_{21} \mathrm{H}_{20} \mathrm{O}_{10}$, etc., and that each variety of Vine contains one or more members of the series. The method he employed for isolation was to decompose the lead salts of the pigments with hydrochloric acid ether, and then to take up with alcohol and to precipitate with water. It has been shown later by Heise that Gautier's pigments were mixtures.

\section{Heise (167), 1889. The colouring matter of grapes.}

Heise maintains that there are two pigments present in the skins of purple grapes. One, soluble in alcohol, which he termed $B$, is chiefly responsible for the colour; the other, almost insoluble in alcohol, he termed $A$. In wine, the soluble pigment $B$ is said to be converted by oxidation into $A$, which is then precipitated from the wine.

The method described for the isolation of the pigments is to precipitate the extract of fresh skins with lead acetate. The mixture of the lead salts is then decomposed with hydrochloric acid ether, washed with ether, taken up with methyl alcohol and precipitated from the alcohol solution by adding ether. The product is again taken up in alcohol and poured into water. The precipitate so formed is a mixture of the two pigments which can then be separated by digesting the dried product with absolute alcohol in the cold. Heise devises two methods for separating the pigments. (1) The mixture of the pigments already isolated is treated as above with absolute alcohol; $B$ goes into solution, whereas $A$ is insoluble. (2) The lead salts of the isolated pigments are treated with acetic acid; the lead salt of $B$ is soluble in that solvent; the salt of $A$ insoluble.

Pigment $A$ is a brown-black substance, insoluble in absolute alcohol, ether, water and acetic acid; but in alcohol containing a trace of acid it is soluble to a red solution.

Pigment $B$ is soluble in alcohol to a brownish solution which. on addition of acid, becomes red with a tinge of violet. 
Heise is, apparently, not able to suggest any formulae for the pigments on the basis of analysis.

Gautier (175), 1892. The pigment from red Vine leaves.

The extract of the pigment from the Vine leaves was precipitated with neutral lead acetate until the colour of the precipitate becomes blue. This first precipitate was then separated off, and precipitation continued with the formation of a dark-green precipitate. The latter precipitate was then decomposed with sulphuretted hydrogen, treated with ether and taken up in $95 \%$ alcohol. A red product was obtained consisting of two substances and having, it is said, the characteristic properties of a tannin. These substances are termed by Gautier ampelochroïc acids; one was found to be insoluble in cold water ( $a$-ampelochroïc acid): the other soluble $(\beta$-ampelochroïc acid).

$\alpha$-ampelochroïc acid. After washing away the $\beta$-pigment with cold water, the insoluble residue was taken up in hot water from which, on cooling, the pigment separated out as a red crystalline powder. On analysis the results were:

$$
\begin{array}{ccc}
\mathrm{C} & \mathrm{H} & \mathrm{O} \\
56.43 \% & 3.96 \% & 39.61 \%
\end{array}
$$

from which the formula $\mathrm{C}_{19} \mathrm{H}_{16} \mathrm{O}_{10}$ is derived.

According to Gautier, the $\alpha$-acid is dibasic, and the normal lead salt is dark green. The pigment is soluble in hot water and cold alcohol, but is insoluble in ether. With ferric salts it gives a green-black coloration.

$\beta$-ampelochroic acid. This is the portion soluble in cold water; on slow evaporation, red crystals are deposited. The product is soluble in water; the solution precipitates gelatine, and gives a violet-black coloration with ferric salts. On analysis the results were:

C $\mathrm{H} \quad \mathrm{O}$

(i) $\quad 53.89 \% \quad 4.34 \% \quad 41.77 \%$

with which the two following formulae agree most closely:

$$
\mathrm{C}_{17} \mathrm{H}_{16} \mathrm{O}_{10} \text { or } \mathrm{C}_{26} \mathrm{H}_{24} \mathrm{O}_{15}
$$

After determination of the molecular weight by means of the neutral zinc salt, Gautier decides in favour of the formula $\mathrm{C}_{26} \mathrm{H}_{24} \mathrm{O}_{15}$.

From the first precipitate originally obtained with lead acetate, Gautier extracted by similar methods a third pigment-- $\gamma$-ampelochroïc acid; to this he gave the formula $\mathrm{C}_{17} \mathrm{H}_{18} \mathrm{O}_{10}$. It is described as 
a brown powder, very soluble in water, and having the properties of a tannin. Gautier, in fact, considers all three acids to be coloured tannins.

Glan (176), 1892. The flower-pigment of Althaea rosea.

The petals, after treatment with petrol ether, were extracted with alcohol; the alcohol was distilled off, and the residue taken up in water and precipitated with lead acetate. The lead salt was then decomposed with sulphuretted hydrogen, and after concentration, the residue was extracted with alcohol and the solution poured into ether, from which the pigment separated out in red flakes. In properties it is a dark red powder, insoluble in ether, chloroform, etc., and soluble in water and alcohol. It gives a green colour with ammonia and alkaline carbonates, a blue pigment with normal, and a green precipitate with basic lead acetate. When the pigment is heated with dilute sulphuric acid, sugar is split off, and the sugar-free product is insoluble in water.

The composition of the pigment before heating with sulphuric acid is :

$\mathrm{C}$

$48.43 \% \quad 6 \cdot 18 \%$

and after heating with acid:

$54.46 \% \quad 5.81 \%$
$\mathrm{H}$
0

$45 \cdot 39 \%$
$\mathrm{H}$

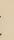
$39.37 \%$

When the solution of the pigment in sulphuric acid is neutralised

When the solution of the pigment in sulphuric acid is neutralised with potash, a neutral potassium compound of the pigment separates out in blue flakes. The potassium salt has the following composition:

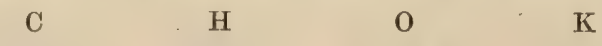

$48.32 \% \quad 5.62 \% \quad 39.73 \% \quad 6.32 \%$

Heise (178), 1894. The pigment from fruits of the Bilberry.

The pigment was first precipitated with lead acetate, and the lead salt was then decomposed with hydrochloric acid ether. After drying, the residue was taken up with methyl alcohol and precipitated with ether. This product was found to consist of two substances, one of which occurs in excess, and is separated from the other by its solubility in acidified water. There are two methods of separating the two pigments (termed $A$ and $B$ ). (1) The mixture is warmed with water acidified with hydrochloric acid; $B$ goes into solution, $A$ does not. The pigment $B$ can be purified again by precipitating with lead acetate, decomposing with hydrochloric acid ether, taking up with methyl 
alcohol and precipitating with ether. (2) The lead precipitates are heated with acetic acid, in which the lead salt of $B$ is soluble, whereas that of $A$ is insoluble. Heise gave to $B$ the formula $\mathrm{C}_{20} \mathrm{H}_{21} \mathrm{O}_{12}$. By heating $B$ with dilute hydrochloric or sulphuric acid, $A$ was formed together with sugar. Hence Heise concluded that $B$ is a glucoside. The decomposition of the glucoside is represented as follows:

$$
\mathrm{C}_{20} \mathrm{H}_{24} \mathrm{O}_{12}+\mathrm{H}_{2} \mathrm{O}=\mathrm{C}_{14} \mathrm{H}_{14} \mathrm{O}_{7}+\mathrm{C}_{6} \mathrm{H}_{12} \mathrm{O}_{6}
$$

The pigment $B$ is described as a reddish-violet powder, soluble in water, alcohol and acetic acid, insoluble in ether, benzene, chloroform and carbon bisulphide. It reduces Fehling's solution: gives. a bluishgreen precipitate with lead acetate, and an intense red colour with acids.

The pigment $A$ is a dark brown powder: it is soluble in $60 \%$ alcohol to a red-brown solution, or 1 acid alcohol to a red solution; it is insoluble in cold water (either neutral or acid), in absolute methyl or ethyl alcohols, chloroform, ether and carbon bisulphide. The reactions of $A$ varied, but were on the whole as follows: dirty bluish-green colour with ammonia, dirty green precipitate with lead acetate and a black precipitate with ferric acetate. On fusion with caustic potash, protocatechuic acid was identified as a product of decomposition.

Griffiths (191), 1903. The flower-pigment of Pelargonium.

The pigment was extracted with alcohol and the solution gave, on evaporation to dryness, a crystalline substance. The analyses of the results were:

\begin{tabular}{|c|c|c|c|c|}
\hline & & C & $\mathrm{H}$ & 0 \\
\hline $\begin{array}{l}\text { Trom anthocyanin } \\
\text { talculated for } \mathrm{C}_{15} \mathrm{H}_{10} \mathrm{O}_{6}\end{array}$ & & $\begin{array}{l}62 \cdot 85 \% \\
62.93 \%\end{array}$ & $\begin{array}{l}3.53 \% \\
3.49 \%\end{array}$ & $\begin{array}{l}33.62 \% \\
33.58 \%\end{array}$ \\
\hline
\end{tabular}

An acetyl derivative was obtained by heating the pigment with acetic anhydride and sodium acetate; it crystallised from methyl alcohol in red needles melting at $125^{\circ} \mathrm{C}$. If potassium acetate is added to a hot alcoholic solution of the pigment, orange prisms are obtained. An analysis of the potassium salt gave the following result:

$$
\text { K.....2.21.50\% }
$$

Calculated from $\mathrm{C}_{15} \mathrm{H}_{8} \mathrm{O}_{6} \mathrm{~K}_{2}$ :

$$
\text { K......21.54\% }
$$

Grafe (197, 209), 1906, 1909. The flower-pigment of Althaea rosea.

Preliminary experiments showed that the extraction of the petals with water or dilute acid is impracticable, since so much mucilage is 
$\lceil\mathrm{CH}$.

present in these solutions. Hence the pigment was extracted from the dried petals with absolute alcohol; the greater part of the alcohol was then distilled off, an equal volume of water added, and the solution precipitated with basic lead acetate. The green lead salt was suspended in water, acidified with hydrochloric acid, decomposed with sulphuretted hydrogen, and filtered from lead sulphide. The deep red filtrate was neutralised and left to evaporate: a dark red metallic powder remained which was taken up in acetone and poured into a large quantity of ether, whereupon the pigment separated out in granular plates. The product was then treated with absolute alcohol, in which only a part was soluble, the remainder being soluble in water.

To the alcohol solution enough ether was then added to precipitate the pigment as a brown precipitate, which was filtered off and taken up again in absolute alcohol. After evaporation, the alcohol-soluble pigment was deposited in tiny crystalline plates of a deep red colour.

The water solution was evaporated in vacuo and the residue taken up again in a little acidified water, from which it was deposited as a granular amorphous mass (the water-soluble pigment) which would not crystallise, but gave concordant combustion results.

The results of analysis of the two pigments were as follows:

C

$\begin{array}{ll}60.10 \% & 5 \cdot 62 \% \\ 60.00 \% & 5.72 \% \\ 50.11 \% & 6.48 \% \\ 50.21 \% & 6.27 \%\end{array}$

$$
50.21 \% \quad 6.27 \%
$$

0 $34.28 \%$ $34.28 \%$ $43.41 \%$ $43.52 \%$

The portion soluble in alcohol

Calculated for $\mathrm{C}_{14} \mathrm{H}_{16} \mathrm{O}_{6} \quad \ldots$

The portion soluble in water

Calculated for $\mathrm{C}_{20} \mathrm{H}_{30} \mathrm{O}_{13} \quad \ldots$

Determinations of the molecular weights were made by the lowering of the freezing point of phenol. The results were:

Molecular weight of the pigment soluble in alcohol $\quad . .274$

Calculated for $\mathrm{C}_{14} \mathrm{H}_{16} \mathrm{O}_{6} \quad \ldots \quad$.

Molecular weight of the pigment soluble in water $\ldots 4 \quad 460$

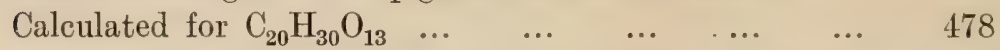

Grafe considers that the two pigments are related in the following way:

$$
\begin{aligned}
& \mathrm{C}_{20} \mathrm{H}_{30} \mathrm{O}_{13}+\mathrm{H}_{2} \mathrm{O}=\mathrm{C}_{14} \mathrm{H}_{18} \mathrm{O}_{8}+\mathrm{C}_{6} \mathrm{H}_{12} \mathrm{O}_{6} \\
& 2 \mathrm{C}_{14} \mathrm{H}_{18} \mathrm{O}_{8}-2 \mathrm{H}_{2} \mathrm{O}-\mathrm{O}_{2}=2 \mathrm{C}_{14} \mathrm{H}_{16} \mathrm{O}_{6}
\end{aligned}
$$

since the portion soluble in water reduced Fehling's solution, whereas the portion soluble in alcohol did not; also dextrose could be split off from the larger molecule by heating the substance in acid solution. 
Further investigations were first made upon the water-soluble portion. The potassium salt was prepared by acidifying the water solution of the pigment with sulphuric acid, and bringing to the neutralisation point with dilute potash. On standing, the potassium compound of the pigment was obtained as a blue-green precipitate. It was found to contain $13.28 \%$ of potassium which, according to Grafe, agrees fairly well with $14.08 \%$ of potassium calculated on the hypothesis that the pigment is a dibasic acid of the formula $\mathrm{C}_{20} \mathrm{H}_{30} \mathrm{O}_{13}$.

The pigment, as in the case of other anthocyanins, was found to be decolorised on the addition of either a solution of sulphur dioxide in water, or a solution of sodium bisulphite. Grafe does not consider this to be a reduction process, since the red colour does not return on standing in air, but on addition of a stronger acid. He considers it rather to be due to the formation of an additive compound with the aldehyde groups present in the anthocyanin molecule. In the formation of these compounds, certain double linkings are destroyed, thereby depriving the substance of colour.

The sodium bisulphite compound of the water-soluble pigment was prepared by adding the salt to an alcoholic solution of the pigment. The alcohol was then driven off, and the residue, after purification from sodium bisulphite, was distilled in vacuo. At about $150^{\circ}-160^{\circ} \mathrm{C}$. there came over a colourless oily substance distilling with difficulty, which showed a violet-red coloration with a trace of acid. The number of aldehyde groups in the anthocyanin was determined by estimating the sodium bisulphite as sulphate, after oxidation with bromine. The results showed that one molecule of sodium bisulphite combines with one molecule of anthocyanin indicating that one aldehyde group is present in the molecule of the water-soluble pigment.

In order to find out whether the sodium bisulphite causes any change in the anthocyanin molecule, some of the bisulphite compound was decomposed with acid, the solution neutralised, evaporated to dryness, and taken up with acidified alcohol; on evaporation, a red granular mass was deposited which gave the same combustion results as the original substance.

The acetyl derivative of the portion soluble in alcohol was made by treating the pigment with acetic anhydride and anhydrous sodium acetate, and pouring into water in which the derivative is insoluble. The acetyl compound came down in red crystals from methyl alcohol. The results of hydrolysing, and estimating the acetic acid, indicated the presence of two hydroxyl groups in the pigment molecule.

W. P. 
In an alkali melt of the alcohol-soluble pigment, pyrocatechin was detected as one of the products of decomposition.

\section{Grafe (222), 1911. The flower-pigment of Pelargonium.}

Molisch (104) had already shown that when Pelargonium petals are mounted in glacial acetic acid on a slide, and covered with a coverslip, very fine crystals are formed both in the cells and in the solution on the slide. After several preliminary trials had been made, the following was considered by Grafe to be the best method for dealing with material on a large scale. The juice is squeezed out of the petals by means of a press; the dry residue is treated with glacial acetic acid for several days, and then filtered off. Both juice and filtrate are shaken up with ether, and the yellowish ethereal layer separated. Glacial acetic acid is added to the juice, and it is mixed with the filtrate, and the mixture again filtered. The filtrate is then dialysed, and this process separates the anthocyanin into two components; the dialysate is deep yellow-red in colour, and deposits groups of crystals on evaporation, while the liquid within the membrane is dark red in colour, and does not crystallise. The separation, however, can be made in another way. By adding ether to the filtered glacial acetic extract, a brown flaky precipitate is deposited. The filtrate is yellowish-red and gives crystalline anthocyanin; the precipitate is readily soluble in water, to which a little alcohol has been added, to a brown-violet fluid which will not crystallise. If, also, to the glacial acetic extract, lead acetate solution is added, a dense violet precipitate is formed, and the deep red filtrate gives no further precipitate with lead acetate, neither will it crystallise. The lead precipitate can be decomposed either with sulphuric acid, or sulphuretted hydrogen, and the solution of pigment therefrom crystallises in characteristic rosettes of needles.

If the glacial acetic extract is dialysed, and the acid removed from the dialysate by diminished pressure, a white crystalline precipitate is formed, while the colour of the fluid becomes lighter. A microscopic examination of the fluid shows a number of colourless crystalline plates, together with a few rosettes of anthocyanin needles.

The crystalline anthocyanin is also unstable and liable to give rise to the amorphous form.

The crystalline product was first investigated. It is soluble with difficulty in absolute alcohol, but readily soluble in acetone. It crystallises from acetic acid in good rosettes of crystals which are very hygroscopic. If warmed, they give rise to the colourless crystalline 
product. The pigment itself decomposes and melts at $270^{\circ} \mathrm{C}$. It gives a deep red colour with acids, even with a trace; with alkalies and ammonia, a greenish-red fluorescent solution: with ferric chloride, a blue-violet coloration. The red colour of the pigment is changed to yellow on standing, or by boiling with hydrogen peroxide.

An analysis of the substance, dried in air, gave:

From anthocyanin ...

Calculated for $\mathrm{C}_{18} \mathrm{H}_{26} \mathrm{O}_{13}$
C

$\mathrm{H}$

$46 \cdot 34 \%$

$46 \cdot 31 \%$
$5.87 \%$

$5 \cdot 96 \%$
0

$47 \cdot 79 \%$

$47 \cdot 73 \%$

After drying in vacuo over caustic potash:

C

From anthocyanin ... $\quad \ldots \quad 48.69 \%$

Calculated for $\mathrm{C}_{18} \mathrm{H}_{26} \mathrm{O}_{13} \quad \ldots \quad 48.00 \%$
$\mathrm{H}$

$5 \cdot 10 \%$

$5 \cdot 78 \%$
0

$46.21 \%$

The molecular weight, found by the lowering of the freezing point of phenol, was 437 , and calculated for $\mathrm{C}_{18} \mathrm{H}_{26} \mathrm{O}_{13}$ it would be 450 .

The number of hydroxyl groups was determined by means of the acetyl derivative which was prepared by boiling the pigment with acetic anhydride. The acetyl derivative crystallises in brown crystalline plates from ethyl acetate. To ascertain the number of hydroxyl groups, the derivative was hydrolysed with barium hydroxide, the acetic acid distilled off, and estimated by means of barium hydroxide. For the molecular weight assumed, the result corresponded with the presence of two hydroxyl groups. The number of carboxyl groups was found by making the potassium salt of anthocyanin by exact neutralisation, and estimating the potassium. For the molecular weight assumed, the result corresponded to three carboxyl groups.

A sodium bisulphite compound was obtained by shaking an alcoholic solution of the pigment with a concentrated solution of sodium bisulphite. The product formed a pale yellow, extremely unstable, crystalline mass, which was soluble in water, and insoluble in ether, chloroform, carbon bisulphide and amyl alcohol. The product is regarded by Grafe as an additive compound with an aldehyde group in the pigment, and the anthocyanin colour returns on addition of a trace of a stronger acid. The aldehyde groups were determined by allowing a known amount of sodium bisulphite solution to react with the pigment, and then estimating the excess of bisulphite used. The result was also confirmed by oxidising the anthocyanin bisulphite, and estimating the 
sulphate formed as barium sulphate. Both methods gave numbers indicating the presence of two aldehyde groups. In the opinion of Grafe, it is the aldehyde groups which determine the colour in the anthocyanin. An alkali melt was made of the pigment, and pyrocatechin was identified as one of the products of decomposition. The formula for anthocyanin is then represented by Grafe as

$$
\mathrm{C}_{13} \mathrm{H}_{19} \mathrm{O}_{3}(\mathrm{OH})_{2}(\mathrm{COOH})_{3}(\mathrm{COH})_{2} \text {. }
$$

An analysis was also made of the colourless crystalline products which are formed when acetic acid is driven off from the acetic acid solution of anthocyanin. The colourless crystals are soluble in water, alcohol and ether. The substance was identified on analysis, etc., as protocatechuic acid. Some doubt is expressed by Grafe as to whether this substance is a decomposition product, or whether it is present as impurity.

The amorphous anthocyanin was next investigated. This product forms the principal part of the total pigment extracted. After drying, it is soluble with difficulty in water, but readily soluble in dilute alcohol. With acids it gives a less bright colour than the crystalline form: with alkalies, a greenish-brown colour, while sodium bisulphite removes the colour.

The analyses gave:

$$
\text { C }
$$

$43.78 \%$

$\mathrm{H}$

0

From anthocyanin $\ldots \quad \ldots$

$44 \cdot 17 \%$

$6.22 \%$

$6.75 \%$

$50 \cdot 0 \%$ $49 \cdot 08 \%$

The molecular weight was determined in phenol, and found to be 663 as compared with 652 calculated for $\mathrm{C}_{24} \mathrm{H}_{44} \mathrm{O}_{20}$.

This latter product was found to be a glucoside, and dextrose was identified as one of the products of hydrolysis with acid. Grafe suggests that the relationship between the two pigments may be represented thus:

$$
\begin{aligned}
& \mathrm{C}_{24} \mathrm{H}_{44} \mathrm{O}_{20}+\mathrm{H}_{2} \mathrm{O}=\mathrm{C}_{6} \mathrm{H}_{12} \mathrm{O}_{6}+\mathrm{C}_{18} \mathrm{H}_{34} \mathrm{O}_{15} \\
& \text { (amorphous) } \\
& \mathrm{C}_{18} \mathrm{H}_{34} \mathrm{O}_{15}-4 \mathrm{H}_{2} \mathrm{O}+\mathrm{O}_{2}=\underset{\text { (crystalline) }}{\mathrm{C}_{18} \mathrm{H}_{26} \mathrm{O}_{13}}
\end{aligned}
$$

He is also of the opinion that the amorphous form arises by changes induced in the crystalline, rather than vice versa, since the crystalline is never produced from the amorphous, but the latter may arise from the former. 


\section{Wheldale $(244,254), 1913,1914$. The flower-pigment of} Antirrhinum majus.

The anthocyanin pigment, as in most flowers, is only present in the epidermis, while the inner tissues contain a flavone, from which, we have reason to believe, the anthocyanin is derived. Pigment was prepared separately from the following varieties (see p. 160): magenta (various shades together), ivory tinged with magenta, crimson, rose doré (various shades) and bronze (various shades). In the magenta and rose doré series, apigenin is present in addition to anthocyanin; in the crimson and bronze, both apigenin and a second pigment, luteolin (see p. 114). All the flowers have, in addition, a patch of deep yellow pigment on the palate. The latter pigment can be eliminated, if desired, by tearing away the lower half of the flower, and using the upper half only for extraction; this device was adopted in the preparation of some samples of pigment. Thus, in any method of extraction, we have to deal, not only with an anthocyanin pigment, but also with one or more accompanying flavones. Two anthocyanins were found to be responsible for the colour varieties, viz. a true red anthocyanin in the rose doré and bronze series, and a magenta (blue-red) anthocyanin in the magenta and crimson series. The following method was employed for obtaining the pigment in quantity.

The flowers are boiled with water in saucepans, and the water extract filtered through large filters into lixiviating jars. The anthocyanins and flavones are then precipitated as lead salts by adding solid lead acetate to the hot solution until no more precipitate is formed. (The colour of the precipitates varies according to the flowers used; it is blue-green for full-coloured magenta, yellow-green for tinged ivory, dirty red for rose doré, and so forth. The colour of the lead salt of the anthocyanin is obviously modified by the amount and colour of the lead salts of the accompanying flavones.) The lead precipitate is filtered off, a vacuum pump being used for filtration; the solid cake of lead salt is then decomposed with $5-10 \%$ sulphuric acid. The lead sulphate is filtered off, and a bright red solution of the pigments is obtained. This solution contains all the pigments in the flower used, both anthocyanin and flavones, in the form of glucosides in dilute acid solution. The solution is now boiled in a large Jena flask, fitted with a reflux condenser, for several hours. On cooling, the anthocyanin and flavones, now less soluble and no longer in the form of glucosides, separate out as a dark purplish- or brownish-red powder, according 
to the flower-colour used. The crude pigment is filtered off through as small a funnel as possible by means of a vacuum pump, washed, and dried over calcium chloride. The well-dried pigment is then finely ground, and placed in a Soxhlet thimble. The thimble is suspended just above the surface of ether contained in a wide-necked Erlenmeyer flask fitted with a condenser, and the ether kept boiling upon an electric heater. This process is continued until the ether ceases to extract any yellow colour. In this way the anthocyanins are obtained practically free from flavones, since the latter are soluble in ether. The anthocyanin residue in the thimble is then taken up in absolute alcohol, and filtered, and is, in this way, frèed from a quantity of brown substance, which is insoluble in alcohol, and which is probably formed during the hydrolysis of the glucoside with sulphuric acid. The absolute alcohol solution, evaporated to its minimum bulk, is then poured into a large volume of ether, and the anthocyanin is precipitated, but any flavone present as impurity is retained in solution. The dried precipitate of anthocyanin is again extracted with ether to remove traces of flavone. The method of precipitation gives better results, as regards the purity of anthocyanin, than crystallisation, for, on crystallising a mixture of anthocyanin and flavone, both substances crystallise out together, and one is unaware of the presence of flavone in the product obtained.

The two forms of anthocyanin, red and magenta, were extracted and purified in this way from the flowers of different varieties of Antirrhinum mentioned above.

Pure red anthocyanin is an indian-red powder. It is readily soluble in absolute alcohol, almost insoluble in water, and slightly soluble in dilute acids and ethyl acetate; insoluble in ether, chloroform and benzene. In concentrated sulphuric acid it forms a reddish solution with a slight green fluorescence. It is soluble in alkalies to a greenish-yellow solution. With ferric chloride it gives a brownish-green coloration. With lead acetate, a brownish-yellow precipitate.

Pure magenta anthocyanin is a magenta-red powder with similar properties and solubilities to the red. In concentrated sulphuric acid it gives a red solution with a slight greenish fluorescence. It is soluble to a green solution in alkalies. With ferric chloride solution it gives a brownish-green coloration. With lead acetate it forms a greenishblack precipitate of a lead salt. In alkaline solutions it is strongly fluorescent, green by transmitted, red by reflected light. 
The results of combustion of the pure anthocyanin were:

\begin{tabular}{|c|c|c|c|c|c|}
\hline \multirow{2}{*}{\multicolumn{2}{|c|}{ Red anthocyanin: }} & & C & H & 0 \\
\hline & & from rose doré & $51.93 \%$ & $5.02 \%$ & $43.05 \%$ \\
\hline , & ,", & " bronze & $51.37 \%$ & $5.05 \%$ & $43.58 \%$ \\
\hline & ;" & , & $52 \cdot 12 \%$ & $4.97 \%$ & $42.91 \%$ \\
\hline Iagenta & ," & magenta & $50 \cdot 26 \%$ & $4.89 \%$ & $44.85 \%$ \\
\hline & " & $\begin{array}{l}\text { ivory tinged } \\
\text { with magenta }\end{array}$ & $50 \cdot 68$ & $5 \cdot 5$ & $43 \cdot 78$ \\
\hline " & ", & from crimson ... & $50 \cdot 56$ & $4.90 \%$ & $44 \cdot 54$ \\
\hline
\end{tabular}

Attempts were made to determine the molecular weight by depression of freezing point, using phenol as a solvent, but the results, though consistent for a series of experiments, were obviously far too low. Acetic acid, and various other solvents, did not dissolve enough of the pigment to give measurable depressions. Attempts to determine the molecular weight by elevation of the boiling point in absolute alcohol gave mean values of 572 for the red, and 717 for the magenta. The elevation of the boiling point was so slight that the error in the value obtained may be very considerable.

The combustion results give, as simplest formulae, $\mathrm{C}_{15} \mathrm{H}_{18} \mathrm{O}_{10}$ for the magenta, and $\mathrm{C}_{8} \mathrm{H}_{9} \mathrm{O}_{5}$ for the red. The boiling point determination of the molecular weight would appear to indicate that the molecule is $2\left(\mathrm{C}_{15} \mathrm{H}_{18} \mathrm{O}_{10}\right)$, i.e. $\mathrm{C}_{30} \mathrm{H}_{36} \mathrm{O}_{20}$, which has a molecular weight of 716 for the magenta, and $3\left(\mathrm{C}_{8} \mathrm{H}_{9} \mathrm{O}_{5}\right)$, i.e. $\mathrm{C}_{24} \mathrm{H}_{27} \mathrm{O}_{15}$, which has a molecular weight of 555 for the red.

An attempt was made to estimate the number of hydroxyl groups present in the anthocyanin molecule by means of Zerewitinoff's modification of Hibbert \& Sudborough's method. This consists in dissolving the substance in thoroughly dried pyridine, treating it in a suitable apparatus with a considerable excess of methyl magnesium iodide, and collecting the gas evolved. Each hydroxyl group causes the evolution of a molecule of methane. It should be noticed that 'hydroxyl groups,' as determined by this method, include those forming part of the carboxyl groups, and also such ketone groups as can give rise to hydroxyl by tautomeric change. The values obtained indicate that the red anthocyanin, taking the formula as $\mathrm{C}_{24} \mathrm{H}_{27} \mathrm{O}_{15}$, contains twelve hydroxyl groups as defined above, while the magenta, taking the formula as $\mathrm{C}_{30} \mathrm{H}_{36} \mathrm{O}_{20}$, contains fifteen hydroxyl groups. 
Willstätter (245), 1913. The flower-pigment of Centaurea Cyanus.

In Centaurea flowers, according to Willstätter, there are three modifications of one anthocyanin pigment: a purple pigment (cyanin), which is itself a free acid; a blue pigment, which is the potassium salt of the purple, and which constitutes the greater part of the colouring matter of the flower; a red pigment, which is the oxonium salt of the purple with some organic acid (other oxonium salts can be obtained artificially with inorganic acids, such as hydrochloric acid). Cyanin, moreover, isomerises to a colourless form which is an acid too, and forms colourless alkali salts ${ }^{1}$; there is also a colourless isomer of the blue pigment. When the anthocyanin of the flower is extracted with water, the deep blue solution rapidly loses its colour; this is due to the above isomerisation, and the colourless solution, on addition of acid, will become as red as a solution of the original blue pigment would on acidification. The red modification also loses colour in absence of acid, i.e. if sufficiently diluted with water or alcohol. On concentration, a colourless solution will return to its original colour, blue, red or violet, as the case may be.

For preparation of the blue pigment on a large scale, dried flowers ground to a fine powder were employed. The blue pigment can be extracted rapidly with water or very dilute alcohol, but change to the colourless isomer tends to take place. This change can be prevented, however, by addition of much sodium nitrate or chloride to the pigment solution. The cyanin salt can then be precipitated from the water solution with alcohol in which it is insoluble. It is further purified by fractional precipitation with alcohol from water solution.

Cyanin is a glucoside, but on hydrolysis it gives the free pigment, cyanidin, and sugar. The pigment, cyanidin, like the glucoside, cyanin, forms crystalline oxonium salts with hydrochloric acid.

The method of isolation of the blue pigment, in greater detail, is as follows. The powder of ground flowers is mixed with sand, extracted with water or $20 \%$ alcohol, and filtered, and finely powdered sodium nitrate is added. The deep blue solution is then mixed with $96 \%$ alcohol ( 2.5 vols. alcohol: 1 vol. extract), and the pigment is precipitated out in blue flakes, which are separated by a centrifuge. The pigment is further purified by taking up in water, and precipitating

1 "Das Cyanin isomerisiert sich zu einer farblosen Modifikation, welche gleichfalls sauer ist und farblose Alkalisalze bildet." The alkali salts of the isomer are, however, definitely stated to be yellow later in the paper. 
with alcohol. For the exact sequence of operations, the original paper should be consulted. The filtrate from the precipitates contained much of the colourless isomer. The pigment was also extracted by another method in which the use of sodium chloride or nitrate was eliminated. This is necessary if one wishes to obtain the naturallyoccurring cyanin salt, for if the method first described is employed the sodium replaces the potassium originally present. In the second method, the flower powder is mixed with sand, and extracted with dilute alcohol ( 80 vols. water : 20 vols. of $96 \%$ alcohol). It is then filtered and precipitated with alcohol (3 vols. of filtrate : 5 vols. $96 \%$ alcohol), and the precipitate separated by a centrifuge. All the operations should be carried out as rapidly as possible in order to avoid isomeric change. The crude pigment was again purified by reprecipitation. It was found that the product obtained by the first method contained sodium nitrate as impurity. This was removed by extracting with $75 \%$ alcohol, in which the impurity is soluble, though not the pigment. The product was, however, still further purified by precipitation, and in the end contained both sodium and potassium, the former as a result of the use of sodium nitrate. The product obtained by the second method (i.e. when the use of sodium salts for protection against isomerisation was avoided), after purification, contained no sodium.

By dialysis of the cyanin salt in a $20 \%$ sodium chloride solution, dark blue crystals were obtained. These Willstätter regards as an addition product of the cyanin salt with sodium chloride.

With regard to properties, the blue cyanin salt is insoluble in alcohol, but soluble in water; a concentrated water solution shows loss of colour only after a day or two, but a dilute solution decolorises in an hour or so. The isomerisation, as already mentioned, is best prevented by sodium chloride or nitrate, but potassium nitrate or chloride has little or no effect. The pure blue product shows practically no change in colour on addition of a little sodium hydroxide solution, but a solution of pigment which has stood becomes blue-green, or green-blue, on account of the presence of the colourless modification.

The next operation was the preparation of a crystalline salt of cyanin with hydrochloric acid. The cyanin alkali salt, obtained by the methods described, is dissolved in $20 \%$ hydrochloric acid. From this solution, some accompanying carbohydrates (pentosans), which are present as impurity, are precipitated by addition of absolute alcohol. After filtration, the pigment chloride is precipitated by ether. The crude product is then taken up in absolute alcohol, which frees it from 
colloidal substance and other impurities. The purified alcoholic solution is then acidified with strong hydrochloric acid, and concentrated in a vacuum desiccator. Cyanin chloride separates out as an amorphous product which is soluble in both alcohol and water to a bright red solution; the solution becomes rapidly paler, but in absolute alcohol, the loss of colour is much less rapid than in the presence of water. To obtain the crystalline form, the amorphous product is dissolved in absolute alcohol, filtered, and mixed with a third of its volume of a $7 \%$ solution of hydrochloric acid in water, and set to crystallise. The crystals are deep blue rhomboidal plates with a golden lustre: in a powdered form, the colour is brown-red. The chloride crystallises out with three molecules of water of crystallisation, and the formula obtained by elementary analysis is $\mathrm{C}_{28} \mathrm{H}_{33} \mathrm{O}_{17} \mathrm{Cl} \cdot 3 \mathrm{H}_{2} \mathrm{O}$. The water-free product on analysis gave $\mathrm{C}_{28} \mathrm{H}_{33} \mathrm{O}_{17} \mathrm{Cl}$. The crystalline cyanin chloride is almost insoluble in water, soluble with difficulty in cold alcohol, acetone and chloroform; insoluble in benzene; slightly soluble in dilute hydrochloric and sulphuric acids. It is stable in acid solution: in water solution it decolorises, with the formation of the isomer, especially if dilute, but the colour returns on acidification. The colourless isomer is also formed by warming with absolute alcohol; such a solution then gives with lead acetate a green precipitate, on account of the mixture of the blue salt of the pigment with the yellow alkali salt of its isomer. Pure cyanin chloride gives with calcium carbonate a violet solution; with sodium hydroxide, a blue solution; with lead acetate, a blue precipitate, which gives a green lead salt on standing; and with sodium carbonate, a violet colour which eventually becomes yellow. The chloride is reduced with zinc and hydrochloric acid, and also decolorised with sodium bisulphite, the colour in the latter case returning on addition of an acid. As a glucoside it reduces Fehling's solution.

The glucoside cyanin is rapidly hydrolysed with $20 \%$ hydrochloric acid, cyanidin being formed which separates out as the chloride from the hot solution. The combined sugar was identified as glucose. The crystals, in the form of needles, of cyanidin chloride are brown-red under the microscope, give a violet streak, and a brown-red powder. They have no water of crystallisation, and an elementary analysis gave the formula $\mathrm{C}_{16} \mathrm{H}_{13} \mathrm{O}_{7} \mathrm{Cl}$. The chloride is soluble in alcohol with a fine violet-red colour; it is also soluble with difficulty in dilute hydrochloric acid. It crystallises from a mixture of alcohol and dilute hydrochloric acid. It is also soluble in amyl alcohol, and when such a solution is shaken with caustic soda solution, the pigment goes into the watery 
layer with a blue colour. With sodium carbonate it gives a violet or blue colour (green when the colourless isomer is also present); with lead acetate, it gives a blue precipitate.

The violet modification of anthocyanin was obtained apparently by precipitating a solution of cyanin chloride with lead acetate, and decomposing the lead salt with excess of sulphuretted hydrogen. On filtration and evaporation, the violet form of the pigment is obtained.

The colourless modification of the pigment is soluble in ether; on evaporation of the ether it remains in the form of colourless crystals, which give an intense red colour on heating with hydrochloric acid. With alkalies it gives a yellow colour, but is apparently not a flavone (see p. 78).

As regards the constitution of anthocyanin, Willstätter, in this first paper, is of the opinion that the pigment of Centaurea contains a nucleus of the following type, colour being due to the presence of the quinonoid and tetravalent oxygen:

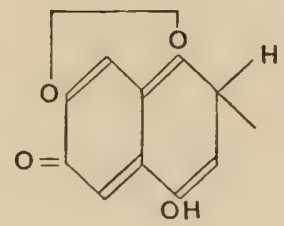

the above would represent the violet pigment as an inner oxonium salt. Under certain conditions, as we have seen, a change readily takes place by tautomerism to a colourless isomer:

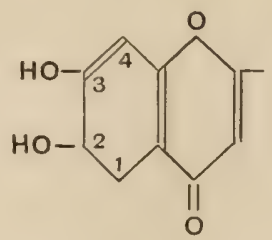

which is really a flavone with an extra hydroxyl in position 2 .

The blue pigment in the plant is the potassium salt of the violet pigment, the position of the potassium being uncertain. If the cell-sap is alkaline, the blue salt predominates, or is alone present. 
If there is excess of acid in the cell-sap, a red oxonium salt with an organic acid is formed. The crystalline salts with hydrochloric acid are regarded as artificial compounds of this kind:

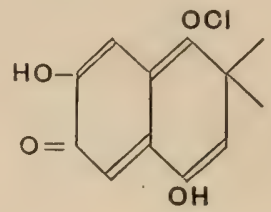

In the presence of excess of water, both the red and the blue forms will pass to the colourless isomer, but in the case of the blue the tautomeric change can be prevented by adding a neutral salt which forms an additive compound:

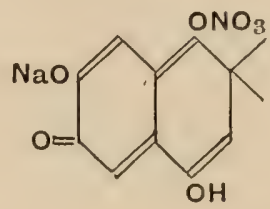

The chief argument against the above hypothesis is that flavones of the above constitution are at present unknown. The analyses so far made only point to the existence of a definite hydrochloric acid compound, and indicate nothing as regards the constitution, the above suggestions being purely hypothetical. Variations in this hypothesis, based upon later work, will be considered in the following paragraphs.

Willstätter, in conjunction with Bolton, Nolan, Mallison, Martin, Mieg and Zollinger $(256,257), 1914$. The flower-pigments of Centaurea, Delphinium, Malva, Pelargonium and Rosa gallica; the fruitpigments of Vaccinium Myrtillus, Cranberry and Vitis vinifera.

\section{Flower-pigment of Centaurea.}

The statement made previously that the cyanin of Centaurea is decomposed on hydrolysis into one molecule of cyanidin and two molecules of glucose is confirmed. But the formula $\mathrm{C}_{16} \mathrm{H}_{13} \mathrm{O}_{7} \mathrm{Cl}$, originally given for cyanidin chloride, is found to be incorrect owing to the fact that the product was insufficiently dried. It is found that reliable numbers can only be obtained after long drying in a ligh vacuum at 
$105^{\circ} \mathrm{C}$. The formula is then found to be $\mathrm{C}_{15} \mathrm{H}_{11} \mathrm{O}_{6} \mathrm{Cl}$ from the following analyses:

\begin{tabular}{|c|c|c|c|c|}
\hline & & $\mathrm{C}$ & H & $\mathrm{Cl}$ \\
\hline From cyanidin chloride & $\begin{array}{l}\text { (i) } \\
\text { (ii) }\end{array}$ & $\begin{array}{l}55.40 \% \\
55.77 \%\end{array}$ & $\begin{array}{l}3.62 \% \\
3.60 \%\end{array}$ & $10.75 \%$ \\
\hline Calculated for $\mathrm{C}_{15} \mathrm{H}_{11} \mathrm{O}_{6} \mathrm{Cl}$. & $\ldots$ & $55 \cdot 81 \%$ & $3.41 \%$ & $11 \cdot 01 \%$ \\
\hline
\end{tabular}

Flower-pigment of Rosa gallica.

This pigment is found to be a diglucoside of cyanidin.

'Pigment from fruit of Cranberry.

This pigment-idaeïn-is found to be a galactoside of cyanidin, formed from one molecule of cyanidin and one molecule of galactose.

\begin{tabular}{|c|c|c|c|c|c|c|}
\hline & & & \multicolumn{3}{|c|}{ Calculated for $\mathrm{C}_{31} \mathrm{H}_{21} \mathrm{O}_{11} \mathrm{Cl}$} & Found \\
\hline tal & . & $\cdots$ & ... & $37 \cdot 2$ & $\ldots$ & $33 \cdot 4$ \\
\hline chloride & & $\ldots$ & $\ldots$ & $66 \cdot 6$ & $\ldots$ & $67 \cdot 5$ \\
\hline
\end{tabular}

Pigment (Oenin) from grapes.

The method employed for preparation was as follows. The skins of dark blue grapes are extracted in the cold with glacial acetic, and the dark red filtrate precipitated with ether. A sticky precipitate is obtained which, after washing with ether, is put into an excess of water picric acid solution, and warmed for a short time. On cooling, the picrate crystallises out from the solution in long prisms of a fine red colour. By changing the solution to methyl-alcohol-hydrochloric acid, it yields the solution of the pigment chloride, which is precipitated with ether-petrol-ether and crystallised from water-alcohol-hydrochloric acid, in the form of hard beetle-green prisms. On hydrolysis, nenin decomposes into oenidin $-\mathrm{C}_{17} \mathrm{H}_{14} \mathrm{O}_{7}$ - and one molecule of glucose.

Pigment (Myrtillin) from the Bilberry (Vaccinium Myrtillus).

The skins of the berries are used after being dried and ground. The pigment is extracted rapidly by warming with ethyl alcohol, which contains a small percentage of hydrochloric acid, and the solution is precipitated with ether. The precipitate, mixed with a large quantity of a colourless product, is separated, by taking up in water, from many of its impurities. By addition, with cooling, of a double weight of concentrated hydrochloric acid, the chloride is precipitated almost pure, and quite pure by repetition of the operation. For crystallisation, a third of its volume of $9 \%$ hydrochloric acid is added to the solution 
of the pigment in wood spirit; on slow evaporation the pigment separates out in beautiful flat prisms. Myrtillin gives, on hydrolysis, one molecule of glucose and one molecule of myrtillidin $-\mathrm{C}_{16} \mathrm{H}_{12} \mathrm{O}_{7}$. Myrtillin was also isolated from flowers of the Hollyhock (Atthaea rosea).

The following anthocyanins were also isolated, but no details are given of the methods.

The flower-pigment of Delphinium-delphinin-which gives, on hydrolysis, two molecules of glucose, two molecules of $p$-oxybenzoic acid and one molecule of delphinidin $-\mathrm{C}_{15} \mathrm{H}_{10} \mathrm{O}_{7}$.

The flower-pigment of Pelargonium-pelargonin-which gives, on hydrolysis, two molecules of glucose, and one molecule of pelargonidin $-\mathrm{C}_{15} \mathrm{H}_{10} \mathrm{O}_{5}$.

The flower-pigment of Malva-malvin-which gives on hydrolysis malvidin $-\mathrm{C}_{17} \mathrm{H}_{14} \mathrm{O}_{7}$.

The chlorides of pelargonidin, oenidin and delphinidin are described as crystalline salts, insoluble in water, but soluble in alcohol. In the glucosidal form, they give, with the exception of delphinidin, colourless isomers in water solution. The anthocyanidins isomerise less readily. The isomerisation is said to take place according to the following equation:

$$
\mathrm{C}_{15} \mathrm{H}_{10} \mathrm{O}_{7} \mathrm{HCl}+\mathrm{H}_{2} \mathrm{O}=\mathrm{HCl}+\mathrm{C}_{15} \mathrm{H}_{12} \mathrm{O}_{8}
$$

In alkali melts of the pigments, the following decompositions were found to take place:

Cyanidin gave phloroglucin and protocatechuic acid.

Pelargonidin gave phloroglucin and $p$-oxybenzoic acid.

Delphinidin gave phloroglucin and gallic acid (not isolated in pure state).

As a result of these further researches Willstätter then suggests that for the formula of cyanidin chloride the choice lies between:

I.

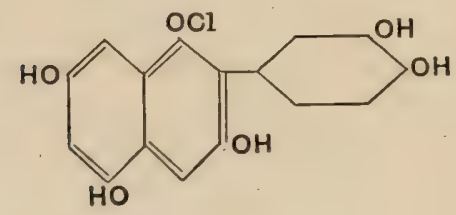

or

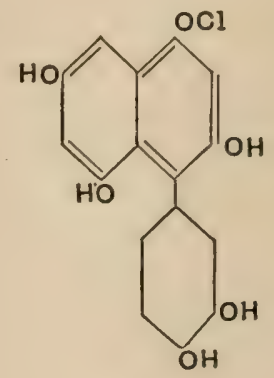


Formula II was discarded because, if such a formula were correct, it should be possible to obtain a substituted benzophenone, for example, maclurin $^{1}$, as a product from cyanidin, and this was not found to be the case.

Willstätter then suggests that the anthocyanidins and flavones are related in the following way:

\section{Flavones Anthocyanidins}

Luteolin, kampherol and fisetin $\mathrm{C}_{15} \mathrm{H}_{10} \mathrm{O}_{6} \rightarrow$ pelargonidin $\mathrm{C}_{15} \mathrm{H}_{10} \mathrm{O}_{5}$

Quercetin $\mathrm{C}_{15} \mathrm{H}_{10} \mathrm{O}_{7} \rightarrow$

Myricetin $\mathrm{C}_{15} \mathrm{H}_{10} \mathrm{O}_{8} \rightarrow$ cyanidin $\mathrm{C}_{15} \mathrm{H}_{10} \mathrm{O}_{6}$ delphinidin $\mathrm{C}_{15} \mathrm{H}_{10} \mathrm{O}_{7}$

that is, that each anthocyanin is derived from a flavone by reduction.

The formulae eventually suggested for the chlorides of cyanidin, pelargonidin and delphinidin are as follows:

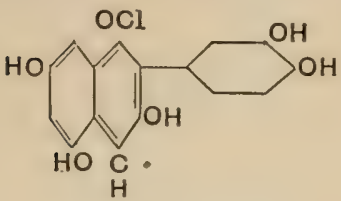

Cyanidin chloride

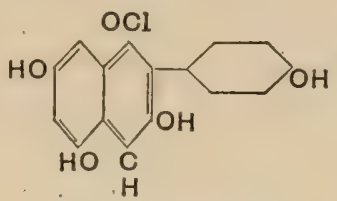

Pelargonidin chloride

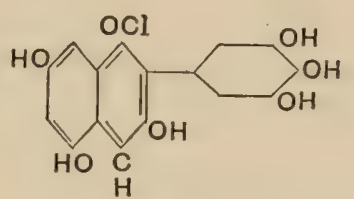

Delphinidin chloride

whereas myrtillidin, oenidin and malvidin are represented as methyl derivatives of delphinidin:

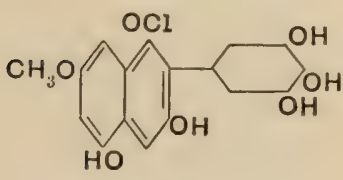

Myrtillidin chloride

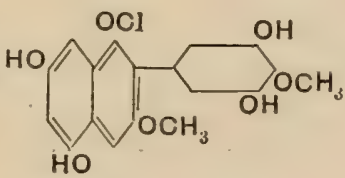

Oenidin chloride

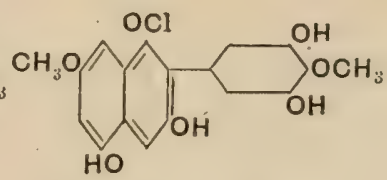

Malvidin chioride

Willstätter also brings forward, as additional evidence in favour of these constitutional formulae, the preparation, artificially, of cyanidin from quercetin (see p. 124).

1 Maclurin is a pentaoxybenzophenone occurring in Morus tinctoria; its constitution is represented as:

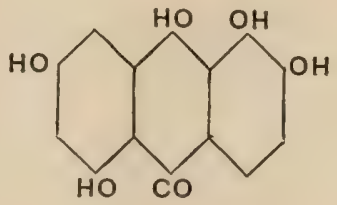




\section{ISOLATION AND CONSTITUTION OF AN'THOCYANINS [CH. v}

A short summary of the formulae ${ }^{1}$ given by various authors for anthocyanins may be stated as follows ${ }^{2}$ :

Flower-pigment of Althaea rosea ’ ...

$$
\begin{aligned}
& \begin{array}{llllll}
\cdots & \cdots & \cdots & x\left(\mathrm{C}_{4} \mathrm{H}_{5} \mathrm{O}_{2}\right) \quad(\mathrm{Glan}) .
\end{array}
\end{aligned}
$$

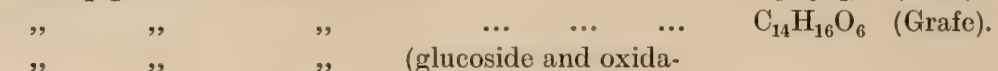

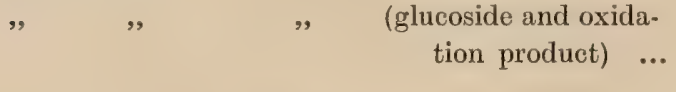

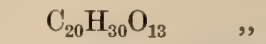

$\begin{array}{ll}" & " \\ " & " \\ " & " \\ " & " \\ " & " \\ " & \quad \\ " & \quad\end{array}$

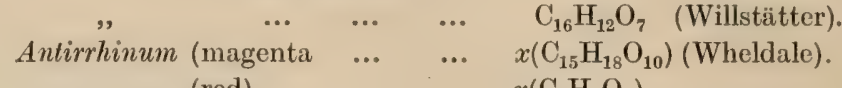$$
\begin{array}{llllll}
\text { Centaurea Cyanus } & \ldots & \ldots & \ldots & \ldots & x\left(\mathrm{C}_{2} \mathrm{H}_{3} \mathrm{O}_{2}\right)
\end{array} \text { (Morot). }
$$$$
\begin{array}{llllllll} 
& \cdots & \ldots & \ldots & \ldots & \mathrm{C}_{15} \mathrm{H}_{10} \mathrm{O}_{6} & \text { (Willstätter). }
\end{array}
$$$$
\text { Delphinium } \quad \ldots \quad \ldots \quad \ldots \quad, \mathrm{C}_{15} \mathrm{H}_{10} \mathrm{O}_{7} \quad \text { " }
$$$$
\begin{array}{llllllll}
\text { Malva . } \quad \ldots & \ldots & \ldots & \ldots & \mathrm{C}_{17} \mathrm{H}_{14} \mathrm{O}_{7} & \text {, }
\end{array}
$$$$
\begin{array}{lllllll}
\text { Pelargonium } \quad \ldots & \ldots & \ldots & \mathrm{C}_{15} \mathrm{H}_{10} \mathrm{O}_{6} & \text { (Griffiths). }
\end{array}
$$

$$
\mathrm{C}_{24} \mathrm{H}_{44} \mathrm{O}_{20} \quad,
$$

$\mathrm{C}_{24} \mathrm{H}_{44} \mathrm{O}_{20} \mathrm{C}_{15} \mathrm{H}_{10} \mathrm{O}_{5}$ (Willstätter).

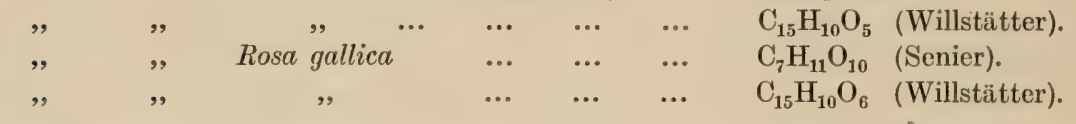

Fruit-pigment of Vaccinium Myrtillus $\quad \ldots \quad \ldots \quad \mathrm{C}_{14} \mathrm{H}_{14} \mathrm{O}_{7}$ (Heise).

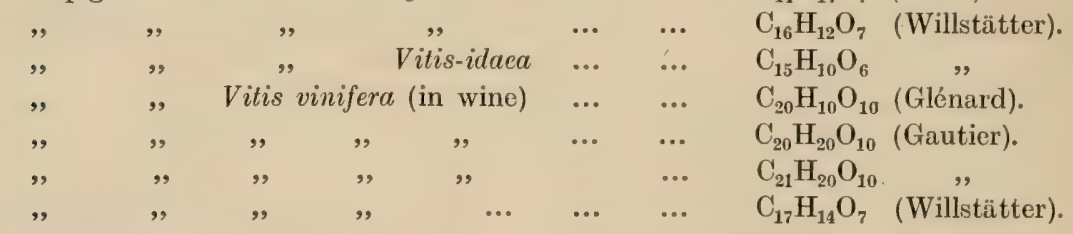

$\begin{array}{lllllll}\text { Red leaf-pigment of Coleus } & \ldots & \ldots & \ldots & \ldots & \mathrm{C}_{10} \mathrm{H}_{10} \mathrm{O}_{5} & \text { (Church). }\end{array}$

$$
\text { " } \quad \text { Vitis vinifera } \quad \ldots \quad \ldots \quad \ldots \begin{cases}\mathrm{C}_{19} \mathrm{H}_{16} \mathrm{O}_{10} & \text { (Gautier). } \\ \mathrm{C}_{26} \mathrm{H}_{24} \mathrm{O}_{15} & , \\ \mathrm{C}_{17} \mathrm{H}_{18} \mathrm{O}_{10} & ,\end{cases}
$$

1 The formulao are so arranged rather as a matter of interest than for comparison, since the earlier workers laboured under disadvantages which would obviously detract from the value of their numbers.

2 See also Appendix. 


\section{CHAPTER VI}

\section{PHYSIOLOGICAL CONDITIONS AND FACTORS INELUENCING THE FORMATION OF ANTHOCYANINS}

\section{Connection with photosynthesis.}

An examination of the relative distribution of anthocyanin and chlorophyll at once suggests that these pigments are more or less complementary as regards their appearance in the plant tissues. In leaves, the chief seat of chlorophyll, anthocyanin is found to a less extent than in any other organ, and under normal circumstances the development is most frequently confined to the epidermis (see p. 37), or to a few sub-epidermal layers, often only where they overlie the midrib or main veins. Moreover, when red pigment is present in the epidermis, the guard cells of the stomata, which contain chlorophyll, are generally free from pigment. In petioles and stems also, anthocyanin is on the whole limited to the epidermis, or to a few sub-epidermal layers. Bracts of all kinds, on both the inflorescence and other parts of the plant, frequently contain anthocyanin and correspondingly little chlorophyll; although flowers in the bud stage and unripe fruits have fairly abundant chlorophyll, as the flowers and fruits mature the chlorophyll disappears and anthocyanin develops.

Since chloroplasts are invariably concerned with photosynthesis, one would naturally conclude that the latter process and the formation of anthocyanin are to some extent mutually exclusive. The existence of some such alternation is further emphasised by the appearance of anthocyanin which accompanies lessened photosynthetic activity, as in plants towards the end of their vegetative season, in autumnal reddening, in leaves in an unhealthy condition and in evergreens during winter. Since all metabolic activity ultimately depends on photosynthesis, it is not a convincing argument that a decline in general metabolism (apart from photosynthesis) may directly bring about the formation of pigment. There is without doubt good evidence for

W. P. 
believing that anthocyanin is not readily produced where carbon assimilation is most active, and that decreased photosynthesis from any outside cause is favourable to its formation.

Hence in any consideration of the direct bearing of outside factors, such as temperature and light, on anthocyanin formation, recognition should be first given to possible indirect effects produced by these factors through the medium of photosynthesis.

\section{Connection with accumulation of synthetic products.}

Even at the height of summer when the vegetative organs are in a condition of maximum activity, quite a number of individual plants may be found having isolated leaves or shoots which are either entirely red or have developed patches or blotches of anthocyanin. In the majority of cases, one will find on careful examination that there has been some injury to the leaf, petiole or stem, as the case may be, and it is to the distal side of the injured spot that the reddening occurs. Such injuries may be classified as: (1) mechanical, caused by chance cutting or breaking; (2) attacks of insects, including gall insects and caterpillars; (3) infection by Fungi.

(1) Let us deal first with mechanical injury. Frequently leaves may be found in which the lamina is partially severed transversely, and the severed portion has reddened. Or the petiole or stem is partially broken, and the leaf or leaves above the point of injury have turned red. In Rumex, Oenothera, Pelargonium, Plantago and many other plants, it is easy to bring about such reddening artificially by pinching the lamina or petiole, and in other cases by decortication. Or sometimes isolated leaves, as for instance those of Rheum, left lying on the ground in a damp place will eventually redden. In other genera and species, it is difficult, or impossible probably, to induce reddening by such means. Reference to these phenomena has often been made by various authors: Gautier (175), Kraus (311), Berthold (64), Linsbauer (341), Küster (350), Daniel (337) and finally Combes (374, 385). Further Combes has made a series of experiments on decortication of stems of many species with a view to investigating the phenomena more fully. By these means he has distinguished three types of results:

(a) Those in which anthocyanin appeared more or less rapidly in the branches, petioles and above all in the leaves. Ex. Spiraea spp., Mahonia aquifolium, Prunus Pissardi.

(b) Those in which anthocyanin appeared more or less rapidly in 
the stems and petioles but not in the leaves. Ex. Ceanothus azureus. Catalpa bignonioides.

(c) Those in which pigment never appeared as a result of decortication. Ex. Rhorlotypos kierrioides, Robinia Pseudacacia, Pinus excelsa.

The time elapsing before the appearance of pigment also varied considerably. In addition it was noted, as would be expected, that no pigment appeared on decortication in albino varieties, although the coloured type might produce abundant pigment under similar treatment.

(2) Injuries brought about by insects present no points of special interest but may be regarded rather as cases of (1). Frequently the midrib or petiole is partly eaten away, and reddening occurs on the distal side; or holes are eaten in the lamina, and red blotches are formed in their vicinity. Mirande (362) has observed that excursions of leafboring larvae in leaves of Galeopsis Tetrahit result in the production of anthocyanin. Under this heading also may be included the development of anthocyanin in or near galls. For details and examples the works of Hieronymus (314), Küstenmacher (326), Küster (350) and Guttenburg (353) may be consulted.

(3) It is frequently found that the pathological conditions called forth by the attacks of Fungi are accompanied by abnormal development of anthocyanin. In leaves of Tussilago, for instance, infected by Puccinia a circular band of anthocyanin often appears surrounding the aecidium spots. Other references to this matter may be looked for in the works of Sorauer (304), Tubeuf (329), Lüdi (342) and Rostrup (345).

There is little doubt that, in the above cases of injury and decortication, the formation of pigment is directly connected with an interference with the translocation current. Injury to the living tissues of the conducting system of the veins, midrib or petiole of the leaf, or of corresponding tissue in the stem, leads to an accumulation of synthetic products in the leaves. Of such products several authors-Mirande (365), Combes (207)--have maintained that it is the carbohydrates and glucosides which most influence the formation of anthocyanin, and Combes has shown by analy'ses that leaves reddened by decortication contain a higher percentage of sugars and glucosides. It seems likely also that parasitic growths may interfere with the progress of the translocation current through the small veins of the leaf, thereby causing congested areas to arise in which the sugar contents are above normal. But it is conceivable that the pathological condition resultant on fungal attacks may be the direct cause, in some way, of pigment formation. 
$[\mathrm{CH}$.

The more intimate connection between anthocyanin and sugars will be discussed in a later chapter.

The experiments of decortication, etc., lead also to the conclusion that the chromogen ${ }^{1}$ of anthocyanin is synthesised in the leaves. For in cases where leaves and shoots have reddened owing to the blocking of the translocation current, less development of pigment has often been noticed in flowers and fruits. Gautier (175) made various experiments on vines in order to illustrate his view that the chromogen of the grape pigment is synthesised in the leaves, and is oxidised after passing into the fruit. Vine branches were deprived of their leaves, and this was shown to prevent a development of pigment in the fruit. In another experiment, the petioles of the leaves were ligatured with the result that the fruits remained green and the leaves themselves reddened. Ravaz (380), on the other hand, grafted a vine with purple grapes on to a white-fruited variety, and found that although the white variety produced no pigment in the leaves, the fruit of the graft was coloured every year. Hence Ravaz concludes that the pigment is synthesised in the fruit itself, though the latter may be nourished by the leaves. A direct connection between leaves and flower-colour may be demonstrated by removing a developing inflorescence from a plant, such as Digitalis purpurea, when the leaves will generally turn red. Gertz (19) observed the same result in a plant of Geum rivale from which the flowers had been cut off.

There is also reason to believe that special richness in nutriment, or synthetic products, is connected with anthocyanin formation. An experiment is quoted by Berthold as illustrating this point. From two- or three-year old individuals of Acer pseudoplatanus all buds were removed but the terminal one, which, as a result, received an excessive amount of nutriment and on development was strongly reddened. Some such explanation, as Gertz suggests, may account for the excessive reddening of leaves of adventitious shoots arising at the base of felled trees (Populus, Tilia, Acer).

Bonnier $(294,307,328)$ and Heckel $(300)$ have noted that a greater intensity of flower-colour is produced in many species when grown at high altitudes, as compared with the colour of the flowers in lowland regions. It is conceivable that this increase in intensity of colour

1 The chromogen, as we shall see later (p. 109), is in all probability a flavone occurring in the form of a glucoside. There is reason to believe that, not only does the synthesis of glucoside from flavone and sugar take place in the leaf, but also the synthesis of the flavone itself from sugars. 
is brought about by increase of synthetic products, due to greater insolation by day accompanied by low night temperature, and to stunted growth, rather than to any direct action of light on pigment formation, but at present there is no conclusive evidence.

In the same way lack of synthetic products due to poor conditions of the plant reduces pigment formation. The experiments of Sachs (271), Askenasy (282), Vöchting (325) and Klebs (360), in which leaves of plants were kept in darkness while the flowers were exposed to light, are not so conclusive as those previously mentioned. The method is so drastic, and may influence the whole nutrition of the plant to such an extent, that the non-development of flower-colour cannot be regarded as having any great significance.

A phenomenon of considerable interest in connection with nutrition and formation of red pigment is that pointed out by Mirande (332) as occurring in the genus Cuscuta, in which anthocyanin is widely produced. From observations made upon the development of many different species of Cuscuta on various hosts, Mirande concludes that the amount of pigment varies not only in different species but also in each species according to the host on which it grows. For instance, the same species growing on Sambucus nigra (poor) and Forsythia viridissima (rich in sugar) becomes green on the former but very red on the latter. Hence Mirande correctly deduces the fact that not only good development of the parasite but also the formation of red colour is correlated with good nutrition. In nature, species of Cuscuta passing from one host to another are seen to show different amounts of pigmentation. Chemical tests made by Mirande on extracts from the host plants showed that the greatest production of colour was found when the host plants were capable of producing most sugar.

The conclusions which may be drawn from all the instances quoted above are that an unnatural accumulation of synthetic products may cause colour to be developed in organs not normally coloured. At the same time a good supply of nutrition will intensify colour in parts of plants which are normally coloured. There is reason to believe that, of the accumulated substances, the most potent in bringing about colour production are sugars and glucosides, and this will be found to be borne out by observations connected with the effect of other factors considered in this chapter. Also an increase of the chromogens from which anthocyanins are produced takes place under the conditions mentioned above. The manner in which glucosides, sugars, chromogens and pigment may be connected is dealt with in the next chapter. 
The relationship between anthocyanin development and sugarfeeding is reserved for a later paragraph (see p. 93).

\section{Effect of temperature.}

Most general observations bear out the conclusion that increase of anthocyanin is correlated with lowering of temperature. The most obvious demonstrations are the autumnal coloration of leaves and, to a lesser extent, the reddening of evergreen leaves in winter (Ligustrum, Hedera, Mahonia). The question of the relationship between low temperature and anthocyanin formation has been specially considered by Overton (333). This author had observed that Hydrocharis plants grown in cane sugar solution became very strongly reddened, and the idea occurred to him that an excess of sugar in the cell-contents might similarly be the cause of autumnal and winter coloration of leaves. In view of this suggestion, it is difficult to estimate any direct effect of low temperature on anthocyanin formation, because of the indirect effect produced by the same conditions on (1) photosynthesis, (2) formation of starch from sugar, (3) growth in general and probably (4) translocation. A decrease of activity of (1) leads to a decrease of sugar contents in the cell; but a decrease of (2) and (4) has the opposite effect. The process of removal of synthetic products from the leaves is, according to Sachs, greatly retarded by low temperature. Hence similar conditions of clogging to those brought about by injury, which were mentioned in the previous section, might arise and there would be a resultant production of pigment. The synthesis of starch from sugar is also a process which is retarded by low temperature. Thus Müller-Thurgau ${ }^{1}$ has shown that at temperatures below $5^{\circ} \mathrm{C}$. quite a considerable portion of the starch contents of the potato is changed to sugar, and with a rise of temperature the greater portion of starch is again regenerated. According to Lidforss ${ }^{2}$, evergreen leaves in winter are also completely starch-free but contain very considerable quantities of glucose, which is again to a large extent changed back to starch if the leaves are artificially warmed. Overton himself examined the sugar content of autumnal leaves and found considerable quantities present, considerably more, at any rate, than in the same species at midsummer.

From the above statements it will be seen that low temperature

1 Müller-Thurgau, H., 'Ueber Zuckeranhäufung in Pflanzentheilen in Folge niederer Temperatur,' Landw. Jahrb., Berlin, 1882, xI, pp. 751-828.

2 Lidforss, B., 'Zur Physiologie und Biologie der wintergrünen Flora,' Bot. Centralbl., Cassel, 1896, LxvIII, pp. 33-44. 
may greatly affect the sugar contents of the tissues, and hence may in this way cause the reddening, apart from any more direct effect.

Overton made some observations on the effect of temperature on reddening of Hydrocharis leaves, and found that the higher the temperature the less anthocyanin is formed and vice versa, but obviously in this case it is impossible to eliminate the effect of temperature on the photosynthetic activity of the leaves, and on growth and respiration in general with the resultant employment of synthetic materials. Klebs also (360) gives an account of the effect of temperature on the colour of the flowers of Campanula Trachelium. From cultures at various times of the year in green-houses, etc., kept at different temperatures, he obtained a variation in flower-colour from white (in heat) through pale blue to deep blue (in cold). He also observed that Primula sinensis produces tinged flowers in a hot-house and full-coloured flowers in the cold. Klebs is of the opinion that the colour changes induced by changes of temperature are not directly due to the effect of temperature on pigment formation but indirectly to the effect of temperature on metabolism. At high temperatures, growth is so rapid that the substances used in pigment formation are not present in sufficient quantity.

\section{Effect of light.}

As regards the effect of light on anthocyanin formation, there have been numerous observations, some more or less conflicting. As with temperature, the main question at issue is again, whether light directly affects anthocyanin formation, or whether its influence is only indirect, in so far as it affects photosynthesis and the accumulation of the products of this process, among which are the chromogens from which pigment is formed $^{1}$.

The effect of the absence of light on the development of pigment in flowers may first be considered. As early as 1799, Senebier (2) noted that the Crocus and Tulip develop coloured flowers in the dark. The same observations were recorded by Marquart (5) in 1835 for Crocus sativus. Later Sachs made definite experiments on various plants either by growing them entirely in the dark, or by enclosing

I I am indebted to Dr F. F. Blackman for drawing my attention to a fact which is interesting in this connection, i.e., that the development of chlorophyll may be affected by nutrition. The statement is founded on the observation that certain Algae develop chlorophyll in the dark when provided artificially with protein; when supplied with nitrates under the same conditions, however, the pigment does not appear. 
in a dark chamber certain shoots or branches only, the other parts of the plant being in the light. Of plants grown entirely in the dark, Sachs (269) was able to distinguish two classes: $(a)$ flowers which develop colour normally in the dark without being previously exposed to light (Tulipa, Iris, Hyacinthus, Crocus); (b) flowers which only develop colour in the dark if the buds have been fully exposed to light until just before opening (Brassica, Tropaeolum, Papaver, Cucurbita). Of Tulipa Gesneriana Sachs specially remarks: "Die schön gefärbten und normal entfalteten Blüthen auf den etiolirten Pflanzen machten einen höchst sonderbaren Eindruck." And of Iris pumila he says: "der zart hellbläuliche Grundton der Perigonzipfel, die dunkelviolette Aderung, welche gegen den Grund der Zipfel hin in das bläulich Purpurescirende übergeht, das Orangegelb der Bärte, das schön warme Blau der Narben und die himmelblaue Färbung des Pollens, alle diese Färbungen waren bei der Blüthe der etiolirten Pflanze eher glänzender und gesättigter als bei den am Lichte entfalteten." In the case of Tropaeolum, Papaver, etc., if the plants were darkened just before the buds unfolded, normally coloured flowers were produced, but later buds develop flowers with decreasing amounts of pigment. In the cases where shoots only were darkened, the flowers borne upon them were normal as regards size, but the coloration was less intense. Further experiments were made by Askenasy (282) who confirmed Sachs' results for Tulipa and Crocus, though he found Hyacinthus flowers rather less coloured in the dark. Other plants (Pulmonaria, Antirrhinum Silene, Prunella) showed less production of anthocyanin in the dark if the buds had not been previously exposed to light; in Prunella, almost white flowers were formed. Sorby (144), Beulaygue (339), Gertz (19) and others have confirmed these results for the flowers of various species, showing that considerably less, very little, or no colouring matter at all, is formed in the dark.

As regards coloration of fruits, observations do not entirely agree. Senebier notes that apples do not redden unless exposed directly to light. However, as pointed out by Gertz, the reddening of apples is more or less accessory, but in fruits of which anthocyanin production is a distinguishing feature (Crataegus, Rosa, Sambucus), Askenasy (282) found by partial darkening when green, the pigment developed equally well in both illuminated and darkened parts. Both Laurent (315) and Müller-Thurgau (298) agree that the coloration of grapes can take place in the dark.

In purely vegetative organs observations are more conflicting. Of 
anthocyanin formed in the dark, the following examples may be quoted:

Leaves of Beta (Morren).

Seedlings of Phalaris and Secale (Hallier, 272).

Intense rose-red coleoptile in Secale (Gertz, 19):

Red coloration in shoots of Opuntia robusta and O. leucotricha.

Spots on leaf of Orchis latifolia (Gertz, 19).

Red-veined leaves of Crepis paludosa (Gertz, 19).

Faint reddening in stolons of Solanum tuberosum (Gertz, 19; Sachs, 269).

On the other hand innumerable cases may be quoted in which light appears necessary for the formation of the pigment:

Reddening of seedlings is entirely absent in the dark in Polygonum tartaricum, Celosia, Beta (Weretennikow, 273). This has been confirmed by Schell (285) for seedlings of Polygonum, Rumex, Rheum and Amaranthus and by Batalin (293) for Fagopyrum. The most casual observation will also afford instances of cases where anthocyanin is developed on the sides of stems, twigs and petioles which are exposed to the sun, the opposite side remaining green ${ }^{1}$. Such phenomena are specially mentioned in stems of Cornus sanguinea, C. sibirica, species of Titia, Rosa and Rubus (Gertz, 19), of Cuscuta (Mirande, 332), of Helianthus, Crataegus and stolons of Fragaria (Dufour, 305).

The development of autumnal coloration often only takes place in the parts of leaves and stems exposed to light, as was noted long ago in Viburnum Lantana (Voigt, 264) and Rhus Coriaria (Macaire Princep, 3). Gertz (19) also points out that, in Viburnum Opulus, V. Lantana, Cornus sanguinea, C. sibirica and Prunus Padus, the autumnal leaves may show quite clear natural photographs of the leaves covering them, because anthocyanin is absent from the covered surface. Similar lines and spots may be observed in winter-reddened leaves (Silene, Viscaria, Armeria, Hieracium, Pilosella).

Development of pigment in roots exposed to light has been observed in Salix (Hallier, 272; Schell, 287) and Zea (Dufour 305; Devaux, 308).

It is difficult to draw conclusions from the rather conflicting statements given above. One fact stands out definitely, namely, that absence of light itself is no bar to the formation of anthocyanin in many cases, such as the root of Beta and the flowers of Tulipa and Iris. But in the majority of such cases there is obviously a plentiful supply of

1 It has been noted by Parkin (77) that the under surface of leaves is more sensitive to light and reddens more easily than the upper. 
synthetic products in the storage tissues of the bulbs, corms, seeds and fruits concerned, from which the chromogen for the pigment can be synthesised, if there is not also already a storage of this substance. But where the supply of chromogen is directly dependent on the photosynthetic activity of the leaves, darkening of the flower-buds, unless they are already practically mature and supplied with chromogen, prevents or diminishes the formation of anthocyanin. The reddening of leaves and stems where exposed to light may in some way be due to local accumulation of synthetic products, though the direct effect of light is superficially more probable.

The effect of light in autumnal coloration is even less well explained on this accumulation hypothesis, except that in the last stages of the leaf's existence, photosynthesis must be best carried out in the parts most exposed to light. There is also a general tendency to accumulation of synthetic products owing to low night temperature.

The formation of anthocyanin in normally uncoloured roots when exposed to light appears to be the most convincing evidence at hand for the production of anthocyanin due to the direct action of light. Until more evidence has been collected from a number of carefully devised experiments, no definite inference can be drawn.

In conclusion we may mention some work on more systematic lines which was published by Linsbauer (371) in 1907. He endeavoured to find out the more precise relationships between light and the formation of anthocyanin. For this purpose he used seedlings of Fagopyrum esculentum which had been grown in the dark and were quite etiolated. Such seedlings were then exposed to light (lamp) of different intensities and for varving lengths of time. From his results Linsbauer concluded that the photo-chemical process of anthocyanin production in light is a typical stimulus reaction, and is dependent upon both the intensity and duration of light. He investigated also the relationship between the times of reaction and presentation, and found it analogous in many respects to that in other stimulus processes, i.e. geotropisin, for instance. Whether, however, the appearance of anthocyarin in these seedlings is due to the direct action of light, or to the products of photosynthesis induced by light, cannot be readily ascertained.

\section{Connection with presence of oxygen.}

That oxidation plays a part in the formation of anthocyanin has frequently been suggested. The production of red pigment through the oxidation of a chromogen was the hypothesis brought forward 
by Wigand (136) as early as 1862, and the same idea has been revived successively by Palladin (203), Wheldale $(211,212)$ and Combes (379). That the process is controlled by a specific oxidase has been postulated by Buscalioni \& Pollacei (17), Mirande (365) and Wheldale (211, 212). The actual dependence of the process on the presence of oxygen is illustrated by the experiments of Mer (284), who mentions the fact that leaves of Cissus do not redden under water, and in 1899 Emery (309) noted that no colour is produced in submerged flowers.

More definite experiments were performed by Katić (354), incidentally, among a series of investigations primarily concerned with the effect of culture solutions on the formation of anthocyanin. Leaves in certain culture solutions of sugars, and other substances, were found to produce anthocyanin, but if enclosed in vessels, from which all oxygen had been removed by alkaline pyrogallol, no trace of colour was observed. Katic also found that colour was less rapidly developed in air under reduced pressure than in normal atmosphere. Also in certain culture solutions an increased pressure of oxygen produced greater development of colour.

Still more elaborate investigations were made by Combes (379). The experiments consisted in analysing the gaseous exchange of red and green leaves under similar conditions. Leaves were employed in which reddening had taken place and was proceeding from different causes, as for instance: leaves of Ampelopsis hederacea reddened by exposure to light; of Rumex crispus and Oenothera Lamarckiana by attacks of parasites; of Spiraea prunifolia and Mahonia aquifolium by decortication; of Rubus fruticosus with autumnal coloration; and finally of young leaves of Ailanthus glandulosa in which reddening, on the contrary, was disappearing.

From observations upon gaseous exchange in the above leaves, which are exemplified in the accompanying table, Combes drew the following conclusions:

Oxygen fixed $(+)$ or lost $(-)$ during one hour, consisting of halfhour of day and half-hour of night.

$\begin{array}{lllllll} & & & & \text { Red leaves } & & \text { Green leaves } \\ \text { Ampelopsis } & \ldots & \ldots & \ldots & -.0872 & \ldots & -.329 \\ \text { Rumex } & \ldots & \ldots & \ldots & +.0963 & \ldots & -.8067 \\ \text { Oenothera } & \ldots & \ldots & \ldots & +.2442 & \ldots & +.1622 \\ \text { Spiraea } & \ldots & \ldots & \ldots & +.1357 & \ldots & -.3226 \\ \text { Mahonia } & \ldots & \ldots & \ldots & +.0829 & \ldots & -.1565 \\ \text { Rubus } & \ldots & \ldots & \ldots & +.2011 & \ldots & -.0435 \\ \text { Ailanthus } & \ldots & \ldots & \ldots & -1.959 & \ldots & -2.589\end{array}$


The appearance of anthocyanin is accompanied by an accumulation of oxygen in the tissues; the disappearance of the pigment is, on the contrary, accompanied by a considerable loss of oxygen. The variations detected in the gaseous exchange during the formation of red pigment are concerned with assimilation; it therefore appears that the production of these pigments is intimately bound up with the phenomenon of assimilation. This accumulation of oxygen on anthocyanin formation can be explained by the diminution in intensity of assimilation, and in the modification produced in the ratio of gaseous exchange in assimilation. Further, the accumulation in the cells of soluble carbohydrates which accompanies anthocyanin production accelerates oxidation, and the gaseous exchange is fundamentally modified.

\section{Effect of drought.}

Here again the direct effect is difficult to estimate owing to the simultaneous effect on photosynthesis, but whether direct or indirect, there is ample evidence that drought increases anthocyanin formation. Molisch (316) found that leaves of Peireskia aculeata, Tradescantia, Panicum variegatum and Fuchsia reddened strongly if only watered a little. The author has made the same observations for pot plants of Pelargonium. Eberhardt (347) also found an increase of anthocyanin in leaves of Coleus Blumei and Achyranthes angustifolia when grown in a very dry atmosphere. According to Warming $(327,346)$ plants such as Tillaea aquatica, Peplis Portula and Elatine are green when growing in water, though individuals on land may be strongly red.

The physiological drought of salt marshes may similarly explain the development of anthocyanin in halophytes (Salicornia, Suaeda).

An interesting case of the connection between reddening and drought has been observed by Miyoshi (375). This author noticed that the leaves of certain tropical trees, especially Terminatia Cattapa, in the East Indies, Ceylon and Java, take on a beautiful red colour before the leaf-fall. The reddening is described as affecting at first a few leaves only, but later the number increases. Of the early stages the author says: "Vor der Ferne betrachtet erschienen die gefärbten Blätter wie rote Blüten in voller Pracht." Since the phenomenon takes place at the dry period of the year, Miyoshi suggests the term 'Trockenröte,' and considers the causes of reddening to be drought coupled with strong insolation. 


\section{Effect of sugar-feeding.}

The term sugar-feeding means that the plant is supplied artificially with extra amounts of sugar. In the case of floating or submerged water-plants, the whole plant can be immersed for experiment in dilute sugar solution; in the case of land plants, the stems of leafy branches, or the petioles of isolated leaves, can be put in the solution; or the leaves can be cut into pieces and floated in the liquid.

The first investigations of the results of this process were carried out by Overton (333). While conducting some experiments on osmosis with Hydrocharis Morsus-ranae, Overton noted that the leaves of this plant tended to become red when the plants were grown in $5 \%$ cane sugar solution. Later, the idea occurred to him that autumnal coloration might be due to excess of sugar in the leaf tissues, and he claims to have shown that autumnal leaves contain more sugar than green leaves. On the basis of this idea, he then commenced some systematic investigations on sugar-feeding with a view to gaining more knowledge of the whole phenomenon.

Experiments were first made with Hydrocharis plants grown in various solutions, and the results were as follows:

Hydrocharis Morsus-ranae. Plants in $2 \%$ invert sugar showed excess of anthocyanin over the control in four days. This was true of pigment in all parts-leaves, petioles, stolons and roots, and the intensity of pigmentation increased with time. In $2 \%$ cane sugar the results were similar.

Plants in both the above solutions flowered rather earlier than control plants, but the flowers were unaffected by the cultures.

In $2 \%$ glucose there was the usual reddening; also in $2 \%$ laevulose. In $2 \%$ galactose there was no reddening, and in $5 \%$ lactose, the reddening was very slight. In $2 \%, 4 \%$ and $10 \%$ glycerine, no colour developed; this was also the case in solutions of potassium nitrate, sodium chloride, sodium sulphate and of other salts.

In $3 \%$ invert sugar in a dark room there was no trace of reddening.

Microscopically it was found that colour was produced in the mesophyll cells, and never in either the upper or under epidermis.

The following species were also used:

Elodea canadensis. In 2-3\% invert sugar, a reddish colour developed in the younger leaves.

Vallisneria spiralis. In sugar cultures there was an increase of red colour which was located in the epidermis as well as in the inner tissues. 
Potamogeton perfoliatus, $P$. pectinatus. In $2-3 \%$ invert sugar there was no result. In $P$. pusillus, a reddish colour appeared.

In Najus major there was no effect but in $N$. minor there was a slight result.

Lemna minor, L. trisulca in various kinds of sugar solutions gave negative results. The same was true for Pistia Stratiotes.

Utricularia Bremii. In $2 \%$ invert sugar reddening in the bladders appeared in two to three days. Finally the leaves and bladders became quite red. In $2 \%$ cane sugar the result was similar. In Utricularia minor, reddening appeared in $.5 \%$ cane sugar; also in glucose, invert and cane sugars $(\cdot 5 \%-5 \%)$. U. vulgaris behaved similarly to U. Bremii and $U$. minor. In $2-5 \%$ lactose, there was no colour in two weeks, but after four weeks a slight colour (due to hydrolysis probably). There was no colour in galactose; slight colour only in glycerine and none in salt solutions.

In Utricularia, reddening in sugar cultures developed just as little in complete darkness as in Hydrocharis.

Ceratophyllum demersum. In 2-3\% invert sugar there was some reddening in the cells of subepidermal and deeper tissues, though the epidermis was uncoloured.

Experiments were next made with land plants, using either leafy twigs or isolated leaves:

Litium Martagon. A leafy stem was placed in $2 \%$ invert sugar. This and control stems in distilled water. were placed in a south-east window. After about seven days, the plant in sugar solution showed reddening in the leaf-tips, which afterwards spread, day by day, over the leaf, while the control showed no reddening. The pigment was found to be located in the inner leaf tissues, the upper and under epidermal cells being free. Experiments were made with about 20 other specimens, and in each case the results were the same. In $2 \%$ glucose solution reddening could be detected in four days, becoming more intense in the course of time. In $2 \%$ fructose, there was a similar result. In $2 \%$ cane sugar the red coloration came later and was less intense. In lactose, galactose and glycerine solutions there was no reddening, and the same was the case with various salt solutions. It was found also that ethyl and amyl alcohols, ketones and ether, in solution, caused development of red pigment, but Overton considers the result to be one of injury. He is inclined to believe that the alcohols, ketones, etc., acted as narcotics and so prevented translocation, rather than that they served as material for building up the pigment. 
Fritillaria imperialis was found to produce no colour in sugar solution.

Ilex Aquifolium. A twig of Ilex was put in $3 \%$ invert sugar. In two days some reddening appeared whereas control plants showed no colour. The pigment was found in the palisade, and to some extent in the spongy parenchyma, but none was present in the epidermis. In glucose and fructose there was also considerable reddening.

Hedera Helix. In $2-3 \%$ invert sugar, red colour appeared in a few days, but it was not intense nor was it uniformly distributed.

Mahonia Aquifolium. A twig of this plant gave a negative result in $2 \%$ invert sugar.

Ligustrum vulgare. In $2 \%$ invert sugar, red pigment appeared after eight days. The pigment was localised in the palisade cells.

Ampelopsis hederacea. In $2 \%$ invert sugar reddening commenced, but the experiment could not be continued as the leaves tended to fall from the leaf-stalks. In autumn, good results of artificial reddening were obtained, green leaves only, of course, being used.

Saxifraga crassifolia. In $3 \%$ invert sugar the leaves reddened in a few days.

Aquilegia vulgaris. Young leaves with petioles in $2 \%$ invert sugar showed distinct reddening in four days.

Taraxacum officinale. When the base of the leaves was placed in a $2 \%$ solution of invert sugar, a very fine red colour developed in two or more days over the whole leaf, and the pigment was located in the inner tissues and not in the epidermis. Leaves, however, in distilled water may redden in time. Reddening of leaves was found to be characteristic of many Compositae, and as this result was often obtained to some extent in distilled water in a good light, they did not afford very suitable material. Leaves of Eupatorium Cannabinum and Prenanthes purpurea which did not redden to any extent in distilled water, became very red in sugar solution.

Epilobium spp. Leafy stems of $E$. parviflorum in $2 \%$ invert sugar gave a good red colour.

Negative results in 2-3\% invert sugar were obtained with Anthriscus sitvestris; also with Rubus species.

From the above researches Overton draws the conclusion that in many species of Monocotyledons and Dicotyledons, both water and land plants, sugar-feeding will bring about anthocyanin formation. There is also this further correlation, that, with the exception of submerged water plants, there is a negative result with sugar-feeding when the plant in normal circumstances produces anthocyanin in the 
epidermal cells. But if in normal circumstances the pigment is formed in the inner tissues, then sugar-feeding (especially with fructose and glucose) produces red pigment in a high percentage of cases, and this pigment is localised in the mesophyll and not in the epidermis.

Overton also tried the effect of putting the inflorescence of whiteflowered varieties into sugar solution. Thus, for instance, the inflorescence stalk of white Pelargonium zonale was placed in $3 \%$ solution of invert sugar, but no trace of red colour was formed in the flowers though the stalk showed reddening. Negative results were also obtained with Anemone japonica. Overton concludes that some other factor, apart from presence of sugar, is necessary in these cases.

Further researches on sugar-feeding were made some years later by Katic (354), and of these the experiments on Hydrilla verticillata (Hydrocharitaceae) are given in the greatest detail as follows:

Inorganic culture media containing various salts of potassium, sodium, calcium, magnesium, ammonium, iron, aluminium and lithium had practically no effect on the formation of pigment. In glucose $(\cdot 05-3 \%)$ solutions, red pigment was formed in the light and in the dark, and in isolated leaves more quickly than in pieces of leafy stem. In laevulose (1-5\%) and cane sugar also pigment developed both in the light and in the dark, but the cane sugar (of concentration $\cdot 5-25 \%$ ) was most favourable to reddening. Only a slight coloration appeared with maltose $(1-3 \%)$ both in the light and in the dark. In lactose (1-5\%), raffinose (1-10\%), inulin (1-3\%) and glycerine (4-5\%) pigment was formed only in the light. Some colour was developed in (1-4\%) ethyl alcohol and in mannite (1-2\%), but none in galactose (up to $5 \%$ ), arabinose, formol $(.001 \%)$, dextrin, salicin or asparagin.

The effect of mixed solutions of carbohydrates and various salts, such as those mentioned above, was tried. It was found that potassium nitrate and mono-potassium phosphate quickened the formation of pigment in sugar solution. Various other potassium salts (except potassium bichromate) had the same effect in a less and varying degree. Katic is of the opinion that the effect of potassium salts is chemical and not osmotic. Sodium salts, on the whole, were found to have little effect; magnesium sulphate and nitrate some positive effect; calcium salts (except $\left.\mathrm{CaH}_{4}\left(\mathrm{PO}_{4}\right)_{2}\right)$, aluminium sulphate, ferric chloride and some ammonium salts a preventative effect.

Various alkalies, sodium carbonate, potassium hydroxide, calcium hydroxide and magnesium oxide were tried with sugar solutions; the result was to quicken the formation of anthocyanin. Acids, as for 
instance, tartaric, salicylic, citric and oxalic, on the contrary, appeared to slow down the formation; to this tannic acid formed an exception, since the reddening appeared more quickly in its presence.

Although anthocyanin was produced in the cultures in the dark, Katic found that the development was always earlier in the light. As regards temperature, it was found that $25^{\circ} \mathrm{C}$. was the optimum for the appearance of the pigment in the light and $28^{\circ} \mathrm{C}$. in the dark.

The absence of carbon dioxide had no effect on the formation of anthocyanin in sugar solutions, except in the case of glycerine, where the development was weaker. Oxygen, on the contrary, was found to be necessary for the reddening.

Katić made further observations with a number of other plants, and although his experiments are described in great detail in his dissertation, no more than a short statement will be given here as they were largely on the same lines as those with Hydrilla.

Elodea canadensis. In $\cdot 26-1 \%$ cane sugar there was a slight coloration in the light, but none in the dark; in $1 \%$ grape sugar there was colour both in the light and in the dark. In the case of cane sugar the development was increased by addition of potassium nitrate and calcium sulphate.

Hydrocharis Morsus-ranae. In cane sugar and laevulose some pigment appeared in the dark; in grape sugar and maltose, there was none in the dark.

Sagittaria natans. In $5 \%$ cane sugar there was a considerable development of colour, but only in the light.

Allium Cepa. The colourless scales of a variety which normally contained some anthocyanin turned red in sugar solution; a white variety, however, produced no colour under any conditions. ment.

Canna indica. Etiolated leaves in 5-15\% cane sugar formed pig-

Veronica Chamaedrys. In sugar cultures colour only developed in the light and was located in the epidermal cells.

Rosa 'Maréchal Niel.' Green leaves, or pieces of leaves, in $15 \%$ cane sugar formed colour only in the light. It was found in both epidermis and spongy tissue.

Saxifraga cordifolia. Pieces of a leaf in $5 \%$ cane sugar only gave a good development of anthocyanin in the light.

Pittosporum (undulatum?). Green leaves and pieces of leaves in $5-15 \%$ cane sugar formed pigment only in the light, and it was found to be located in the inner tissues and not in the epidermis.

W. P. 
Bellis perennis. In $15 \%$ sugar solution green leaves developed a weak red coloration only in the light, and it was confined to the epidermal cells.

Thus we see that Katić's results differ from those of Overton in two points. First, anthocyanin may develop in sugar cultures in the dark, and secondly, it is not necessarily confined to the epidermis.

The question of the results of sugar-feeding has been taken up more recently (1912) by Gertz (386). The following account is taken entirely from his paper. He deals with a point in Overton's results we have just mentioned, i.e. the statement that by sugar-feeding anthocyanin can be induced to form in the mesophyll, but not in the epidermal cells. Thus it would appear possible that the chloroplastids might have some influence on the formation of pigment, and the failure of petals to produce anthocyanin in sugar culture might be considered a corroboration of this view. In Vallisneria spiralis and Elodea, Overton found epidermal anthocyanin on sugar culture, but this is no proof, since the epidermis in those plants contains chlorophyll. General evidence is, moreover, against the view of the connection with chloroplasts, as the epidermis often contains anthocyanin, and this pigment is also developed in chlorophyll-free saprophytes and parasites and in perianth leaves.

In order to investigate this point, Gertz made some sugar culture experiments with parts of albino leaves which were free from chloroplastids. For this purpose he used first the leaves of Oplismenus imbecillis (Graminaceae), and found that anthocyanin may be induced to form in the complete absence of chlorophyll. Therefore the question of the activity of the chloroplastids is definitely solved, but as only this one species had been used, further experiments were made with other plants. A modification of Overton's method was employed; portions, $20 \times 20 \mathrm{~mm}$. square, were cut out from the leaves and floated upside down on the solutions in glass dishes, and in this way free transpiration and respiration could go on through the stomata. The solutions were also changed from time to time, and the edges of the leaves freshly cut. Cane sugar only was used of $5-10 \%$ concentration. The following results were obtained.

Oplismenus imbecillis. The leaves are variegated-red, green and white. In the white portions there are no chloroplastids, not even in guard cells of the stomata. When white portions were used, anthocyanin appeared in quantity in the epidermis after four days. In the dark, however, there was only slight, though definite, coloration. Hence Gertz concluded that, though not absolutely necessary, light is 
a powerful agent in assisting the formation. Cultures in distilled water, both in the light and in the dark, produced no anthocyanin. To obtain absolutely comparable results, parts of the same leaf, $A, B, C$ and $D$ were treated as follows. $A$ and $B$ were placed in $5 \%$ sugar solution, $C$ and $D$ in distilled water; $A$ and $C$ were exposed to the light, $B$ and $D$ kept in the dark. The results were as before. Both $A$ and $B$ formed anthocyanin, but it was insignificant in $B ; C$ and $D$ were free from anthocyanin.

Tradescantia Loekensis. Again the leaves are variegated-red, white and green. No chlorophyll occurs in the white parts except in the guard cells. In cane sugar the result was negative and no anthocyanin was formed. Gertz has no suggestions to offer except that possibly some unknown factor is essential to the formation of pigment.

Beta vulgaris. Only negative results were obtained.

Rumex domesticus. A variegated green and white form was used, of which the white parts, including the guard cells of the stomata, are entirely free from chlorophyll. In less than one day in $5 \%$ sugar solution, anthocyanin appeared, and was found to be located in the lower as well as in the upper epidermis. In the dark, less pigment was formed. Experiments were made with ordinary Rumex, and were in complete agreement, since anthocyanin was formed chiefly in the epidermis (except stomata). Similar observations on $R$. Patentia have also been made by Palladin (203).

Cormus florida. The leaves have green and white parts, the latter being free from chlorophyll. After a week in $10 \%$ cane sugar they showed only traces of anthocyanin which was located in the spongy parenchyma.

Euonymus radicans. In $10 \%$ sugar, the albino parts showed a faint reddening in the lower epidermis with the exception of the stomata.

Lonicera brachypoda. The leaves have white reticulations on a green ground. After a week in $10 \%$ cane sugar solution, anthocyanin was found in the palisade parenchyma.

Other experiments were made with green leaves as follows:

Plantago major. In $10 \%$ sugar solution, the pieces of leaves reddened strongly, and anthocyanin was located entirely in the lower epidermis except the stomata. Attempts were made to induce anthocyanin formation in sugar cultures in isolated epidermal layers, but they were unsuccessful.

Sium latifolium. In $10 \%$ sugar solution, anthocyanin appeared readily in pieces of leaves, as well as in entire leaves and shoots, and 
was found to be localised in cells of the mesophyll. With Cerefolium sylvestre negative results were obtained.

Epilobium parviflorum. In $5 \%$ sugar solution, anthocyanin developed plentifully in the lower epidermis and occasionally in the upper.

Euphorbia Cyparissias. In bracts in $10 \%$ sugar solution, anthocyanin was formed in both the upper and lower epidermis. In Phytolacca decandra it appeared in the epidermis (except stomata).

Thus Overton's view, which is expressed as follows-“...mit Ausnahme der untergetauchten Wasserpflanzen scheinen solche Versuche fast durchweg bei denjenigen Pflanzen negativ auszufallen, deren natürliche Rothfärbung...der Gegenwart von rothem Zellsaft in den Epidermiszellen zu verdanken ist," is, as Gertz points out, not correct; for colour due to anthocyanin appears entirely in the epidermis in Optismenus imbecillis, Euonymus radicans, Plantago major, Euphorbia Cyparissias and Phytolacca decandra; both in the epidermis and mesophyll in Rumex domesticus, Tussitago Farfara and Epitobium parviflorum. On the other hand in Cormus florida, Lonicera brachypoda and Sium latifolium it appears in the ground parenchyma. These results are also in accordance with those of Katić.

Thus it would appear to be definitely settled that chloroplastids are not essential to anthocyanin formation from the results with leaves of Oplismenus-imbecillis, Rumex domesticus, Cornus florida, Euonymus radicans and Lonicera brachypoda, though the results with Tradescantia and Beta are negative. Yet Gertz does not seem to be quite assured on the point, partly because, as be points out, the epidermal leucoplastids are closely related to chloroplastids, and partly because the epidermis is connected with chloroplast-containing cells.

As regards the effect of light on the results of sugar-feeding, Overton maintained that colour was not produced in the dark. This was not found by Gertz to be the case with Oplismenus and Rumex, and Katié, moreover, demonstrated that Hydrilla, Hydrocharis, Allium and Phalaris develop pigment in sugar cultures in the dark. Gertz is of the opinion that under natural conditions the appearance of anthocyanin may not be very largely affected by illumination, as a whole constellation of factors may take part in its formation in the kind of way we have tried to indicate in the previous sections.

Gertz finally considers the formation of anthocyanin in petals resulting from sugar-feeding. As we have seen, Overton failed to get any result with Pelargonium and Anemone. Gertz considers that such 
a result, if it were possible, would give an even more important proof that anthocyanin production is independent of chloroplastid activity. A striking observation in this connection has been made by Goiran (310) on Cyclamen persicum giganteum of which the flower is white except for a patch of red anthocyanin at the base of the petal. Goiran made transverse cuts through part of the petal, and though the petal tips remained fresh, after a time they developed red pigment. This result is akin to the formation of anthocyanin in leaves when the conducting system is injured by cutting, or by insects, Fungi, etc. There is also an observation by Gertz on white petals of Saxifraga in which anthocyanin appeared as a result of insect attacks. Gertz, however, failed to get any result from sugar cultures of Bellis perennis, Anemone japonica, Magnolia acuminata, Tropaeolum majus, Deutzia gracilis, Begonia sp., and Pisum sativum. But eventually a positive result was obtained with white petals of Viburmum Opulus (the cultivated form with neuter flowers). These petals in sugar solution formed anthocyanin in either one or both epidermal layers. Thus Overton's prophecy that petals might be found which would redden in sugar culture appears to be justified in this case.

It is not an easy task to set forth any general explanation of all the facts recorded in the previous sections, but a short review, as far as possible, of the situation may be useful at this stage. Thus, we may say that two points emerge from the preceding considerations: (1) that the chromogen for anthocyanin is formed in the leaf; (2) that an accumulation of carbohydrates (sugars) and glucosides (including the glucoside of the chromogen) leads to the formation of anthocyanin.

One explanation offered for the reddening phenomenon has been advanced by various authors, Palladin (203), Hirande (365) and Combes (379), that presence of excess of carbohydrates increases oxidation processes, and hence, if anthocyanin is an oxidation product, the formation of this pigment. Such an explanation would meet practically all cases of anthocyanin formation, but there is no special evidence for its justification.

Another suggestion is that made by the author (226); it is based on certain reversible reactions involving pigment, chromogen, glucosides and sugars, and will be considered in detail in the next chapter. For the moment we need only say that the hypothesis assumes that the chromogen is formed from sugars in the leaf, and that increase in amount of sugar leads to increased formation of chromogen with the resultant production of anthocyanin, unless the chromogen be removed. 
Let us now consider how this explanation fits various cases.

(1) In a normal plant with green leaves, coloured flowers and tinged stems and petioles, the chromogen is synthesised from sugars in the leaves and translocated away when formed. If the plant is kept in the dark or shade, photosynthesis stops or is lessened, the supply of chromogen falls below normal, and the flower-colour may be pale and the stems and petioles green. Conversely, great photosynthetic activity produces a plentiful supply of chromogen which results in rich flower-colour and appearance of pigment in the vegetative organs. (In addition, light itself may directly increase pigment formation.) The intense colours in the flowers and the development of anthocyanin in the vegetative parts of High Alpine plants may be explained by strong insolation, stunted growth employing little material, and slow translocation due to low night temperature ${ }^{1}$. The power of some

1 Exception will probably be taken to this statement on the ground that many High Alpine plants can be grown in lowland regions and their flowers do not then show any perceptible loss of colour, whereas if the statement were true, we might expect to find considerable diminution of colour under these conditions. As a matter of actual fact, on the basis of observation, this criticism is not altogether valid, for, as we have previously stated, Gaston Bonnier (328). Kerner (398) and others have shown that in many cases the flowers of plants growing at high altitudes and in high latitudes have a more intense colour than those of individuals of the same species grown either in the plains or in lower latitudes. There is also a more general aspect of the question, which may be outlined as follows. Every plant is the expression of a chemical (or, fundamentally, physical) entity, and this expression can only fluctuate within limits on account of the definiteness of the chemical (or physical) constitution underlying it. Broadly speaking these chemical (or physical) entities are adapted to their habitats, that is, they are only able to exist under those conditions in which the chemical reactions (or physical processes) essential to their existence can take place. Sometimes a plant, for example species of Opuntia, will live and flourish to a certain extent in a habitat to which it is not adapted, such as the temperate zones. The conditions for its metabolic processes do not in this case lie beyond the limits of such a climate. But the expression of its entity, of necessity, remains the same. We may assume that, for Opuntia, variation in the direction of the characters of plants of the temperate zones does not occur, since such changes would involve chemical reactions (or physical processes) which are outside the sphere of its constitution. Hence it remains a typical species of Opuntia. Other examples no doubt could be selected where there were greater fluctuations on change of habitat, but these again would depend either on the wideness of the sphere of chemical (or physical) activity of the particular plant, or on the relation of the particular fluctuation to the environment. The same line of argument we have applied to Opuntia can be applied to the members of any plant formation, and among them, to High Alpine plants. These are on the whole adapted to their environment, and intense flower-colour is one of the expressions of the entity of this particular type of plant. Transferred to lowland regions, such a plant is still able to grow and flourish, and of necessity it retains its entity. Yet fluctuations in colour intensity of the flowers and in the amount of pigment in the vegetative organs are, within limits, the kind of variation we should suppose possible, though not necessarily inevitable; for such fluctuations depend merely on the 
plants to produce normally coloured flowers and fruits in the dark is due to a plentiful supply of reserve material (flowers of Tulipa).

(2) If there is more than a plentiful supply of chromogen owing to the flowering parts being removed or to a large supply of carbohydrates, a certain amount of abnormal reddening may take place, ex., leaves of plants deprived of the inflorescence, adventitious shoots from tree trunks; possibly this may explain reddening in sugar cultures.

(3) A still further increase of carbohydrates and chromogen such as is caused by blocking the translocation current leads to still more abnormal reddening, ex. injured leaves, decorticated stems, etc.

(4) In autumnal and winter leaves, there may be an accumulation of sugar and chromogen owing to the slowing down of the translocation current, and the lack of starch formation at low temperatures. The effect of low temperature may also retard growth in general and the using up of synthetic products.

(5) In young leaves it is possible that the mechanism for translocation is not developed so early as the powers of synthesis of sugar and chromogen. Hence again there is accumulation of these products.

direction, or amount, of certain chemical reactions which are, in any case, part of the essential metabolism of the plant. If we are to believe the evidence of Gaston Bonnier and others, it is just these variations which may occur. 


\section{CHAPTER VII}

\section{REACTIONS INVOLVED IN THE FORMATION OF ANTHOCYANINS}

Nehemiah Grew (1) evolved, as a result of his observations, an elaborate scheme to explain the origin of the various pigments in plants. It is expressed in the scientific language of the period and is difficult to translate into modern conceptions, but it is clear that he believed the presence of air to play an important part in the process. Speaking of colours in roots, he says these organs show less variety in this respect than leaves and flowers-" The Cause hereof being, for that they are kept, by the Earth, from a free \& open Aer; which concurreth with the Juyces of the several Parts, to the Production of their several Colours. And therefore the upper parts of Roots, when they happen to stand naked above the Ground, are often deyed with several Colours."

A publication by Schübler \& Franck (117) in 1825 perhaps contains the first definite hypothesis as to the origin of red and blue pigments. These investigators treated extracts from coloured flowers and leaves with acids and alkalies, and the results led them to the view that green pigment of leaves occupies a mean position, from which an oxidised yellow-red series is formed, on the one hand, by the action of acids. and a deoxidised blue-violet series, on the other hand, by the action of alkalies. The hypothesis was further reinforced in 1828 by MacairePrincep (3), who maintained that chlorophyll, when treated with acids, becomes oxidised first to yellow, then to red and orange pigments, and this oxidised chlorophyll can be turned green again by alkalies. The red plant pigments are, in his opinion, oxidised chlorophyll, and the blue, a mixture of red chlorophyll with a vegetable alkali. All colours may thus be looked upon as simple modifications of chlorophyll.

These erroneous ideas were accepted, without any real experimental basis, by plant physiologists of the day as $\operatorname{Von} \operatorname{Mohl}(7,8)$ very clearly points out in 1838. "Les physiologistes s'occupaient plutôt généralement de faire des spéculations sur les couleurs des plantes, de les 
rapporter aux couleurs du prisme, que de chercher à connaître la nature des matières colorantes elles-mêmes. Comme dans le prisme, le vert tient le milieu et se trouve bordé, d'un côté, par le jaune et le rouge, et de l'autre côté, par le bleu et le violet, on croyait que le vert des plantes était de même le point indifférentiel entre la série de couleur rouge-jaune et celle du bleu, et c'est par l'oxygénation et la désoxygénation de la couleur verte, qu'on cherchait à expliquer l'origine de ces couleurs, en se fondant sur des expériences chimiques incertaines, sur des idées fausses d'oxygénation et de désoxygénation, sur l'action des alcalis et des acides." A more correct point of view was reached too by Leopold Gmelin (137) in 18281; he refused to accept the fact that chlorophyll is reddened by acids, and that the products formed from chlorophyll by acids, or naturally in autumnal leaves, again become green with alkalies. He notes, also, that red autumnal leaves contain both yellow chlorophyll, and a blue colouring matter which is reddened by acids.

Gmelin's criticisms, as well as others of the same kind, appear to have been unconvincing; for again, in 1835, Clamor Marquart (5) returns to the origin of anthocyanin from a metamorphosis of chlorophyll. Though objecting to the oxidation and deoxidation hypothesis, he retains the idea of the formation of other pigments from chlorophyll, this time, however, by addition and subtraction of water. By the action of strong sulphuric acid, i.e. by subtraction of water from chlorophyll, a blue colouring matter ${ }^{2}$ (anthocyanin) is obtained which turns red with acids and green with alkalies. This blue substance, he says, forms the basis of all blue, violet and red flower pigments.

Marquart's evidence was thought to be insufficient by Von Mohl $(7,8)$; for, with regard to the sulphuric acid reaction, the latter very naturally remarks: "Si, dans ce cas, la couleur bleue doit annoncer la formation artificielle de l'anthocyane par la chlorophylle, il est impossible de concevoir pourquoi, malgré la présence de l'acide sulfurique libre, la chlorophylle reste bleue et ne devient pas rouge." Also, with respect to Marquart's evidence that cells which originally contained chlorophyll, later contain anthocyanin, as for instance petals which are primarily green, and then become blue or red. Von Mohl points out, among other evidence, first, that anthocyanin is characteristic of the epidermis while chlorophyll is found in the inner tissues; secondly, that chlorophyll may be found, apparently in no lessened quantity,

1 Earlier edition than that in the Bibliography.

2 This is of course, as we now know, a reaction given by plastid pigments. 
in cells which have become reddened with anthocyanin. In the course of time, as investigations proceeded, it became clear that anthocyanin is not derived from chlorophyll; Macaire-Princep and Marquart had been led astray in their views by the close connection between the disappearance of chlorophyll, and the appearance of anthocyanin, and vice versa. Yet, in the light of the additional knowledge which we now possess, it can still be stated with truth that there is a certain relationship, though an indirect one, between the two pigments, or, more strictly perhaps, between the spheres of their chemical activity.

The hypothesis of Wigand (136) in 1862 came very near to those held at the present time. Wigand maintained that anthocyanin arises by oxidation from a colourless substance which occurs in solution in the cell, and which changes to red under certain circumstances, and may, after a time, become colourless again. He considers it to be a tannin on the grounds that:

1. The red colouring of spring and autumn appears only in tannincontaining plants, and though it is not always found in these, yet it never develops in plants free from tannin.

2. Only in those tissues or cells (especially the epidermal cells and veins) in which the tannin was previously present does the colouring matter develop later.

3. The red sap, like the tannin, is turned green or blue with iron salts, and yellow with potash or ammonia.

The tannins of Wigand were very probably, in many cases, flavones, from which it is now believed that the anthocyanins may arise.

From analyses of pigments of wine and grapes, Gautier $(149,175)$, in 1893 , also formed the opinion that anthocyanin is an oxidised product of tannic acids, but no suggestions are made as to the particular reactions involved. At a later date, in 1897, Overton (333) concluded, on the basis of many observations and experiments, that red pigment is formed when there is an accumulation of sugars, but beyond stating that anthocyanin is probably a tannin-like substance existing, in combination with sugar, as a glucoside, Overton makes no definite statement as to the mode of formation. Mirande (365) in 1907 suggested that the appearance of anthocyanin when leaves are injured by insects is due to an accumulation in the tissues of tannins and glucose, accompanied by the presence of an oxidase. Laborde $(199,200,201)$ in 1908 also came to the conclusion that there is a relationship between tamnins and anthocyanins. To quote Combes: "l'auteur (i.e. Laborde) assimile le phénomène du rougissement à une action diastasique qui 
donnerait naissance à une matière colorante rouge aux dépens d'un noyau chromogène de nature phénolique que posséderaient tous les tannins." Laborde was able to obtain red pigments from tannins by means of certain chemical reagents and other treatment.

The authors mentioned are only a selection of those who have believed in the origin of anthocyanin from tannins, and the hypothesis held the field for many years; we find it accepted in most text-books even of fairly recent date (Pfeffer) ${ }^{1}$, though the evidence for its acceptance is far from satisfactory.

The next hypothesis of importance is that of Palladin $(203,210)^{2}$; he considers anthocyanin to be a member of a class of pigments which he himself terms 'respiration pigments.' Although this hypothesis is connected primarily with the function of anthocyanin, nevertheless certain reactions are involved which justify its consideration in this chapter. Since Palladin's views are largely based on the action of oxidising enzymes, some preliminary account of these substances may not be out of place at this point.

Certain organic compounds, such as guaiacum tincture, $\alpha$-naphthol, paraphenylene-diamine, benzidine, etc., are used as tests for oxidases since they become oxidised to coloured products when treated with oxidising enzymes under certain conditions. When the juice or water extract of some plants is added for instance to guaiacum tincture, a blue colour is immediately developed, and the plant is said to contain a direct oxidase. Of other plants the juice or extract gives no colour until hydrogen peroxide is added, and the plant is said to contain an indirect oxidase. A direct oxidase has been considered by many authors to consist of a system, peroxide-peroxidase; in the case of the indirect oxidase, the peroxide is missing, and has to be supplied in the form of hydrogen peroxide. If a systematic examination be made of all natural orders as to their oxidase content, it will be found that the direct oxidase reaction is characteristic on the whole of certain orders or genera (Compositae, Labiatae, Umbelliferae, etc.), and the indirect oxidase reaction of other orders (Cruciferae, Ericaceae, Crassulaceae, etc.). It may be noted, in addition, that the plants giving the direct

1 The Physiology of Plants, translated by A. J. Ewart, Oxford, 1900.

2 Also Palladin, W., 'Das Blut der Pflanzen,' Ber. D. bot. Ges., Berlin, 1908, xxvia, pp. 125-132. 'Die Verbreitung der Atmungschromogene bei den Pflanzen,' ibid. pp. 378-389. 'Ueber Prochromogene der pflanzlichen Atmungschromogene,' ibid. 1909, xxvir, pp. 101-106. 'Ueber die Bedeutung der Atmungspigmente in den Oxydationsprozessen der Pflanzen,' ibid. 1912, xxx, pp. 104-107. 'Die Atmungspigmente der Pflanzen,' Zschr. physiol. Chem., Strassburg, 1908, Lv, pp. 207-222. 
oxidase reaction turn brown on injury, or on exposure to chloroform vapour, or often when placed in absolute alcohol. The juices and extracts of such plants also turn brown or reddish-brown on exposure to air.

The results of investigations made by the author ${ }^{1}$, considered in conjunction with those obtained by other workers, led to the suggestion that the direct oxidase reaction is given only when, in the plant metabolism, certain substances are formed which can (after the death of the plant) autoxidise in presence of air, and which then in the state of organic peroxide form a system capable of oxidising certain artificial acceptors, such as guaiacum, etc. There is evidence ${ }^{2}$ that such a substance is either pyrocatechin or some compound containing the pyrocatechin nucleus. Hence, if this supposition be true, it is obvious that the classification into direct and indirect oxidase, on the basis of the blueing of guaiacum, etc., is a purely artificial one. The important element is the peroxidase which is practically universally distributed in plants. There is no direct evidence that the peroxide-peroxidase system exists in the living cell, though the presence of some such system is extremely probable. The formation of brown or reddish-brown pigments in extracts or tissues of those plants which contain direct oxidase may then be regarded as the outcome of the oxidation of a mixture consisting of a peroxidase and a number of aromatic substances. of which one at least is capable of acting as a peroxide by autoxidation.

It is upon reactions of the kind just mentioned that Palladin's hypothesis of 'respiration pigments' is based. Palladin makes extracts from a number of plants throughout the vegetable kingdom, and after boiling to destroy any enzyme in the extracts themselves, adds peroxidase solution (obtained from Horse-radish root) and hydrogen peroxide. In all cases, red, reddish-brown, brown or purple pigments are produced in the extracts; these pigments, moreover, are formed most readily and in greatest quantity in extracts of plants we know to contain, previous to heating, a direct oxidase, i.e. an organic peroxide. From his results Palladin deduces the fact that chromogens of an aromatic nature are universally distributed, and may be oxidised in the presence of oxidising enzymes and a peroxide (though these, let it be noted, he always adds to the extract). The whole series-chromogen, enzyme, peroxide and pigment-form a system for transferring oxygen to respirable materials,

1 Wheldale, M., 'On the Direct Guaiacum Reaction given by Plant Extracts,' Proc. R. Soc., London, 1911, Lxxxiv B, pp: 121-124.

2 Wheldale, loc. cit. 
and hence the term 'respiration pigments.' The chromogens, moreover, are considered by Palladin to be present in the living plant as prochromogens of the nature of glucosides, the hydrolysis and synthesis of which are controlled by glucoside-splitting enzymes, and chromogen is only produced as required for oxidation. After the death of the plant the hydrolysis of the glucosides is rapidly increased, and the chromogen becomes entirely oxidised:

$$
\begin{gathered}
\text { prochromogen (glucoside) }+ \text { water } \rightarrow \text { chromogen }+ \text { sugar } \\
\text { chromogen }+ \text { oxygen } \rightarrow \text { 'respiration pigment' }
\end{gathered}
$$

Palladin includes anthocyanin ${ }^{1}$ among the respiration pigments, and explains its appearance in leaves fed on sugar, in young leaves and autumnal leaves, as due to excess of carbohydrates: "Diese Tatsache kann in der Weise gedeutet werden, dass durch Zuckerzugabe die Atmungsenergie so gesteigert wird, dass ein Teil des oxydierten Chromogens nicht momentan wieder reduziert werden kann."

It was first suggested in 1909 by the present writer (212) that many anthocyanins may be derived from the flavones or possibly xanthones2. The flavones are a group of natural colouring matters, some of which have been artificially synthesised by Kostanecki ${ }^{3}$. As a group they are widely distributed, and the greater number have been isolated by Perkin $^{4}$ from plants used commercially for dyeing. They may be regarded as oxy-derivatives of $\beta$-phenyl-benzo- $\gamma$-pyrone:

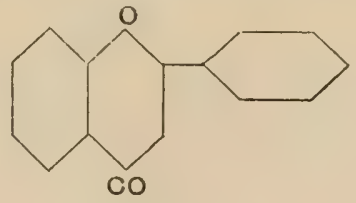

The flavones differ from each other in the number and position of their hydroxyl groups. They are all substances coloured yellow,

1 It must be clearly understood, however, that anthocyanins, apart from the fact that they are aromatic substances, have very little in common with the respiration pigments. The latter are formed only after death (unless we believe, with Palladin, that they are reduced immediately in the living plant), the former only in living plants. It is possible that the reactions taking place in the formation of the two sets of pigments are upon similar lines, but there is no reason for thinking that they arise from the same chromogens.

${ }^{2}$ Later work, however, has not yet confirmed the origin of any anthocyanin from the xanthones.

${ }^{3}$ See Abderhalden, E., Biochemisches Handlexikon, Berlin, 1911, Bd. vI.

1 Perkin, A. G., various papers in Chem. Soc. Trans., 1895-1904. 
Table giving properties and characteristics of the commoner flavones.

Flavone

Quercetin

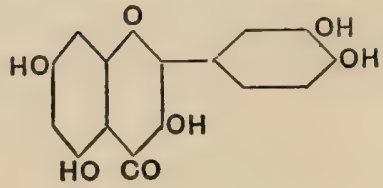

Myricetin

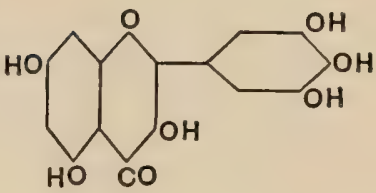

$357^{\circ}$ Sublimes
above 250

Products of

Decomposition

from Alkali Melt

Distribution and protocatechuic acid

Phloroglucin and gallic acid
Free and as various glucosides in Quercus (bark), Rhamnus (berries), flowers of Cheiranthus, Crataegus, Viola, Prunus, Hibiscus, leaves of Ailanthus, Rhus, Arctostaphylos, Calluna, Eucalyptus and many others

Myrica (bark), leaves of Rhus, Haematoxylon, Arctostaphylos

Fisetin<smiles>O=CC1CCC(O)C(C2CCOCC2)OC1CO</smiles>

\section{Above $360^{\circ}$ Resorcinol Rhus (wood)

$$
\text { and }
$$

protocatechuic

acid

$275^{\circ}$

Phloroglucin Populus (buds)

and

benzoic acid

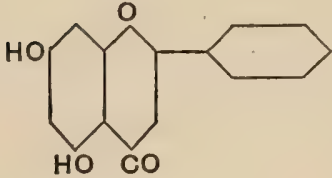

$347^{\circ}$

\section{Phloroglucin and \\ p-oxybenzoic \\ acid}

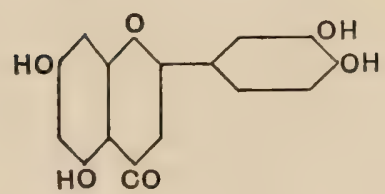

$327^{\circ}$ Phloroglucin
and protocatechuic acid

Leaves of Apium, Reseda

$276^{\circ} \quad$ Phloroglucin and p-oxybenzoic

In flowers of Prunus, Delphinium, leaves of Polygonum, Indigofera, Robinia

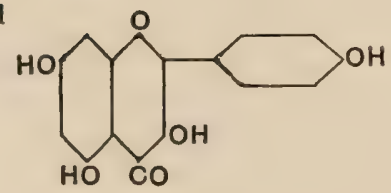
acid 
and according to Witt the colour is due to the chromophore group:

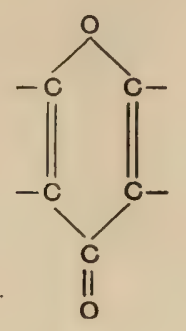

in combination with the auxochrome (hydroxyl), $-\mathrm{OH}$, and the intensity of coloration is said to depend on the position of the hydroxyl groups.

The flavones, as a class, are yellow crystalline substances with high melting points (see accompanying table). They give either a deeper yellow, or an orange-yellow, coloration with alkalies, correspondingly coloured precipitates with lead acetate, and a green or brown coloration with iron salts. That their distribution in plants is practically universal can be readily demonstrated by the colour reaction with alkalies. This reaction is best shown by colourless parts of plants, such as white flowers. Placed in ammonia vapour, almost any white flower will turn bright yellow (with the exception of certain albinos of Antirrhinum and Phlox Drummondii, see pp. 158, 209). The same yellow reaction is given by green organs, though it can only be detected microscopically on account of the presence of chlorophyll. On reference to the accompanying table, it will be seen that some flavones occur in genera of many natural orders, while others are limited to one or a few ; this apparent limitation is probably only due to lack of knowledge of their occurrence in a number of plants. Further investigation will no doubt show a very much wider field of distribution for all the flavones.

There is little doubt that the flavones, as well as many other aromatic substances, are synthesised in the leaves from sugar. The actual steps of the process would be very difficult to demonstrate. On fusion with alkalies, the flavones split, as a rule, into phloroglucin and an oxybenzoic acid. Conversely, they are probably synthesised from oxybenzoic acids, or their derivatives, and phloroglucin. As we know, somewhere in the plant and at some stage of plant metabolism, some aromatic nucleus must be synthesised, that is an aromatic substance such as phloroglucin must be synthesised from an aliphatic substance such as glucose. Putting together what physiological and chemical evidence 
there is to hand, it seems most likely that the leaf is the organ where such a synthesis takes place.

The flavones, moreover, are usually present as glucosides in the plant, one or more hydroxyl groups being replaced by sugar; hence the crude alcohol or water extracts of many plants are only pale yellow (the auxochrome groups being replaced). On hydrolysis with dilute acids, the sugar is split off, and the colour deepens; at the same time a deposit of flavone is formed, as the free pigment is less soluble than the glucoside. According to Witt, the capacity for dyeing of the flavones depends on the presence of free hydroxyl groups. Thus, it comes about that aqueous or alcoholic extracts of most plants dye but slightly when boiled with mordanted cloth, but after hydrolysis of the glucoside with dilute acid, and neutralisation, the same extract dyes more deeply.

It has been suggested by the author (226) that the flavones may, in many cases, be the chromogens from which anthocyanins are derived. The reactions involved would then be expressed in very general terms as follows:

$$
\begin{gathered}
\text { glucoside }+ \text { water } \leftrightarrows \text { chromogen (flavone) + sugar } \\
x \text { (chromogen })+ \text { oxygen } \rightarrow \text { anthocyanin }
\end{gathered}
$$

It is suggested that the first reaction is controlled by a glucosidesplitting enzyme or enzymes, and the second reaction by an oxidising enzyme. Also that several of the hydroxyl groups of the flavones, as they actually exist in the cell-sap, are replaced by sugar. After hydrolysis of one or more, but not necessarily all, of these hydroxyl groups, oxidation of the flavone molecule, accompanied by condensation of either two flavone molecules, or of a flavone with other aromatic substances, may take place at these points. Hence the final productanthocyanin-would be itself a glucoside, and the reacting substances would at all times be in the glucosidal state.

Exception has been taken by Everest (248) to the above hypothesis, which will in future be referred to as the glucoside hypothesis, and it is advisable to consider his criticisms at this point, since they do not affect the general evidence for the hypothesis to be considered later.

Everest makes the following statements which are to some extent the outcome of his investigations:

1. No known glucoside of a flavone has more than two hydroxyl groups replaced by sugar; most of the glucosides contain only one sugar molecule.

2. All anthocyanin pigments present in the natural state in plants are glucosides. No free anthocyanidins (non-glucosidal) have been detected (Willstätter \& Everest, 245). 
3. Artificial pigments identical with natural products can be prepared from flavones. From the flavone glucosides (except in the case of quercitrin, a glucoside of quercetin) anthocyanins are formed, and from the flavones themselves, anthocyanidins.

4. When anthocyanins are prepared artificially from flavone glucosides, no anthocyanidin stage is passed through. This may be shown by conducting the experiment under amyl alcohol, in which the anthocyanidins are soluble, should they be formed.

5. When flavone glucosides are hydrolysed, and the flavone converted artificially into anthocyanidins without removal of sugars, the latter do not again combine with anthocyanidins to form anthocyanins.

On the basis of the above statements Everest maintains that the glucoside hypothesis is untenable. For (1) precludes the possibility of the reacting substances being, as a rule, in the glucosidal state throughout the reaction; (2) makes it essential for the final product to be a glucoside, whereas (5) appears to make it impossible for such a recombination, i.e. between anthocyanidin and sugar, to take place. Finally (3) and (4) render hydrolysis unnecessary.

Let us now consider these points. As regards (1), it is by no means proved that flavones in the living plant have at most two hydroxyls replaced by sugar. It is quite conceivable that in the living cell more hydroxyls are replaced, and that only stable glucosides containing one or two molecules of sugar have been isolated, and this by virtue of their stability. No definite investigations have been made as to how many hydroxyls are replaced in the flavone in the plant, and in absence of further evidence, no conclusive statements can be made. With (2) the author is in agreement (Wheldale, 244). Again, it is not yet determined whether the artificial products mentioned in (3) and (4) are anthocyanins, and the matter is discussed later in the chapter. But, for the moment, grant them to be so. Then, with regard to statement (3), that it is not essential for hydrolysis to precede the formation of anthocyanin, it may be pointed out that nothing is known of the reactions giving rise to the artificial pigment; nor is there any reason for supposing the artificial and natural reactions to be the same. As regards (4), the glucoside hypothesis is still in agreement with a mode of formation which does not involve complete hydrolysis at any moment. Criticism (5) is of no value since it is well known that glucosides are not synthesised in vitro in the absence of an enzyme. Moreover, in the presence of an enzyme, synthesis only takes place to a small extent under special

w. P. 
conditions which are certainly not realised in Everest's experiments. In this respect, the results obtained in vitro have no bearing upon the reactions taking place in the plant.

Hence the original hypothesis is not affected by Everest's criticisms. First, it is quite conceivable that some of the hydroxyls of the chromogen (flavone) remain unhydrolysed, so that all the products are in the glucosidal state. Secondly, should this be disproved, there still remains the alternative, suggested by Everest himself and not disproved by his experiments in vitro, that the anthocyanidins formed in the plant immediately recombine with sugar. There is no reason to believe that the artificial reactions carried out by Everest at all reproduce the course of events in the living plant.

Apart from the similarity in distribution and reactions of flavones and anthocyanins, evidence in favour of the glucoside hypothesis may be collected and arranged under the following headings:

1. Evidence from results obtained in the cross-breeding of Antirrhinum. These results will be discussed in greater detail in Part II, but a short statement is necessary at this point, since the facts recorded are of value in this connection. The original type of Antirrhinum has magenta flowers, the colour being due to anthocyanin. During cultivation, two varieties, among others, have arisen as sports, viz. an ivory, and a white, both incapable of producing anthocyanin. Ivory, as the name suggests, is ivory-white in colour, and has on the palate a spot of yellow which is common to all varieties of Antirrhinum, except white. White is dead white, without the yellow spot on the palate. When a white 1 is crossed with an ivory, a plant having magenta flowers like the type is produced, and in these flowers, magenta anthocyanin is present in the epidermis of the corolla. Hence the original ivory and white varieties must between them contain the materials for the formation of anthocyanin. It has been shown by Wheldale \& Bassett ${ }^{2}$ that the pigment in the ivory variety is the flavone, apigenin:

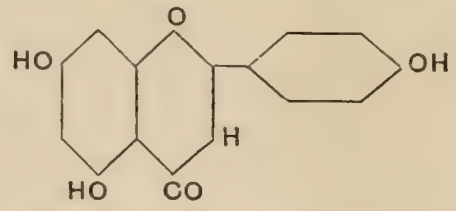

which occurs in the plant as a glucoside.

1 Of certain ancestry. See p. 161.

2 Wheldale, M., \& Bassett, H. Ll., 'The Flower Pigments of Antirrhinum majus. II. The Pale Yellow or Ivory Pigment,' Biochem. Journ., Cambridge, 1913, vI, pp. 441-144. 
No flavone is present in the white variety, but it must nevertheless contain a factor which, in some way, acts upon the chromogen, apigenin, with the production of magenta anthocyanin. The magenta flowers contain apigenin in the inner tissues of the corolla, and anthocyanin in the epidermis. This anthocyanin, isolated according to methods given elsewhere and purified from apigenin, gave on combustion the following percentages as compared with apigenin ${ }^{\mathbf{1}}$ :

C $\quad \mathrm{H} \quad \mathrm{O}$

From anthocyanin $\quad \ldots \quad \ldots \quad 50.50 \% \quad 5 \cdot 11 \% \quad 44.39 \%$

$\begin{array}{llllll}\text { From apigenin } & \ldots & \ldots & 66.66 \% & 3.70 \% & 29.64 \%\end{array}$

from which it will be seen that anthocyanin in Antirrhinum is a more highly oxidised substance than apigenin. Determinations of the molecular weight of this anthocyanin gave results of the order of 700 showing that the red pigment has a much larger molecule than apigenin, the molecular weight of the latter being 270 . Hence it is possible that in the formation of anthocyanin, either two or three molecules of flavone condense with oxidation, or the flavone condenses with some other aromatic substance present in the plant.

2. Evidence from analogous reactions. It has been suggested above that sugar is first split off from certain hydroxyl groups of the flavones (which we know to occur as glucosides), and only then can changes, such as oxidation and condehsation, take place at these points - the hydroxyl groups. Co-ordinated reactions of this kind are known to be common in plant metabolism, the most familiar case being that of indigo which may be represented:

$$
\begin{gathered}
\mathrm{C}_{14} \mathrm{H}_{17} \mathrm{O}_{6} \mathrm{~N} \text { (indican) }+\mathrm{H}_{2} \mathrm{O}=\mathrm{C}_{8} \mathrm{H}_{7} \mathrm{ON} \text { (indoxyl) }+\mathrm{C}_{6} \mathrm{H}_{12} \mathrm{O}_{6} \\
2 \mathrm{C}_{8} \mathrm{H}_{7} \mathrm{ON}+\mathrm{O}_{2}=\mathrm{C}_{16} \mathrm{H}_{10} \mathrm{O}_{2} \mathrm{~N}_{2} \text { (indigo) }+2 \mathrm{H}_{2} \mathrm{O}
\end{gathered}
$$

The first reaction is brought about by a glucoside-splitting enzyme, indimulsin, which hydrolyses the glucoside indican; the second by an oxidase which oxidises the colourless indoxyl to the pigment indigo.

The development of a bright red pigment which rapidly appears when flowers and leaves of Schenckia blumenaviana are placed in chloroform vapour has led Molisch ${ }^{2}$ to form the opinion that the reactions

1 It should be noted that in preparation, the glucosides of both the anthocyanin and apigenin are split up, and the pigments obtained for analysis free from sugar. Any sugar present in the molecule would naturally raise the percentage of oxygen to a considerable extent.

2 Molisch, H., 'Ueber ein neues, einen carminrothen Farbstoff erzeugendes Chromogen bei Schenckia blumenaviana,' Ber. D. bot. Ges., Berlin, 1901, xIx, pp. 149-152. 
involved are the hydrolysis of a glucoside and subsequent oxidation. Quite similar pigments have been described by Parkin, Bartlett, Tammes and others ${ }^{1}$. The reactions taking place in the formation of the respiration pigments of Palladin are probably of the same nature. An analogous case too is the development of blue pigment in the white flowers of an Orchid (Phajus sp.) on the death of the tissues. The change of colour has been used to determine the death-point of the protoplasm when subjected to freezing ${ }^{2}$.

3. Evidence from the connection of unthocyanin formation with pholosynthesis. It has already been stated in Chapter vi, that a very definite comnection exists between photosynthesis and the appearance of anthocyanin. In organs, such as green leaves, in which photosynthesis takes place to the greatest extent, there is least production of anthocyanin. In organs, on the other hand, such as flowers, which are unable to carry on photosynthesis, there is the greatest formation of pigment. All intermediate conditions may be found between these two extremes and the same relationship will be found to hold. From these data, the deduction can be made that the greatest concentration of sugar arises in tissues where photosynthesis is most active. Thus, in leaves, there is abundant sugar to combine with the chromogen, and provided translocation of all synthetic products away from the leaf is unhindered, the direction of the reaction suggested in the hypothesis will be:

$$
\text { chromogen }+ \text { sugar } \rightarrow \text { glucoside }+ \text { water }
$$

Under these conditions there would be no tendency for free chromogen to exist, and consequently no anthocyanin would be formed.

4. Evidence from the results of the blocking of the translocation current. It has also been stated that injury to the tissues, through

1 Parkin, J., 'On a brilliant Pigment appearing after Injury in species of Jacobinia,' Ann. Bot., Oxford, 1905, xix, pp. 167-168.

Bartlett, H. H., 'The Purpling Chromogen of a Hawaiian Dioscoreu,' U.S. Dept. of Agriculture, Bureau of Plant Industry, Bull. 264, 1913.

Tammes, T., 'Dipsacan und Dipsacotin, cin neues Chromogen und ein neuer Farbstoff der Dipsaceae,' Rec. Trav. Bot. Néerl., Nijmegen, 1908, v, pp. 51-90.

Palladin, W., 'Die Bildung roten Pigments an Wundstellen bei Amaryllis vittata,' Ber. D. bot. Ges., Berlin, 1911, xxтx, pp. 132-137.

2 Müller-Thurgau, H., 'Ueber das Gefrieren und Erfrieren der Pflanzen,' Landw. Jahrb., Berlin, 1880, IX, pp. 133-189. Also:

Prillieux, Ed., 'Coloration en bleu des fleurs de quelques orchidées sous l'influence de la gelée,' Bul. soc. bot., Paris, 1872, xIx, pp. 152-157.

Bommer, J. E., 'Étude sur le bleuissement des fleurs du Phajus maculatus Lindl.,' Bull. soc. bot., Paris, 1873, xx, pp. xxvii-xxxiii. 
which the products of synthesis pass from the leaves, may cause reddening in the portion distal to the point of injury. Analyses, made by Combes (207) of leaves of Spircea which had turned red owing to decortication, show that red leaves contain greater amounts of both glucosides and sugars to the following extent:

$\begin{array}{llccc} & & & \text { Glucosides } & \text { Sugars } \\ \text { Green leaves } & \ldots & \ldots & 1 \cdot 64 & 2 \cdot 21 \\ \text { Red leaves } & \ldots & \ldots & 6 \cdot 15 & 4 \cdot 26\end{array}$

and that the inerease of glucoside in red leaves is proportionally greater than the increase of sugar. When we assume also that the chromogen (flavone) is being continually synthesised in the leaves from sugar (see p. 111), then it follows that in red leaves the hydrolysis reaction, owing to the increased concentration of the glucosides, may take place in the reverse direction:

$$
\text { glucoside }+ \text { water } \rightarrow \text { chromogen }+ \text { sugar }
$$

Hence more free chromogen and consequently more pigment will be formed.

5. Evidence from data as to the absorption of oxygen in gaseous excharige in red and green leaves. By making analyses of gaseous exchange in red and green leaves respectively, Combes (379) has shown that the red absorb more oxygen during the reddening process than the normal leaves. Katic (354) also demonstrated that leaves kept in culture (sugar) solutions in the absence of oxygen, failed, although they remained alive, to form any anthocyanin in contrast to similar leaves when the experiments were conducted in air. Molliard (376) also showed that oxygen is necessary for the formation of anthocyanin in radishes by totally submerging the roots in sugar solution, under which conditions the pigment failed to appear.

That anthocyanin is produced by the action of an oxidase on a chromogen forms the basis of the hypothesis of Keeble, Armstrong \& Jones $(230,231)$. It would appear to be evident from the results obtained by these authors that there is an intimate relationship between the distribution of oxidase and the development of anthocyanin. There is every reason to believe, on their evidence, that oxidation processes would readily take place in those tissues in which anthocyanin is found. These authors consider that the formation of anthocyanin is represented by the following equation:

$$
\begin{aligned}
& \text { glucoside }+ \text { enzyme } \rightarrow \text { sugar }+ \text { chromogen } \\
& \text { chromogen }+ \text { enzyme }+ \text { peroxide } \rightarrow \text { pigment }
\end{aligned}
$$


Their evidence may be summed up under two headings : viz. evidence from (1) presence of oxidising enzyme, (2) presence of chromogen.

1. Presence of oxidising enzyme.

In order to demonstrate the existence of oxidising enzymes in the tissues, Keeble \& Armstrong have adopted an excellent microchemical method. The mode of procedure is to place the tissue to be examined in either a $1 \%$ solution of benzidine in dilute alcohol, or in an equally dilute solution of $\alpha$-naphthol and incubate at $37^{\circ} \mathrm{C} .1$ If no direct oxidase reaction results, the material is removed from the tube and washed with a dilute solution of hydrogen peroxide. The above method was employed with great success on petals of Primula sinensis. It was found that $\alpha$-naphthol gave a delicate lilac-blue colour with oxidases, but only detected them in the bundle sheath of the veins, whereas benzidine gave a brown coloration and detected oxidases both in the epidermis and in the bundle sheath. The results as regards Primula sinensis may be summed up as follows:

Flowers from all coloured varieties and recessive whites (see p. 177) gave a benzidine reaction in the epidermis and an $\alpha$-naphthol reaction in the bundle sheath. These tissues being the chief seat of the pigment, it may be said that the distribution of enzyme and pigment in coloured varieties is practically coincident. Flowers of dominant white varieties gave no oxidase reaction. In the case of a blue variety with inhibited white patches on the corolla segments, there was a more or less corresponding lack of oxidase reaction in the inhibited patches. It was found that the inhibitor could be removed by treatment with hydrocyanic acid and other methods, and the above varieties then gave the usual benzidine and $\alpha$-naphthol reactions. Flowers of certain flaked (magenta and white) varieties showed no oxidase reaction in the white parts.

Other genera were also investigated by the same method. In Sweet William (Dianthus barbatus) flowers, it was found that the oxidase reaction was entirely proportional to the amount of pigmentation. Of white varieties, some were found to contain oxidase; white parts of other varieties were found to contain no oxidase. In Geranium sanguineum the purple type contains epidermal oxidase, but the white variety gives no such reaction. In the Sweet Pea (Lathyrus) and Garden Pea (Pisum), no whites were found which did not contain

1 Benzidine and naphthol are artificial acceptors. Whether the reaction obtained is direct or indirect depends on the presence of a natural peroxide suitable for acceptors used. Absence of direct action does not preclude a system peroxide-peroxidase in the plants. 
oxidase. Hence Keeble \& Armstrong hold the view that in those cases where albinos give the oxidase reaction, albinism is due to lack of chromogen, but in the case of Geranium sanguineum, Dianthus and flaked Primula, lack of oxidase causes lack of pigmentation.

The assumption that albinism in Primula, Lathyrus and Pisum is due to loss of chromogen must thus remain for the present until we have further experimental data either for or against it. In the author's experience the only instances of absence of chromogen (as determined by the flavone reaction) are the albinos of Antirrhinum and Phlox Drummondii. Flavones can be detected by the intense colour given with alkalies, and this reaction was given by all albinos of Lathyrus and Pisum examined. Nevertheless it must be admitted that this is no direct proof, since there may be several flavones from only one of which anthocyanin is derived. Keeble \& Armstrong's views cannot however explain the case of Antirrhimum, for we must suppose the ivory variety to be an albino through lack of enzyme, since it contains the chromogen (apigenin). Yet all ivory individuals tested by the author have contained peroxidase. A possible explanation for this universal presence of enzyme in ivories is that several oxidases are involved in pigment formation. Thus only individuals free from all factors (and these are extremely rare, as for instance 1 in 1024 when five factors are concerned) would show no enzyme action. Yet at present there is no evidence that more than one enzyme is involved. Another possibility is that in Antirrhinum some third factor of a different nature is essential, conceivably for condensation (see pp. 71, 211, 212).

Consequently, as methods for detection of enzymes and chromogens, one qualitative reaction is of no more value than another. Tissues may give the flavone reaction, and yet we cannot be sure that the actual chromogen of anthocyanin is present. Similarly, we have no absolute proof from qualitative reactions for peroxidase that we are dealing with a factor for colour. We may be localising areas where any oxidative process is carried on (anthocyanin formation among others, if it is oxidative). Apart, then, from the case of Antirrhinum of which the chromogen has been isolated, and there is good evidence that only one exists, little can be gained from speculations as to the presence or absence of chromogens and oxidising enzymes, without more definite isolation and analysis. Atkins $(233,246,258)$, too, working with Iris flowers has found that there is no satisfactory evidence for the coincidence of anthocyanin formation with the presence of oxidases.

Keeble, Armstrong \& Jones (239) have also maintained that the 
behaviour of anthocyanin in alcohol further confirms the view that the pigment is formed by oxidation from a colourless chromogen. According to these authors when coloured petals of stocks (Matthiola) are placed in absolute alcohol, some colour is extracted by the alcohol, but both petals and alcohol become colourless in the course of an hour or so. If now the colourless petals are removed from alcohol and placed in water, the colour returns, and more rapidly if the water be hot. Keeble, Armstrong \& Jones explain these phenomena in the following way. Anthocyanin is formed from a colourless chromogen by oxidation, the agent being an oxidase which can only act in the presence of water; there is present also a reducing agent (which is not an enzyme), and this reduces anthocyanin to its colourless chromogen when the action of the oxidase is inhibited by absolute alcohol. The validity of this explanation has been questioned both by Wheldale \& Bassett (621) and Tswett (252). The two former authors note that an extract of anthocyanin made in boiling absolute alcohol (which cannot according to Keeble \& Armstrong contain oxidase) loses its colour on standing. The colour can be brought back by dilution with water. Hence obviously no oxidase is necessary. Moreover colour can be restored to the alcohol solution by dry hydriodic acid gas, a powerful reducing agent. Colour is also restored to petals, decolorised in alcohol, when they are placed in boiled water through which a stream of hydrogen has passed for some time and still continues to pass; a condition under which any leuco-compound should be stable. Similar criticisms to these are also offered by Tswett.

We now turn to the second class of evidence. (2) Presence of chromogen.

Evidence for the presence or absence of chromogens is given by Jones (237). According to this author four classes of white flowers may be distinguished. (a) Those, such as Lychnis coronaria, Anemone japonica, Chrysanthemum sp. which produce a brown or brownish-red pigment when subjected to alcohol, chloroform, etc. Such flowers contain a direct oxidase; $(b)$ those, such as varieties of Dianthus Caryophyllus and $D$. barbatus, which give similar pigments only on addition of hydrogen peroxide and contain peroxidase only; $(c)$ those, such as white varieties of Plumbago capensis and Swainsonia Tacsonia, which do not produce a brown pigment even after addition of hydrogen peroxide but contain a peroxidase, and $(d)$ those, such as varieties of Sweet William mentioned above under (1) which have no peroxidase and hence no oxidase. Reference to the account previously given of 
Palladin's 'respiration pigments' at once makes it clear that Jones' chromogens are identical with these pigments. Class $(a)$ contains some substance which can act as an organic peroxide, class $(b)$ no such substance, so that hydrogen peroxide must be added in order to give a pigment. Class $(c)$ apparently contains no substance which can act as a respiration pigment. There is no evidence whatever that the chromogens of the respiration pigments are in any way the chromogens of anthocyanin, and hence their absence has no bearing on albinism with regard to anthocyanin (see footnote on p. 109).

More recently Combes $(234,235,620)$ has brought forward evidence which he considers to be in complete contradiction to the oxidation hypothesis of the formation of anthocyanin. Combes' work may be summed up under three headings:

1. The isolation of two pigments from leaves of Ampelopsis hederacea: namely, a brownish-yellow pigment crystallising in rosettes of needles and having the properties of a flavone, and a purple pigment also crystallising in rosettes of needles and having the properties of an anthocyanin.

2. The transformation of the flavone into a purple pigment identical with anthocyanin by reduction.

3. The transformation of anthocyanin into a flavone by oxidation.

The method employed by Combes of obtaining anthocyanin from flavone (from Ampelopsis) is to dissolve the flavone in alcohol, acidify with hydrochloric acid and add sodium amalgam. The solution thus treated with nascent hydrogen becomes violet-red and increases in intensity of coloration. After neutralisation and filtration, the solution obtained gives a purple substance on evaporation. The latter crystallises in needles grouped in rosettes like the natural anthocyanin and has the same melting point and properties as the natural product. Combes also obtained crystalline anthocyanin from a crystalline flavone isolated from leaves of the Privet (Ligustrum vulgare) and from a similar substance extracted from a variety of Vine which does not redden in autumn. From these results he concludes that the phenomena observed for Ampelopsis are not confined to that plant. And, moreover, though the variety of Vine (Chasselas doré) does not redden in autumn, yet its leaves produce a substance capable of being reduced to form an anthocyanin. In addition, he employed flowers of Narcissus incomparabilis. The genus Narcissus, as is well known, contains a readily crystallisable flavone, and from this substance he also prepared an anthocyanin-like product by reduction. 
As a converse to the above experiments, Combes oxidised anthocyanin and obtained a flavone. The method employed consisted in taking Ampelopsis anthocyanin and purifying it by crystallisation, first from alcohol, and secondly from water. The pure product is dissolved in alcohol, and an equal volume of hydrogen peroxide is added. The purple colour of the anthocyanin gradually disappears, and a yellow solution is left which deposits crystals of a flavone identical in properties and melting point with the natural product derived from the plant. Hence he concludes that the anthocyanin has been oxidised with the formation of flavone.

A criticism of this last experiment and the deduction therefrom may be made at this point. It is not mentioned in Combes's paper whether the crystalline anthocyanin had been tested in order to ascertain if it were free from flavone. It is the experience of the author (Wheldale, 254 ) that when a mixture of flavone and anthocyanin obtained from Antirrhinum is allowed to crystallise from alcohol, both pigments crystallise out together in plates which, in spite of the fact that they may consist largely of flavone, are deep red in colour, and very careful purification is necessary before anthocyanin can be obtained entirely free from flavone. When pure anthocyanin from Antirrhinum is treated with hydrogen peroxide, the pigment is destroyed but no flavone is found. Hence it is possible that the flavone derived from Combes's anthocyanin may have been present as impurity. If, however, this were not the case, it still may be possible that the action of the hydrogen peroxide is not necessarily one of oxidation.

Before making any criticism upon the question of the action of sodium amalgam, the work of Keeble, Armstrong \& Jones, Tswett and Everest on similar lines, must be considered.

Keeble, Armstrong \& Jones (240) have obtained red pigments, giving, in some cases, the anthocyanin reaction by treating alcoholic extracts of a number of plants with zine dust and hydrochloric acid. Under these conditions, extracts from the following plants gave red pigments: pale yellow 'primrose' variety of Cheiranthus, yellow Daffodil, yellow Crocus, cream Polyanthus, and the dominant white variety, but not recessive white variety, of flowers of the Chinese Primrose (Primula sinensis). The red pigment which is first formed will, after continued treatment with nascent hydrogen, become colourless, the colour returning on exposure to air. This phenomenon led the authors to conclude that a preliminary reduction, followed by oxidation, is the sequence of events. 
Tswett (243) also found that an 'artificial anthocyanin' could be prepared from apple juice by the action of strong mineral acids in the presence of formaldehyde or acetic aldehyde. The artificial anthocyanin had properties and reactions very like the natural pigment, but was soluble in ether, whereas natural anthocyanins are insoluble in this solvent. Tswett produced similar pigments, though he did not study them in detail, from extracts of white grapes, bananas, flesh of purple grapes, white petals of Rosa and Cyclamen. He failed however to get any formation of pigment on treatment of the following: leaves of white Cabbage, mesophyll of red Cabbage, leaves of Pelargonium, Orange skins, petals of white Pinks, white petals of buds of red Pinks, flowers of Lily of the Valley, Carrots, Potatoes, Kohlrabi and Barley seedlings.

Artificial anthocyanin resembles natural anthocyanin in the following respects. It is soluble in alcohol, gives a green reaction with alkalies, red with acids and a green precipitate with lead acetate; it is decolorised by sodium bisulphite, but the colour returns again on acidifying with sulphuric acid. It differs from the natural product in its solubility in ether and also its ready solubility in water, the natural pigments being only slightly soluble in water, except in the condition of glucosides.

The work of Everest $(248,249)$ in this direction has been more elaborate. Mention has been previously made of the fact that Everest has prepared from the flavones, substances which give some of the qualitative reactions of anthocyanin. Everest's methods are as follows: He reduces an alcoholic solution of flavones, to which is added $2 \mathrm{~N}$ acid solutions, by means of nascent hydrogen formed by (1) addition of granulated zinc, (2) sodium amalgam, (3) electrolysis, using sulphuric acid and lead electrodes, and (4) magnesium ribbon. The materials employed were quercetin, quercitrin and extracts from various flowers and tissues. In many cases a red pigment is obtained as reduction proceeds. When quercetin was employed, the product could be extracted quantitatively from the acid solution by amyl alcohol showing it to be an anthocyanidin. When quercitrin, a monoglucoside of quercetin, was used, anthocyanidin, contrary to expectation, was also obtained. Extracts, however, from flowers and other tissues, in which the flavones are presumably in the glucosidal state, gave anthocyanins in the cold and anthocyanidins on hydrolysis.

Everest also lays stress upon the fact first noted by Keeble, Armstrong \& Jones (240), that the artificial anthocyanin is reduced to a colourless substance by vigorous reduction with nascent hydrogen. This is also the case with the natural pigment (see p. 55). This similarity 
in behaviour, together with the solubility in amyl alcohol and the green reaction with alkalies, he considers to be a complete proof of the identity of the two pigments.

The author, in conjunction with Bassett (255), has prepared red products from both quercetin and apigenin. In the case of apigenin, the substance was analysed and found to be a reduction product, but its reaction with alkalies in no way resembled that of anthocyanin. On the other hand, there is every reason to believe that the anthocyanin of Antirrhinum may be derived from apigenin by oxidation and condensation. Hence, in the only instance where both artificial and natural anthocyanins have been obtained from a flavone and have been analysed, they appear to be by no means identical.

More recently Willstätter (257) has investigated the problem of the artificial formation of anthocyanin, and maintains that two substances are produced when quercetin is reduced with nascent hydrogen. In his experiments, an alcoholic solution of quercetin acidified with hydrochloric acid is reduced with sodium amalgam or magnesium. A purplishred product is obtained, and the bulk of this substance he terms allocyanidin; on the basis of analysis (by combustion) of the product he suggests the following constitution and reactions:

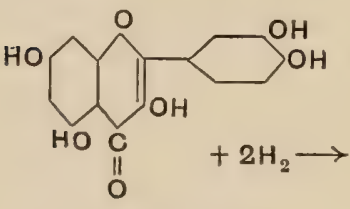

Quercetin

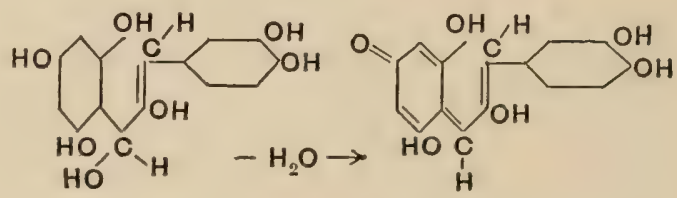

Allocyanidin

Allocyanidin forms a crystalline compound with hydrochloric acid, but is unstable on heating with the dilute acid. When, however, the crude solution obtained from the reduction of quercetin is diluted and heated, it does not entirely lose colour owing to the presence, in Willstätter's opinion, of a small amount of a second product. Isolated and analysed, this latter product was found to be identical with cyanidin chloride, and it is suggested that the reaction takes place as follows:

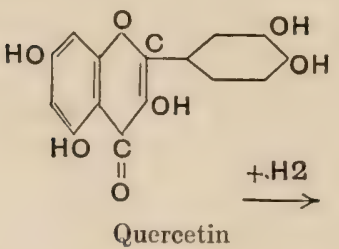

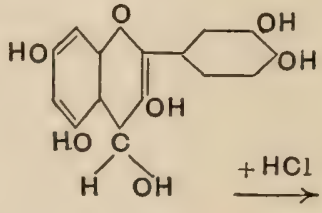

$\stackrel{\mathrm{HCl}}{\longrightarrow}$

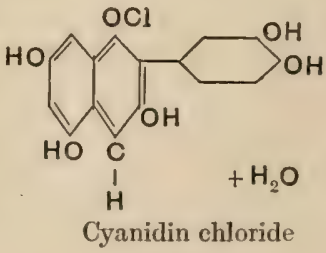


From 33 gms. of quercetin, $0 \cdot 165 \mathrm{gm}$. of the product was obtained. It seems to be open to criticism to assume that this product is formed by reduction; it is also doubtful whether the analysis (by combustion) forms an efficient proof of its identity with cyanidin, though its resemblance in chemical and physical properties certainly lends support to the statement. Granted, however, that cyanidin is formed from quercetin by reduction, we still have no proof that this is the process employed by the living plant.

The contents of the present chapter may be summarised as follows. There is strong evidence for the belief that anthocyanins are formed from the flavones, and that these substances are the chromogens of the Mendelian writers. But the actual processes involved are still debatable. There is evidence, from Keeble \& Armstrong's work, that the presence of anthocyanin is often connected with the presence of oxidases, but there is no proof that oxidases are the agents in transforming flavones into anthocyanins. From the analyses of pigments of Antirrhinum, it appears that the anthocyanins of that genus are more oxidised than the flavone, apigenin, which is present in the plant, and the artificial product formed by reduction from apigenin is moreover not identical with a natural anthocyanin. On the other hand, there is the evidence from Willstätter's experiments that quercetin on reduction will produce, as a by-product, a substance identical with a natural anthocyanin. To obtain a satisfactory solution to the problem, further experimental work is necessary, especially on the lines of isolation and analysis of other plant anthocyanins and the flavones which accompany them ${ }^{1}$.

1 See also Appendix. 


\section{CHAPTER VIII}

\section{THE SIGNIEICANCE OF ANTHOCYANINS}

\section{Biological significance.}

The function of anthocyanins in rendering the corolla, perianth, bracts and other parts of the inflorescence attractive to insects may be regarded as their biological significance; so also the function of making ripe fruits conspicuous to birds. Neither of these subjects is dealt with in the present volume, but references are given to the work of Knuth (426), Focke (423) and others, from which further information can be obtained.

\section{Physiological significance.}

Several physiological functions have been assigned to anthocyanins but, broadly speaking, they fall into three classes. Though each hypothesis has been closely criticised by the various investigators of the problem, the final issue is far from being complete and satisfactory. The three main ideas are:

1. That of shielding the chloroplastids from too intense insolation; this is known as the 'light-screen' hypothesis. In slightly different forms it has been advocated by Kerner, Kny, Wiesner, Keeble and Ewart.

2. That of assisting the action of diastase by screening it from deleterious rays, and thereby facilitating the hydrolysis of starch and subsequently translocation. This view has been mainly supported by Pick, and Koning \& Heinsius.

3. That of absorbing certain light rays and converting them into heat. Though the conception of anthocyanin as a medium for raising the temperature of tissues was due to earlier writers, notably Comes and Kerner, yet it was Stahl who first regarded this property as a valuable asset in assisting transpiration; he also considered other processes of 
general metabolism, including translocation and fertilisation, to be furthered by the warming effect of the pigment.

The 'light-screen' hypothesis had no doubt a basis in the work of Pringsheim. About 1880 Pringsheim ${ }^{1}$ published the results of various experiments on carbon assimilation, and among these, the effect of light of different colours and intensities on chlorophyll. He found that white light of a high intensity decolorised chlorophyll, but in red light the effect was suppressed. In yellow, green, or blue light, on the other hand, it is easy to decolorise and kill the cells of many Algae, Characeae, Musci, Filices and Phanerogams. Thus in white light, the result was attained in two or three minutes, in green and blue in five minutes, whereas in red light of the same intensity and after twice or four times as long exposure, no changes took place. Hence he supposes the red rays to be photochemically inactive, or only very slightly active, on plant cells. That the injurious effects were not due to heat is shown by the fact that in green light the temperature did not rise sufficiently to be harmful to plant cells. For instance even in red light, the temperature of the water drop in which the tissue was placed, was raised to over $45^{\circ} \mathrm{C}$. within five minutes, and yet after $15-20$ minutes' exposure, there was neither decolorisation nor death of the cell. On the other hand, in green and blue light, cells were decolorised and killed in five minutes, although after 15-20 minutes' exposure, the water scarcely reached $35-36^{\circ}$, a temperature quite harmless to the cells. The solutions used were for red light, iodine in carbon bisulphide, for yellow, potassium bichromate, for green, copper chloride, and for blue, ammoniacal copper sulphate.

It would seem, however, that Pringsheim may have overrated the destroying effect of sunlight on chlorophyll, for Reinke ${ }^{2}$, in a paper published in 1883, mentions some results he obtained by exposing both the green and red (anthocyanin) parts of plants to light intensified by a lens, the heat rays being cut off by a screen of alum solution. He found that the chlorophyll in leaves of Elodea and Impatiens and the red pigment in the petals of Papaver and Rosa were not decolorised unless the light intensity became $800-1000$ times greater than normal

1 Pringsheim, N., 'Ueber Lichtwirkung und Chlorophyllfunction in der Pflanze,' Jahrb. wiss. Bot., Leipzig, 1879-1881, xII; 1882, xII. Also 'Pringsheim's Researches on Chlorophyll,' translated and condensed by Bayley Balfour, Q. J. Microsc. Sci., London, 1882, xxII, pp. 76-112, 113-135.

2 Reinke, J., 'Untersuchungen über die Einwirkung des Lichtes auf die Sauerstoffausscheidung der Pflanzen,' Bot. Ztg., Leipzig, 1883, xLI, pp. 697-707, 713-723, 732-738. 
sunlight. When in light of only 200 times the intensity, there was no bleaching of Elodea even after two hours' exposure.

Kerner (398) appears to be one of the first, if not the first, to make suggestions as to the significance of anthocyanin, though in his Pflanzenleben $(1885)^{1}$, he by no means confines himself to one use of anthocyanin to explain its appearance in different places under various conditions. Thus, for instance, in stems and petioles, he says, it may be of use in keeping back light rays which would decompose the travelling materials. (This view may be original or may be taken from Pick, see p. 131.) In other cases it is produced temporarily for the same purpose when there is a transmission of metabolic substances on a large scale as in the seedlings of certain starchy seeds (polygonums, oraches, palms and grasses). Again, in spring, it appears in young leaves and shoots when supplies are travelling to them from their place of storage in the stem. In autumnal leaves, all materials of use to the plant are passing out for storage; hence the value of autumnal coloration. Anthocyanin developed on the under surfaces of leaves, is, on the contrary, not protective but abscrbs light and changes it into heat which is serviceable for growth, metabolism and translocation. When, in shrubs and herbs, anthocyanin appears on the under leaf-surfaces, this is only the case in the lowest leaves near the ground; the upper leaves remain green and so do not prevent light from passing through to the leaves beneath them. The development on the under surface of leaves of marsh plants and floating plants has similar uses. Thus, there is not only retention by anthocyanin of rays injurious to metabolism, but there is, at the same time, a useful transformation into heat. When, he continues, the surrounding temperature is low, plants are often entirely reddened, as in some small annuals developing early in the spring (Saxifraga, Hutchinsia, Androsace); also in seedlings germinating at low temperatures. It is, for the same reason, common in the vegetative parts of many High Alpine plants. Of similar value is its distribution on the under surface of petals and perianth leaves of flowers which close by night.

Two further observations of interest are mentioned by Kerner. One, that plants which have leaves covered with a felt or wool of hairs rarely develop anthocyanin, since such leaves do not need so much protection from light.

The second observation is that made on Salureja hortensis, a plant

1 The Pflanzenleben appears to have been issued in parts several years before the first edition in 1888 . 
growing wild in the Mediterranean region and in cultivation in gardens where it is known as the Summer Savory. In the shade it is green; exposed to the sun its stems and leaves are dark violet. Kerner sowed the seeds of this plant in his Alpine garden, 2195 metres above sea-level, in the Tyrol. There, as a result, it is supposed, of the intensity of the sun's rays, it produced anthocyanin in extraordinary abundance. Such an adaptation, as he points out, can only take place in plants which are able to form the pigment. Seeds of Linum usitatissimum were sown next to the Savory; the seedlings turned yellow and failed to survive owing to the fact, in Kerner's opinion, that they are unable to form anthocyanin to protect the chlorophyll and are also without any development of hairs.

In 1885 Reinke ${ }^{1}$ published further results which, if accepted, make it difficult to uphold the 'light-screen' hypothesis. The problem he set out to investigate was the effect of the different parts of the spectrum on the destruction of chlorophyll, and he claims to have shown that the red rays have the maximum destructive effect, and that this power decreases in the other parts in the following order-orange, violet, yellow, blue, dark red and green: when this sequence is compared with the absorption spectrum of chlorophyll, it will be seen that the rays which are most absorbed by chlorophyll have the greatest destructive effect upon it, and those which are least absorbed, do not have any effect upon it.

Further support was given by Hassack (393)' in 1886 to the screen hypothesis, though his work is chiefly confined to the histological distribution of anthocyanin in leaves.

In 1887 a paper appeared by Engelmann (394) which has considerable bearing on the problem. By means of a microspectral photometer, Engelmann investigated the spectra of the pigments in red leaves, and found that the absorption of red pigment is, on the whole, complementary to that of chlorophyll. Hence we are confronted with this dilemma. Anthocyanin absorbs those rays which are not absorbed by chlorophyll; the rays least absorbed by chlorophyll are, according to Reinke, the least harmful to chlorophyll. Therefore anthocyanin absorbs the rays which are least, and not most, harmful to chlorophyll. How then can it be a protective screen? If we accept Reinke's results, a green screen would be the best protection as it would absorb the rays

1 Reinke, J., 'Die Zerstörung von Chlorophylllösungen durch das Licht und eine neue Methode zur Erzeugung des Normalspectrums,' Bot. Ztg., Leipzig, 1885, xLIII, pp. 65-70, 81-89, 97-101, 113-117, 129-137.

W. P. 
which are most absorbed by chlorophyll and are, at the same time, most injurious. If, however, we accept Pringsheim's results that the green portion of the spectrum is most harmful, then it is possible to consider the question as to whether anthocyanin is a screen or not.

The matter was again brought up by Kny (397) in 1892. To test the efficiency of anthocyanin as a light screen, Kny placed a solution of chlorophyll behind a parallel-walled glass vessel which was filled in one case with an extract of red, in another with an extract of white, Beet-root. Behind the red extract, the chlorophyll retained its colour much longer than behind the white. This experiment is of little value since chlorophyll in a dull light (such as would be the case behind the red solution) invariably retains its colour much longer than in a bright light.

Again, in 1894, Wiesner (400) supported the screen theory for the protection of chlorophyll, especially in young leaves.

In 1895 Keeble (403) published a paper of some significance on the hanging foliage of tropical trees. The characteristic pendent position and red coloration of young leaves of some of these trees has been mentioned in Chapter II. Keeble is of the opinion that, though the development of red pigment is not universal among them, yet it may serve as a protection against strong insolation, not only as a screen but also by protecting the leaf from too great heating. This view is based on an experiment carried out with red and green leaflets of Amherstia nobitis. These were laid side by side in the sun, and the temperature taken by thermometers placed upon the upper surfaces of the leaves; the thermometers were then placed under the leaves and the temperature again taken. His results and conclusions are expressed as follows: "... when young thin red and older tougher green leaves of Amherstia are exposed side by side to the direct rays of the sun, the temperature, as registered by the thermometer, is higher to the extent of $1^{\circ} \mathrm{C}$. at the upper surface of the red leaves: conversely, of the temperatures registered at the lower surfaces of the leaves (i.e. behind them), that beneath the green is higher than that beneath the red, by a similar amount.

"Put in general terms, the surface-layers of the red leaf reflect more heat than those of the green leaf. The green leaf, conversely, absorbs more of the sun's thermal rays than the red. Now, the two sets of leaves differ in two respects: first, in colour; then in that the green has a thicker, more developed cuticle (and mesophyll) than the 
red. This might, therefore, be expected to oppose a more solid resistance to the heat-rays than the thin immature cuticle of the red leaf. That such is not the case must be regarded as due to the fact that the different colouring-matters have different powers of reflection and absorption of heat, and that this difference is of such a nature that the red colouringmatter more effectually cuts off heat-rays from the body of the leaf than does the green. That is to say, the red colouring-matter acts as a screen by which the thermal effects of the sun's rays are moderated." In conclusion Keeble says: "In addition, then, to its value as a screen, the red or reddish coloured saps of such trees as Amherstia nobilis have the capability of affording to the young leaf, if necessary, a protection against too great heating effects of the rays of a tropical sun."

Later, Keeble's conclusions have been adversely criticised by both Stahl (405) and Smith (420): the latter remarks, alluding to Keeble: "From his somewhat rough experiments he drew the novel conclusion, which...is exactly the opposite of the conclusion logically to be drawn from his observations, that the red colour is a protection against too great heating up of the leaf."

In 1895 a long paper appeared by Ewart (401) on 'Assimilatory Inhibition in Plants.' Ewart maintains that leaves, especially of shade plants, when exposed for a long time to strong illumination, suffer from inhibition of photosynthetic power. He considers the development of anthocyanin, on exposure to light, to be an adaptation for protection against this light rigor, rather than a protection against the destruction of chlorophyll. We shall return later to further criticisms by Ewart.

We will now pass on to another suggestion as to the uses of anthocyanin, though it was the first in point of time. It is that made, in 1883, by Pick (391), who maintained that red light increases the rate of hydrolysis and translocation of starch, while it allows photosynthesis to go on unhindered. Hence its frequent occurrence in stems and petioles; also in young leaves where there is active metabolism and in autumnal leaves from which there is a migration of substances which may be useful for storage. Pick brings forward certain evidence, namely that in red leaves the palisade parenchyma contains less starch than the spongy, on account of the increased translocation under the influence of the red light. He, moreover, gives the results of an experiment with a view to proving the same point. Of the lobes of a large leaf of Ricinus, one was illuminated by light coming through orange 
glass, a second by light through ruby glass, a third by light passing through anthocyanin solution (of beet-root), while a fourth remained in bright insolation. All the lobes were illuminated thus for four hours. He then found that the insolated lobes had more starch in the palisade parenchyma, though there was a considerable amount in the spongy tissue too, whereas the lobes covered by red glass and anthocyanin solution had more starch in the spongy parenchyma; of the lobe covered by orange glass, there was nothing in particular to note. From these results Pick concludes that the lobes illuminated by ruby glass and anthocyanin solution had assimilated as much as the directly insolated lobe, but translocation had been more rapid.

Pick's conclusions were adversely criticised by Wortmann (619) who maintained that the observations on starch distribution in red leaves are valueless because, first, it was not noted whether green leaves behave differently under similar circumstances, and secondly, the effect of red light on diastase activity outside the cell should be investigated also. As regards the experiment on the Ricinus leaf, he points out that, according to Stahl, the palisade cells and chloroplastids are adapted to starch formation in bright light, while those of the spongy parenchyma are adapted to diffuse light. Hence the distribution of starch in the lobes exposed to red light may be explained on the ground that they receive less light than the directly insolated leaf. Since Wortmann's criticisms have not been refuted, the question still remains unsolved. Later, Ewart (406) also criticises Pick's deductions. Pick has stated at one point that young red leaves have little starch because the translocation is furthered, but as the leaves mature, and the pigment disappears, more starch develops. Ewart makes what appears to be a more natural suggestion, namely that photosynthetic activity increases as the leaf matures and this is so even if the leaf should retain its red colour.

More recently Koning \& Heinsius (416) have again reopened the question as to whether anthocyanin acts as a screen for diastatic activity. These authors quote the results of Brown \& Morris to the effect that the diastase content of leaves decreases after a period of exposure to bright light, and that the enzyme is chiefly destroyed by the violet and ultra violet rays. Koning \& Heinsius claim to have shown experimentally that the above-mentioned rays are absorbed, not only by a water extract of anthocyanin, but also by the pigment in the living leaves; also, by placing branches of Quercus rubra and other species under double-walled vessels filled with anthocyanin solution, that it 
is these same rays which cause the formation of anthocyanin. Finally, it was shown that red leaves always contain more diastase than green. From these results the authors conclude that anthocyanin has a protective action on diastase.

The third theory which has been so largely supported by Stahl (405) is based on the power shown by anthocyanin of converting light rays into heat. Kerner, as previously mentioned, had the idea of this function of anthocyanin, but Stahl laid stress on a special aspect, viz. that of accelerating transpiration in red leaves.

Stahl, however, was by no means the first to suggest a connection between light absorption and transpiration. As early as 1879-80, Comes $(388,389,390)$ published the results of work on the effect of light on transpiration. He used pot plants which were enclosed in a zinc case with a glass front, and the loss of water was determined by weighing. The plants were also exposed to differently coloured light obtained by using potassium bichromate, ammoniacal copper, and alcoholic chlorophyll solutions. The transpiration of various coloured corollas was observed, the absorption bands of the pigments being also ascertained. From his experiments Comes arrives at the following conclusions. Transpiration is affected by light as well as by physical conditions; other things being equal, a plant transpires more in the light than in the dark, and the effect of light is proportional to its intensity. Light favours transpiration only in so far as it is absorbed by the colouring matters, and thus, that organ transpires most which is most highly coloured. (This point was demonstrated by the coloured corollas; those of which the pigment showed absorption bands in the greatest number, breadth and intensity, transpired most strongly.) Moreover, the rays which are most favourable for transpiration in a coloured organ are those which are most absorbed by it. Hence the transpiration of an organ is slightest under the influence of light which is of the same colour as the organ itself, and strongest when under the rays of the complementary colour. We have here then in Comes' results the basis of Stahl's hypothesis, that the red pigment of leaves brings about additional absorption and heating of the leaf, and consequently greater transpiration.

In addition, Kny (397) claims to have shown, by means of a simple experiment, that red leaves do attain a higher temperature than green. Kny filled two parallel-sided vessels with green and red leaves respectively of the same plant, and then filled up the vessels with water. When these were exposed to light, the heat rays being cut off by alum 
solution, the temperature in the vessel containing red leaves rose higher than that in the one containing green.

Stahl's (405) experiments and his criticism of the work previously done in this direction are all included in his paper 'Ueber bunte Laubblätter.' An account is first given of his experimental work on the method of finding the respective temperatures of red and green leaves. The apparatus used was a thermo-junction with spathulate electrodes which could be buried in the substance of the leaf. The source of light was a gas burner, and sometimes a Leslie cube was used by which dark heat only was obtained. Owing to the size of the electrodes, thick and fleshy leaves were most suitable for use. One of the species employed was an epiphytic orchid, Sarcanthus rostratus. On taking the temperature of both green and red leaves, it was found that the red had a temperature of $1.5^{\circ}$ above the green in one experiment, in another of $1 \cdot 82^{\circ}$. Similar results were obtained with the red and green parts of one and the same leaf of Sempervivum tectorum. Though more difficult to manipulate, some thin-leaved plants were used with similar results; for example, a difference of temperature of $1.35^{\circ}$ for Begonia heracleifolia var. nigricans, $0 \cdot 22$ for Pelargonium peltatum and $0 \cdot 14$ for Tulipa Greigi. A rise in temperature of red leaves over green was also obtained when the Leslie cube was used. In addition, other investigations were made using coco-butter instead of the thermopile. The melting-point of the butter was raised by mixture with beeswax, and was then spread in a liquid condition as thinly as possible on the under surface of the leaf. When the butter was set, the upper leafsurface was exposed either to the sun's rays or to the heat of the Leslie cube. The butter was found to melt more rapidly, and to a greater degree, on red leaves, or parts of leaves, than on green.

Stahl then proceeded to apply these results to cases which have been discussed by previous investigators. With regard to Kerner's experiments on Linum and Satureja in the Tyrol, which we have already noted, Stahl suggests that it is not from lack of protection of chlorophyll that the flax suffers, but from the low night temperature, against which it would be protected were it able to form anthocyanin with the resultant raising of temperature. Stahl proposes that the additional experiment should be conducted of covering up the Iinum by night. If then the plant is still unable to survive, Kerner's view is more feasible. In general, also, with Alpine vegetation, Stahl is of the opinion that the red leaves and stems take a higher temperature than the green, and thus in a wider and more general sense than Pick he says "in dem 
wärmeabsorbierenden Blattrot besitzt die Pflanze ein Mittel, die Stoffund Kraftwechselprocesse zu beschleunigen." Stahl suggests that at such low night temperature, Linum is unable to translocate starch and thus the plant becomes 'starch-sick,' and synthetic reactions cannot proceed; but he admits that the experiments require further attention. He has himself made observations upon cultures of Linum and Satureja at Pontresina and found, after a night with temperature about $0^{\circ} \mathrm{C}$., in the morning the Linum leaves were still full of starch, whereas Satureja leaves were starch-free, although exposed during the previous day to intense sunlight. Stahl's view on this function of anthocyanin was also applied to autumnal leaves.

Again, the reddening of stigmas of anemophilous flowers is considered by Stahl to be another illustration of the value of the heating properties. As examples of trees and plants possessing such a characteristic, he quotes species of Populus, Salix, Platanus, Ulmus, Ostrya, Carpinus, Corylus, Alnus, Acer, Fraxinus, Poterium sanguisorba and Rumex scutatus, and of these, the trees, he points out, flower early in the year. Hence the presence of anthocyanin is a special adaptation for raising the temperature and thereby furthering the growth of the pollen-tube.

Stahl next deals with his own suggestion as to a special significance of anthocyanin which it possesses by virtue of its temperature-raising properties. He maintains that anthocyanin is frequently found in leaves of water-plants inhabiting marshy places; also to a considerable extent in the leaves of shade-loving plants in damp tropical regions. The presence of anthocyanin in these leaves leads to a rise of temperature, and thereby accelerates transpiration which is rendered difficult by the conditions of such habitats. He quotes as examples the red under surfaces of leaves of Nymphaea, Villersia and the frond of Lemua; of marsh plants, Orchis maculata. O. latifolia, Ranunculus acris; of shady wood plants, Arum maculatum. Phyteuma spicatum, Hypochaeris maculata. These are, however, insignificant as compared with tropical plants of which he quotes many examples from Borneo, Java and Mexico, of the orders Begoniaceae, Orchidaceae, Acanthaceae, Gesneriaceae, Marantaceae, Araceae and Melastomaceae; Stahl even goes so far as to say that in the case of leaves which develop blotches of anthocyanin. the lower leaves near the moist ground are more strongly marked than the upper leaves which may not be marker at all (Polygonum Persicaria). Also in Java he has noted that shaded pitchers of Nepenthes lying on the ground amongst ferns and mosses were deep red, while those borne high up above the vegetation had only a slight reddening. 
One item of special interest he also notes, namely, that red blotches on leaves give off less water (tested by cobalt paper method) than green; this he found to be due to the fact that the red parts contained fewer stomata. Stahl, however, seems to think this compatible with his views, as too greatly increased transpiration might otherwise occur. Branches of the red-leaved Beech and Hazel he finds to transpire more strongly than branches of the ordinary species when both were placed in the shade, but in the sun and a dry atmosphere, the opposite was the case.

As regards the coloration of young leaves, Stahl considers that reddening in temperate regions assists metabolic processes at low temperatures. In the tropics, on the other hand, the most intense colouring, he says, frequently occurs in the densest shade forests, and is then an adaptation for promoting transpiration by heating up of the leaf; a view completely opposed to that held by Keeble (403).

Ewart's (406) work and criticisms are so much connected with both the screen hypothesis and that of Stahl, that it will be more convenient to consider the arguments in the order which he follows in his papers. He first concludes, from a number of observations and experiments, that strong insolation may bring about inhibition of photosynthesis, and hence too bright light may be injurious in this way rather than in the destruction of chlorophyll, and this is especially so in the case of shade plants. He is of the opinion, moreover, that anthocyanin does act as a protection in such cases, for he apparently trusts Pringsheim's observations, in preference to Reinke's, that concentrated blue or green sunlight will kill and bleach chlorophyll grains in five minutes, whereas concentrated red rays (the heat rays being eliminated) will only cause bleaching after twenty minutes. Anthocyanin absorbs 70-90\% of the green and $50 \%$ of the blue, that is just those rays which are most harmful to chloroplast activity, while rejecting those useful for photosynthesis. If, according to Stahl's view, its function were that of a heat absorber it would, instead of absorbing the green and yellow rays (of which the heating effect is comparatively slight), show a marked absorption of the dark heat rays, and this is not the case. But he admits that Stahl has obtained a rise in temperature of one or two degrees in red leaves by exposure to dark heat rays. This higher temperature, he considers, to be a disadvantage, and since the red leaves might thus be liable to transpire too much, excess of transpiration is prevented by development of fewer stomata. Stahl has, as we have seen, shown that red leaves, or areas, have fewer stomata than green, 
and that green leaves also give off more vapour in sunlight and dry air than red ones.

The development of anthocyanin in young leaves and many tropical shade-loving plants is not considered by Ewart to be an adaptation for promoting transpiration. Its purpose, on the other hand, is to guard against assimilatory inhibition to which shade plants may be especially liable if accidentally exposed to intense light. He points out that in trees and shrubs with young red foliage, individuals growing in shady positions are less red than those in the sun, whereas, according to Stahl, it should be the reverse. Further, though it is true that certain plants growing in the shade form a considerable amount of pigment, yet of these, again, individuals growing in the more exposed positions have more colour than those in the deepest shade. Ewart infers that such plants are extremely sensitive to, and are injured by, light of marked intensity. He further points out that in many plants which have anthocyanin on the under surfaces, the ventral surface of the young leaves is exposed to light; in one variety of $M u s a$, for instance, anthocyanin develops on the under surface when the young leaves are vertical and rolled up, but it disappears as the leaf unrolls and expands horizontally. In Uncaria sclerophylla the young leaves are so folded that the ventral surface is most exposed and this develops anthocyanin which disappears as the leaf expands. Several other instances are also quoted, one of the most interesting being Mimosa pudica, in which red coloration is developed on the parts of the under surfaces of the leaflets which are exposed when folded. Ewart, however, does admit that, in the case of certain Begonias which have horizontally expanded leaves with red under surfaces, Stahl's view of the function of anthocyanin may be the correct,one, and there are other cases where it is difficult, he says, to find any use at all for the pigment.

That the distribution of anthocyanin does not conform to Stahl's hypothesis is emphasised in the following passages from Ewart's paper. "If the primary function of the red dye in the tropics were to increase the amount of transpiration, then it would be only natural to expect that it would be formed in greatest abundance where the temperature is lower and the air more nearly saturated with water-vapour. The very opposite is however the case. Thus at the foot and sides of the volcanic mountain of Gedeh, and in the valleys around, very many plants have a reddish colour, especially in the young leaves. As one ascends this becomes less marked, until at Tjibodas and in the forests above it (4500 ft. to $6500 \mathrm{ft}$.), the number of plants showing a red colouration, 
and the intensity of the latter when present, reach a minimum. The vegetation at this elevation is almost entirely green, a few plants only, especially if growing in open clefts or glades in the forest, having more or less reddish young leaves. Yet it is just here where a power of stimulating transpiration is apparently most needed; for at this elevation the air is, during the greater part of the time, at or near saturation-point. On the other hand if the red pigment acts as a protection against sunlight, it is easy to understand why here, where the sun rarely shines for more than a few hours daily and then generally through a haze of clouds, the protective red pigment should almost entirely disappear; for it is just the more refrangible photochemical rays which the air saturated with water-vapour absorbs in greatest amount."

And again, "In Java at the commencement of the wet S.W. monsoon and in Ceylon at the rainy commencement of both monsoons, the vegetation acquires a more marked reddish tinge than the dry periods between the monsoons. This is, however, simply due to the fact that the young foliage, which in most tropical plants is more or less tinged with red, is very much more abundantly formed at this period than during the dry season. Even during the wet season in West Java, there is almost always bright sunlight until mid-day, lasting often till 3 or 4 p.m., and occasionally all day; so that the young foliage which the rain has caused to be produced in such abundance is exposed for six hours on the average to very bright illumination, the sunlight from 9-12 being the brightest of the day. Hence the protective red colouration is perhaps quite as necessary during the wet season as during the dry."

The question as to the significance of the non-development of pigment in the stomata in leaves with red epidermal cells is also considered by Ewart. Stahl's view is that the stomata by this means transpire less, and so are able to keep open longer for purposes of transpiration and photosynthesis. Ewart, on the contrary, regards the absence of anthocyanin as being due to the fact that the stomata are organs which react to light, and it is important that they should be exposed to the same intensity of light as that falling on the rest of the leaf even at the risk of injury.

Again, Stahl, as we mentioned previously, looks upon the development of anthocyanin in stigmas of anemophilous plants as an adaptation for increasing the temperature and aiding the growth of the pollen-grain. Ewart. however, notes that it has been shown that the pollen-tube 
growth is retarded by light and hence is protected by the pigment. Similarly, Stahl considers the reddening of young shoots in temperate regions in the spring to be protective against cold, whereas Ewart considers the function to be protective for the chloroplast, since the latter is more sensitive to light when the temperature is low. Reddening of submerged plants in sugar-cultures Ewart explains as being due to an unhealthy condition of the plant in which state it requires more protection against light.

Ewart concludes thus: "There can be little doubt that, both in the tropics and in temperate climes, the main and primary function of the red dye, when present in exposed parts, is to act as a protection against light of too great intensity; though in all cases its presence at the same time confers upon the plant a slightly increased power of absorbing heat. For calling attention to this latter possibility Stahl deserves full credit from both the physiologist and the biologist: in a few cases, such as in the horizontal leaves of shade plants having the red colouration present on the under surfaces only, the relatively slight heat-absorbing power of the dye may, by secondary adaptation, have become its most important function."

The latest work on the physiological significance of anthocyanin, and undoubtedly the most accurate, is that published by Smith (420) in 1909. This author determined the temperature of leaves in tropical insolation in Ceylon, using a thermo-electric apparatus. The latter was of the improved pattern which had been employed by Blackman \& Matthaei, and had the advantage that it could be used even in the lamina of thin leaves and also for the internal temperature of leaves in natural illumination.

In the first of a series of experiments connected with this point young leaves of Amherstia nobilis and Saraca indica were compared. Both trees have young foliage of the pendent type we have previously described. The leaves of Amherstia are of a deep brownish-red colour due to the presence of anthocyanin, and after this pigment is removed by a solvent, there is seen to be but a slight development of chlorophyll. The leaves of Saraca are greenish-white and have, in the same way, a small development of chlorophyll. Both leaves are also thin and flaccid and hence form good objects for comparison. On exposing the leaves and testing the temperature, it was found that the coloured leaf of Amherstia reached a temperature of $2^{\circ} \mathrm{C}$. higher than the leaf of Saraca. Another experiment was conducted with a young red leaf of Mesua ferrea as compared with a young leaf of Saraca indica. The 
red Mesua leaf registered a temperature of $2 \cdot 8^{\circ} \mathrm{C}$. higher than the Saraca leaf.

It was next found by comparing green and white leaves, that a green leaf also reaches a higher temperature than a white one. Hence it seems clear that any pigment, either chlorophyll or anthocyanin, raises the temperature of the leaf, and that the simultaneous presence of anthocyanin and chlorophyll in the leaf will raise the temperature considerably above that of a leaf without either pigment. The latter point was demonstrated in a comparison between a green and white leaf of Caladium sp. and a red and green leaf of the same genus, the electrodes being placed in the green and white leaf where there was little chlorophyll. The red and green leaf then showed a most striking rise of $3.9^{\circ} \mathrm{C}$. above the green and white leaf temperature.

Attention was finally given to the differences between the temperature of young flaccid and coloured leaves as compared with older green leaves from the same tree. With Saraca indica, a mature green leaf showed a difference of $4^{\circ} \mathrm{C}$. above a young colourless leaf. When, however, a young leaf of Theobroma Cacao which is red, was compared with a mature green leaf, the young leaf showed a difference of $3 \cdot 5^{\circ} \mathrm{C}$. above the mature leaf, and this one would suppose to be due to the presence of the anthocyanin. On the other hand, comparisons of young red leaves with mature green leaves of Amherstia nobitis, resulted in a decidedly higher temperature in the mature leaf.

"Thus," Smith concludes, "it seems, that we have a series beginning with Saraca indica, in which anthocyan is almost absent, and in which the mature leaf is always higher in temperature than the young leaf. Then comes Amherstia nobitis with a brownish-red colour, in which the mature leaf is, as a rule, only slightly higher in temperature than the young leaf. Lastly, we have Theobroma Cacao with the young leaf an intense pinkish-red and the mature leaf lower in temperature than the young leaf.

"No doubt the relative temperatures of mature and young leaves are to be correlated with the amount of anthocyan in the young leaf. The young leaves, without this pigment, would be always cooler than the mature leaf, as is the case in Saraca indica. The presence of more or less anthocyan produces a temperature in the young leaf, which almost reaches (Amherstia) or exceeds (Theobroma) the temperature of the mature leaf. Thus the general tendency of these results is to confirm and extend Stahl's conclusion that the presence of anthocyan tends to raise the internal temperature of the leaf. What biological advantage. 
if any, is gained by the plant in this way is quite another question, but it is well to have this physical effect definitely established."

When we review the work on the subject of the uses of anthocyanin, we find it singularly unconvincing in any direction. In favour of the light-screen hypothesis, there is undoubtedly a greater development of anthocyanin in sun-exposed leaves than in leaves of the same plant in the shade; and, conversely, in red-leaved plants like the Blood Hazel and Copper Beech, a lack of colour in leaves which happen to be shaded. But, on the other hand, Kerner's experiments on Satureja and Linum are not very convincing, since so many factors might account for the unhealthiness of the Flax plants. And again, even if Pringsheim's red screen were protective to chlorophyll, it consisted of iodine in carbon disulphide which has a different absorption spectrum from anthocyanin. Moreover, Engelmann's analyses seem to prove that the anthocyanin only absorbs those rays which pass through chlorophyll, and an effective screen would be one with a similar absorption spectrum to chlorophyll itself. As regards Stahl's hypothesis, it is certainly supported by a definite piece of evidence, viz. that the temperature of red leaves is higher than that of green. Also, there are without doubt a number of shade plants which do possess anthocyanin to a considerable extent. Yet it is difficult to find a hypothesis which would fit all cases of anthocyanin distribution without reduction to absurdity. The pigment is produced, of necessity, in tissues where the conditions are such that the chemical reactions leading to anthocyanin formation are bound to take place. For the time being we may safely say that it has not been satisfactorily determined in any one case whether its development is either an advantage or a disadvantage to the plant. 



\section{PART II}

\section{ANTHOCYANINS AND GENETICS}





\section{PART II \\ ANTHOCYANINS AND GENETICS}

\section{Classes of Variation.}

As pointed out in Chapter II, practically all flowering plants produce anthocyanin; moreover, when this pigment is developed in the flower, we are able to see that each specific type forms anthocyanin of a certain characteristic colour. In nature to some extent, but under cultivation very commonly, colour-varieties arise from the type. The underlying cause of these variations is still a matter for conjecture, though such suggestions as can be offered will be given later. Colour-varieties have afforded plentiful material for Mendelian research, and it is to the cases of inheritance involving anthocyanin as a character that the following pages are devoted.

Among the colour-varieties of different genera and species, there is a certain correspondence in the series of varieties produced, that is, we may find one series in a number of plants not necessarily related, and another series in a number of other plants, and so forth. The kinds of variation which may occur we are able to classify as follows:

1. The loss of power to form anthocyanin pigments which results in albinism. The albino may be white or yellow; if yellow, the pigment may be either plastid or soluble.

2. The loss of power to produce blueness. The type has blue, or purple, anthocyanin: the variety has red anthocyanm.

3. The loss of power to produce redness. The type has red anthocyanin: the variety blue, or purple, anthocyanin.

4. The loss of power to augment the formation of anthocyanin and hence to intensify its colour. The type is fully coloured: the variety tinged only.

5. The loss of power to inhibit the formation of anthocyanin and hence to diminish its intensity. The type may be pale in colour and the variety deep: or the type may be tinged only and the variety fully coloured.

The following rariations are independent of variation in the

w. P. 
anthocyanin pigments, and may (with a certain exception in 9) take place simultaneously with variation in the anthocyanins.

6. The loss of power to produce yellow pigment in the plastids. The type has yellow plastids: the variety colourless plastids.

7. The loss of power to inhibit the formation of pigment in the plastids. The type has colourless plastids: the variety yellow plastids.

8. The loss of power to inhibit the formation of yellow soluble pigments. There is no yellow in the type: the variety is yellow.

9. The loss of power to produce yellow soluble pigment. This variation is of rare occurrence. The type may contain both yellow soluble pigment and anthocyanin, and the variety may be without one or both: or the type may be without yellow colour, but may produce a soluble yellow variety, which, in turn, may lose its power of forming yellow pigment and is then also unable apparently to form anthocyanin.

It should be understood that the above is only a classification on the broadest basis; when we come to the details of variation it is almost necessary to consider each case separately. It is difficult, for various reasons, to make any kind of comprehensive classification, apart from the fact that no two cases are exactly alike; in many species, for instance, the inheritance of colour has not been systematically worked out, and relationships between variations cannot be correctly judged; new 'breaks,' moreover, are continually occurring in horticultural plants; there are also the complexities introduced by speciescrossing, and in these circumstances it is often difficult to identify the type from which the variety has arisen. In the following paragraphs an attempt is made to indicate some of the main series or ranges of variation. It has only been possible to include a selection from the great mass of material provided by observations on plants under cultivation, but it is hoped that the lines suggested may provide a basis for further classification, as our knowledge of the inter-relationships of varieties increases.

A point to be emphasised is that one cannot judge correctly of the inter-relationships of varieties from appearances. For true knowledge it is not only necessary, as we have said, to find out the behaviour of the pigments in heredity, but we must examine their properties, and above all we should know their chemical composition. The colour series in Dahlia and Tropacolum, for instance, are similar to the eye, but are really fundamentally different. Hence, in the following series, from lack of knowledge, instances may be grouped together which are not in reality of the same nature. 
We may now consider the ranges of variation in greater detail. The simplest series is that which involves variation to albinism only, and, in the case of some genera grown as horticultural plants, this is the only important colour-variation known: the type produces anthocyanin, and the albino is without that pigment. As examples we may quote: Datura Stramonium (Thorn-apple), Dictamnus Fraxinella (Rue), Geranium sanguineum, Epilobium angustifolium, Lavatera trimestris, Linaria Cymbalaria, Malope trifida, Malva moschata and Polemonium caeruleum (Jacob's Ladder); in some of these species there may also be different intensities of type colour due to heterozygous forms (see p. 183).

If it should happen that the type produces both anthocyanin and plastid pigment, then loss of anthocyanin will not give a white variety but a yellow. Examples of such a case are the yellow varieties of Abutilon spp., Fritillaria imperialis and the variety lutea of Atropa Belladonna; in all these species the type is yellow suffused with anthocyanin.

Variation to redness, in addition to variation to albinism, is characteristic of another series. Variation to redness is a more complex phenomenon than albinism, and the series requires analysis. In the first place the type may be one of two kinds; it may be either some shade of magenta, purple, or purplish-red, or it may be blue. As examples of the first group we may suggest Anemone Pulsatilla which has a variety rubra; Clarkia elegans (Bateson, 524) which has a red (pink) variety, the type being magenta. Linaria alpina (Saunders, 586) and Pisum sativum (Garden Pea) (Lock, 518) have definite red varieties; Salvia Horminum (Saunders, 487) is violet in type with a red variety, and of Viola odorata there is a variety redder than the type. With the exception of the last, all the above mentioned also give true albinos. Examples of the second group (type blue) are Centaurea Cyanus (Cornflower) of which purplish-red and pink varieties are known; Lobelia Erinus and Vince minor (Periwinkle) produce a purplish-red variety and Myosotis sylvatica (Forget-me-not) a pink; Delphinium Ajacis (Larkspur) and Campanula medium have both mauve and pink varieties; in Aquilegia vulgaris (Columbine) the type is violet-blue, and there are several purplish-red and pink varieties. This second group also varies to white, though it is doubtful in some cases whether there is complete albinism. In other species there is more than one grade of variation to redness. In the garden Stock (Matthiola) (Saunders, 487) it is believed that the type was some shade of purple; there is a crimson (blue-red) variety and also a true red, 'Terra-cotta.' Of Dianthus barbatus (Sweet 
William) the type was doubtless of a magenta shade and there is variation to crimson and also to a true red, 'Scarlet.' Similarly Primula sinensis (Chinese Primrose) had in all probability a magenta type (Hill, 577) and varies to crimson and true red, 'Orange King.' In Antirrhinum majus (Wheldale, 535, 548) the type is magenta and the red variety, 'Rose Doré'; the case of Antirrhinum (Snapdragon) is further complicated by the existence of a yellow variety (see below). Variation to redness also occurs in Cheiranthus (Wall-flower), Hyacinthus and others, but these are dealt with later in connection with more complex series.

Another variation-series is that which includes a yellow variety. Colour in the yellow variety may be due either to plastid or soluble pigment, and the two series have very different characteristics. It should be emphasised that the soluble-yellow series is essentially different from the plastid-yellow series. In the latter, as we have already pointed out, the yellow is really the albino as regards anthocyanin pigment, whereas a soluble yellow variety is formed, as a rule, by the loss of a factor from an albino. In the case of the plastidyellow series, further complexities, in addition to the simple loss of anthocyanin, are introduced by variation in the plastid colours, or by total loss of these pigments.

To deal first with the soluble-yellow series: Antirrhinum majus forms a typical example. The type is magenta; loss of anthocyanin gives an ivory-white variety. From the ivory a soluble-yellow variety is derived; mixture of yellow with the magenta anthocyanin of the type, i.e. simultaneous presence of both pigments, produces another variety, crimson. A red variety, 'Rose Doré,' has arisen from the magenta, and a mixture again of rose doré with yellow results in another variety, bronze. Finally there is a white variety which contains neither anthocyanin nor yellow pigment. Hence the series can be expressed: magenta, crimson, rose doré, bronze, ivory ${ }^{1}$, yellow and white. Though we have no exact knowledge of the colour relationships in Althaea rosea (Hollyhock), Dahlia variabitis and Dianthus Caryophyllus (Carnation), yet these species in the main exhibit a similar series to Antirrhinum, for they produce magenta, crimson, yellow and ivory-white varieties; D. Caryophyllus, however, is characterised by many other shades. It

1 In the soluble-yellow series ivory or ivory-white is used for the albino, which is without anthocyanin, in contrast to the true white which is without both anthocyanin and soluble yellow pigment. At present the only two species in which both these varieties are known are Antirrhinum majus and Phlox Drummondii. 
cannot at present be stated whether Dahlia and Althaea have a rerl corresponding to rose doré. In many respects Phlox Drummondii shows the same series as Antirrhinum, though violet is included in addition. It is interesting to compare the series given by Primula sinensis (Gregory, 557) and Dianthus barbatus with Antirrhinum. In the two former there is a crimson similar in appearance to the crimson of Antirrhinum, but it is not due to mixture with yellow, since a soluble yellow variety is unknown in Primula and $D$. barbatus. But the 'Scarlet' of $D$. barbatus and the 'Orange King' of $P$. sinensis appear to be truly comparable to the rose doré of Antirrhinum.

The Marvel of Peru, Mirabilis Jalapa (Marryat, 533), produces a variety with soluble yellow pigment, and although this species must obviously be included in the present series, yet it is, in a sense, fundamentally different from Antirrhinum. From our knowledge of the colour-inheritance of Mirabilis, one is led to believe that the original type was crimson, and this apparently contains a mixture of magenta anthocyanin and soluble yellow pigment. Loss of anthocyanin gives a yellow variety, and further loss of yellow pigment, a white variety. Anthocyanin may also be present on a pale yellow ground and then we have a magenta variety. Thus the series is an inversion, so to speak, of Antirrhinum and runs: crimson, magenta, yellow and white. It is further complicated by the existence of heterozygous forms, but these will be considered later (see p. 170).

Cheiranthus Cheiri (Wall-flower), on the other hand, is typical of the plastid-yellow series. The original wild type has deep yellow flowers tinged with brown, from which has arisen in cultivation the ordinary brown variety (see p. 153). The brown colour is due to the simultaneous presence of purple anthocyanin and deep yellow plastids. Loss of anthocyanin from the brown gives a yellow variety, which, strictly speaking, is the albino as regards anthocyanin. Some loss from, or change in, the deep yellow plastids results in a lemon yellow variety. When the purple anthocyanin is present with pale yellow plastids, the latter are masked, and we get the purple variety now commonly grown. During recent years further varieties have appeared, some of which are practically cream in colour. The purple anthocyanin, too, has produced a red variation comparable to the red group previously mentioned. This red, on a background of lemon or pale yellow plastids, gives us the varieties 'Eastern Queen' and 'Ruby': on a background of deep yellow plastids, the new 'Scarlet.' Thus the Cheiranthus series runs: crimson (brown), purple, scarlet, ruby, yellow, lemon 
and cream. In main outline a similar series, brown or crimson, purple or magenta, deep yellow and pale yellow is shown by Zinnia elegans, and also by the new varieties of the Sunflower, Helianthus annuus (Cockerell, 602, 603, 611). Variation in the Garden Nasturtium (Tropaeolum majus) is on the same lines as in Cheiranthus, though it differs in one respect, namely that in Cheiranthus the type anthocyanin is purple and gives rise to a red variety, while in Tropaeolum the type anthocyanin is scarlet, or carmine red, and gives rise to a purple variety. The colour representing the original type of Tropaeolum is the orangered due to carmine anthocyanin on yellow plastids. A deep yellow variety is the albino after the loss of anthocyanin and, as in the case of Cheiranthus, it produces several pale yellow varieties approaching to cream as a result of the loss of some factor from the plastids. On this pale yellow ground the red anthocyanin appears as carmine or ruby. The red anthocyanin also varies to a blue-red or purple, which, on the deep yellow plastids, appears as maroon, and on the pale yellows as purple. There is additional variation caused by anthocyanin blotches at the base of the petals; these may be carmine or purple, and may be retained when the main part of the flower is free from anthocyanin; they may, however, be entirely lost, so that the flower is wholly yellow. Variation in Salpiglossis sinuata is also in all probability on similar lines to Cheiranthus.

We may next consider an additional range in the plastid-yellow series due to complete loss of colour from the plastid. In this way a white arises and it may exist as such, or anthocyanin may be present on the white ground. Typical of this series is Chrysanthemum; the type was in this case yellow, probably slightly tinged with anthocyanin. Loss of an inhibiting factor (see p. 152) would give rise to a crimson variety, i.e. purple anthocyanin on yellow plastids. Loss of yellow plastids, without loss of anthocyanin, gives purple, purplish-red or magenta; loss of anthocyanin gives either yellow or white. The series is then: crimson, magenta, yellow and white. Helianthemum vulgare (Rockrose), Viola tricolor (Pansy) and the garden Tulips probably come into the Cheiranthus-Chrysanthemum class, but our knowledge of these species is not very systematic. Viola tricolor possibly contains species-crosses. We can readily distinguish two groups of the garden Pansy: one includes white, reddish-purple, purple and purple-blue; the other yellow, brown and crimson. But we have no evidence as to how the groups are related.

We can thus differentiate two groups or series, soluble-yellow and plastid-yellow: in the former the type is generally magenta and gives 
the series crimson, red, orange, yellow and ivory-white: in the latter the type is, as a rule, crimson and gives the series magenta, orange, red, yellow, pale yellow and sometimes cream or white.

There is another series we may best consider at this point, and that is one in which a particular variety of plastid pigmentation occurs known as 'cream.' The plastids contain an orange-yellow pigment, but only in sufficient quantity to give the petals a cream appearance, and the variety is further characterised by being recessive to white containing colourless plastids. Such a 'cream' variety is found in the Sweet Pea, Lathyrus odoratus (Bateson, 524) and Matthiola (Saunders, 475); in Matthiola the series runs: purple, crimson, terra-cotta, white and cream. The cream may underlie any of the anthocyanin pigments, but it is too pale to affect the resultant colour, and such individuals are indistinguishable from those having anthocyanin on a white ground, except at the 'eye' of the corolla where the cream or white ground, as the case may be, is shown. In Lathyrus there is a very great range of colour, and the exact inter-relationships of many varieties are still unknown; the series includes blue, purple, mauve, crimson, pink, salmon, white and cream. In some varieties (Thoday, 547) the underlying cream modifies the effect of the anthocyanin. Cream plastids are also found in Hyacinthus ovientalis in which they produce a fairly deep yellow; in this species the range of colour is also very great, since it includes several shades of blue, purple, magenta, pink, as well as white and cream, but, as there have been no systematic breeding experiments, their relationships to each other cannot be stated. It is not known whether the cream plasticls in varieties of Rosa are of the same nature as those of Lathyrus and Matthiola.

Finally there is the series which includes a blue variety. Variation to redness when the type is blue or purple is, as we have seen, a common phenomenon, but variation to blueness is much less frequent. In Lathyrus odoratus varieties have appeared which are bluer than the type, 'Purple Invincible,' and the same is true for Phlox Drummondii. In Primula sinensis, true blue-flowered varieties, 'Cambridge' and 'Oxford' blues, occur, the type in all probability having had pale magenta flowers (Hill, 577); so also from the original Cineraria with flowers of a pale magenta, blue-flowered varieties have arisen, though probably under the influence of species-crossing. A striking instance of a blue variation from a scarlet is the variety, coerulea, of Anagallis ariensis (Scarlet Pimpernel) ${ }^{1}$.

3 Kajanus (579) states that blue is recessive to red in Trifolium (Clover). 
We may next consider those variations which afiect the intensity of colour. If a colour series such as we have described for Lathyrus or Antirrtinum be examined, a number of definite varieties will be found of a paler or deeper shade of the same colour. Without Mendelian analyses it is not as a rule possible to arrive at the underlying significance of the shade differences. Thus, a paler shade than the type may signify either loss of a factor for full-colour, or the existence of a heterozygous form between type and albino. Hence, in dealing with this kind of variation, we can only quote as satisfactory instances those cases of which we have knowledge from experimental breeding. The main expressions of intensity-variation are tinged and deep varieties. The tinged variety forms a case in which a deepening, or full-colour factor, affecting anthocyanin formation has disappeared from the type, leaving the flower flushed or tinged with colour only. Examples are the 'tinged ivory' variety of Antirrhinum (Wheldale, 535) and the 'tinged white' and 'picotee' of Lathyrus (Bateson \& Punnett, 500). The variation of tingeing is common to both red and blue classes.

The deep variety can be defined as one having a deeper shade of anthocyanin, i.e. more pigment, than the type from which it is derived, as the result of the loss of an inhibiting factor. Since it is often difficult, and sometimes impossible, to ascertain the original type in many horticultural plants, this definition cannot be rigidly applied: Like tingeing, the variation of deepening is common to both red and blue classes. Examples of such varieties are the deep shades of magenta, crimson, rose doré and bronze of Antirrhinum (Wheldale, 535, 548), purplewinged 'Purple Invincible' and 'Miss Hunt' varieties of Lathyrus odoratus (Bateson \& Punnett, 500); deep shades of crimson and magenta in Primula sinensis (Gregory, 557) and deep purple and crimson in Mattiiola (Saunders, 487); also deep varieties of Cyclamen. The following species, among many others, have varieties obviously deeper than the type: Althaea rosea, Dahtia variabilis, Dianthus Caryophyllus, D. barbatus, Hyacinthus orientalis and Phlox Drummondii.

In the instances quoted above, the type, from which the deeper variety is derived, is itself fully pigmented. There are, however, other cases in which the type is either unpigmented, or only slightly pigmented, and, on the loss of an inhibiting factor, a coloured variety is produced. As examples may be quoted Anemone japonica in which the type has a white petaloid calyx tinged with anthocyanin on the under surface, whereas the variety is purple-flowered; the wild Bellis perennis (Daisy) has white ray florets tinged with anthocyanin and the garden variety 
is red-flowered. Cheiranthus Cheiri, also, in the wild state is only tinged with brown (anthocyanin), and from it in cultivation have appeared varieties fully coloured with anthocyanin of deep shades of brown and purple. In Crataegus Oxyacantha (Hawthorn) the white-flowered type has produced a red-flowered variety. In Cyclamen persicum the type has white flowers with a basal magenta spot on the petals and has given rise to varieties with fully-coloured magenta and crimson flowers. In Helianthemum vulgare, Primula acaulis (Primrose) and P. veris (Cowslip), the types are yellow and the varieties both crimson and magenta. Further examples are Freesia and Achillea Millefolium (de Vries, 498) with coloured flowers. De Vries (498) also notes this phenomenon. He says: "a pink-flowered variety of the "Silverchain" or 'Bastard-Acacia' (Robinia Pseud-Acacia) is not rarely cultivated. The 'Crown' variety of rice, oats and barley are also to be considered as positive color-variations, the black being due in the latter cases to a very great amount of the red pigment." And again: "The best known instance is that of the ever-flowering begonia, Begonia semperforens. which has green leaves and white flowers, but which has produced garden varieties with a brown foliage and pink flowers." Cockerell (602, 603,611 ) has also drawn attention to a red-flowered variety of Helianthus of which the type is yellow. Again, the red colour may be developed in the carpels as in the varieties of Primula with red stigma (Gregory, 557) and the purple-podded forms of Pisum and Phaseolus. The variety appears in other fruits too (the 'Blood Orange' and the red Banana); also in the Gooseberry, Ribes Grossularia (de Vries, 498).

Another phenomenon which sometimes appears in variation is that which may be termed partial albinism; the type has coloured flowers but the variety has white flowers, though all the vegetative organs may still form anthocyanin. This is the case in the blue Vinca minor with its white-flowered variety of which the corolla is slightly tinged with purple. Of Geranium Robertianum (Herb-Robert), also, there is a white-flowered variety with red stems and leaves. A similar variation is sometimes found in the native flora, i.e. Polygala vulgaris, Jasione montana, and others, but it is not really possible, in the absence of Mendelian evidence, to distinguish these varieties from the tinged varieties already mentioned. Partial albinos, moreover, are similar in appearance to types in which anthocyanin is inhibited; but an important distinction lies in the fact that partial albinos cannot give rise to coloured varieties though inhibited types may.

A case difficult to place is that of the dominant or inhibited white 
of Primula sinensis (Gregory, 557). This variety has apparently the power to form pigment in the flower but colour is prevented from appearing by an inhibiting substance. Hence the case most closely resembles the inhibited types of Anemone, Crataegus, Primula veris, etc., mentioned above, and must, for the present, be included in this class.

Up to this point we have been solely concerned with variation in flower colour. But it should be borne in mind that the colour-varieties already described may be characteristic of the fruit and seed and also of the vegetative organs; in fact, the whole plant may either be a total albino, or pigment may be lost from various organs or parts independently of each other. These phenomena will be dealt with later in greater detail (see p. 180). A few instances of colour-variation in different organs may however be mentioned. Of albinism in fruits we have the white-fruited varieties of Atropa Belladonna, Daphne Mezereum, Fragaria vesca, Ribes rubrum, Rubus Idaeus, Solanum nigrum, $V$ itis vinifera and many others. De Vries (565) also notes a red-berried variety of Empetrum nigrum. In seeds there are white-seeded varieties of Pisum and Phaseolus. Of coloured roots also, white varieties may occur as in Beta vulgaris. Variation to redness may also affect the vegetative organs as for instance in the red-flowered varieties, rose doré of Antirrhinum and 'Orange King' of Primula sinensis, in which the leaves, stems and petioles develop red anthocyanin instead of purple. In the tubers, moreover, of the Potato, Solanum tuberosum (Salaman, 544 ), one may have both red and purple varieties (pigment due to anthocyanin) as well as dominant and recessive white tubers.

Loss of an inhibiting factor which in the case of the flower gives a coloured from a white variety, is quite common in the vegetative organs. This coloration of vegetative organs may be connected with deepening of flower-colour, for example, deep varieties of Antirrhinum and Primula sinensis which have pigment in leaves and petioles. Or it may occur more obviously as a red-leaved variety, as in the following: Atriplex hortensis, Berberis vulgaris, Beta vulgaris, Brassica oleracea, Canna indica, Corylus Avellana, Fagus sylvatica, Lactuca sativa, Perilla. nankinensis, Plantago major; de Vries (498) also notes Tetragonia expansa and the brown-leaved Trifolium ${ }^{1}$. Lastly a very interesting

1 With regard to red-leaved varieties, de Vries $(498,565)$ notes that they may produce green-leaved branches (red Corylus, Fagus, Betula). Also red bananas have produced a green variety with yellow fruits. Whether this phenomenon is bud variation, or whether it may be in some instances due to the production of the true albino and not the inhibited type, is uncertain. An analogous example in flower-coloration would be Cheiranthus 
case of the occurrence of a red variety in roots is recorded by Wittmack (495), that is the variety of the Carrot, Daucus Carota Boissieri Schweinfurth, which has anthocyanin in the root. in addition to the orange plastid pigment (carotin).

As to variation in nature, that of albinism is most frequent. It is found in the wild state among the British flora in Armeria vulgaris, Calluna vulgaris, Campanula rotundifolia, Carduus nutans, C. palustris, Digitalis purpurea, Erica cinerea, Lamium purpureum, Lychnis Floscuculi, Ononis arvensis, Pedicularis sylvatica. Symphytum officinale and Scilla nutans. Bentham \& Hooker ${ }^{1}$ also mention varieties of Ajuga reptans, Campanula latifolia, Centranthus ruber, Delphinium Ajacis, Iris foetidissima and Malva moschata without anthocyanin in the flowers, but it cannot be deduced from the text in each of the above cases whether there is complete absence of the pigment from the plant, or loss from the flower only. As regards variation to redness, among native species Polygala vulgaris has a red-flowered variety. Bentham \& Hooker ${ }^{2}$ record in addition red-flowered varieties of Delphinium Ajacis, Veronica spicata, V.officinalis, V. Beccabunga and V.Chamaedrys. Of species in which the flowers are normally white though they may produce red varieties, or red pigmentation under certain conditions, Gillot (457) gives a considerable list. Guinier (456) also notes a variety of strawberry (Fragaria) with purple flowers, and Chabert (461) records red flowers of certain species of Gatium which are normally whiteflowered. A variation, extremely rare in nature, if not altogether unknown, is that of white from a type with plastid yellow pigment, though as a species differential character it is quite common, for instance in the Ranunculaceae and Compositae.

\section{Details of Cases of Mendelian Inheritance in Colour-VARIETIES.}

Many of the varieties mentioned in the last section have provided material for cross-breeding work on Mendelian lines. Since most of the species investigated differ more or less in their colour series and behaviour, a separate account will be given of the more important cases in turn. The genera and species which have been employed in these investigations are the following:

Cheiri; the type is yellow tinged with anthocyanin: this varies to deep brown and this again gives a yellow (the albino) free from anthocyanin.

1 Handbook of the British Flora, London, 1896.

2 Loc. cit. 
Agrostemma Githago (Corn Cockle), de Vries (474, 498).

Amaranthus caudatus, de Vries (498).

Anagallis arvensis (Scarlet Pimpernel), Heribert-Nilsson (576), Weiss (566).

Antirrhinum majus (Snapdragon), Bateson (480), Baur $(517,536)$, Wheldale (514,

$535,548)$, de Vries (565).

Arum maculatum, Colgan (552).

Aster Tripolium, de Vries (474, 498).

Atropa Belladonna (Deadly Nightshade), Saunders (475).

Beta (Beet-root), Kajanus (559, 580, 598).

Brassica (Cabbage), Hallqvist (631), Kajanus (580, 598).

Canavalia ensiformis, Lock (504).

Canna indica, Honing (608, 633).

Cattleya, Hurst (502, 531, 540, 596).

Clarkia elegans, Bateson \& Punnett (524), de Vries (498).

Corchorus capsularis (Jute), Finlow \& Burkill (572).

Coreopsis tinctoria, de Vries (474).

Cypripedium (Paphiopedilum), Hurst (502, 531, 540, 596).

Datura Stramonium (Thorn-apple), Saunders (475, 487), de Vries (474).

Dendrobium, Hurst (596).

Digitalis purpurea (Foxglove), Jones (578), Keeble, Pellew \& Jones (542), Saunders (563).

Geum (Avens), de Vries (498).

Gossypium (Cotton), Balls (515, 523), Fletcher (508), Leake (561).

Helianthus (Sunflower), Cockerell (602, 603, 611), Shull (520).

Hepatica (Anemone), Hildebrand (473).

Hieracium (Hawkweed), Ostenfeld (505, 543).

Hordeum (Barley), Biffen (501).

Hyoscyamus (Henbane), Correns (490), de Vries (474).

Lathyrus odoratus (Sweet Pea), Bateson (499), Bateson \& Punnett (487, 496,

$500,516)$, Thoday (547).

Linaria alpina, Saunders (586).

Linum usitatissimum (Flax), Tammes $(564,610)$.

Lychnis dioica, Correns (485), Saunders (475), Shull (520, 546, 588), de Vries (474).

Matthiola (Stock), Correns (472), Saunders (475, 487, 496, 500, 506, 562),

Tschermak $(494,590)$.

Mirabilis Jalapa (Marvel of Peru), Baur (517), Correns (482, 497, 537), Marryat (533).

Nicotiana (Tobacco), Lock (532), Haig Thomas (594).

Oenothera (Evening Primrose), Davis (592, 604), Gates (539, 555, 573, 606),

Heribert-Nilsson (575, 632), Shull (609).

Oxalis, Nohara (635).

Papaver somniferum (Opium Poppy), Hurst (502), de Vries $(474,498)$.

P. Rhoeas (Field Poppy), Shull (588).

Phaseolus multiflorus (Scarlet-runner), P. vulgaris (French Bean), Emerson (483,

492 , 528, 529), Lock (504), Shull $(513,521)$, Tschermak $(479,494,590)$.

Phyteuma (Rampion), Correns (486). 
Pisum sativum (Common Pea), Bateson (487), Lock (512, 518), Tschermak (479, 494, 590).

Polemonium (Jacob's Ladder), Correns (486), de Vries (498).

Primula sinensis (Chinese Primrose), Gregory (557, 607), Keeble (582), Keeble \& Pellew (541).

Reseda (Mignonette), Compton (569).

Salvia Horminum, Saunders (487).

Senecio vulgaris (Groundsel), Trow (589).

Silene Armeria (Lobel's Catchfly), de Vries (474, 498).

Solanum nigrum, de Vries (474).

S. tuberosum (Potato), East (538), Salaman (544, 585).

Trifolium (Clover), Kajanus (579).

Tropaeolum (Nasturtium), Weiss (534).

Veronica longifolia, de Vries $(474,498)$.

Viola cornuta, de Vries $(474,498)$.

Zea Mays (Maize), Burtt-Davy (568), Correns (476), East (570), East \& Hayes (553), Emerson $(554,571,605,629)$, Lock (493, 504, 583).

Agrostemma Githago. Pigmented type dominant to albino. De Vries $(474,498)$.

Amaranthus caudatus. Red-leaved type dominant to green-leaved variety. De Vries (498).

Anagallis arvensis. Weiss (566) crossed the scarlet-flowered type with the blue-flowered variety and obtained the red type in $\mathrm{F}_{1}$. In $\mathrm{F}_{2}$ there was segregation into red and blue in the proportion $3: 1$. Hence the blue arises from the red by the loss of a single dominant factor.

Heribert-Nilsson (576) crossed a variety which had pink, almost white, flowers, which bred true, with the red type. $F_{1}$ was red like the type. In $\mathrm{F}_{2}$ there was segregation into red and pink in the proportion $3: 1$.

Antirrhinum majus. De Vries (565) made the first experiments on this species using the following varieties:

Rot .............tube and lips of the corolla red, the lips deeper.

Fleischfarbig......tube and lips pale red.

Delila.............tube pale or white, lips fairly deep red.

Weiss ..............white, often with a distinct very pale red tinge.

De Vries regarded red as made up of fleischfarbig, F, and delila, D, two dominant characters, and white as carrying two characters, $w$ and $w^{\prime}$, recessive to $F$ and $D$ respectively. Then $F_{1}$ from red $x$ white would be $\mathrm{FDww}^{\prime}$, and $\mathrm{F}_{2}$ would give red, flesh, delila and white in the proportion $9: 3: 3: 1$, which de Vries maintains agrees with his experimental results. Various $F_{1}$ reds, delilas, and flesh colours were selfed, and the $\mathrm{F}_{2}$ was in accordance with the above scheme. 
Bateson (480) suggested that a better interpretation of de Vries' results would be to suppose that the $\mathrm{F}_{1}$ plants produced, in each sex, in equal numbers, gametes having the characters, $R, F, D$ and $W$, and these, on fortuitous mating, would give $9 \mathrm{R}: 3 \mathrm{~F}: 3 \mathrm{D}): 1 \mathrm{~W}$. In view of more recent work, both views have to be revised.

In 1907 the author (514) published results of work on a number of colour-varieties; those used were

1. White-lips and tube of the corolla pure white.

2. Yellow-lips yellow; tube ivory.

3. Ivory-lips and tube ivory.

4. Crimson-lips crimson; tube magenta.

5. Magenta-lips and tube magenta.

With the exception of white, all varieties have a constant orangeyellow palate. Further varieties occur in which the lips are magenta or crimson, and the tube is ivory; the term 'delila' was used by de Vries for these varieties and has been retained.

The inheritance of colour in the varieties employed was represented by the following factors:

Y. A factor representing yellow colour in the lips associated with ivory tube-colour.

I. A factor representing ivory colour in the lips.

L. A factor representing magenta colour in the lips.

T. A factor representing magenta colour in the tube.

It was found also that certain relationships existed between the factors, i.e.

1. All zygotes, from which $\mathrm{Y}$ is absent, are white, though they may contain any of the factors $\mathrm{I}, \mathrm{L}$ and $\mathrm{T}$.

2. The effects of the factor $\mathrm{T}$ are not manifested unless $\mathrm{L}$ is also present in the zygote; that is, no magenta colour appears in the tube unless there is magenta colour in the lips.

3. All zygotes containing $\mathrm{Y}$ are coloured, the actual colour being modified and determined by the presence of one or more of the remaining factors. A zygote containing $\mathrm{Y}$ only, or $\mathrm{Y}$ and $\mathrm{T}$ is yellow.

4. Ivory is dominant to yellow; a zygote containing $\mathrm{Y}$ and $\mathrm{I}$, or $\mathrm{Y}, \mathrm{I}$ and $\mathrm{T}$ is ivory.

5. Since magenta superposed upon yellow gives crimson, a zygote containing $\mathrm{Y}, \mathrm{L}$ and $\mathrm{T}$ is crimson, $\mathrm{Y}$ and $\mathrm{L}$ only, crimson delila.

6. Magenta upon ivory gives magenta. A zygote containing $\mathrm{Y}, \mathrm{I}, \mathrm{L}$ and $\mathrm{T}$ is magenta, $\mathrm{Y}, \mathrm{I}$ and $\mathrm{L}$ only, magenta delila.

A further variety termed 'rose' was employed, but full details of 
the results of crossings with this variety are not given, though it was shown to be recessive to magenta.

Rose, which has the lips of the corolla tinged with magenta and a pale magenta tube, was identified with de Tries' fleischfarbig; magenta with rot, delila with magenta delila, and weiss with ivory.

Hence de Vries' results may be expressed:

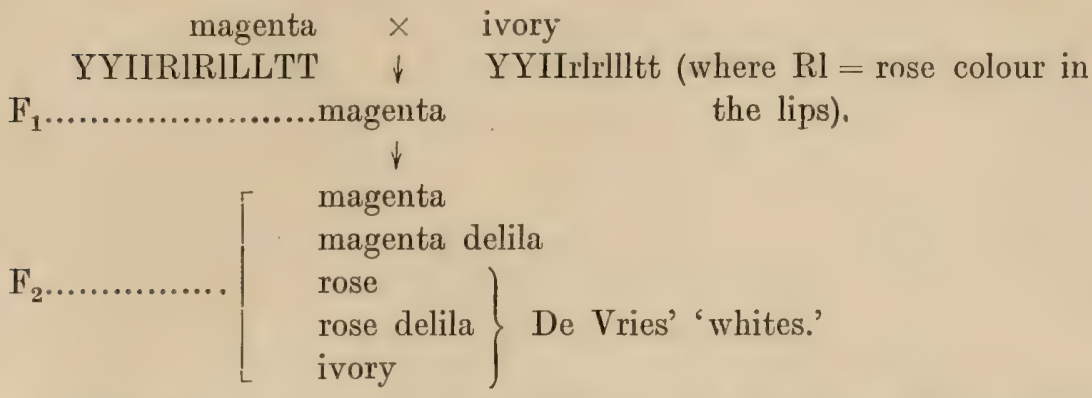

Since magenta is dominant to rose, and the tube of the corolla always takes the same depth of colour as the lips, rose $\times$ magenta delila would give magenta which would also corroborate de Vries' suggestion that rot consists of fleischfarbig and delila.

In 1908 Baur (517) published some results of his work on the same species. He worked with magenta (rot), ivory (elfenbein), yellow and white, and his results are entirely in agreement with those published by the author in 1907 .

In 1909 the author (535) published further work and certain additional results of which the most important are as follows:

'Rose' is now termed 'tinged ivory,' and the factors $\mathrm{L}$ and $\mathrm{T}$ represent tingeing in lip and tube respectively.

$\mathrm{D}$ is used to denote a deepening, or full-colour, factor which converts tinged ivory into magenta.

It was found that zygotes heterozygous for $\mathrm{L}$ in the presence of $\mathrm{D}$ are pale magenta in colour, whereas those homozygous for $\mathrm{L}$ are intermediate magenta. The colour remains unaltered whether the plant be homo- or heterozygous for D.

Sometimes the deeper colour occurs only in streaks and blotchings when S may be substituted for D. When the zygote is heterozygous for $I$, the streaks are pale magenta; when homozygous for $L$, intermediate magenta. In non-striped forms, as mentioned above, the flower-colour is the same whether the zygote is homo- or heterozygous in D. But striped forms, heterozvgous in $\mathrm{S}$, have magenta stripings 
on a ground tinged with magenta, whereas, when they are homozygous in $\mathrm{S}$, the ground colour between the stripings is ivory. The four zygotic types may be represented as follows:

1. YYIILLTTSS...... Ivory striped with I magenta.

2. YYIILITTSS ......Ivory striped with $\mathrm{P}$ magenta.

I. YYIILLTTSs......T. ivory striped with I magenta.

A. YYILLITTSs ......T. ivory striped with $P$ magenta.

In 1910 Baur (536) published a full account of his work on Antirrhinum; his results are in complete agreement with those of the author. A comparison of the two sets of results was published by the author (548) in 1910, together with further observations on the crossing of certain additional, true red, varieties, rose doré (on ivory) and bronze (rose doré on yellow). Rose doré is shown to be recessive to bluered or magenta; similarly bronze is recessive to crimson. Both rose doré and bronze occur in the tinged, pale and intermediate states.

The work, published in 1913 and 1914 by Bassett and the author ${ }^{1}$ on the pigments of Antirrhinum, has shown yellow to be identical with the known substance luteolin, and ivory with the known substance apigenin. The pigment in rose doré was shown to be a red anthocyanin. and the same pigment mixed with yellow gives the colour, bronze; similarly magenta contains a magenta anthocyanin, and this mixed with yellow gives crimson colour.

All the varieties may now be expressed in terms of the following factors:

Y. A factor leading to the production of luteolin in the lips and apigenin in the tube.

I. A factor leading to the suppression of luteolin in the lips, apigenin being formed instead.

L. A factor leading to the production of a tingeing of red pigment in the lips.

T. A factor leading to the production of a tingeing of red pigment in the tube.

D. A factor leading to the production of more anthocyanin pigment, i.e. a deepening, or full-colour, factor.

B. A factor converting red into magenta anthocyanin.

1 Wheldale, M., \& Bassett, H. Ll., 'The Flower Pigments of Antirrhinum majus. II. The Pale Yellow or Ivory Pigment,' Biochem. Joum., Cambridge, 1913, vIr, pp. 441-444. 'The Chemical Interpretation of some Mendelian Factors for Flower-colour,' Proc. $R$. Soc., London, 1914, LxxxviI B, pp. 300-311. 
The different varieties may be represented as:

$\operatorname{yyI}(\mathrm{i}) \mathrm{I}(\mathrm{i}) \mathrm{L}(\mathrm{l}) \mathrm{L}(\mathrm{l}) \mathrm{T}(\mathrm{t}) \mathrm{T}(\mathrm{t}) \mathrm{D}(\mathrm{d}) \mathrm{D}(\mathrm{d}) \mathrm{B}(\mathrm{b}) \mathrm{B}(\mathrm{b})$ - white.

YY(y)iillT(t)T(t)D(d)D(d)B(b)B(b)-yellow.

YY(y)II(i)llT(t)T(t)D(d)D(d)B(b)B(b)-ivory.

YY(y)iiLL(l)ttddbb-yellow tinged bronze delila.

YY(y)iiLL(l)TT(t)ddbb-yellow tinged bronze.

YY(y)II(i)LL(l)ttddbb-ivory tinged rose doré delila.

YY(y)II(i)LL(1)TT(t)ddbb-ivory tinged rose doré.

YY(y)iiLL(l)ttDD(d)bb-bronze delila.

YY(y)iiLL(l)TT(t)DD(d)bb-bronze.

YY(y)II(i)LL(1)ttDD(d)bb-rose doré delila.

$\mathrm{YY}(\mathrm{y}) \mathrm{II}(\mathrm{i}) \mathrm{LL}(\mathrm{l}) \mathrm{TT}(\mathrm{t}) \mathrm{DD}(\mathrm{d}) \mathrm{bb}$-rose doré.

$\mathrm{YY}(\mathrm{y}) \mathrm{iiLL}(\mathrm{l}) \mathrm{ttDD}(\mathrm{d}) \mathrm{BB}(\mathrm{b})$-crimson delila.

$\mathrm{YY}(\mathrm{y}) \mathrm{iiLL}(\mathrm{l}) \mathrm{TT}(\mathrm{t}) \mathrm{DD}(\mathrm{d}) \mathrm{BB}(\mathrm{b})$ - crimson.

YY(y)II(i)LL(l)ttDD(d)BB(b)-magenta delila.

YY(y)II(i)LL(l)TT(t)DD(d)BB(b)-magenta.

Certain varieties deeper than intermediate magenta are know'n to exist; they are recessive to intermediate magenta, but otherwise they have been very little worked with. The heterozygous forms have already been mentioned above. The original wild type is thought to be intermediate magenta and would have the constitution YYIILLTTDDBB. As would be gathered from the above statements, ivory $\times$ white will give magenta; hence two albinos, as regards anthocyanin, will give colour. Whether or no this case is strictly comparable to the results of crossing two whites in Lathyrus and Matthiola will be discussed later.

Arum maculatum. A. maculatum occurs in nature in two forms; one has black (anthocyanin) spots on the leaves, the other is without spots. Colgan (552) obtained seeds from a spotted plant, and found, out of 11 seedlings, 5 were spotted and 6 unspotted. Colgan suggests the female parent was heterozygous for spotted character and was fertilised by the unspotted form, but there was no evidence in support of the suggestion bevond the fact of equality of forms among the offspring.

Aster Tripolium. De Vries (498) notes that pigmented type is dominant to albino.

Atropa Belladonna. Saunders (475) made crosses between A. Belladonna typica and A. Belladonna var. lutea. The type has brown (anthocyanin on plastid) flowers, black (anthocyanin) fruits, and stem tinged with anthocyanin: the variety, which is without anthocyanin,

w. $\mathbf{P}$. 
has yellow flowers and fruits, and a green stem. $F_{1}$ was found to have the fruits of the type, but the intensity of colour in flowers and stems was sometimes diminished. Further results clearly indicated that there was normal Mendelian segregation in $\mathrm{F}_{2}$.

Beta. Kajanus $(559,580)$ has experimented with a large number of varieties. As far as anthocyanin pigmentation in the root is concerned three classes can be differentiated:
(a) Red
(b) Rose
\} With anthocyanin.
(c) White, yellow Without anthocyanin.

The results from crossing are at present rather obscure. Red was obtained in $F_{1}$ from crossing:

Red $\times$ red, rose, white and yellow.

Rose $\times$ yellow.

White $x$ white and yellow.

Rose was obtained in $\mathrm{F}_{1}$ from crossing:

Rose $\times$ rose.

White $\times$ yellow.

In $\mathrm{F}_{2}$ red gave red, rose, white and yellow, and also every selection and combination of these varieties except red only.

Rose, on the other hand, gave red, rose, white and yellow, and again every combination and selection except red only, and red, white and yellow.

White gave:

Red, rose, white and yellow.

Red, rose and white.

Rose and white.

Kajanus suggests a number of factors, but in the absence of further data, very little light is thrown on the results.

Kajanus notes that the pigment is not always confined to the skin of the root. In the salad beet, the flesh is completely violet-red; in the common red beet it is red, reddish or colourless; in the rose and in the white it is colourless.

The leaves on the whole are green, but in red beets they are sometimes red. Quite red leaves only occur in the case of red-fleshed beets. In red-fleshed beets there are also varieties in which the petioles and larger veins only are red, the leaf tissue being green. The results of crossing red- by green-leaved varieties seems to show that in some cases the sreen colour is due to inhibition of red, in other cases, not. 
Brassica. Kajanus (580) has worked with two species $B$. napus and B. rapa.

B. napus. As regards the colour of the root, distinction must be made between upper and lower parts. Anthocyanin is only found in the upper part, which may be violet-red, intermediate, or green. When the root is intense violet, the neck (the lower basal portion of the stem) is also violet-red. If the root-colour is reddish only, the neck is usually green. Hence there are three classes:

1. Red with red neck.

2. Red with green neck.

3. Green with green neck.

It has been deduced from crossing the varieties that there are two factors involved in anthocyanin pigmentation, i.e. $\mathrm{P}_{1}$ which gives pale violet-red, and $P_{2}$ which gives deep violet-red colour. $P_{2}$ is dominant to $P_{1}$. When both $P_{1}$ and $P_{2}$ are absent, the root is green. The differentiation between the classes is often not sharp.

B. rapa. Here also anthocyanin is only found in the upper part of the root, which may be violet-red (deeper or paler), or if pigment be absent, green. The violet-red colour may be continuous or blotched. It has been deduced, from crossing varieties, that anthocyanin is due to the presence of one dominant factor, $\mathrm{P}$, and when this is absent, the root is green.

Canacalia ensiformis (Leguminosae). Lock (504) showed pink colour in the flower to be dominant, or nearly so, to white, the latter reappearing in $\mathrm{F}_{2}$. Absence of red pigment from the testa (the author does not. state whether this is anthocyanin) is dominant to red. In $\mathrm{F}_{2}$ red reappeared, but in nothing like its former intensity. Some of the plants of $\mathrm{F}_{2}$ bore mottled grains, but in these also the pigmented patches were of a very faint reddish colour. In $\mathrm{F}_{2}$, plants with no red pigment in the testa were more numerous, probably three times so, than those with reddish and mottled testas taken together.

Canna indica. Inheritance of anthocyanin when red- are crossed with green-leaved plants. Honing (608).

Cattleya. Hurst $(502,531,540,596)$ notes that purple pigment is dominant to its absence in the flower.

Clarlia elegans. Bateson (524) states that the magenta-flowered type is dominant to the salmon-pink variety.

Corchorus capsularis. Finlow \& Burkill (572) investigated the inheritance of anthocyanin in the Indian Jute plant. As regards pigmentation 33 races were broadly classified into the following types: 
( $\iota$ ) Deep red stem, petioles and fruits; the teeth of the leaves also tipped with red.

(b) Brownish red stems, petioles and fruits, with no distinct red borders to the leaves.

(c) Green stems with reddish petioles and fruits.

(d) Pure green stems, petioles and fruits.

The red pigment is found:

1. Chiefly in the parenchyma cells which lie immediately under the epidermis of the stems and petioles.

2. In the parenchyma of the petioles, sporadically, even as deep as the phloem.

3. In sub-epidermal cells near the margin of the leaf.

4. In small multicellular hairs on the leaf and on the stipules.

The intensity of coloration is due to the general distribution of the pigment. Conversely, the fewer the pigment cells, the less red in the stem. The authors point out that, in fact, there are only two real colour types, red and green, since the classes $(a),(b)$ and $(c)$ are without definite boundary lines.

The results of crossing red races with green were as follows. When pure green is crossed with a fixed red, red is dominant. In $F_{1}$ the hybrids appear to consist entirely of plants of one tint of redness, which is less dense than the colour of the red parent. The red plants of the $\mathrm{F}_{2}$ generation vary widely in the amount of red colour they contain. $F_{3}$, from red $F_{2}$, though fixed as regards red colour, shows the same variation in intensity as $\mathrm{F}_{2}$. As a result of the experiments examples were produced, either fixed or unfixed, of all intermediate colour types of jute hitherto met with, including a pure fixed culture of one of the commonest of these.

Coreopsis tinctoria. De Vries (474) has shown that the yellow type is dominant to the variety, 'brunnea,' in which the brown colour is due to the development of anthocyanin. The type has evidently an inhibitor of anthocvanin.

Cypripedium (Puphiopedilum). Pigmented (anthocyanin) flower is dominant to albino. Hurst (502, 531, 540, 596).

Datura Stramonium. Saunders $(475,487)$ used two types, D. Talula having reddish stems and violet flowers, and $D$. Stramonium with green stems and white flowers. The $F_{1}$ had red stems and violet flowers, though the intensity of colour varied. In $\mathrm{F}_{2}$ there was evidence of typical Mendelian segregation. 
Dendrobium. Pigmented (anthocyanin) flower dominant to albino. Hurst (596).

Digitulis purpurea. Keeble, Pellew \& Jones (542) made certain observations on the inheritance of anthocyanin in flowers of this species. The plants used were:

1. White with yellow spots (mmddww).

2. White with red spots $(M m d d W w)$.

3. White with red spots (MMddWw).

4. Purple with red spots (MmDdww).

5. White with purple flush and red spots (???).

Colour is due to the factor, M, producing magenta sap. Absence of $\mathrm{M}$ gives a recessive white. A deepening factor, $\mathrm{D}$, is dominant to M and changes it to purple. The colour may be inhibited by a dominant factor, W, so that the corolla is white except for red spots. The spots on the corolla are always present. In recessive whites they are brown or yellow: in magenta and dominant whites they are red. They depend on the presence of the factor. II and they are not inhibited by W.

Saunders (563) confirms the results of Keeble, Pellew \& Jones for the inheritance of spot colour. It is stated that white-flowered plants with red spots may either breed true, or give a mixture of whites with red spots (dominants) and white with greenish-yellow spots (recessives) according as they are of pure-bred or cross-bred parentage. Coloured flowers may vary from deep purplish-red to white with a faint flush. The white-flowered plants with red spots frequently become tinged as they get older.

Geum. De Vries (498) mentions the inheritance of anthocyanin in hybrid from the cross of type (yellow plastids plus anthocyanin) by yellow (plastids) variety.

Gossypium. Balls $(515,523)$ working on Figyptian cotton recognised the following pairs of Mendelian characters which are comnected with anthocyanin :

Full red spot on the leaf and faint spot.

Large purple spot on the petal and no spot.

The red spot on the leaf is due to the development of anthocyanin in the epidermal and sub-epidermal cells of the petiole at the point where it divides into the leaf-veins. Crosses of spotted with spotless give spotted $\mathrm{F}_{1}$, but the intensity of colour in the spot is less than in the spotted parent. In $\mathrm{F}_{2}$ the heterozygote spot can be distinguished from the homozygote. In the case of flower spot, the homozygote has a large purple spot, the heterozygote a small purple spot. 
Leake (561) worked with Indian cotton. Four varieties connected with anthocyanin pigmentation were used, i.e.

1. A variety in which the petal is entirely red having a darker spot at the .base.

2. A variety in which the petal is yellow with a deep red spot at the base.

3. A variety in which the petal is pale yellow with a basal spot.

4. A variety in which the petal is white with a basal spot.

Leake identifies the following factors. A factor for yellow which is dominant to white, and a factor for red which is dominant to white and yellow. Individuals heterozygous for the reddening factor have petals only partially coloured; this is very obvious in red on yellow, but less so when on white. A scheme of the factors nay be represented as:

YRr.........red on yellow.

YRR ......red.

$R R(r)$......red on white.

Y............yellow.

- ............white.

In some of the strains used there was also anthocyanin in the vegetative parts, that is in the young leaves, and in the ribs and veins of the mature leaf; in other strains, these were quite green. In the $\mathrm{F}_{1}$ from a cross between these red-foliaged and green-foliaged strains, the red colour was dominant, though diminished in amount. In $\mathrm{F}_{2}$ there was segregation into red and green in the proportion 3:1. Among the individuals with red colour there was a considerable range in intensity, though the DD individuals had more pigment in the leaf than the DR, and by this means they could be separated with a fair degree of certainty. There is an association also between anthocyanin in the vegetative parts and the complete redness of the flowers.

Helianthus. Shull (520) has made some experiments with this genus. The wild Heliantlus annuus of the Prairie region has a purple disk, the colour being found in the tips of the paleae which are a deep metallic purple, the margin of the corolla which is brownish-purple and the style and stigmas which are reddish-purple. The 'Russian Sunflower' (Helianthus annuus, var.) has the tips of the paleae yellnwishgreen, the corolla a clear lemon yellow, and the styles and stigmas usually have the same colour as the corolla. Shull concluded, on the results of crossing, that the purple disk is a strict Mendelian character and is dominant to the yellow disk.

The red sunflower mentioned by Cockerell $(602,603,611)$ appears 
to be dominant to the yellow, though the $\mathrm{F}_{1}$ may vary in the amount of anthocyanin it produces. The red variety is no doubt formed owing to the loss of an inhibiting factor, and the $F_{1}$ plants would only receive the inhibitor from one parent. When anthocyanin appears in the primrose-coloured variety of Helianthus, the result is purple and not chestnut red.

Hordeum. Biffen (501) mentions that in Hordeum the paleae may be white, black, brown or purple. The grain also may be white, bluishgrey or purple. Apparently the purple colour is due to anthocyanin. According to Biffen, purple paleae as contrasted with white, and dark grain with light grain, form pairs of Mendelian characters.

Lathyrus odoratus. Bateson \& Punnett $(487,496,500,516)$ have carried out extensive work on the colour inheritance in the Sweet Pea.

The original wild type is probably most nearly represented by the variety now known as 'Purple Invincible' with chocolate standard and bluish-purple wings.

Loss of a diluting factor produces a variety with deeper wings, 'Purple-winged Purple Invincible.' Loss of a full-colour factor gives a tinged variety, 'Picotee.'

When the blueing factor is absent, a series of red varieties appears comparable to the abuve: 'Painted Iady, with a deeper variety, 'Miss Hunt,' and a tinged variety, 'Tinged White.'

It was shown early in the experiments with Sweet Peas that two white varieties, indistinguishable excent that one has long, the other short pollen, gave a 'Purple Invincible' hybrid, and from this result the fact was deduced that colour production is dependent on two factors, or that the two factors taking part in its formation can be inherited independently. As in Matthiolu, we must suppose that two factors produce the most hypostatic colour, i.e. 'Tinged White,' and that 'Purple Invincible' resulted in the original cross because the white varieties employed carried both B and a full-colour factor.

These facts may be represented in tabular form as follows (De = fullcolour factor, $\mathrm{Di}=$ diluting factor):

CRBDeDi.....Purple Invincible.

CRBDe.........Purple-winged P.I.

CRBDi.........Picotee (see Bateson \& Punnett, 498).

CRB ............Picotee.

CRDeDi ......Painted Lady.

CRDe .........Miss Hunt.

CRDi............Tinged White.

CR.............Tinged White. 
Any plant without $\mathrm{C}$ or $\mathrm{R}$ is white. Hence whites can carry any of the other factors in any combination or arrangement, but never $\mathrm{C}$ and $\mathrm{R}$ simultaneously. There is also a certain connection between colour and the hooded form of the standard. In hooded varieties the standard always approaches in colour to the wings, and has never the bicolor appearance of the varieties with erect standard.

M. G. and D. Thoday (547) have given an account of experiments with certain varieties of Lathyrus, and the crosses form a very complex series in $\mathrm{F}_{2}$. The chief point of interest is that they find a scarlet anthocyanin, distinct from, and recessive to. the bluish-pink of the 'Painted Lady' variety.

Linaria alpina. Saunders (586) made crosses between the type and a variety. The type has purplish-blue flowers and the variety pink flowers. Both pigments are anthocyanins. It was found that blue is dominant to pink.

Linum usitatissimum. Varieties of this species have been investigated by Tammes (564). Among other species, four varieties of L. usitatissimum were used, i.e. common flax, Egyptian flax (deep blue flowers), and two other varieties, one with pale blue, the other with white, flowers. Among other crosses are the following which are fairly typical.

From Egyptian flax $x$ white-flowered variety of common flax, the $\mathrm{F}_{1}$ had paler flowers than Egyptian flax. In $\mathrm{F}_{2}$ there were 8 pale blue, 3 pure white and 3 like Egyptian flax. This was regarded as an ordinary Mendelian ratio of $1: 2: 1$. From the white-flowered variety $\times$ pale blue-flowered variety of common flax, the $F_{1}$ was fairly constant, and still paler than the blue parent. In $\mathrm{F}_{2}$, out of 39 plants, 11 were pure white; the remainder were a mixture of pale blues like the parent and grandparent, but were difficult to separate. The author however believes the ratio to be again $1: 2: 1$.

In a later paper (610) Tammes shows that in the second and following generations from a cross between the Egyptian and the white-flowered varieties of common flax there is a deficiency of white-flowering plants. This is found to be due to two causes, i.e. first, a deficiency of seed formed from the mating of gametes without the factor for forming colour, and secondly, an inferior germinating power of the seed of the white-flowered individuals.

Lychnis dioica. Saunders (475) used this species in certain crosses. $L$. dioica was crossed with a glabrous form of $L$. vespertina, and a glabrous variety of $L$. dioica was crossed with $L$. vespertina. $\mathrm{F}_{1}$ and their offspring showed pink, the depth of colour varying according 
as the wild hairy species or de Vries' glabrous strains (see original paper) were employed in the cross.

Shull (520) first mentions the results of crosses between white- and purple-flowered Lychnis dioica, the purple being dominant.

Later, Shull (546) published further results, in which he states that two varieties of coloured flowers can be detected in Lychnis, i.e. a reddish-and a bluish-purple. The former is dominant to the latter, this being the reverse of what is found in other plants. Two factors are necessary for formation of the bluish-purple, and a third factor modifies this to reddish-purple.

In a still later paper Shull (588) again states that the type has reddishpurple flowers, and that there is a bluish-purple variety recessive to the type. The albino is without anthocyanin. No albinos mated together produced colour. Two new German strains were introduced Melandrium album and $M$. rubrum. A certain individual of $M$. album $\times$ white dioica gave reddish-purple offspring. $M$. rubrum $\times M$. album gave a mixture of both purple- and white-flowered offspring in the proportion of $4: 23$.

Matthiola. Our knowledge as regards the inheritance of colour in this genus is due to the work of Saunders $(475,487,496,500,506$, $562)$.

It is not known what variety represents most nearly the original type, but if it be assumed that each variety arises by loss of some factor from the type, then the latter would be represented by a plant with pale purple flowers. Loss of a diluting factor gives rise to deep purple; loss of another factor from the deep purple gives a duller shade of purple termed 'plum.'

Loss of the blueing factor-B-from each of the above varieties gives rise to the corresponding blue-red series; rose, a dilute variety; carmine and crimson, deep varieties; and 'copper,' a dull red variety represented by plum in the bluer series.

Loss of a further factor from the blue-red class reveals a true, less blue, red class containing a dilute variety, 'flesh,' and a recessive deeper variety, 'terra-cotta.'

Early in the experiments with Matthiola it was ascertained that two factors are necessary for the production of colour, and that certain white varieties crossed together produce coloured offspring, purple in the original experiment, since one at least of the original whites used contained the hlueing factor, B.

The varieties may be represented in the following scheme. $\mathrm{C}$ and 
$\mathrm{R}$ are the factors for colour, $\mathrm{B}$ modifies the blue-red class to the purple class, $\mathrm{D}$ causes dilution in colour and $\mathrm{X}$ the difference between the pure and dull, or impure, colour:

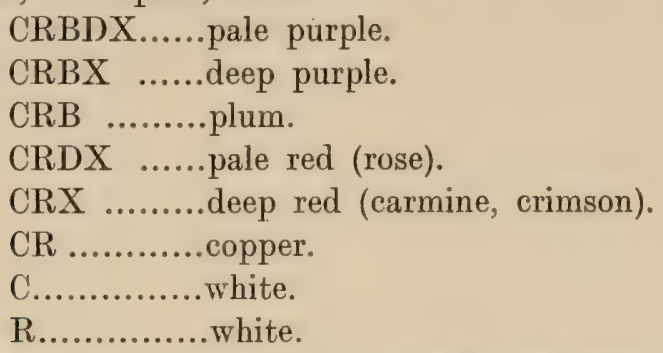

In some families, other varieties, such as terra-cotta, flesh and lilac, appear in addition, but, apart from the fact that they are recessive to crimson and purple, their relationship to each other and to the other colours is not clear at present. As we see from the table, individuals without either $\mathrm{C}$ or $\mathrm{R}$ are white; thus white can carry every factor and combination of factors, except $\mathrm{C}$ and $\mathrm{R}$ simultaneously.

Many of the above results have been confirmed by Tschermak (590).

Mirabilis Jalapa. Correns $(482,497,537)$ published the first work on the colour-inheritance in this genus. He used several varieties, white, yellow and 'red.' In $\mathrm{F}_{1}$ he obtained a 'rose' by crossing white $x$ yellow, but as he did not realise the existence of heterozygous forms (see below), he was unable to solve successfully his results in the $\mathrm{F}_{2}$ generation.

Baur (517) made crosses with two varieties, and obtained a heterozygous form in $\mathrm{F}_{\mathbf{1}}$, but his results are similar to those of Marryat (533) to whom we owe the bulk of our knowledge on the inheritance of flowercolour in Mirabilis. The work of the latter author leads to the following conclusions:

We must suppose that the original type had crimson flowers. Loss of a factor for anthocyanin production from crimson gives a variety with yellow flowers free from anthocyanin. Further loss of a factor produces white, an albino both as regards red and yellow pigment. The peculiar interest of Mirabilis (among other points) is centred in the occurrence of heterozygous forms which may be best represented by the following scheme:

CCMM......crimson.

CcMM ......magenta.

CcMm.....magenta rose.

CCMm......orange red. 


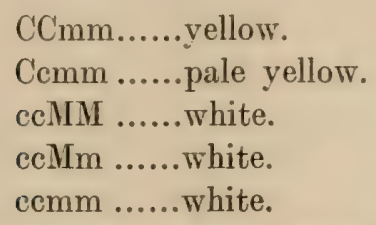

It was also found that a certain two white individuals crossed together gave coloured (anthocyanin) $\mathrm{F}_{1}$, as in Matthiola and Lathyrus. Hence the factors for anthocyanin production can be separated into two components, of which one is $\mathrm{M}$, and the other is not represented in the above scheme. Absence of colour may be due to loss of either of these components, or to loss of the yellow pigment.

Nicotiana. Inheritance of anthocyanin in species-crosses. Lock (532), Haig Thomas (594).

Oenothera. Since Oenothera is a plant which forms anthocyanin in its stems, petioles, burls, etc., the complex inheritance of characters among the numerous strains which have been employed experimentally involves also the inheritance of this pigment. Mention will only be made of one or two cases in which anthocyanin pigmentation has been considered an important character.

The first case to be dealt with is that introduced by Gates (539, $555,573)$, and which concerns the appearance of 0 . rubricalyx. This variant was found among the offspring of self-fertilised rubrineriv plants, the latter being characterised by having the calyx of the buds streaked with anthocyanin, whereas $O$. rubricalyx has a completely red calyx. The segregation of the offspring from self-fertilised rubriculyx plants in two generations, into rubriculyx and mibrineris, led Gates to consider the case purely Mendelian. The original rubricalyx plant was regarded as a heterozygote which has acquired a dominant IIendelian character, the character being purely quantitative, i.e. as causing an increased formation of anthocyanin.

In a later paper (606) Gates again states that the red pigmentation character, $\mathrm{R}$ (which originated by a mutation and distinguishes mubicalyx from rubrinervis), is more or less completely dominant in $\mathrm{F}_{1}$ from the cross grandiflora $\times$ rubricalyx and its reciprocal. In $\mathrm{F}_{2}, 3: 1$ ratios were obtained, and also ratios of $5: 1$ and $10: 1$ as well as $3: 1$. Gates has no satisfactory explanation of these facts.

Shull (609) makes further experiments on rubricalyx by selfing this strain and crossing it with rubrinervis and with Lamarckiana; he obtains what he calls a series of negative correlations in the distribution of the red pigment, the pigmented buds of rubricalyx being 
invariably associated with a low degree of pigmentation in stems and rosettes. Moreover, the segregation of the rubricalyx character was not found to be a simple Mendelian case. Shull maintains also that certain of Gates' conclusions are erroneous, viz. that the rubricalyx character represents a quantitative difference, and that it can be expressed by one factor.

The other case of interest in connection with anthocyanin is that considered by Davis $(592,604)$ in connection with the stem coloration (the formation of papillae or glands coloured with anthocyanin at the base of long hairs) in parents and hybrids of crosses, 0 . grandiftora $\times$ biennis, O. franciscana $\times$ biennis and their reciprocals. Davis considers this character to be dominant to the green stem, but it has not been shown to segregate in a Mendelian way.

Oxalis. Nohara (635) worked with varieties of the so-called Oxalis corniculata $\mathrm{L}$. which differed from each other in the presence or absence of purple (anthocyanin) in the eye of the corolla and in the leaves. The presence of anthocyanin was found to be dominant to its absence, and the intensity of pigmentation in $\mathrm{F}_{1}$ from pigmented by unpigmented was found to be intermediate. The purple colour in eye and leaf is due to one factor so that eye- and leaf-purples are associated, but the leaf-purple can appear without the eye-purple.

Papaver somniferum. De Vries (474) and Hurst (502) have shown that the basal patch on the petals is dominant to its absence. Hurst (502) also states that colour in the rest of the petal is dominant to albinism, and that purple is dominant to red.

Papaver Rhoeas. Shull has published work (588) on this genus. It was found that varieties with a white margin were dominant to varieties without the margin, i.e. the type. Certain whites crossed with some reds gave white or striated offspring, but the same whites were found to be recessive to pink or orange. Some red-flowered varieties crossed together gave whitish offspring. Two suggestions are made: $(a)$ that only spectrum red is inhibited; $(b)$ that two factors are necessary for inhibition.

Phaseolus multiflorus. The characters which have received most attention in this genus are those concerned with the pigmentation of the seed-coat.

Lock (504) made some preliminary experiments by crossing a dark purple-seeded bean with a dark yellow-seeded bean. The $\mathrm{F}_{1}$ was dark purple. The $\mathrm{F}_{2}$ could be subdivided into two groups: $(A)$ containing beans of various shades of purple; $(B)$ of various shades of yellow. 
It was found that members of $(A)$ might throw $(B)$ but not rice versa.

Shull (513) gives an account of the results obtained by crossing several varieties, i.e.

'Prolific black wax'-purple-black seeds (anthocyanin in testa).

'Ne plus ultra'- yellow-brown seeds.

'Long yellow six-weeks'-light greenish-yellow seeds.

'White flageolet'-seed coats white.

The results in $F_{1}$ were as follows:

Purple $\times$ yellow-brown $=$ purple.

Purple $\times$ yellow $=$ purple.

White $\times$ purple

White $x$ yellow-brown

White $\times$ yellow

All gave similar $\mathrm{F}_{\mathbf{1}}$ with testa mottled with purple.

Shull then postulates the following factors:

$\mathrm{P}=$ pigment.

$\mathrm{B}=$ modifier which changes pigment to purple.

$\mathrm{M}=$ mottling factor.

Then the constitution of the different beans is

Brown and yellow-Pbm.

Black beans-PBm.

White-pBM.

Shull concludes that the mottling factor is carried by the white bean, whereas Bateson and Tschermak had regarded the mottling factor as latent in the pigmented bean.

Shull in a later paper (521) gives the proportions of the varieties in $\mathrm{F}_{2}$ from the above cross. They were found to be

Purple mottled-18.

Purple self-colour-18.

Brown or yellow mottled-6.

Brown or yellow self-colour-6.

White-16.

Shull's explanation for this result is that beans containing $\mathrm{PB}$ and heterozygous in the $\mathrm{M}$ factor are mottled, whereas those beans homozygous in M are self-coloured. Hence it is possible for purple to carry the mottling factor, and Tschermak, Bateson and Lock are also correct. Mottled beans of the above constitution are heterozygous and should never breed true, and this was found to be the case. Shull 
points out that there are however other strains of mottled beans which do breed true.

Emerson (528) publishes a long paper on pigmentation in bean seeds. He gives first a list of the crosses made by Tschermak, Shull and himself. He points out, as Shull has done, that there are two kinds of mottled beans, viz., strains which breed true, and heterozygous forms not breeding true. Emerson then suggests a scheme to explain the existence of two sorts of mottling, namely by postulating two factors for mottling: M the sort of mottling which breeds true, and $\mathrm{X}$, the sort which is visible only in the heterozygous condition. The results he obtained experimentally can be explained on the basis of this scheme. In a later paper (529) Emerson gives further results of the inheritance of total and eyed (round hilum) pigmentation, but since the kind of pigment is not described, it is not clear how far it concerns anthocyanin. Emerson also mentions another hypothesis suggested to him by Spillman to explain the two kinds of mottling mentioned above. Spillman supposes that the mottled races which breed true have in them two correlated factors, and that there are three types of non-mottled beans resulting from the losss of one, or the other, or of both of the correlated factors. On Spillman's plan, just as on Emerson's two factor hypothesis, a definite formula can be assigned to all the races used in crossing, and in this way all the results, with one or two exceptions, can be accounted for. Emerson himself inclines to the coupled-factor, rather than the independent-factor, hypothesis.

Phyteuma. Inheritance of anthocyanin in the cross Ph. Halleri $\times P h$. spicatum. Correns (486).

Pisum sativum. Here again as regards pigmentation, the colour of the testa has received a great deal of attention. Bateson \& Killby (487) noted that greys and browns in the seed-coat are associated with coloured flowers, and crossed with whites they occasionally give 'reversionary' $F_{1}$ with purple (anthocyanin) spots, though spots were absent from the parents.

Lock $(512,518)$ sums up many of the results on pea colour. He states that the albino variety has no anthocyanin. The presence of a factor $\mathrm{C}$ produces grey (chromogen) in the testa, and red anthocyanin in the leaf axils and flowers. The presence of $\mathrm{S}$ produces spotting of a reddish shade on the testa. The presence of $\mathrm{P}$ modifies red anthocyanin of the axils, flowers and spots on the testa to purple.

Polemonium. Inheritance of blue anthocyanin in $\mathrm{F}_{1}$ from cross of $P$. caeruleum by $P$. flavum. Correns (486). 
Primula sinensis. The bulk of the work on this genus is due to Gregory \& Bateson. The following is a summary of the results which have been published by Gregory (557).

All colour in $P$ sinensis is due to anthocyanin except the yellow of the eye which is plastid pigment.

\section{Varieines of flower-solour.}

Albinos: The flowers contain no anthocyanin; they are differentiated into dominant and recessive whites, but the flowers of both look alike.

Full colours:

Salmon-pink.

True red-'Orange King:

Blue reds-Light (dilute) and deep shades of magenta and crimson. Crimson is less blue than magenta but is more blue than 'Orange King.'

Blues-various shades.

Pale colours: Shades of pink, of which 'Reading Pink' is the deepest; of these apparently some correspond to magentas, and others to crimsons, but the difference cannot be detected except by crossing.

\section{Distribution or pattern of colour.}

'Sirdar.' The pigment of the petals occurs in separate minute dots, and the edges of the petals are white. The pigment itself may be either magenta, crimson or blue.

'Duchess.' The pigment occurs as a flush round the eye of the corolla, and may be either magenta or crimson.

\section{Colour in the spot external to the eye.}

In certain varieties, there are spots of deep colour on the petals just external to the eye. Deep spots are not fully developed unless the stigma is coloured; nor even if the stigma is coloured, are they developed in plants which have no yellow (plastid) eye. Spots are deeply coloured only in deeply coloured flowers; on light flowers they are similar to those in the flowers with a green stigma. They also depend on the base colour, since they are not visible in pale coloured flowers, nor in flaked flowers unless the stripe occurs on the area occupied by the spot.

Colour in the ovary, style and stigma.

By loss of an inhibiting factor, colour may be formed in these organs. 


\section{Varieties of stem-colour.}

Anthocyanin may be entirely absent when the stem is green. This condition is associated with recessive white flower-colour (occasionally dominant white, i.e. 'Pearl'), or with pale colours of which the deepest is 'Reading Pink,' and no flower-colour deeper than 'Reading Pink' is ever found on plants devoid of anthocyanin in the stem.

There may be faint colour in young leaves and petioles associated with pale flower-colour.

There may be pigment at the bases only of petioles and pedicels, associated with 'Sirdar' flower-colour.

The stem may be fully coloured with purplish-red sap, either light (dilute), or deep, associated with full flower-colours, i.e. salmon-pink, crimsons and magentas; but whereas light magentas and crimsons can be borne on both light- and deep-stemmed plants, the deepest magentas and crimsons can only be borne on deep-stemmed plants.

The stem may be coloured with pure red sap associated with 'Orange King' flowers.

The stem may be coloured with blue sap associated with blue flowers.

Hence the direct relationship between stem and flower-colour may be summed up as

Recessive whites and green stem.

Pale flower-colours and green, or faintly coloured, stem.

Full flower-colours and full-coloured stem (and of these deep flowercolour and deep stem).

True red ('Orange King') flower-colour and true red stem.

Blue flower-colour and blue stem.

\section{Factors (stems).}

Colour in both flowers and stems can be produced by two or more complementary factors. Keeble \& Pellew (541) obtained an $\mathrm{F}_{1}$ with magenta flowers from two whites. As regards stem, there is no case of colour from mating two greens, but plants heterozygous for colour in the stem have given 9 coloured: 7 green stems.

Slight colour in the stem is due to the factor $Q$, which is dominant to complete absence of colour.

The difference between full colour and faint colour is due to a dominant factor, $\mathrm{R}$.

The difference between 'Sirdar' and full colour is due to a factor, 
F, which regulates distribution of colour. Thus an individual heterozygous for all three factors will give

$$
\begin{aligned}
& 9 \text { FRQ...full colour (magenta or crimson). } \\
& 3 \mathrm{RQ} \text {...Sirdar (magenta or crimson). } \\
& 3 \mathrm{Q} \text {......faint colour (pinks). } \\
& 1 \text { - ......green (whites). }
\end{aligned}
$$

Purplish-red in the stem is dominant to the true red of 'Orange King,' and one factor only is necessary to produce the change.

Blue in the stem is recessive to all colours.

No case is known of inhibition in the stem, that is, there is no dominant green stem.

Light shades in the stem colour (flowers light) are dominant to deep shades (flowers light or deep). Probably one factor is concerned with heterozygous forms, but there may be more.

In some cases there is one factor between crimson and magenta; other cases indicate two factors.

It is doubtful whether there exists one or more diluting factors. There is one factor diluting stem colour and another flower-colour, and these are inherited independently.

\section{Factors (flowers).}

Colour in flowers may be produced by two or more complementary factors.

The difference of one factor regulates the distribution of colour between 'Sirdar' and full colour, and also between pale and full colour as in stems.

Full colours are dominant to pale colours.

Magenta is dominant to crimson.

Maģenta and crimson are dominant to full red ('Orange King').

Blue is recessive to all magentas and reds.

Whites may be dominant or recessive to colours.

Dominant whites are generally red-stemmed. A green-stemmed white variety, 'Pearl,' is a dominant white (Keeble \& Pellew, 541); the same authors also report that a full red-stemmed white, 'Snow King,' may be recessive. The flower is only white in dominant whites if homozygous for the inhibiting factor. It has also been suggested that suppression of colour is due to two inhibiting factors, central and peripheral, one of which is represented in 'Duchess.'

Keeble \& Pellew (5t1) provide further results on dominant whites. Hitherto all whites with red stems have been regarded as dominant

w. P. 
whites. Keeble \& Pellew give evidence for regarding 'Snow King,' which is a red-stemmed variety with white flowers, as a recessive white. Crosses between various plants of 'Snow King' and fully coloured varieties showed that 'Snow King' may be homo- or heterozygous for the dominant white factor, or may be entirely without it.

'Snow King' $x$ 'Snow Drift' gave magenta $F_{1}$. Hence these two white-flowered varieties can give colour.

Reseda odorata. Compton (569) has shown that orange-red colour (anthocyanin) in the pollen is dominant to bright yellow; self-fertilised heterozygotes throw about three reds to one yellow.

Salvia Horminum. Saunders (487) has worked with the type and varieties of this species. The type has violet flowers, and the bracts of the inflorescence are also coloured violet. A red variety was used in which the flowers and bracts were red. Both pigments are anthocyanins. Loss of pigment gives an albino from which anthocyanin is completely absent.

The inheritance can be represented by the following scheme:

$$
\begin{aligned}
& \text { BR .....purple. } \\
& \mathrm{R} \text {........red. } \\
& \text { B .........white. } \\
& \text { - .........white. }
\end{aligned}
$$

Senecio vulgaris. Trow (589) has published results of crossing a number of elementary species. It was found that red colour, anthocyanin, in the stem is dominant in some elementary species. It is suggested that one factor is involved, or possibly two.

Silene Armeria. Colour in flower dominant to albinism (de Vries, 498).

Sclanum tuberosum. East (538) has published some results. He states that presence of anthocyanin in the stem is dominant to its absence, and segregates on Mendelian lines. Purple in the flower is probably dominant to its absence. The colour of the tubers is either red or purple, and purple is dominant to red.

Salaman (544) has published more extensive results. Black tubers of the variety, 'Congo,' have purple anthocyanin in the skin. The red-tubered variety has red anthocyanin. White tubers have no anthocyanin. Two factors are required for colour (red), and a third dominant factor gives purple. S. eluberosum has a dominant white factor inhibiting the purple.

In the flowers all pigment is anthocyanin. Heliotrope colour is due to two factors, and purple to a third factor. In varieties of 
tuberosum, colour is confined to the upper surface. In S. etuberosum, pigment is developed on the lower, and is inhibited on the upper surface. In S. verrucosum both surfaces are probably free from inhibitors.

Trifolium. Inheritance of anthocyanin in flowers and seeds. Red in flower-colour is dominant to both white and blue (Kajanus, $\check{7} 79$ ).

Veronica longifolia. Colour (anthocyanin) dominant to its absence (de Vries, 498).

Viola cormuta. Colour (anthocyanin) dominant to its absence (de Vries, 498).

Zea Mays. Correns (476) made the first investigations on this species. As regards characters connected with anthocyanin he states that two such characters behave in a Mendelian way, i.e. colour in the pericarp (red or absence of red), and colour in the aleurone layer (blue or white). The degree of dominance was found to vary.

Lock $(493,504)$ has published further results. He states that blue, black or purple pigments are confined to cells of the aleurone layer. Red is confined to the pericarp. The pigment is situated in the cells, and to some extent also in the cell walls of the pericarp. He points out that in cross-bred cobs, blue will occur mixed since the character is not maternal; the pericarp colour, on the other hand, appears in either all or none of the grains, as it is a maternal character. The work includes a large number of results in comnection with the cross, blue $\times$ white and the reciprocal. The results show that there is irregularity in the dominance of blue. Red colour in the pericarp is dominant to its absence, and forms a simple Mendelian case.

East \& Hayes (553) have published extensive results on Maize. They show that Leck's irregular results were due to the fact that the whites he employed in crossing were carrying different factors. They themselves worked with a variety having red (anthocyanin) pigment in the aleurone layer, and the formation of this pigment was found to be due to two factors, $\mathrm{C}$ and $\mathrm{R}$. A third factor, $\mathrm{P}$, modifies the red to purple. There is also a fourth factor, I, which inhibits the red and purple colour. Red pigment in the pericarp, cobs and silks, is dominant to its absence. It may be present in each of these parts separately and independently of the others. No plant has been obtained which has red glumes and yet shows no red colour in other parts of the plant. One, however, has been found that is pure for red glumes, and shows no red in other parts with the exception of the silks. 
Connection of Flower-colour with the Presence of Anthocyanin in Vegetative Organs. Frutts and Seeds.

Such cases are illustrated among the following genera and species:

\author{
Antirrhinum majus, \\ Atropa Belladonna, \\ Beta, \\ Corchorus capsularis, \\ Datura, \\ Digitalis purpurea, \\ Gossypium,
}

\author{
Helianthus, \\ Lathyrus odoratus, \\ Oenothera, \\ Pisum sativum, \\ Primula sinensis, \\ Salvia Horminum, \\ Zea Mays.
}

There appear to be several possibilities in the inheritance of colour in such cases as these we are considering. Colour (anthocyanin) in the plant may be represented by one factor which causes the flowers, as well as other organs, to develop pigment. When this factor is absent, pigment disappears from the whole plant including the flower; this is perhaps the most common case. Colour, however, may disappear from the flower, or any other organ, independently of the rest of the plant. One of the most striking examples of independent connections of this kind we find in Maize; the plant may have pigment in the sheath, cob, pericarp, silks, etc., and practically in all or any of these parts. In such a case, if colour in each part is represented by a separate factor, we should expect by crossing suitable plants to obtain all the Mendelian combinations. This, however, is not always so, as for instance in Maize (Emerson, 554), and a number of other plants. The lack of some combinations may be due either to reduplication phenomena (see p. 185), or to some form of genetic correlation, and to decide between these alternatives often involves further data than we have at present. In the following genera indication is given of such colour relationships as we know to exist:

Antirrhinum majus. The white, ivory and yellow-flowered varieties never produce anthocyanin in any part of the plant. The author has noticed that the stems and leaves of deep magenta- and crimsonflowered varieties produce anthocyanin to a considerable extent, whereas in intermediate and pale varieties these organs are practically free from anthocyanin.

Atropa Belladonna. The type has anthocyanin in the flowers (brown), fruits (black) and stems (tinged with red). The albino has yellow flowers and fruits, and a green stem (Saunders, 475). 
Beta. Some varieties have leaves coloured quite red with anthocyanin. This only happens in red-fleshed varieties, i.e. when anthocyanin is formed in the inner tissues, as well as in the skin, of the root. In varieties having colourless flesh, the leaves are green (Kajanus, 559).

Corchorus capsularis. Varieties with deep red (anthocyanin) stems, petioles and fruits have the teeth of the leaves also tipped with red. Other strains with less pigment in the stem have no colour in the leaf teeth (Finlow \& Burkill, 572).

Datura. D. Tatula has violet flowers and red stems (anthocyanin). D. Stramonium has white flowers and green stems (Saunders, 475, 487).

Digitalis purpurea. The presence of a factor, M, for magenta pigment always brings with it colour in the spots on the lower inner surface of the corolla. Even in the presence of II the general colour in the corolla may be inhibited by another factor I, but the spots remain red (var. white spotted with magenta). If $M$ is absent, the spots are colourless (Keeble, Pellew \& Jones, 542; Saunders, 563).

Gossypitim. In the Indian cotton, strains having yellow flowers, or white flowers with only a basal spot on the petals, have green foliage. In strains having red pigment, the varieties having red flowers (forms homozygous for the reddening factor, see p. 166) have the veins and lamina of their leaves suffused with red. In leaves of the plants which have flowers red on yellow, or red on white (forms heterozygous for the reddening factor) the anthocyanin is confined to the veins (Leake, 561).

Helianthus. In the wild $H$. annures the disk is purple, the colour (anthocyanin) being in the tips of the paleae, the margin of the corolla and the styles and stigmas. The 'Russian Sunflower' has the tips of the paleae yellowish-green, the corolla, styles and stigmas yellow (Shull, 520).

The chestnut-red-flowered Sunflower, which has anthocyanin on yellow in the ray florets, has dark reddish-purple stems. The purpleflowered variety, anthocyanin on primrose, has no reddish-purple in the stems (Cockerell, 611).

Lathyrus odoratus. The albinos always have green leaf-axils. When a certain factor for production of colour in the axils is present and the flowers are coloured, there is a reddish-purple spot in the axil; when the axil colour factor is absent, the axils are green (Bateson, 524). Red tendrils are (?) always associated with red in the axils of leaves (Bateson, 499).

Oenothera. In the variant Oenothera mbricalyx red buds and hypanthia are said to be associated with red stems (Gates, 5.5)). In 
the $\mathrm{F}_{1}$, however, from reciprocal crosses between $O$. mubricalyx $\times O$. Lamarckiana, plants appeared in which red buds were associated with a low degree of red pigmentation in stems and rosettes, whereas pale red buds and green hypanthia were associated with brilliant red stems, and buds entirely free from anthocyanin with dark stems (Shull, 609).

Pisum sativum. White-flowered plants have no colour in the leafaxils and no red or purple (anthocyanin) colour in the testas. Redflowered plants have red colour in the leaf-axils and red spots on the testa. Purple-flowered plants have purple colour in the leaf-axils and purple spots on the testa (Lock, 518).

Primula sinensis. Recessive white-flowered varieties may have green or red stems (Keeble \& Pellew, 541). Pale-flowered varieties may be on green or faintly coloured stems; deep-flowered varieties appear on deep red stems only; whereas light-flowered varieties may be borne on either deep- or light-stemmed plants. The 'Sirdar' variety, in which the pigment is in minute dots and the edges of the petal are white, has stems with a red 'collar,' i.e. base of stem. If the flowercolour is crimson or magenta, the stem colour is purplish-red; if the flower is true red ('Orange King') the stem pigment is also true red. Blue flowers have blue stem pigment.

The deep spots of colour external to the eye are not fully developed unless the stigma is coloured. They are deeply-coloured only in deeply-coloured flowers: in light flowers they are similar to those in flowers with a green stigma. They also depend on base colour as they are not present in pale flowers, nor in striped flowers, unless the stripe occurs in the area occupied by the spot (Gregory, 557).

Sulvia Hominum. The bracts of the inflorescence are purple, red, or green according to whether the flowers are purple, red, or white (Saunders, 487).

Zea Mays. Red pigment may appear in the pericarp, cobs and silks (stigmas) separately and independently in each part. If the glumes are red, red is present in some other part of the plant, though it may only be in the silks (East \& Hayes, 553; Emerson, 554).

The various relationships between flower-colour and the presence of anthocyanin in the vegetative organs may therefore be classified as follows:

1. Simple case. Loss of colour in the flower accompanied by total loss from vegetative organs. Ex.: true albinos of Antirrlinum, Atropa, Lathyrus, Pisum, Primula, etc. 
$2(A)$. Loss of the B factor from the flower will give red anthocyanin. Accompanying this there is a corresponding change in the pigment of the stem and leaves. Ex. Antirhinum: rose doré and bronze varieties; the same red pigment is developed in the stem and leaf. Primula sinensis: 'Orange King'; the same pigment appears in the stem and petioles. Salria Horminum: red-flowered plants have red inflorescence bracts. Prsum: red flowers are accompanied by red spots on the testa and red leaf-axils.

$2(B)$. Blue-flowered varieties of Primula sinensis develop blue anthocyanin in the stem.

3. In pale varieties (flower-colour), there is less anthocyanin in the stems and leaves. Ex. Primula sinensis: pale varieties and faintly coloured stems; light-flowered varieties and light stems; 'Sirdar' flower-colour and the pigment in the collar of the stem. Gossypium (Indian): plants with petals with a basal spot have green leaves; plants with red petals have leaves suffused with red.

4. Deep varieties. Ex. Antirrhinum: the deepest flower-colours have red leaves and stems. Primula sinensis: deep flower-colours have deep red stems.

Then follow the more complex cases in which pigmentation in different organs appears to be inherited independently, either partially or completely. Ex. Helianthus: flower-colour apart from stem colour in the purple variety. Lathyrus odoratus: coloured flower and coloured leaf-axil; yet at the same time there may be coloured flowers and a colourless leaf-axil. Oenothera: red bud pigmentation with green stems; green buds with red stems. Primula sinensis: white flowers and red stems. Zea Mays: independent inheritance of colour in cobs, pericarp, silks, etc.

\section{Heterozygous Forms.}

Just as in the case of factors for other characters, so also in the case of factors concerned with pigmentation we find heterozygous forms. The one of most frequent occurrence is that due to the inheritance in the zygote, from one parent only, of the factor which actually produces colour (anthocyanin). We find it, for instance, in the following genera :

In Atropa Belladonna: when the red-stemmed, brown-flowered type is crossed with the green-stemmed, yellow-flowered variety, the colour in stems and flowers of $\mathrm{F}_{1}$ is less intense than the parent (Saunders, $475)$. 
In Corchorus capsularis: when deep red-stemmed varieties are crossed with green-stemmed varieties, the colour in stems of $\mathbf{F}_{1}$ is less intense (Finlow \& Burkill, 572).

In the cross Datura Tatula, with red stems and purple flowers, by D. Stramonium, with green stems and white flowers, the colour in flowers and stems in $\mathrm{F}_{1}$ is less intense (Saunders, 475).

In Egyptian cotton, Gossypium: when the variety with a spot on the leaf is crossed with the non-spotted variety, the spot in $F_{1}$ is paler in colour (Balls, 515, 523).

In Indian cotton: when strains with anthocyanin in the vegetative parts are crossed with green-leaved strains, the colour in leaves and stems in $\mathrm{F}_{1}$ is paler (Leake, 561).

In Linum usitatissimum: a cross between a blue-flowered and a white-flowered variety gave an $F_{1}$ with paler blue flowers than the parent (Tammes, 564).

On the other hand, in many cases where there are factors producing colour (anthocyanin) no heterozygous forms at all exist, as in Lathyrus and Matthiola.

Cases, fundamentally different, though giving a similar result to those above, are those in which the type has anthocyanin inhibition by an inhibiting factor, and the variety has lost the inhibitor and produces anthocyanin. When the type is crossed with variety, the $F_{1}$ is heterozygous for the inhibitor and is less intensely coloured than the parent. Examples of such are the $\mathrm{F}_{1}$ from Coreopsis tinctoria with yellow (plastid pigment) flowers and the variety brunnea (anthocyanin on plastids) (de Vries, 474); the $\mathrm{F}_{1}$ has paler flowers than brunnea; also the $F_{1}$, probably, from the yellow Sunflower by its chestnut-red variety.

Somewhat similar, though not strictly comparable, is the case in Primula sinensis where whites tinged with anthocyanin are obtained in $\mathrm{F}_{1}$ from the cross-dominant white $\times$ fully-coloured variety (Gregory, $557)$.

In connection with the class mentioned above which is heterozygous for the factor for colour, Antirrhinum offers an interesting illustration. Colour, i.e. anthocyanin, in Antirrhinum is produced by the action of one factor, L, which gives ivory tinged with magenta, but there is no apparent difference in the flower-colour between individuals of the composition LL and Ll. In the presence of an additional factor D, a deepening factor, the zygote develops more pigment and is a deeper colour, but the ultimate colour depends on whether the zygote is homozygous or heterozygous for $\mathrm{L}$, its condition as regards $\mathrm{D}$ having no 
effect; thus $\operatorname{LIDD}(\mathrm{d})$ is pale magenta, and $\operatorname{LLDD}(\mathrm{d})$ is intermediate magenta.

A second heterozygous form in Antirrhinum is also interesting. Individuals heterozygous for the striping factor have magenta stripes on a tinged ground, individuals homozygous for the striping factor, magenta stripes on an ivory ground (Wheldale, 535).

Mirabilis Jalapa is of special interest in this connection since it is a species. in which individuals heterozygous for any of the factors so far identified have a heterozygous form, and this applies, not only to the factor converting yellow chromogen into anthocyanin, but also to the factor for the presence of chromogen (Marryat, 533).

In Indian cotton, individuals heterozygous for the factor which produces anthocyanin in the flower have this pigment diffused through part only of the petal, whereas homozygotes have anthocyanin throughout the flower (Leake, 561).

In some strains of Phaseolus, plants which are heterozygous for mottling with anthocyanin in the testa have mottled seeds, whereas homozygotes in this factor have self-coloured purple seeds (Shull, 521). It is at the same time well known that homozygous true-breeding mottled races do exist, and Emerson has attempted to explain this anomaly by postulating two factors concerned in mottling.

\section{Colour Factors in Redupitcation Series}

It was first observed by Bateson \& Punnett $(549,550)$ that in the case of certain factors, which for the moment we may call $A$ and $B$, the nature of the $\mathrm{F}_{2}$ generation varies according to whether $\mathrm{A}$ and $\mathrm{B}$ are carried into the $\mathrm{F}_{1}$ heterozygote by the same gamete or by different gametes. Thus if the heterozygote $\mathrm{AaBb}$ is formed from the gametes $\mathrm{AB}$ and $\mathrm{ab}$, then the gametes of the heterozygote are not formed in the proportion

$$
1 \mathrm{AB}: 1 \mathrm{Ab}: 1 \mathrm{aB}: 1 \mathrm{ab}
$$

but may be formed in the following proportions:

$$
\begin{aligned}
& 3 \mathrm{AB}: \mathrm{Ab}: \mathrm{aB}: 3 \mathrm{ab} \\
& 7 \mathrm{AB}: \mathrm{Ab}: \mathrm{aB}: 7 \mathrm{ab} \\
& 15 \mathrm{AB}: \mathrm{Ab}: \mathrm{aB}: 15 \mathrm{ab}, \text { etc. }
\end{aligned}
$$

If, on the other hand, the heterozygote is formed from the gametes $\mathrm{Ab}$ and $\mathrm{a} \mathrm{B}$, the gametes from the heterozygote so derived are produced in some one of the following proportions: 


$$
\begin{aligned}
& \mathrm{AB}: 3 \mathrm{Ab}: 3 \mathrm{aB}: \mathrm{ab} \\
& \mathrm{AB}: 7 \mathrm{Ab}: 7 \mathrm{aB}: \mathrm{ab} \\
& \mathrm{AB}: 15 \mathrm{Ab}: 15 \mathrm{aB}: \mathrm{ab}
\end{aligned}
$$

'Coupling' was the term first emploved for the phenomenon observed among the offspring for the heterczygote AB.ab, 'repulsion' for the phenomenon from the heterozygote Ab.aB. The terms are now rejected in favour of the expression 'reduplication.'

From evidence first obtained, it was thought that the repulsion was complete, but later evidence is strongly in favour of partial repulsion such as is expressed above.

\begin{tabular}{|c|c|c|c|c|c|}
\hline \multicolumn{4}{|c|}{ Gametic series } & \multirow{2}{*}{$\begin{array}{c}\text { Number } \\
\text { of } \\
\text { gametes } \\
\text { in series }\end{array}$} & \multirow{2}{*}{$\begin{array}{c}\text { Number } \\
\text { of } \\
\text { zygotes } \\
\text { formed }\end{array}$} \\
\hline$\widehat{A B}$ & $\mathbf{A b}$ & $\mathrm{aB}$ & $\overline{a b}$ & & \\
\hline 1 & $(n-1)$ & $(n-1)$ & 1 & $2 n$ & $4 n^{2}$ \\
\hline 1 & 31 & 31 & 1 & .64 & 4096 \\
\hline 1 & 15 & 15 & 1 & 32 & 1024 \\
\hline 1 & 7 & 7 & 1 & 16 & 256 \\
\hline 1 & 3 & 3 & 1 & 8 & 64 \\
\hline
\end{tabular}

The relation between the gametic and zygotic series for a few terms is explained in the following table:

\begin{tabular}{|c|c|c|c|c|c|c|c|c|c|}
\hline 3 & 1 & 1 & 3 & 8 & 64 & 41 & 7 & 7 & 9 \\
\hline 7 & 1 & 1 & 7 & 16 & 258 & 177 & 15 & 15 & 49 \\
\hline 15 & 1 & 1 & 15 & 32 & 1024 & 737 & 31 & 31 & 225 \\
\hline 31 & 1 & 1 & 31 & 64 & 4096 & 3009 & 63 & 63 & 961 \\
\hline 63 & 1 & 1 & 63 & 128 & 16384 & 12161 & 127 & 127 & 3969 \\
\hline$(n-1)$ & 1 & 1 & $(n-1)$ & $2 n$ & $4 n^{2}$ & $3 n^{2}-(2 n-1)$ & $2 n-1$ & $2 n-1$ & $n^{2}-(2 n-$ \\
\hline
\end{tabular}

\begin{tabular}{crrr} 
Nature of zygotic series & \\
AB & \multicolumn{1}{c}{ Ab } & \multicolumn{1}{c}{ a B } & ab \\
$2 n^{2}+1$ & $n^{2}-1$ & $n^{2}-1$ & 1 \\
2049 & 1023 & 1023 & 1 \\
513 & 255 & 255 & 1 \\
129 & 63 & 63 & 1 \\
33 & 15 & 15 & 1
\end{tabular}

Partial repulsion from zygote of form $\mathrm{Ab} \times \mathrm{aB}$

Only those cases connected with anthocyanin pigmentation are quoted in this account. As it happens, the first example noticed of these phenomena was in the Sweet Pea (Lathyrus) from $\mathrm{F}_{1}$ plants heterozygous for blue and red colour, and for long and round pollen. The blues were, for the most part, long-pollened, and the reds, for the most part, round-pollened. The partial coupling was shown to be:

$$
7 \mathrm{BL}_{\mathrm{s}}: 1 \mathrm{BI}: 1 \mathrm{bL}: 7 \mathrm{bJ}
$$

where $B$ is blue colour, and $\mathrm{L}$ is long pollen.

The second example was that of $\mathrm{F}_{1}$ plants heterozygous for dark and light axils, i.e. pigmented (anthocyanin) and unpigmented axils, and fertile and sterile anthers. The coupling was shown to be

$$
15 \mathrm{DF}: 1 \mathrm{Df}: 1 \mathrm{dF}: 16 \mathrm{df}
$$

where $\mathrm{D}$ is dark axil, and $\mathrm{F}$ is fertile anthers.

The first example of repulsion was noted in the $F_{2}$ from a plant heterozygous for blue and red flowers, and for erect and hooded 
standards. No red hooded individual was found. Also in the cross between a dark-axilled plant with sterile anthers (Df) and a lightaxilled plant having normal anthers $(\mathrm{dF})$, i.e. the converse of the case quoted above, no sterile light-axilled plants were found.

As previously mentioned, the repulsion cases were originally thought to be total, and, on consulting the above table, it will be seen that, unless the repulsion is of small intensity, the form aabb is very rare. There is, however, some evidence that the case of blue colour and long pollen is of the $1: 7$ order. This case is the reverse of that quoted above and occurs in the $\mathrm{F}_{2}$ from the cross-- $\mathrm{BI} \times \mathrm{bL}$. One red roundpollened plant was found in 419 individuals. The coupling, as we have seen, is on the $7: 1: 1: 7$ system. The coupling between blue and erect standard, i.e. from $\mathrm{BE} \times$ be, is of the $127: 1: 1: 127$ system, so that if there should be the same intensity in the coupling and repulsion systems, the number of plants required to give 1 hooded red would be 65,536 , which would lead to the impression first gained, i.e. that there is total repulsion.

Gregory (558) has also discovered a case of coupling in Primula sinensis between magenta colour and short style, which are dominant respectively to crimson colour and long style; the case is on the $7: 1$ system. There is also evidence of partial coupling with a third factor which suppresses the development of pigment in the stigma, giving rise to the dominant green stigma. Yet another instance of complete repulsion is that between the above-mentioned factor suppressing colour in the stigma and a factor suppressing colour in the stem. Thus a heterozygote from $\mathrm{L}$ stem $\mathrm{r}$ stigma $\times g$ stem $\mathrm{g}$ stigma gave no plants with red stem and red stigma.

It is not proposed here to enter further into the complexities of the question of reduplication though one more point may just be mentioned. In a recent paper ${ }^{1}$, Trow has suggested a distinction between what he calls primary and secondary reduplication series. Thus, he says, if we take a case of three factors, A, B and C, where there is reduplication between $\mathrm{A}$ and $\mathrm{C}$ of the form $\mathrm{n}: \mathrm{l}: \mathrm{I}: \mathrm{n}$, and between $A$ and $B$ of the form $m: 1: 1: m$, then the secondary form of reduplication derived from these primary ones, and denoting the relation between $\mathrm{B}$ and $\mathrm{C}$; has theoretically the form

$$
\mathrm{nm}+\mathrm{l}: \mathrm{m}+\mathrm{n}: \mathrm{m}+\mathrm{n}: \mathrm{nm}+\mathrm{l} \text {. }
$$

Experimentally this hypothesis appears to fit the above-mentioned case occurring in Primulu sinensis (Gregory, 558) between the three

1 Trow, A. H., 'Forms of Reduplication,' J. Genetics, Cambridge, 1913, II, pp. 313-324. 
factors M (magenta, dominant to crimson, colour), S (short, dominant to long, style) and $\mathrm{G}$ (green, dominant to red, stigma). The $\mathrm{MG}$ reduplication is of the form $2: 1$, the MS of the form $7: 1$; the secondary reduplication, SG, calculated on the above hypothesis, should be $5: 3: 3: 5$, and this is fairly near the experimental result. Further confirmation of Trow's hypothesis is also given by results published by Punnett (599) for the Sweet Pea crosses, BEL $\times$ bel and BeL $\times$ bEI, where $\mathrm{B}$ is blue, dominant to red, colour, $\mathrm{E}$ erect, dominant to hooded, standard, and L, long, dominant to round, pollen.

\section{Pattern in Colour Variation}

Most of the following cases have been mentioned in the previous accounts, but they are enumerated again here for the convenience of reference. Pattern generally implies the localisation of pigment. in definite areas.

Antirrhinum majus. The 'delila' variety may perhaps be regarded as an instance of pattern. For every variety with anthocyanin there is a corresponding 'delila form,' that is one in which the lips are coloured but the tube is ivory; there is always a sharp line of demarcation at the point of union of the tube and lips (Wheldale, 535).

Arum maculatum. The black spots (anthocyanin) on the leaf are probably due to a Mendelian factor which is dominant to the lack of spots (Colgan, 552).

Cypripedium (Paphiopeditum). Patterns of spots or stripes (anthocyanin) may be present. On crossing, there is segregation into striped and spotted; the former appears to be dominant (Hurst, 502).

Digitalis purpurea. The presence of spots on the inner lower surface of the corolla is bound up with the presence of pigment in the corolla generally. The ground colour of the corolla can be inhibited by an inhibiting factor, but not the spot colour (Keeble, Pellew \& Jones, 542).

Erodium cicutarium. A variety occurs without patches at the base of the petals (de Vries, 565).

Gentiana punctata. There is a variety in which the dark patches in the flower are absent (de Vries, 565).

Gossypium. The red anthocyanin 'spot' on the leaf is a Mendelian character, and is less intense in the heterozygous forms. In Indian cotton a red spot on the flower is characteristic of the heterozygote, but an almost completely red flower is characteristic of the homozygote (Balls, 515, 523; Leake, 561).

Mimulus quinquevulnerus. "Here the dark brown spots vary between 
nearly complete deficiency up to such predominancy as almost to hide the pale yellow ground-color" (de Vries, 498).

Papaver orientale. The dark patches of anthocyanin at the base of the petals are absent in some varieties (de Vries, 565).

$P$. Rhoeas. In some varieties there is a white margin to the petals due to the presence of a dominant inhibiting factor (Shull, 588).

$P$. somniferum. Some varieties have dark basal patches of pigment (anthocyanin) on the petals. From others it is absent. On crossing dark "'Mephisto' with the white-hearted 'Danebrog' the hybrid shows the dark pattern" (de Vries, 498).

Phaseolus. In some strains the mottling of anthocyanin in the testa is due to a factor $\mathrm{M}$, but the pattern only shows when the plant is heterozygous for M. In other strains the mottling occurs in both heterozygous and homozygous forms (Emerson, 528, 529; Shull, 513, 521; Tschermak, 479, 590).

Pisum. The mottling of anthocyanin in the testa is due to a definite Mendelian factor (Lock, 518).

Primula sinensis. The patches of anthocyanin outside the yellow eye are a definite Mendelian character. They do not develop to their fullest intensity unless the stigma is red, or the flower is deep-coloured; the spots are pale in pale-coloured flowers and in flowers with a green stigma.

The 'Duchess' distribution of pigment, i.e. a ring of colour round the eve, spreading to a flush, may be regarded as pattern. So also the 'Sirdar' variety, where the colour is present in minute dots giving the flower a dusty appearance, the margins of the petals being white (Gregory, 557).

Solanum tuberosum. The flowers of several white varieties have 'tongues' of colour radiating out from the throat to the tips of the corolla segments. The 'tongues' show different degrees of intensity of coloration, governed, probably, by different factors (Salaman, unpublished work).

Tropueolum majus. There is at present no published work on the flower colour of this genus but, as far as observations go, there is a definite inheritance of the blotch at the base of the petals. The original type has an orange-red (anthocyanin and yellow plastids) flower, rather deeper in colour at the base of the petals, and with dark 'honey-guides' running into the 'claw.' There are varieties in which the anthocyanin has disappeared from the main part of the flower so that the flower is yellow with orange-red blotches at the base of the petals. If the 
flower-colour varies to pale yellow (see p. 150) the orange-red blotch then appears as carmine. The red anthocyanin may give rise to a purple variation and there are correspondingly coloured blotches, maroon on a deep yellow and purple on a pale yellow ground.

Reviewing the cases of pattern set out above we are able to distinguish several different types. One type, for instance, includes all those spots, lines and streaks which form a normal part of flower-coloration and which, in the opinion of biologists, have a significance as signals or guides to insect visitors. This group would include the markings in Cypripedium, Digitalis, Erodium, Mimulus, Pupaver, Primula and Tropaenlum. As far as can be judged from the evidence at hand, some of these patterns (Papaver, Tropaeolum) are inherited independently of the ground colour of the flower; the factors for others are intimately associated in various ways with the ground-colour factors (Digitalis, Primula). A second type of pattern is that which is not a feature of the normal flowercoloration, but is only revealed in varieties from which some of the colour factors are absent, for example the 'delila' variety of Antirrhinum and the 'Duchess' and 'Sirdar' varieties of Primula. A third type of pattern, for instance the spots on Arum leaves, the leaf-spot of Gossypium and the mottling of seeds of certain strains of Pisum and Phaseolus, forms a normal attribute of the plant to which we can assign no special significance.

As regards the nature of the factor which produces mosaics or mottling in seed-coats we cannot at present offer any interpretation. It apparently limits the distribution of colour to certain areas; whether this is due to inhibition of pigment, or whether it is due to the fact that the pigment formed in the plant is less, and hence insufficient to give self-colour, cannot be decided. But it is evident that the mottling factor is one apart from colour and can be carried by albinos. Bateson (524) draws an interesting comparison between colour-pattern and dilution. In both cases, he points out, less pigment is present in the zygote, but in one case the area is diminished though the intensity remains the same, in the other: the intensity is diminished, but the area of coloration is constant.

\section{Striped Varieties and Bud-Variation.}

A common form of variation in many flowers is striping, i.e. the arrangement of colour in bands or stripes; these markings may vary in thickness from the narrowest hair-like streaks to broad bands, or elongated patches, which may then occupy almost the whole of the 
flower. It is difficult to define the limits of striping for, on the one hand, among striped varieties we frequently find sectorial variations in which colour is definitely and symmetrically confined to a half, a third, or some other fraction of the flower. On the other hand, striping may pass into spotting or blotching, and it is questionable whether spotted and blotched flowers. should be placed in the same category, though their genetical behaviour may be similar. Some of the genera and species in which striping occurs are the following:

Antirrhinum majus,

Cheiranthus Cheiri,

Dahlia variabilis,

Dianthus Caryophyllus,

D. barbatus,

Mirabilis Jalapa,
Papaver,

Petunia,

Primula sinensis,

Tageles,

Tulipa,

Zinnia elegans.

As further examples of striping and sectorial variation, we may add those mentioned by de Vries (565), i.e. Celosia variegata cristata (inflorescence), Centaurea C'yamus, C'lartiva pulchella, Convolvulus tricolor, Cyclamen persicum, Delphinium Ajacis, D. Consolida, Geranium pratense, Helichrysum bracteatum, Hesperis matronalis, Impatiens Balsamina, Nemophita insignis, Papaver nudicaule, Portulaca grandiflora and Verbena.

Striping may be regarded as a variation under normal conditions ${ }^{\mathbf{1}}$; there is, however, a kindred phenomenon called flaking which appears in flowers, otherwise self-coloured, towards the end of the vegetative season, or when the plant is in an unhealthy condition. Ex. Dahlia (Hildebrand, 458, 466), Matthiola.

Striping is apparently not a phenomenon which occurs in plants in the wild state, and, according to the theory of Louis Vilmorin, as expounded by de Vries (565), it only appears in coloured plants which have already produced a white or yellow variety, that is a variety free from anthocyanin pigment. It is certainly true that striping is most usual in connection with anthocyanin; as a rule it is not shown by soluble yellow pigments (Antirrhinum, Althaea), though in Papacer nudicaule, according to de Vries (565), one finds a yellow variety with dark orange stripes. In Mirabilis, also, yellow pigment may be found striped upon a white ground. Flowers with yellow plastids rarely, if ever, occur in the striped condition; such yellow flowers may, however, occasionally show light segments containing paler derivative plastid

1 De Vries (565) notes, however, that striping in Camellia japonica may depend on the time of flowering. 
pigments. The common form of striping is that of anthocyanin on an albino ground, either white (Primula sinensis) or yellow; the yellow may be a soluble pigment (Antirrhinum majus var. yellow striped crimson), or a plastid pigment (Cheiranthus Cheiri, Tagetes, Tulipa spp.). Less commonly one finds deep anthocyanin stripes on a pale anthocyanin ground of the same colour (Antirrhinum, see p. 160), or stripes of one coloured anthocyanin on the ground of another colour, as in the case mentioned by de Vries (565) of Delphinium Consolida striatum plenum in which the flowers may be red striped with blue ${ }^{1}$. Mirabilis Jalapa presents a remarkable series of striped varieties: there may be stripes of magenta (anthocyanin) on a white ground, or of soluble yellow pigment on a white ground, or both magenta and yellow stripes on white (tricolour). Moreover Mirabilis is characterised by a number of heterozygous forms, and we may find a homozygous stripe-colour on a heterozygous ground-colour, for instance, deep yellow stripes on a pale yellow, or orange-red stripes on a magenta-rose ground (Marryat, $533)$.

Another curious phenomenon is the limitation of striping in most species to one colour, for instance in Antirrhinum the anthocyanin of rose doré and bronze varieties does not occur in stripes, and the same is true of the pale 'tingeing' of anthocyanin. It is only the factor for full colour that is affected by the striped condition.

With regard to sectorially coloured flowers de Vries (565) notes that they appear to manifest a tendency towards a simple proportion between the two parts. "Frequently exactly half of the flower is atavistic, sometimes a quarter or three quarters. I observed the proportion $\frac{3}{8}$ in white and red striped tulips and in partially dark blue and partially pale blue flowers of Iris xiphioides, etc."

The inheritance of striping has received a certain amount of attention. De Vries (565) has investigated the problem in Antirrhinum and other striped flowers. He noted that the striped variety of the larkspur (Delphinium Ajacis and D. Consolida) produces self-coloured flowers as well as striped ones; the self-coloured, moreover, may appear on the same racemes as the striped ones, or on different branches, or some seedlings from the same parent may be self-coloured while others are striped. Seeds, on the other hand, of these blue sports give rise again to the striped variety. Such a variety as this Larkspur, de Vries called 'eversporting,' for as he says: "Here the variability is a thing of absolute constancy, while the constancy consists in eternal changes." His more

1 There is also a tricolour of red, white and blue. 
definite cultures were made with Antirrhinum majus luteum nubrostriatum. In Antirrhinum (see p. 160) the flower may be ivory striped with magenta anthocyanin, or yellow striped with crimson, this latter colour being merely magenta superposed upon yellow; the yellow pigment (luteolin) does not show striping. In the offspring of de Vries' plant, which was yellow striped with crimson, there were no pure yellows, though all grades of striping were found, ranging from yellow, with a few of the finest stripes, through intermediates, to those with the broadest stripes, or even whole sections of red; and with these occurred a certain number of pure red flowers. The red flowers will appear suddenly as a sport (though without graduated links with striped forms) among the striped individuals, and conversely, the striped flowers will appear among the offspring of the self-form. Thus red can be obtained from striped, and striped from red, and both variations can be obtained by seed; but de Vries noted bud-variations and variations within the spike, only in striped individuals, though he is of the opinion that they might be found on red plants if sufficiently large numbers of individuals were dealt with.

The following table ${ }^{1}$ represents the successive families obtained by de Vries from one striped plant:

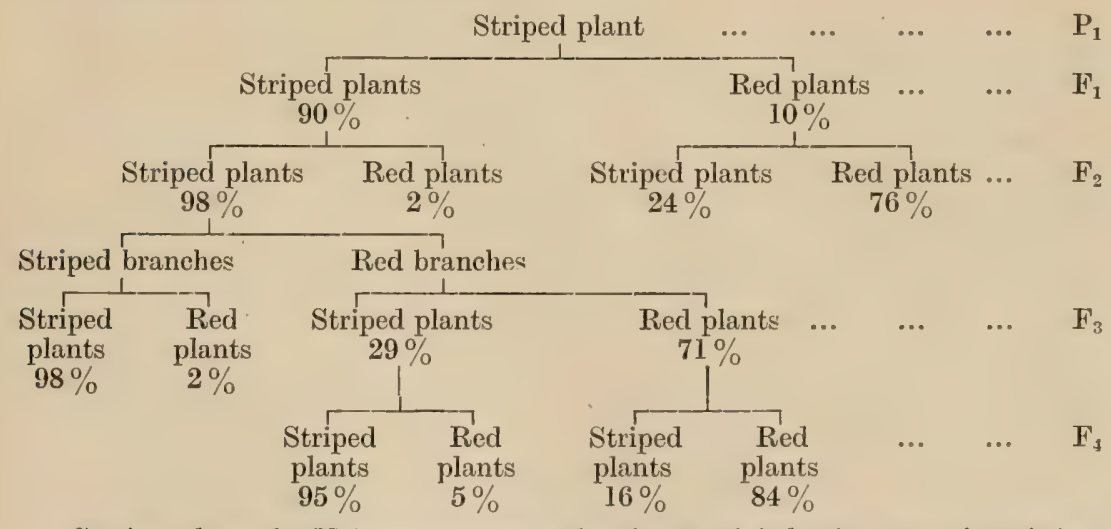

So far then de Vries expresses the facts of inheritance of striping thus:

1. The striped race is an inconstant one and consists of striped and red-flowered plants.

2. Striping itself varies continuously, but there is discontinuity between the striped and red forms.

3. The intensity of inheritance of finely striped plants is about ${ }^{1}$ See also Emerson (605)

w. P 
$95-98 \%$, and they give rise to the red type either by seed or bud variation.

4. The broadly-striped individuals produce more reds than the narrow-striped, the average being about $39 \%$.

5. The red individuals thrown by the striped resemble the red type, but differ in again throwing striped. The intensity of inheritance of the red character is about $70-85 \%$.

6. The yellow variety (without anthocyanin) does not arise from the striped race.

De Vries draws attention to the fact that striped varieties do not occur in nature. Other examples he gives of striping are in Stocks, Liver-leaf (Hepatica), Dame's Violet (Hesperis), Sweet William (Dianthus barbatus) and Periwinkle (Vinca minor); also in Hyacinthus, Cyclamen, Azalea, Camellia, and in the Meadow Crane's-bill (Geranium pratense) when cultivated. Also these, he says, are known to come true to striping when seed is taken from striped individuals, and from time to time to throw self-coloured individuals. He made pedigree cultures of the Dame's Violet (Hesperis mutronalis) for five years, and of Clarkia pulchella for four years, and they both behaved in exactly the same way as Antirrhinum. He further points out that other parts of plants may be striped, as, for instance, the red and white striped roots of Radishes, and the inflorescence of the Cockscomb (Celosia cristata).

From these results one would gather that the inheritance of striping is non-Mendelian. More recently Emerson (605) has suggested that striping, on the basis of a certain hypothesis, may conform to the Mendelian scheme of inheritance. It appears that ears of certain varieties of Maize show striping in the red pigment developed in the pericarp. Fmerson says: "Plants in which this pigment has a variegated pattern may show any amount of red pericarp, including wholly selfred ears, large or small patches of self-red grains, scattered self-red grains, grains with a single stripe of red covering from perhaps ninetenths to one-tenth of the surface, grains with several prominent stripes and those with a single minute streak, ears with most of the grains prominently striped and ears that are non-colored except for a single partly colored grain, and probably also plants with wholly self-red and others with wholly colorless ears." A number of selfings were made for several generations of both homozygous and heterozygous variegated cobs; homozygous and heterozygous variegated cobs were also crossed with true-breeding white male plants. From his experiments Emerson deduces the following results: 
1. That the amount of pigment in the pericarp of a variegated grain bears a definite relationship to the amount of pigment in the grains of the plant which grows from it. The relationship is such that the more red pigment there is in the grains planted, the more likely are the plants which come from them to produce self-coloured red ears, and the less likely to produce variegated ears.

2. That when $F_{1}$ red ears produced by selfing a homozygous variegated-eared plant are selfed and sown they give rise to red-eared and variegated-eared plants in Mendelian proportions; in the same way when crossed with white-eared races, they behave as if they had been produced by a cross between red-eared and variegated-eared races.

3. That the $\mathrm{F}_{\mathbf{1}}$ red ears arising from selfed heterozygous variegatedeared plants behave in some cases as if they were hybrids between red-eared and variegated-eared races, and in other cases as if they were hybrids between red-eared and white-eared races.

4. That the $\mathrm{F}_{1}$ reds arising from crosses between both homozygous and heterozygous variegated-eared plants and white-eared races behave as if they were hybrids between red-eared and white-eared races.

Thus, says Emerson, any interpretation of the above results must take into account these facts: (1) that the more red there is in the pericarp, the more frequently do red ears occur in the progeny; (2) that such red ears behave just as if they were $\mathrm{F}_{1}$ hybrids between red and variegated, or red and white races.

To explain these phenomena Emerson suggests the following hypothesis. The zygotic formula for a plant homozygous for variegated pericarp may be regarded as VV; heterozygous for variegated pericarp as $\mathrm{V}$-. If in any somatic cell $\mathrm{VV}$, from some unknown cause, a $\mathrm{V}$ factor were transformed into a factor for self-colour, $\mathrm{S}$, that cell would then be represented as VS. Any pericarp cells descended from such a cell would be red, and if all the pericarp cells of a grain were thus descended the grain would be self-red, just as if the plant bearing it were a hybrid between pure red and variegated races. Of the gametes, moreover, arising from such somatic cells, one-half would carry $\mathrm{V}$, and one-half $\mathrm{S}$, again just as if the plant were a hybrid between red and variegated races. If both the $\mathrm{V}$ factors were changed to $\mathrm{S}$, the grain would be red as before, but all, instead of half, of the gametes would carry S. If the modification from VV to VS should occur very early in the life of the plant, or even in the embryo, then all the ears of the plant might be self-red, and one-half of all the gametes, both male and female, might carry $\mathrm{S}$, and the other half $\mathrm{V}$ as in an ordinary hybrid. 
If the modification should occur much later, for instance when the ear is beginning to form, there might be then only a patch of red grains on a variegated ear, and only those gametes arising from these red masses of tissues would carry half $\mathrm{S}$ and half $\mathrm{V}$. Finally if the modification should occur after the grains begin to form, the latter would have broad or narrow stripes according to the amount of pericarp directly descended from the modified cell, and the larger the amount of modified tissue the greater the chance that the gametes concerned would carry S. Similarly in any cell of a heterozygous, variegatedeared plant, $\mathrm{V}-$, he assumes that the $\mathrm{V}$ factor may be changed to $\mathrm{S}$. The effect on the pericarp colour would be the same as before, and of the gametes arising from the modified tissue one-half, and never more, would carry S, the other half would carry no factor, and would be represented by - .

Emerson then applies his hypothesis to results obtained in the $\mathrm{F}_{2}$ and $F_{3}$ generations. As stated above $F_{1}$ red-eared plants which had arisen from selfed homozygous variegated ears gave in $\mathrm{F}_{2}$ only red-eared and variegated-eared offspring. On the hypothesis quoted, the constitution of the $\mathrm{F}_{1}$ red-eared plants would be either VS or SS, the former being more frequent than the latter on account of the rarity of $S$ in the $\hat{o}$ gametes. The $\mathrm{F}_{1}$ red ears tested were evidently of the composition VS. Of two $\mathrm{F}_{2}$ reds from selfed $\mathrm{F}_{1}$ 's, one gave reds and variegated, the other bred true to red. Hence the hypothesis is in accordance with the results. Again $\mathrm{F}_{1}$ red-eared plants which had arisen from heterozygous variegated selfed plants, as we have seen, behaved in some cases like hybrids of red and variegated races, in other cases like hybrids of red and white races. On the hypothesis that variegated-eared plants were $\mathrm{V}$ - and their red grains $\mathrm{S}-$, the $\mathrm{F}_{1}$ plants would be SV, SS, $\mathrm{S}-, \mathrm{V}-$, or - - . Of the $\mathrm{F}_{1}$ reds tested some were evidently $\mathrm{SV}$, and others $\mathrm{S}-$. Of the $\mathrm{F}_{2}$ reds, one bred true in $\mathrm{F}_{3}$, and others segregated into reds and variegated.

Finally when $\mathrm{F}_{1}$ red-eared plants arose from either homo- or heterozygous variegated ears that had been crossed with whites they gave only red-eared and white-eared oftspring, never variegated. By hypothesis the parent variegated-eared plants were $V-$ and $V V$, and the red grains S - and SV (or SS possibly) and the male parents were - - . The $\mathrm{F}_{1}$ plants therefore would be $\mathrm{S}-, \mathrm{V}-$ and - - , and only $\mathrm{S}$ - would be red-eared. The red-eared $\mathrm{F}_{1}$ plants tested gave redand white-eared in Mendelian ratios. Of the $\mathrm{F}_{2}$ red-eared, one bred true in $\mathrm{F}_{3}$, and the others segregated into reds and whites. 
Emerson further maintains that de Vries' results for striping in Antirrinum indicate that this case is of a similar nature to Zea. Also the results obtained by Correns (537) in striped-flowered plants of Mirabilis; these results show that plants with self-coloured flowers behave as if they had occurred in an $\mathrm{F}_{2}$ from a cross of striped by selfcoloured plants. But flowers from self-coloured branches on striped plants produce few, if any, more self-coloured plants than flowers on branches with striped flowers. As an explanation of this anomaly Emerson suggests that in the case of seed sports the factors for variegation are affected, whereas in somatic variations there is no corresponding change in the Mendelian factors.

A curious phenomenon in connection with striping in Antirrhinum is one noted by the author and previously mentioned (see p. 159). If the factor for tingeing with anthocyanin be denoted by $\mathrm{L}$, and the factor for full colour by $\mathrm{D}$, then $\operatorname{LLDD}(\mathrm{d})$ is magenta and $\operatorname{LIDD}(\mathrm{d})$ pale magenta. If in the striped variety we represent $D$ by $S$, then LLSS is ivory striped with magenta, LISS, ivory striped with pale magenta, LLSs is tinged ivory striped with magenta and LiSs tinged ivory striped with pale magenta. No explanation of this interesting result can be offered at present.

In Primula sinensis (Gregory, 557) striping appears to belong to a different category from that in Antirrhimum, Mirabilis, etc., for it behaves as a simple recessive to a self-coloured form.

Bearing in mind the facts just recorded one cannot fail to realise that the common occurrence of reversion to self-colour among striped varieties is but one expression of the much more widely distributed phenomenon of bud-variation. Of the latter there are a number of cases known, many of them involving pigmentation. Some are concerned with the distribution of chlorophyll, and these it is not necessary to consider here. Of those connected with anthocyanin there are several recorded by de Vries $(498,565)$, for instance in Ribes sanguineum, Veronica longifolia and others. Ribes sanguineum has red racemes of flowers and a certain amount of anthocyanin in its twigs and petioles, and there is a variety which has white flowers tinged slightly with red, while the vegetative parts lack pigmentation. Of the variation de Vries says: "Occasionally this white-flowered currant reverts back to the original red type and the reversion takes place in the bud. One or two buds on a shrub bearing perhaps a thousand bunches of white flowers produces twigs and leaves in which the red pigment is noticeable and the flowers of which become brightly colored. If such a twig is 
left on the shrub, it may grow further, ramify and evolve into a larger group of branches. All of them keep true to the old type." Another case is that of the hybrid from Veronica longifolia and its variety alba; the blue hybrid occasionally produces white flowers. We may also include the production of green-leaved branches by the purple-leaved Beech, Hazel, etc. Other cases are mentioned by Bateson (591): for example, Azalea, of which there are white varieties streaked with red giving rise to self-red sports. Also Pelargonium; here the variety altum which is normally red may produce very occasionally one or two magenta petals, and, conversely, there is a variety 'Don Juan' which may bear trusses or branches of red flowers, though the normal colour is magenta. Another case of exceptional interest is that in which an individual of the purple-winged 'Purple Invincible' variety of Lathyrus developed a flower of the variety 'Miss Hunt' which is lacking in the blue factor (Bateson, 524).

With regard to bud-variation there are several fundamental points to be borne in mind, and these have been well expressed by Bateson (524, 591) from whom the following quotations are taken. First: "when a bud-sport occurs on a plant, the difference between the sport and the plant which produced it may be exactly that which in the case of a seminal variety is proved to depend on allelomorphism." This is exemplified in the cases given above, i.e. in the presence or absence of factors controlling pigment formation (Antirrhinum, Ribes, Veronica, Fagus, etc.). Secondly, on consideration of these cases, we may arrive at the conclusion that the segregation of the allelomorphs which control the production of colour must have taken place at some somatic division, and "we are thus obliged to admit that it is not solely the reductiondivisions which have the power of effecting segregation." The third point is that: "The distribution of colour in this case (bud-variation) lies outside the scheme of symmetry of the plant." For "though the parts included in the sports show all the geometrical peculiarities proper to the sport-variety, yet the sporting-buds themselves are not related to each other according to any geometrical plan," just as striping itself in the Carnation or Antirrhinum is not under geometrical control. And it is precisely the plants with this disorderly arrangement of striping which so often give rise to bud-sports ${ }^{1}$

1 Bateson (591) notes a most interesting case of bud-variation in the Azalea Vervaeana. The flowers have symmetrical markings of one shade of red, and red streaks of another shade. When self-red sports arise they are of the shade of the red streaks, not of the symmetrical markings. 
At the present moment it is difficult to form any general conception of the mechanism of the change which underlies bud-variation. In a recent paper Emerson (629) describes the occurrence of anomalous seeds of Maize (Zea), two of which are concerned with pigmentation. In one, the seed was half colourless and half purple: in the other, half purple and half red. He admits that the occurrence of this phenomenon could be explained on the hypothesis that, subsequent to normal endosperm fertilisation, there occurs a vegetative segregation of genetic factors. But such a segregation, he maintains, cannot be typically Mendelian because in neither of the cases quoted are all the genetic factors (in a heterozygous condition) involved. He prefers to interpret the phenomenon as a somatic mutation, that is as a change in genetic constitution rather than a segregation of genetic factors. He proceeds to apply this conception to the case of bud-sports in general. His hypothesis in fact has already been mentioned in connection with striping in Zea and Antirrhinum. In his opinion the somatic mutation may be a gain of at least one new factor, the loss of a factor, or the permanent modification of a factor. Against the segregation hypothesis he brings the following considerations. In material homozygous with respect to the Mendelian factors concerned it is not possible for bud-sports to arise by segregation. Nor is it possible if a new character previously unknown to the species, should arise; nor if a dominant character appears as a bud-sport in material known to be homozygous in a recessive character which is allelomorphic to the dominant character in question (ex. striping in Zea). If however the bud-sport be due to the loss of a character, and the material be also heterozygous for the character, then the case can be interpreted equally well as a segregation or a mutation.

Bateson, on the other hand, inclines to the view that bud-sports are the result of somatic segregation, the sporting branches being the outgrowth from cells containing one only of the segregating factors. He also suggests that the phenomenon of striping may be due to the fact that there is an insufficient amount of the colour factor in the gametes to make the zygote self-coloured. And this may also apply to some cases of pattern (see p. 190). In these cases the more intimate the mixing, the more likely are the offspring to he striped, and this, as we have seen, is borne out by observations upon Zect and Antirrhimem. 


\section{The Effect of Outside Factors on Colour-variation.}

It has very often been stated that the colours of flowers are affected by the soil in which the plants are growing, and the belief is still prevalent. In any discussion upon the subject we generally meet with one or other of two illustrations of classical interest. One is the change of colour in Hydrangea (or Hortensia) flowers when the roots are supplied with some form of iron or aluminium salts; the other is the 'zinc Violet' which is a blue-flowered form of Viola lutea. This variety grows in a soil containing as much as $20 \%$ zinc oxide, and in the ash of the plant may be found $1 \%$ zinc oxide. Hence the idea arose that the 'zinc Violet' might derive its blue colour from the presence of zinc in the tissues. The effect of soils on Hydrangea must have been noticed at a very early date, for Schübler \& Lachenmeyer (429) in 1834 gave an account of analyses of soils which change the colour of the flowers. Trials have been made from time to time with other chemical substances upon other plants, but no striking results have been obtained. In view, however, of the value attached to such results, it may be well to give an account of some of the experiments.

As regards the 'zinc Violet,' Hoffmann was led to conclude that the presence of zinc had no influence on the colour, because, when transferred to another soil which did not contain zinc, the blue colour remained; the colour, moreover, may vary even when the soil contains zinc. Though practically only confirming the fact that colour-changes in Hydrangea are brought about by iron and aluminium salts, the work of Molisch (467) in this direction is important, since he treated the subject on an experimental basis. His method was to grow Hydrangea plants in pots and to mix with the soil the substances of which he wished to test the effect. The following table will give a general idea of his results:

Substance added to soil

Normal soil

Aluminium sulphate

Common alum

$\mathrm{Al}_{2}\left(\mathrm{SO}_{4}\right)_{3}+\mathrm{K}_{2} \mathrm{SO}_{4}+24 \ddot{\mathrm{H}}_{2} \mathrm{O}$

Ferrous sulphate ... ...
Colour of flowers

Red

... Strongly blue

Blue, sometimes bluish sometimes pink with blue filaments

Pink, bluish, or blue...
Remarks

Leaves became brown in some cases and died

In most cases, after a few days, the leaves turned brown and commenced to fall off 
Substance added to soil

Iron oxide (Hammerschlag) $\mathrm{Fe}_{3} \mathrm{O}_{4}$

Moor soil (from Wittingau in Bohemia)

Heath soil (from Cibulka near Prague)

Peat

Aluminium oxide, $\mathrm{Al}_{2} \mathrm{O}_{3} \cdots$

Iron filings

Iron shavings

Iron tacks ...

Ochre

Granulated rin

Tin foil (clippings)

Charcoal

Emery powder

Powdered slate

Powdered sulphur

Soda

Lime

Ferric chloride

Potassium sulphate

Ammonium sulphate

Manganese sulphate

Copper sulphate ..

Nickel sulphate ... ...

Cobalt sulphate ... ...

Zine sulphate

Potassium carbonate
Colour of flowers

Two plants bluish, the rest red

Blue

Red, with blue filaments

All red

$$
\text { ", }
$$

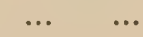

Some tendency to become blue in filaments and fruiting flowers

Leaves died in most cases after a week: plants weakly

Used in too large quantity

Leaves tended to fall off

Leaves became brown

Only one plant: red flowers
Substance very poisonous: plants died

Molisch found the filaments of the stamens very sensitive to the substance added, and notes that if one is in doubt as to whether any effect has taken place, one should examine these organs. In the case of alum, it is evidently the aluminium salt which is effective, since potassium sulphate produces no blue colour by itself. Aluminium sulphate alone, moreover, produced the most intense blue colour. Aluminium oxide has no effect on account of its insolubility, whereas in the slate there must be some slightly soluble iron or aluminium compound. From his researches Molisch draws the conclusion "dass Alaun, schwefelsaure 
Thonerde und Eisenvitriol die rothe Farbe der Hortensienblithe in die blaue umzuwandeln vermöge." He points out that the pigment of the flowers is anthocyanin, and in sections of the petals the colour is similarly turned blue on addition of solutions of iron and aluminium salts. He further emphasises the fact that all plant anthocyanins do not behave in the same way, and hence this may be one of the reasons why it has not been possible to change the flower-colour of other plants by adding salts to the soil.

In 1906, Kraemer (503) gives an account of a number of experiments which he made to test whether flower-colours can be modified by treating the soil with chemical substances. The compounds he used were: acetic acid, citric acid, malic acid, phosphoric and other acids; various iron salts, such as acetate, citrate, chloride and sulphate; certain aluminium salts, such as sulphate, phosphate, and the double salts of aluminium and potassium sulphate, and aluminium and ammonium sulphate; ammonia water, potassium hydrate, ammonium nitrate, potassium nitrate, potassium iodide, iodine and potassium cyanide. These were supplied in solution through the soil, beginning with $1: 10,000$ of water, and the strength gradually increased until $1: 1000$ of water was reached. Most of the substances could be supplied in this strength every five days for some months without injury to the plants. There were no marked effects. In yellow roses supplied with aluminium and potassium sulphate, the leaves and stems became slightly reddish. 'La France' roses treated with iron citrate and citric acid had uniformly pink petals. Some rather insignificant changes were noted in other plants. The scarlet carnation showed a tendency to form white streaks with iron and ammonium sulphate, aluminium phosphate, iron citrate and citric acid; also a maroon carnation treated with ferrous sulphate. The petals of a white carnation when fed with potassium and aluminium sulphate showed a tendency to form red streaks.

Later, in 1908, Vouk (522) repeated a number of experiments on the same lines as Molisch, using plants of Hortensia (Hydrangea hortensis). Vouk remarks, as a preliminary, that Miyoshi (? 187) has succeeded in changing the lilac colour of Cullistephus chinensis and Campanula alliariaefolia into blue, and the red of Lycoris radiata into lilac by artificial treatment. Of Molisch's experiments he observes that the leaves of the plants used were frequently injured, and this may be due to too large quantities of salts added. He therefore set out to determine (1) bow the change to blue colour is affected by different quantities 
of aluminium saits (potassium alum and aluminium sulphate): (2) what amount of salt is sufficient to bring out the blue colour without injury to the plant. His methods were to water plants with $.5 \%, 1 \%$, and $3 \%$ solutions of potassium alum and aluminium sulphate respectively. His results show that cultures watered with $3 \%$ potassium alum produced the finest blue colour, though the leaves were affected with brown spots. The $1 \%$ cultures he regarded as best, since the plants were quite sound, and there was at the same time almost complete blueing of the flowers. This was true for the same concentrations of aluminium sulphate, but the blue coloration was weaker. Hence Vouk does not agree with Molisch that aluminium sulphate has a better effect on the blueing than alum, but he maintains that the latter salt gives the most intense results. His experiments, moreover, show that the change of flower-colour depends, not only on the quality, but also the quantity of the salt used. Other experiments of a similar nature were tried with Phlox decussata but with no result.

Thus we may conclude that, with the exception of Hydrangea, there is no experimental evidence for the belief that chemical substances in the soil can materially affect flower-colour. There are accounts of various experiments where dyes have been employed, by means of root absorption, for colouring flowers, but the results are purely temporary and negligible as far as scientific interest is concerned. We may in this respect well agree with Nehemiah Grew (1) when he remarks: "From what hath heen said, we may likewise be confirmed in the use of the already known Rules, and directed unto others yet unknown, in order to the variation of the Colours of Flowers in their Growth. The effecting of this, by putting the Colour desired in the Flower, into the Body or Root of the Plant, is vainly talked of by some: being such a piece of cunning, as for the obteining a painted face, to eat good store of white and Red Lead."

Another set of experiments concerned with changes in flower-colour though involving a different external factor, viz. insolation, are those of Rawson (519). These experiments have been conducted upon Tropaeolum plants growing in South Africa and the principle followed was "to shade off with a perfectly opaque sereen all direct rays of the sun for certain intervals of daylight." Otherwise there was no other special treatment. By this means Rawson claims to have changed ordinary scarlet and orange varieties into a new mauve variety, and "no known instance occurred of its reverting to the original. Experiment so far goes to show that seeds from it after the second year may be 
planted in any aspect, and will come true even if sown in such different climates as those of York and Pretoria. The crimson variety similarly treated in York and in Pretoria gave the same flowers of a bronze oldgold colour in both places, and the seed of this latter variety brought from Pretoria and sown in York gave the same curious colour, in spite of the great difference of altitude between the two localities. Cuttings of the mauve variety could be grown in any aspect at Pretoria, without any change in the mauve colour of the flowers. In addition to the mauve and bronze old-gold colours, varieties of rose-salmon and of sallow flesh-colour have been obtained, and no difficulty has been experienced in changing any of the known orange, yellow, or scarlet flowers into these curious colours." In a later paper, Rawson (600) states that still further varieties have been obtained in England by adopting the same methods. Pending confirmation it is difficult to make anything of the significance of these facts.

\section{Connection between Colour and other Plant Characters.}

There is little doubt that albinism, the most common form of variation, brings with it in many cases a general weakness of constitution. The true albino (see p. 158) of Antirrhinum majus, for instance, is more stunted in growth than the coloured forms; it is also less resistant to cold, drought and other adverse conditions. In connection with this point there is a paragraph which may be quoted from the Flora Anomoia (1817) by Hopkirk (428). This author evidently believed that lack of robustness may cause variation for he says: "That these varieties of colour are produced very frequently by weakness, is evident from the circumstance of the variety being often much more tender than the original species. The white-flowered variety of the Virginian Spiderwort (Tradescantia virginica) is with difficulty preserved in the open air during winter, whilst the blue is perfectly hardy; in like manner, the white Snapdragon ${ }^{1}$ is much more tender than the common Antirrlinum majus." We now know that the white variety of Antirrhinum is lacking in the flavone, apigenin, as well as in anthocyanin; both these substances are of the aromatic group, and no doubt play a certain part in general metabolism. It is also possible that other, more fundamental compounds, such as oxybenzoic acids, the progenitors of the flavones, are in addition absent from the white variety, and so its metabolism, as regards aromatic substances, may in a sense be

1 This may be the ivory and not the true white. It is of course impossible to know. 
pathological, and may quite well be responsible for the general weakness of the variety.

As to the connection between colour and other characters such as flavour and odour, information is rather scanty. Some interesting suggestions in this direction have been made by Goff (444). He maintains the truth of the statement that white varieties of fruits and vegretables have a milder and more delicate flavour than coloured forms, and he quotes the following instances. White varieties of onions, he says, are less strong in flavour than red ones, the blood-red variety being the strongest flavoured; white currants are less acid than red or black; white and yellow tomatoes are sweeter than the scarlet; white raspberries have a more delicate flavour than the coloured type. The same idea is involved in the blanching of celery, endive and seakale, and in the use of the inner leaves only of lettuce and cabbage for eating. Similarly, 'sun-burned' potatoes, that is tubers which have been exposed to light and sun, have a strong and bitter flavour; shoots of seakale also, if allowed to come above the earth, develop purple pigment and become strong flavoured. Red cabbage, when cooked, is less mild and tender than the green varieties. In the sugar-pea, too, the purple-flowered form has seeds spotted with brown which are strongly flavoured when cooked. He also points out that the percentage of sugar in the Beet increases as the percentage of colouring matter decreases. Further data would be necessary before we could definitely prove the truth of these suggestions, but what evidence we have is certainly in their favour. For odour, flavour, astringency, bitterness, etc., are essentially connected with aromatic compounds, as for instance bitterness and astringency with the tannins, and we know that absence of colour is in some cases, as in Antirrhinum, accompanied by the absence of certain aromatic complexes. The subject is well worth investigation, and now that cases of Mendelian segregation offer such well-defined material, it should not be beyond the scope of the plant chemist. Also, the possibility of a connection between colour and sweetness is materially strengthened by the evidence, given in previous chapters, of a relationship between pigmentation and sugar concentration. Goff states, for instance, that the red-fleshed Peach is of little value for eating purposes, and cases of this kind should offer suitable material for research.

There are certain relationships of a more precise nature between colour and other plant characters which have come to light in Mendelian investigations. One group of such relationships includes the phenomena 
(in which a certain number of colour factors are known to be involved) termed reduplication (see p. 185). Another kind of relationship is that existing in Matthiolu (Saunders, 587) between the factors for hoariness of the leaves and flower-colour In Stocks, as we have already seen, colour (anthocyanin) is due to the presence in the zygote of two factors $(C$ and $R$ ), and if either of these be absent, the plant is an albino as regards anthocyanin. In certain strains of Stocks, the hoariness of the leaves has been found to depend also on the presence of two factors $(H$ and $K)$. Between these two pairs of factors there is a certain relationship, viz. that the hoariness due to $H$ and $K$ is only manifested when $\mathrm{C}$ and $\mathrm{R}$ are both present. Hence an albino may contain both $\mathrm{H}$ and $\mathrm{K}$, and may yet be glabrous because it cannot contain at the same time both $\mathrm{C}$ and $\mathrm{R}$. An anthocyanin form, on the other hand, which is glabrous carries of course $\mathrm{C}$ and $\mathrm{R}$, but can only contain either $\mathrm{H}$ or $\mathrm{K}$, and not both; when it carries $\mathrm{C}$ and $\mathrm{R}$, as well as $\mathrm{H}$ and $\mathrm{K}$, it is hoary and coloured. Thus a heterozygote in all four factors would give on selfing:

\begin{tabular}{|c|c|c|c|}
\hline 81 CRHK & $\ldots$ & $\ldots$ & Red hoary. \\
\hline $27 \mathrm{CRH}$ & $\ldots$ & $\ldots$ & Red glabrous \\
\hline 27 CRK & $\ldots$ & $\ldots$ & Red glabrous. \\
\hline 27 RHK & $\ldots$ & ... & White glabrous. \\
\hline 27 CHK & $\ldots$ & $\ldots$ & White glabrous. \\
\hline $9 \mathrm{CR}$ & $\ldots$ & $\ldots$ & Red glabrous. \\
\hline $9 \mathrm{CH}$ & $\ldots$ & $\ldots$ & White glabrous. \\
\hline $9 \mathrm{CK}$ & $\ldots$ & $\ldots$ & " \\
\hline $9 \mathrm{RH}$ & $\ldots$ & $\cdots$ & ", \\
\hline $9 \mathrm{RK}$ & $\ldots$ & $\ldots$ & , \\
\hline $9 \mathrm{KH}$ & $\ldots$ & ... & , \\
\hline $3 \mathrm{C}$ & $\ldots$ & $\ldots$ & " \\
\hline $3 \mathrm{R}$ & $\cdots$ & $\cdots$ & , \\
\hline $3 \mathrm{H}$ & ... & $\ldots$ & , \\
\hline $3 \mathrm{~K}$ & $\cdots$ & $\cdots$ & , \\
\hline $1-$ & $\ldots$ & $\ldots$ & ,, \\
\hline
\end{tabular}

Finally a relationship between shape and colour occurs in the Sweet Pea (Bateson, 524). All those varieties with an erect standard are 'bicolor,' that is, within the variety, the standard differs more or less in colour from the wings; ex. 'Purple Invincible' and 'Painted Lady.' Varieties, on the other hand, with a hooded standard have wings and standard more of a uniform tint; ex. 'Duke of Westminster" and 'Duke of Sutherland.' 
The Chemical Interpretation of Factors for Flower-colour.

If we write out the factorial composition of the type of any species which bas been investigated on Mendelian lines, as for instance, Antirrhinum (see p. 161):

\section{YYIILLTTDDBB}

or Lathyrus (see p. 167):

\section{CCRRBBDiDiDeDe}

we see that a number of definite factors go to build up the colour-both the amount and kind of colour-of the type, and each of these factors must represent a power in the plant to control a chemical reaction; the sum-total of these reactions is the production of the pigment of the plant. To know with what kind of process each of the factors corresponds is of very great importance for the understanding of genetical problems. It may be stated without hesitation that we can only find out what these processes are by means of exact chemical analyses.

Such chemical analyses have been attempted in the case of Antirrhinum, and we may first consider the kind of deductions which can be drawn from the results. The factors which have been most investigated are the yellow $(Y)$ and ivory (I). The tissues (except those of the palate) of the flowers of the ivory variety contain a very pale yellow soluble pigment, the flavone, apigenin, which is present in all the cells, both epidermal and mesophyll. The pigment is not recognisable in the petal, for, as we have pointed out in earlier chapters, the flavones, though practically ubiquitous, are too slightly coloured to affect the colour of the cell-sap. The presence of apigenin in the ivory Antirrhinum can be demonstrated by placing the corolla in ammonia vapour, when the flower turns bright yellow owing to the formation of a more intensely coloured salt of the pigment. If, on the other hand, we examine sections of the corolla of the yellow variety, we find the epidermal cells filled with a soluble yellow pigment, the flavone, luteolin, while the inner tissues appear colourless. On treatment with ammonia vapour, the yellow epidermis turns orange, and the inner tissues yellow, showing that the latter contain apigenin. These observations are confirmed by analyses of the extracted pigments; apigenin, only, is found in the ivory variety: both apigenin and luteolin can be extracted and identified from the yellow. From the true white variety no apigenin could be extracted, nor do the flowers turn vellow when treated with ammonia 
vapour. Hence we may assume that the white variety contains no flavone.

Now let us see how this information can be connected with the facts of Mendelian inheritance. It has been assumed that the yellow plant contains a factor, $\mathrm{Y}$, and when this is absent, the flower is white, whatever other factors may be present. The ivory contains an additional factor, I, which is dominant to yellow. Thus ivory is $\mathrm{YY}(\mathrm{y}) \mathrm{II}(\mathrm{i})$ and may, if heterozygous, throw either yellow or white, or both. Yellow is $\mathrm{YY}(\mathrm{y})$ ii and may throw white. Hence the factor which has been termed $\mathrm{Y}$ must represent the formation of luteolin in the epidermis, and apigenin in the inner tissues of the corolla, while the factor, I, represents the inhibition of the formation of luteolin. A better understanding may be reached, perhaps, by considering the constitution of the flavones, apigenin and luteolin:

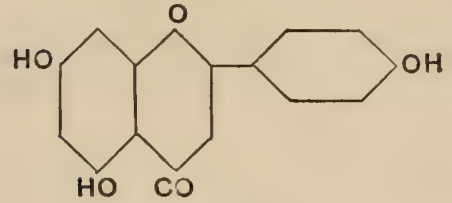

Apigenin

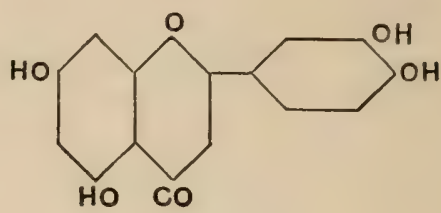

Luteolin

It will be seen that luteolin contains one more hydroxyl group than apigenin, and this number and special grouping of hydroxyls accounts, it is said, for the greater intensity of colour. The behaviour also of the flavones, on heating with caustic alkali, indicates that each flavone can be considered to be built up of phloroglucin and an oxybenzoic acid; thus apigenin decomposes into phloroglucin and $p$-oxybenzoic acid :<smiles>OC1CCCCC1</smiles><smiles>O=C(O)C1CCC(O)CC1</smiles>

and luteolin into phloroglucin and protocatechuic acid:<smiles>OC1CCOC(O)C1</smiles><smiles>O=C(O)CCCO</smiles> 
It is probable that the converse represents the synthesis in the plant; phloroglucin and the oxybenzoic acids and their derivatives are widely distributed, and it is from these, no doubt, that the flavones are synthesised. Hence the kind of oxybenzoic acid present affects the kind of flavone formed. Thus the ivory variety might be supposed to form only one type of oxybenzoic acid, whereas the yellow forms two. As yellow arises from ivory by the loss of a factor, we must look upon this factor as the power of inhibiting the formation of luteolin, or the oxybenzoic acid from which it is synthesised. This result is interesting as a demonstration of the suggestion made by Bateson in the Presidential Address to the British Association in 1914. He says: "I feel no reasonable doubt that though we may have to forgo a claim to variations by addition of factors, yet variation both by loss of factors and by fractionation of factors is a genuine phenomenon of contemporary nature. If then we have to dispense, as seems likely, with any addition from without we must begin seriously to consider whether the course of Evolution can at all reasonably be represented as an unpacking of an original complex which contained within itself the whole range of diversity which living things present."

As regards the true white variety ${ }^{1}$, it lacks either the constituents, one of them, or both, which go to make up the flavone, or the power of synthesising the constituents. Many interesting lines for investigation are suggested by these points, both in Antirrhimum and in allied cases. The true whites might be tested for phloroglucin and oxybenzoic acids, and the chemical composition of white individuals bearing the I factor might be compared with those which are derived from yellow, and which therefore do not carry $I^{2}$. One point which may be emphasised with regard to the $\mathrm{Y}$ and $\mathrm{I}$ factors is that their power is not affected in the heterozygote; a plant may be homo- or heterozygous for $\mathrm{Y}$ or $\mathrm{I}$, and there is no apparent difference in its colour. This is not always so for factors concerned in anthocyanin formation, as we shall see later; nor is it universal even for factors controlling the formation of yellow pigment, as for instance in Mirabilis. In the

1 A similar case to Antirrhinum is that of Phlox Drummondii, in which there is an ivory white and a true white, the latter giving no canary yellow colour with ammonia. I am indebted to Miss Killby for this information.

2 I have noted that extracted solutions of white flowers almost inrariably give brown products, after standing, similar to Palladin's respiration pirments. This is rarely so with extracts of ivory and yellow. The phenomenon surgests that aromatic substances are present in the white which are not developed in the yellow and irory. But further and more careful investigation is necessary.

W. P. 
case of other species which give rise to varieties with soluble yellow sap pigments, such as Dahlia variabilis and Althaea rosea, we must suppose that some relationship exists similar to that in Antirrhinum, that is that the plant loses an inhibitor which suppresses the formation of a more highly coloured flavone. Research upon these points is much needed.

While we are attempting to identify the functions of the various Mendelian factors, it may not be out of place, at this point, to emphasise certain facts concerning the nature of many reactions in plant metabolism. It is known that a large number of the chemical reactions in the plant are what are termed reversible reactions. An example of such a reaction (outside the plant) is the formation of acetic acid and alcohol from ethyl acetate and water:

\section{ethyl acetate + water $\leftrightarrows$ ethyl alcohol + acetic acid.}

The characteristic of a reaction of this kind is that it progresses in one direction or the other until a certain equilibrium, specific to the reaction, is established. Any alteration in concentration of the reacting substances is immediately followed by reaction towards equilibrium again. The velocity of the reaction, moreover, may be accelerated by the addition of a little hydrochloric acid, which, though it does not affect the final products, accelerates the process. Such a substance has been termed a catalyst. In the plant many reactions are known to be of the above type, as for instance the hydrolysis of starch into sugar, and the synthesis of starch again from sugar. Outside the plant, hydrolysis of starch, by purely chemical methods, would take place only at a high temperature. Within the plant, it occurs at ordinary temperatures with considerable rapidity, and is controlled by the enzyme diastase; diastase is therefore a catalyst produced by the living plant. The extraction of diastase and the demonstration of its hydrolytic action in vitro is of course a perfectly simple experiment. But the synthesis of starch from sugar by the same enzyme has not been carried out in vitro. It is reasonable, however, to assume that diastase controls the process in both directions, for there are other cases where the synthetic power of enzymes has been demonstrated in vitro under special conditions. It is nevertheless possible that in some cases one enzyme may control the synthetic, and another the hydrolytic process. Diastase is moreover only one example; numbers of plant reactions concerned with oxidation, pigment formation, hydrolysis of proteins, glucosides, fats, etc., are known to be controlled by enzymes. 
Bearing in mind then the reversible nature of many reactions in the plant, we may suppose, assuming the factors to represent the power to bring about plant reactions, two possibilities; when a factor is lost, the reaction it represents may not take place at all; or it may take place, from lack of control, in the opposite direction from the normal.

Thus it would be possible to regard the ivory factor, I, as a reducing agent, since luteolin is more highly oxidised than apigenin. When the control of the reducing agent is removed from the epidermis, the oxidising action can progress and luteolin is formed. The explanation, however, may rest upon a more fundamental basis: the structure of the living molecule in the ivory and yellow plants may be different, so that one casts off, or synthesises, a different type of flavone or acid from the other.

We may next turn to the factors concerned with anthocyanin formation. There are three groups of factors to be considered:

(a) Those concerned with the actual formation of pigment.

(b) Those controlling the amount formed.

(c) Those modifying the colour of the pigment after it is formed.

From results obtained with Lathyrus and Matthiola, it appears that two factors, which have been termed $C$ and $R$, are necessary for the process of anthocyanin formation. The question before us is-what reactions of the process do $\mathrm{C}$ and $\mathrm{R}$ control? It has been suggested that they represent respectively a chromogen, $\mathrm{C}$, and an oxidase or oxidising enzyme, $R$. The recent work of Willstätter on anthocyanin, coupled with the results from Antirrhinum, makes it practically certain that the anthocyanins are derived from flavones. The flavones therefore are the chromogens of anthocyanin. In Antirrhimum it is clear that the ivory variety carries the chromogen, $\mathrm{C}$, and the white variety, a factor $\mathrm{R}$-it is only necessary to postulate one in this case-for the production of anthocyanin.

With regard to Lathyrus and Matthiola, in the absence of exact chemical investigation, we can only make the following surmises. The two whites which produce colour must differ in sone respect; one may contain the chromogen, $\mathrm{C}$, the other the colour producer, $\mathrm{R}$; or both may contain chromogen, and some other unknown factor in addition to $\mathrm{R}$ may be involved in colour formation. We can deduce very little from the facts observed. Both the whites (which when mated give colour) contain a flavone or flavones, for both turn yellow with alkalies, but this need not necessarily imply that both contain the chromogen, 
for there may be more than one flavone. In fact it is impossible to know until the flavones are isolated and analysed as in Antirrhinum, what the chromogen is.

As regards the colour-producing factor, which we have called $R$, and which is carried by the white in Antirrtinum and by one of the whites in Lathyrus, it has been suggested that it is an oxidase or oxidising enzyme which acts upon the chromogen with the formation of pigment. The evidence in favour of this hypothesis is not very convincing. If the hypothesis be true, then the ivory variety in Antirrhinum, one of the whites of Lathyrus and Matthiola, and possibly the recessive whites of Primula should be without oxidase. This is not yet confirmed, for all the varieties which have been tested contain oxidase. Nevertheless, this statement needs amplification. The $\mathrm{R}$ factor, it is true, produces colour, but there are other factors - to be considered later-which modify this colour, making it deeper or paler. These may also be oxidising enzymes, so that it is essential, when testing for $\mathrm{R}$, that one should use carefully selected individuals. In Antirrhinum, for instance, the individual should be yyiiLLttddbb, in Lathyrus, ccRRbbdededidi, and so forth; individuals for the finding of which several years' breeding experiments are often needed. In the testing of Lathyrus, Matthiola, Antirrhinum and Primula for oxidases, adequate precautions to secure the right individuals on these lines have not been taken; the same criticism holds good for the testing for chromogens in Primula, Lathyrus and Mattliola. In addition, even if oxidases prove to be connected with colour, it seems likely that there may be in the plant other oxidases controlling reactions essential to metabolism, in fact it is difficult to conceive of a plant-albino or otherwise-which is entirely free from oxidases. Until some reagents can be found which differentiate between oxidases, it is impossible to draw safe conclusions.

Nevertheless there appears to be some connection between oxidase distribution and colour distribution. For Keeble \& Armstrong found that in Primule flowers where colour is inhibited, the oxidase reaction is inhibited too, but could be detected after removing the colour inhibitor with certain reagents. The author (213), also, found that the whites extracted from differently coloured varieties of Matthiola and Lathyrus, though all giving the oxidase reactions, did not give the reaction to the same extent, that is, it varied in intensity.

The foregoing suggestions are based upon the assumption that anthocyanin is formed from a flavone by oxidation. Willstätter, as we have seen in earlier chapters, considers the process of colour formation 
to be one of reduction of a flavone, accompanied by a change of linking of atoms in the molecule, which leads to change of colour. If this should be the case, then the $\mathrm{R}$ factor is a reducing agent. We now await further evidence, and from the preceding paragraphs it should be obvious that the only method of ascertaining the actual relationships between flavones and anthocyanins, and incidentally the nature of the $\mathrm{R}$ factor, is to isolate and analyse both these substances from a considerable number of selected species.

Let us now turn to the factors controlling the amount of pigment formed. These are the deepening (or full-colour) and diluting factors, and they appear to work for the maintenance of an intermediate type. As a rule, loss of the full-colour factor from the type gives a tinged variety in which little pigment is formed; loss of a diluting factor from the type gives a deeper variety in which excess of pigment is formed. For the defining of the chemical nature of these factors we have at present no experimental basis. The full-colour factor may control and increase the actual supply of chromogen, and hence may increase the production of pigment. A second suggestion can be made in connection with the glucoside hypothesis mentioned in the previous chapters. In this hypothesis the idea is that some of the hydroxyl groups of the flavones are combined with sugar, so that the pigment is a glucoside, and it is not until the sugar is split off by a glucoside-splitting enzyme that the reactions which change the chromogen (flavone) to pigment can take place through the vulnerable points of the hydroxyl groups. The control of the amount of free chromogen, and hence pigment, may well be in the power of such enzymes. Or, again, the full-colour factor, in the form of a kind of activator, may increase the oxidation power of the oxidase.

As regards the diluting factor, it seems not unreasonable to suppose that it is in nature the converse of the full-colour factor; that is, it may limit the hydrolysis of the glucoside, or the oxidising action of the oxidase. But, as we have said, speculation, unless it is in the direction of suggesting lines for research, is not very profitable. An estimation, for instance, of sugar and glucoside content of varieties with different intensities of pigment might lead to some conclusive results.

Finally, we turn to the factors which modify the colour of the pigment when it is formed. The view is prevalent among botanists in general, as well as among. many of those who have worked with anthocyanin, that the variation in colour of anthocyanin, i.e. the shade of red, blue, 
or purple, as the case may be, is determined by the nature of the accompanying substances in the cell-sap. This idea is further corroborated by the fact that anthocyanin outside the cell is modified in colour by acids, alkalies and inorganic and organic salts of various kinds. When we see in one and the same flower a number of shades of red and purple, or red and blue, it is difficult to avoid accepting this explanation, especially as we know that various products of metabolism, such as organic acids, are produced locally.

This point of view has been recently advocated by Willstätter. As a result of his researches on the anthocyanin of the Cornflower, he maintains that the blue flower pigment is the potassium salt of a neutral purple pigment (itself an acid), and the red pigment is an acid salt of the purple, with some organic acid. If all three pigments are present in one flower, we must suppose that the blue cells have alkaline contents, the purple, neutral, and the red, acid. That the pigment of a plant may be modified in colour in different regions of the plant according. to the chief organic and inorganic substances present in the cells, seems reasonable, but the difficulty lies in finding some explanation for the existence of red and blue varieties. Thus, for instance, Willstïtter maintains that the pigments of the blue Cornflower, the magenta Rosa gallica and the red fruits of the Cranberry are one and the same substance. If so, its colour must be modified by other substances in the cell-sap. But in the Cornflower there is the blue type, having blue outer and purple inner florets; there is a variety in which the outer florets are bright pink; another in which they are purple-red. According to Willstätter, in the ray floret cells of the type, the cell-sap is alkaline; in the pink variety, acid, and in the purple, neutral. How can this be expressed in Mendelian terms? We must imagine that the blue type loses some factors which either inhibit acidity, or produce alkalinity. These are the blueing factors; let them be $B_{1}, B_{2}$, etc. Loss of these will give rise to the purplish-red and pink varieties. Without further evidence, such as would be derived from analysis of the pigments extracted from the purple and pink varieties (which has not so far been accomplished), it is difficult to arrive at any satisfactory explanation. But even if the above hypothesis fits the case of Centaurea, it can scarcely be adapted to the case of Antirrhinum. In this genus, there are two forms of anthocyanin, a red and a bluish-red, or magenta. There is certainly no evidence at present for regarding the magenta is the potassium, or alkaline salt, of the red, nor for considering the red to be the acid salt of the magenta. 
The suggestions which the author has made from time to time are first, that the blues and purples are more oxidised conditions of the reds, and secondly, that the blues and purples may be formed by the condensation of the red with some other aromatic substances in the cell. The hypothesis of further oxidation, though possible, has as yet no definite evidence in its favour, and would involve the postulation of a second oxidase in addition to the $\mathrm{R}$ factor. The condensation hypothesis is perhaps more probable; in this case the blueing factors $B_{1}$ and $B_{2}$ would be the power to form the substances with which condensation takes place. It will be necessary also that any hypothesis for the blueing factors should explain the difference between recessive blues, like those of Primula, Cineraria, and Anagallis, which are recessive to red or purple, and dominant blues, like those of Centaurea and Campanula, which are dominant to red, pink and purple.

The identification of luteolin in the yellow variety of Antimhinum has made clear the difference between crimson and magenta in that species. Crimson is, in fact, magenta pigment mixed with the yellow luteolin, whereas in the magenta type the mixture is with apigenin only which does not affect the colour. The same explanation can probably be applied to the crimson and magenta series in Althaea rosea, Dianthus Caryophyllus and Dahtia variabitis in which both ivory, and a yellow variety with soluble pigment, appear. The same range of colour, it is true, is found in Primula sinensis and Dianthus barbatus, and in these there is no soluble yellow pigment; hence the difference between magenta and crimson in these latter species cannot be explained on the ground of mixture of pigments.

The most reasonable interpretation of the blueing factors at the noment seems to be to regard local differences of colour in the flower as due to local presence of various organic substances; this may explain also the change of colour with age in the same flower (Myosotis). But the change of the pigment of the whole plant from magenta, for instance, to red in Antirrhinum, and from blue to pink, as in Centuurer, is likely to be something more fundamental than change in alkalinity and acidity of the cell-sap ${ }^{1}$.

Another line of speculation is opened out by some further results obtained by Willstätter. He notes a fact, which indeed had been noted before, that the blue pigment of the Cornflower is unstable in water solution. The colour disappears fairly rapidly, and a colourless solution is left. This he explains on the hypothesis of the formation 
of a colourless isomer of the pigment. If, however, a neutral salt, such as sodium nitrate or chloride, is added to the solution of the blue pigment, the latter remains stable, and the isomerisation does not take place, or at any rate takes place in a lesser degree. The neutral purple pigment, too, isomerises in solution; also the red acid salt, unless the acidity of the solution is maintained. The colour returns again, on acidification, to a colourless solution containing the isomer. It has been suggested recently by Schiemann (262) that in these reactions lies the explanation of the 'dominant white' phenomenon, and one may add also the phenomenon of pigmented plants with white flowers. The pigment is supposed to be present, though inhibited, in these varieties. Applying Willstätter's results we may consider the pigment to be developed in the flower as the isomer, and that lack of salts in solution in the cell-sap, or diminution in acidity of the cell-sap, prevents the pigment from existing in its coloured state. This may possibly be the cause also of the lack of colour in tinged forms, and increase in concentration of the neutral salts in the cell-sap may increase the intensity of the colour. But it is difficult to conceive of any factor, or process, which would lead to this result. It has been observed that treating tissues with concentrated acid may bring about development of red colour. There is no real evidence in this case that the reddening is due to anthocyanin; yet the fact is significant, and it may indicate that the isomer is present in the tissues, and that acidification will cause isomerisation to the coloured form.

The bearing of the chemical interpretation of colour factors on the phenomenon of striping is worth a brief consideration. The curious limitation of the condition of striping to certain factors is well exemplified in Antirrhinum. In this species we never find, apparently, striping of yellow or ivory on a white ground; nor do we find striping in the red anthocyanin. The magenta anthocyanin may show stripes, though not in the tinged varieties, but only when the full-colour factor is present (see p. 159).

Much of what has been said in this section is purely speculative; it may however be of value in suggesting material and openings for the additional research which is much needed to place the whole subject on a sound basis. As we have seen, very little is known of the causes and mechanism of colour variation. Yet we can recognise, among the factors concerned, three types: (1) those which control the formation of some definite substance as in the $\mathrm{Y}$ factor of Antirrhinum, (2) those which modify the substance when it is formed, as the I and 
$\mathrm{R}$ factors, and (3) those which intensify or diminish a reaction, such as colour-formation, which is already in being in the plant, as for instance the De and Di factors of Lathyrus.

It is worthy of note that of all factors it is more often the actual colour-producing factor which gives rise to a heterozygous form; apart from Mirabilis, the factor for chromogen is unaffected by the heterozygous condition, and the same can be said for the factors for concentration and dilution. When we learn more of the reactions taking place, we may find that this point has some considerable significance.

Though we now know something of the material to be employed for research and the methods to be adopted for finding out the cause of colour variation, we cannot add very much to the excellent account and statements by Hopkirk (428) in his Flora Anomoia published in 1817. "An astonishing number," he says, "of varieties of colour and its different combinations, have been produced in flowers, especially in the Pink, Carnation, Hyacinth. Anemone, Ranunculus, and Tulip,

'and while they break

On the charm'd eye, th' exulting Florist marks

With secret pride the wonders of his hand.'

"The causes of these variations in colour, are at present unknown, some peculiar circumstances in the soil, or the different combinations with oxygen, with acids, or with alkalies, may tend to produce them, but we often find that in the same soil, and under the same management, one plant always retains its colour, whilst another will most readily acquire a new one."

We can however say now that the soil does not bring about genetical variation in flower-colour. In the case of Hydrangen, no doubt, the colour is modified by the iron and aluminium salts absorbed by the plant, and the same kind of phenomenon may happen in a lesser degree in other plants. But a continual supply of salts is needed to keep up the variation; failing this, the red colour returns; nor does the plant transmit this acquired character of blueness to its offspring. 


\section{APPENDIX}

Since the previous chapters were written, further work has been published by Willstätter, Bolton, Mallison, Martin, Mieg, Nolan, Zechmeister and Zollinger on the anthocyanins. These publications give, in the main, more detailed accounts of the isolation and properties of the pigments already mentioned in Chapter v. The following is a short summary of the additional methods of preparation contained in the later papers.

The flower-pigment of Rosa gallica (Willstätter \& Nolan, 643). This pigment was found to be identical with the cyanin of the Cornflower. The dried and powdered petals are digested with methylalcohol-hydrochloric acid $(2.5 \%)$. From the extract the colouring matter is precipitated with ether, and the precipitate contains impure cyanin chloride. After purification, the crystalline product was found on analysis to yield cyanidin and two molecules of dextrose.

The pigment from the fruits of the Cranberry, Vaccinium Vitis-idaea (Willstätter \& Mallison, 638). The skins of the berries are digested with glacial acetic acid for several days, and the extract precipitated with ether. The crude precipitate is again taken up in glacial acetic, and fractionally precipitated with ether; the second fraction is dissolved in water and picric acid added. A precipitate of the picrate of the pigment is formed which is extracted with methyl alcohol, reprecipitated by ether, and finally crystallised from water. Analysis proved the pigment, idaeïn, as previously stated, to be a monogalactoside of cyanidin. The picrate is converted into the chloride by treatment with methyl-alcohol-hydrochloric acid. The difference in the attached sugar molecule, i.e. galactose instead of glucose, causes idaeïn to differ in properties (solubilities and behaviour with alkalies) from cyanin.

The flower-pigment of Pelargonium (Willstätter \& Bolton, 637). The fresh flowers are digested for several days with alcohol (96\%), and to the extract alcohol-hydrochloric acid $(20 \%)$ is added together with ether. The precipitate of pigment is dissolved in boiling methylalcohol-hydrochloric acid (2\%), and to the solution hydrochloric acid 
$(10 \%)$ is added, and the pelargonin chloride is precipitated. The crystallised product gives, on hydrolysis with hydrochloric acid, as previously mentioned, pelargonidin and two molecules of dextrose.

The flower-pigment of Delphinium (Willstätter \& Mieg, 641). The dried and powdered flowers are extracted with aqueous alcoholic hydrochloric acid. To the extract ether is added, thereby precipitating impure delphinin chloride, which is then purified by further treatment with methyl and ethyl alcohols and ether. The amorphous delphinin chloride is finally again precipitated by concentrated hydrochloric acid, and it does not readily crystallise. It is hydrolysed by water with the precipitation of the violet base. With hot, moderately concentrated hydrochloric acid it is hydrolysed into two molecules of dextrose, two molecules of $p$-oxybenzoic acid, and delphinidin chloride.

The pigment of grapes (Willstätter \& Zollinger, 645). The method of extraction in general has already been described (p. 77). Oenidin contains two methoxyl groups, and is converted into delphinidin by hydriodic acid and acetic anhydride.

The pigment from fruts of thie Bilberry, Vaccinium Myrtillus (Willstätter \& Zollinger, 645). The general method of extraction has been described (p. 77). Myrtillin, on hydrolysis, gives myrtillidin and a sugar which apparently has not yet been identified. Myrtillidin contains only one methoxyl group, and gives delphinidin in the Zeisel reaction.

The flower-pigment of the Hollyhock, Althaea rosea (Willstätter \& Martin, 640). The dried and powdered flowers are digested with methyl-alcohol-hydrochloric acid, and ether is added to the extract, which precipitates the pigment-althaein--as chloride. The methods for purification of the crude product have not yet been devised. On hydrolysis with boiling, moderately concentrated hydrochloric acid althaeïn yields myrtillidin and one molecule of (?) dextrose.

The flower-pigment of the Mallow, Malva sylvestris (Willstätter \& Mieg, 642). The dried and powdered flowers are digested with methylalcohol-hydrochloric acid $(2 \%)$ and about $\frac{1}{33}$ of the volume of concentrated hydrochloric acid, and the extract is precipitated with ether. The precipitate, after some purification, is warmed with aqueous picric acid $(1.5 \%)$. The pigment-malvin--crystallises out as picrate, and is converted into chloride by treatment with methyl-alcohol-hydrochloric acid. Malvin yields, on hydrolysis with boiling $20 \%$ hydrochloric acid, malvidin and two molecules of dextrose; it contains two methoxyl groups, and yields delphinidin in the Zeisel reaction. 
Cyanin

Composition $\quad \ldots \quad \ldots \quad \mathrm{C}_{27} \mathrm{H}_{31} \mathrm{O}_{16} \mathrm{Cl} \cdot 2 \frac{1}{2} \mathrm{H}_{2} \mathrm{O}$; $\frac{3}{4} \mathrm{~mol} . \mathrm{H}_{2} \mathrm{O}$ given off in vac. at $105^{\circ}$

\section{Components $\quad \ldots \quad \ldots \quad \mathrm{C}_{15} \mathrm{H}_{11} \mathrm{O}_{6} \mathrm{Cl}+2$ glucose \\ Crystallisation $\quad . . \quad \ldots \quad$ Rhomboidal plates (grey violet); M.P. 203-204 \\ Colour in dilute acid ... Red tinged violet \\ Solubility in water and Almost insol. in cold alcohols water; readily in hot; v. difficultly sol, in alcohol}

\begin{abstract}
Reaction with soda
\end{abstract}
... Violet, then blue

Reaction with $\mathrm{FeCl}_{3}$

... Blue (in alcohol); violet (in water)

Isomerisation $\quad \ldots \quad \ldots$ Readily isomerises

Pseudobase

Oenidin

Composition

$$
\begin{array}{cc}
\ldots \quad \ldots \quad \mathrm{C}_{17} \mathrm{H}_{15} \mathrm{O}_{7} \mathrm{Cl} .1 \frac{1}{2} \mathrm{H}_{2} \mathrm{O} ; \\
\frac{1}{2} \text { mol. water given off } \\
\text { first in vac, at } 100^{\circ}
\end{array}
$$

Components

Crystallisation $\quad . . \quad \ldots \quad$ Prisms or needles (brown)

Colour in dilute acid

... Brown-red

Solubility in water and alcohols

Readily sol. in water; v. readily sol. in methyl and ethyl alcohols

Reaction with soda ... Violet

Reaction with $\mathrm{FeCl}_{3} \quad \ldots$ No reaction

Isomerisation
Cyanidin

$\mathrm{C}_{15} \mathrm{H}_{11} \mathrm{O}_{6} \mathrm{Cl} \cdot \mathrm{H}_{2} \mathrm{O}$; water given off with difficulty

$\mathrm{C}_{41} \mathrm{H}_{38} \mathrm{O}_{21} \mathrm{Cl}$. $12 \mathrm{H}_{2} \mathrm{O}$;

$2 \mathrm{H}_{2} \mathrm{O}$ held fast

$\mathrm{C}_{15} \mathrm{H}_{11} \mathrm{O}_{7} \mathrm{Cl}+2$ glucose $+2 p$-oxybenzoic acid

Long needles (brown-red) or platelets; M.P. $220^{\circ}$

Red tinged violet

Insol. in water; v. readily sol. in alcohols

Violet, then blue

Blue (in alcohol); violet (in dil. alcohol)

\section{$-$}

$\mathrm{C}_{15} \mathrm{H}_{12} \mathrm{O}_{7} \cdot \mathrm{H}_{2} \mathrm{O}$, crystalline

\section{Malvin}

$\mathrm{C}_{29} \mathrm{H}_{35} \mathrm{O}_{17} \mathrm{Cl}$. $8 \mathrm{H}_{2} \mathrm{O}$

water-free in desiccator

$\mathrm{C}_{17} \mathrm{H}_{15} \mathrm{O}_{7} \mathrm{Cl}+2$ glucose

Long prisms and needles (purple-red); M.P. $165^{\circ}$

Blue-red

Difficultly sol. in water; readily sol. in methyl alcohol; less in ethyl alcohol

Blue

No reaction

Readily isomerises
Prismatic tables (bluishred); M.P. 200-203

Blue-red

Decomposed by water with pptn. of violet base; difficultly sol. abs. alcohol; sol. in methyl alcohol

Violet, then blue

Blue (in water and alcohol)

Does not isomerise

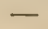

\section{Malvidin}

$\mathrm{C}_{17} \mathrm{H}_{15} \mathrm{O}_{7} \mathrm{Cl}$. $2 \mathrm{H}_{2} \mathrm{O}$; 1 mol. water given off with difficulty

Long prisms and needles (olive-brown); does not melt at $300^{\circ}$

Brown-red

Considerably sol. in water; readily in ethyl alcohol; difficultly in methyl alcohol

Violet, then blue

No reaction 
Delphinidin

$\mathrm{C}_{15} \mathrm{H}_{11} \mathrm{O}_{7} \mathrm{Cl} .2 \mathrm{H}_{2} \mathrm{O}$; half water given off with difficulty

$\mathrm{C}_{15} \mathrm{H}_{11} \mathrm{O}_{5} \mathrm{Cl}+2$ glucose

Platelets or prisms (red. Fine needles (scarlet-red). brown); do not melt M.P. $180^{\circ}$

Bluc-red

Orange-red; fluorescent

Readily sol. in alcolol somewhat sol. in water; and water sol. in methyl and ethyl alcohols, less in latter

\section{Violet, then bluc}

Only violet

Blue (in alcohol); blue. No reaction violet (in dil. alcohol)

Readily isomerises

$\mathrm{C}_{15} \mathrm{H}_{12} \mathrm{O}_{8} \cdot 4 \mathrm{H}_{2} \mathrm{O}$ crystalline

Myrtillidin

$\mathrm{C}_{16} \mathrm{H}_{13} \mathrm{O}_{7} \mathrm{Cl}$. $2 \mathrm{H}_{2} \mathrm{O}$

Needles or prisms (yellow- Needles (red-violet); brown)

\section{Brown-red}

Considerably sol. in water; v. readily sol. in ethyl and methyl alcohols

Violet, then blue

Blue (in alcohol); violet (on dilution)
Pelargonidin

$\mathrm{C}_{15} \mathrm{H}_{11} \mathrm{O}_{5} \mathrm{Cl}, \mathrm{H}_{2} \mathrm{O}$; water given off with difficulty

$\mathrm{C}_{23} \mathrm{H}_{25} \mathrm{O}_{12} \mathrm{Cl} \cdot 4 \mathrm{H}_{2} \mathrm{O}$ and $6 \mathrm{H}_{2} \mathrm{O}$; becomes almost free from water in desiccator

$\mathrm{C}_{17} \mathrm{H}_{15} \mathrm{O}_{7} \mathrm{Cl}+1$ glucose

Platelets or prisms (red- Prisms (brown-red) brown)

\section{Orange-red}

Readily sol. in hot water; Readily sol. in water and readily sol. in methyl methyl alcohol; modand ethyl alcohols

Violet, then blue

No reaction erately sol. in ethyl alcohol

Blue-violet

No reaction (in water)

Readily isomerises

$\mathrm{C}_{15} \mathrm{H}_{12} \mathrm{O}_{6}$ crystalline

Paeonin

$\mathrm{C}_{28} \mathrm{H}_{33} \mathrm{O}_{16} \mathrm{Cl} .5 \mathrm{H}_{2} \mathrm{O}$; water given off completely in desiccator

M.P. $165^{\circ}$

Red, tinged violet

Paeonidin

$\mathrm{C}_{16} \mathrm{H}_{13} \mathrm{O}_{6} \mathrm{Cl} . \mathrm{H}_{2} \mathrm{O}$; water given off in desiccator

Long needles (redulish. brown)

Rather readily sol. in water; v. readily sol. in alcohol

Violet, then blue

Violet, then blue

Violet-red (in alcohol) red (on dilution)

Rapidly isomerises 
The flower-pigment of the Peony, Paeonia (Willstätter \& Nolan, 644). The dried and powdered flowers are digested with methyl-alcoholhydrochloric acid ( $2 \%$ ), and the extract precipitated with ether. The crude pigment is purified by various processes, and finally crystallised as the chloride from boiling $\mathrm{N} / 2$ hydrochloric acid. Paeonin, on hydrolysis by boiling with $20 \%$ hydrochloric acid, yields paeonidin and two molecules of dextrose. Paeonidin is a mono-methyl ether of cyanidin, and is converted into the latter on treatment with hydriodic acid.

Some of the properties of the above anthocyanins are set out in the accompanying table (see pp. 220,221 ), but the original papers should be consulted for fuller details.

In a further publication (Willstätter \& Zechmeister, 628), Willstätter describes the preparation of synthetic pelargonidin. The synthesis is carried out first by the action of $3: 5: 7$-trimethoxycoumarin and magnesium anisyl bromide. The resultant product is next treated with hydrochloric acid which gives anisyltrimethoxypyryliumchloride:

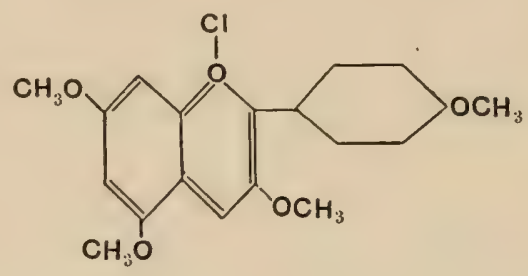

The product is then demethylated, and finally the iodide is converted into the chloride. The compound obtained, oxyphenyl-trioxybenzopyryliumchloride, is shown to be identical with the chloride of pelargonidin by analyses, crystalline form, absorption spectra, solubilities and qualitative reactions. This result, though it determines the constitutional formula for pelargonidin, does not unfortunately give any clue to the course of synthesis in the plant.

Some of the most important of these later results are those concerned with the isolation and analysis of flower-pigments of different colour-varieties of certain plants (Willstätter and Mallison, 639). Briefly the genera and species examined are:

Centaurea Cyanus. The dark purple-red variety contains neutral cyanin, and the blue type the potassium salt of cyanin as previously stated. But the pink variety was found to contain pelargonin identical with the pigment of the scarlet Pelargonium. 
Pelargonium. The pigment of the scarlet P. zonale, var. 'Meteor,' is pelargonin as previously stated; so also is that of the bluish-pink $P$. peltatum. But a violet-red variety of $P$. zoncle was found to contain cyanin, chiefly, accompanied by a little pelargonin. This is the first case which has arisen of a flower containing two anthocyanins.

Dahlia.. The deep brown-red double (Cactus) varieties, 'J. H. Jackson,' 'Harold,' 'Matchless,' 'Night' and 'Othello' form eyanin: the scarlet-red varieties 'Rakete' and 'Alt-Heidelberg,' pelargonin. Pelargonin, together with a little cyanin probably, was also found in a dark-violet variety.

Delphinium. The violet variety contains delphinin; the blue type the potassium salt of delphinin.

We may now set out the distribution of the anthocyanins ${ }^{1}$ as far as they are known, as follows:

\section{Pelargonidin $\mathrm{C}_{15} \mathrm{H}_{10} \mathrm{O}_{5}$.}

Pelargonin $=$ diglucoside of pelargonidin .

Flowers of scarlet Pelargonium zonale ..

" violet-red var. of $P$. zonale

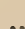

bluish-pink $P$. peltatum $\quad \ldots$

", scarlet-red var. of Dahlia ...

,. dark violet var. of Dahlia

, pink var. of Centaurea Cyanus
Pelargonin as an acid (tartaric) oxonium salt

Pelargonin (together with cyanin)

\section{Pelargonin}

... Pelargonin

... Pelargonin (together with (?) cyanin)

Pelargonin

Cyanidin $\mathrm{C}_{15} \mathrm{H}_{10} \mathrm{O}_{6}$.

Cyanin = diglucoside of cyanidin .

Flowers of violet-red var. of Centaurea Cyanus

, blue type of $C$. Cyanus ... ...

, brown-red var. of Dahlia ... ...

" magenta Rosa gitlica ... ...

, violet-red var. of Pelargonium zonale

,

Cyanin

Potassium salt of cyanin

Cyanin

Cyanin

Cyanin (with pelargonin)

Paeonin $=$ diglucoside of paconidin which is a monomethyl ether of eyanidin

Fruits (red) of Vaccinium Vitis-idaea ... ... Idaeïn=monogalactoside of cyanidin

1 It should be borne in mind that all data given below dopend upon the analyses of the oxonium salts of the pigments and not of the pigments themselves. 
Delphinidin $\mathrm{C}_{15} \mathrm{H}_{10} \mathrm{O}_{7}$.

Delphinin $=$ diglucoside of delphinidin +2 mols. of $p$-oxybenzoic acid.

Elowers of purple var. of Delphinium ...

blue type of

Fruits (purple) of Vitis vinifera ...

Flowers of reddish-purple Malva sylvestris

Fruits (purple) of Vaccinium Myrtillus

Flowers (? purple) of Althaea rosea
Delphinin

Potassium salt of delphinin

Oenin $=$ monoglucoside of oenidin which is the $3: 4$ dimethyl ether of delphinidin

Malvin = diglucoside of malvidin which is a dimethyl ether of delphinidin and is isomeric with oenidin

Myrtillin=glucoside ( ? sugar) of myrtillidin which is the 7 -monomethyl ether of delphinidin

Althaeïn $=$ monoglucoside $($ ?dextrose) of myrtillidin

From the data given above certain conclusions can be drawn. First, that the purple anthocyanidins, delphinidin and cyanidin, contain more oxygen than the redder pelargonidin, and this is in accordance with the hypothesis originally suggested by the author $(212,217)$. Moreover, when a purple type gives rise to a red variety, the variety may contain a less oxidised anthocyanin, and not necessarily the acid salt of the pigment of the purple type, as in Centaurea and Dahlia, of which the purple variety contains cyanin, and the red pelargonin. This is again in agreement with the author's original views. Secondly, the evidence at present seems to point to the fact that variation may also be due to the effect of other substances in the cell-sap, as for instance in Delphinium and Centaurea, of which the blue type contains the alkaline salt of the pigment of the purple variety. Willstätter is of the opinion that variation in flower-colour largely depends on the presence of these other substances, acids, alkalies, salts, etc., in the cell-sap. For instance, he says, the scarlet Pelargonium contains an acid salt of pelargonin, but in the flowers of the bluish-pink $P$. peltatum and in the pink Cenlaurea the pelargonin is probably in either an acid-free or basic form. This view is supported by the fact that artificial basic salts of pelargonin can be formed:

$$
\left(\mathrm{C}_{27} \mathrm{H}_{31} \mathrm{O}_{15} \mathrm{Cl}\right)_{2}+\mathrm{C}_{27} \mathrm{H}_{30} \mathrm{O}_{15} \text {. }
$$

In the flowers also of the variety, 'Alt-Heidelberg', of the Dahlia the florets vary from scarlet to violet, and yet pelargonin only is present.

A third point to be considered is that a flower may contain two anthocyanins simultaneously as in the violet-red variety of Pelargonium 
zoriale, and a dark-violet variety of Dahlia, both of which contain pelargonin and cyanin. In such cases variation might be due to the loss of either pigment.

It is important to keep in mind two considerations in connection with colour-variation. On the one hand, the same anthocyanin may be present in several species, but may not give the same colour owing to the presence in the cell-sap of other substances which are peculiar to the respective species, and which may enter into combination with the pigment to form various glucosides, salts, etc. On the other hand, there are the changes in colour in the Mendelian varieties of a species, and these may be due to the formation of different pigments from that in the type: or to the formation of one pigment only, should the type contain two: or to the modification of the pigment of the type owing to loss or gain of some other substance in the cell-sap.

Willstätter has also shown by analyses that the amount of pigment in flowers of different shades and colours may vary. The following are some of his results expressed as percentages of dry weight of flowers:

\begin{tabular}{|c|c|c|c|c|}
\hline \multirow{2}{*}{\multicolumn{2}{|c|}{ Blue Centaurea Cyanus }} & & & Cyanin \\
\hline & & $\cdots$ & $\ldots$ & $0.7 \%$ \\
\hline Deep purple Cent & curea & Cyanus & ... & $13-14 \%$ \\
\hline Rosa gallica & ... & ... & $\ldots$ & $2 \%$ \\
\hline Dark red Dahlia & $\ldots$ & $\ldots$ & ... & $20 \%$ \\
\hline Pelargonium pelta & $u m$ & .. & • & $\begin{array}{c}\text { Pelargonin } \\
1 \%\end{array}$ \\
\hline P. zonale ... & $\ldots$ & $\ldots$ & ... & $6-14 \%$ \\
\hline Scarlet Dahlia & $\ldots$ & $\ldots$ & ... & $4-5 \cdot 6 \%$ \\
\hline Pink Centaurea & $\ldots$ & ... & ... & $4 \%$ \\
\hline Paeonia & $\ldots$ & ... & ... & $\begin{array}{c}\text { Paeonin } \\
3-3.5 \%\end{array}$ \\
\hline Malva sylvestris & $\ldots$ & $\ldots$ & .. & $\begin{array}{l}\text { Malvin } \\
6.4 \%\end{array}$ \\
\hline
\end{tabular}

Many phenomena in colour-variation still remain unexplained. One of the most striking anomalies is the absence of blue from some genera, for example Rosa. If Rosa gallica and purple Centaurea Cyanus both contain the same anthocyanin, it is difficult to imagine why Rosa should not give a blue derivative. Since, in Willstätter's opinion, potassium replaces one of the hydroxyls of the anthocyanin molecule

W. P. 
in the blue compound, it might be possible to explain the non-appearance of a blue derivative of some anthocyanins on the assumption that all available hydroxyls are replaced by sugar or methoxyl groups. But to the case of Rosa, apparently, this suggestion cannot be applied. Equally difficult is an explanation for the occurrence of the soluble yellow variety in Dahtia variabilis, when from Centaurea Cyanus it is absent; for both these species are capable of forming the same anthocyanins, cyanin and pelargonin. At one period of investigation it seemed as if the whole range of colour-variation in a species might depend upon the molecular structure and chemical potentialities of the initial chromogen or flavone. But it now seems possible that the explanation of difference in colour-range may be found to lie in the difference in type of the oxybenzoic acids formed in variation by the genus or species in question. From some oxybenzoic acids certain anthocyanins and flavones will be synthesised, from others, a totally, or partially, different set of anthocyanins and flavones. So that the possible extension of the colour-series may depend rather upon these types of oxybenzoic acids than upon the subsequent inter-relationships between the products synthesised-flavones and anthocyanins. 


\section{BIBLIOGRAPHY}

It seemed advisable to classify, to some extent, the list of publications in the Bibliography in order to help the reader, should he require information upon certain branches of the subject. In several cases where publications deal with anthocyanin from more than one aspect, there has been some difficulty in classification. When this was so, a decision has been made in favour of the point of view, physiological, chemical, etc., to which most prominence has been given in the publication in question. In each class of the Bibliography, the publications are arranged chronologically, and, within the year, in the alphabetical order of the authors' names. In this way the arrangement gives information as to the development of the subject along some of the main lines of investigation.

The classes selected are:

1. General work on anthocyanins.

2. Distribution of anthocyanins.

3. Natural occurrence of solid and crystalline anthocyanins.

4. Chemistry of anthocyanins.

5. Factors and conditions influencing the formation of anthocyanins.

6. Physiological significance of anthocyanins.

7. Biological significance of anthocyanins.

8. Anthocyanins and genetics.

9. Unclassified references.

The title, etc., of each paper is accompanied by a short descriptive notice which should not be regarded as a summary of results, but rather as an indication of the nature of the contents. Since many of the shorter and less important publications are not mentioned in the text, they frequently receive in proportion more attention in the Bibliography. On the other hand, the longer and more important publications are usually referred to in detail in the text; in all cases references are given to the text pages. 
The abbreviations for journals, etc., are those used in the International Catalogue of Scientific Literature. Publications marked * are those to which direct access has not been possible; the notice is then taken from a summary or other reference if such has been available.

The publications are numbered 1-645. When reference is made in the text to any publication, the number of the publication is quoted. Under the name also of every author in the General Index, will be found the number or numbers referring to his publications.

\section{GENERAL WORK ON ANTHOCYANINS}

1. 1682. Grew, N., The Anatomy of Plants, with an Idea of $a$ Page of text on which reference Philosophical History of Plants, and sevieral other Lectures, read before the Royal Society, London, 1682.

General consideration of the colours of plants and views as to their origin. Investigations upon yellow, green, red and blue pigments, as regards solubilities and reactions to acids and alkalies, are described.

pp. 2, 47, 104, 203

2. 1799. Senebier, J., Physiologie végétale, Genève, 1799, T. v, pp. 53-77.

A chapter is devoted to the colours of flowers and other parts of plants. Mention is made of the solubilities of pigments, their reactions towards acids and alkalies, and the influence of light and air on their formation.

3. 1828. Macaire-Princep, 'Mémoire sur la coloration automnale des feuilles,' Mém. Soc. Phys., Genève, 1828, Iv, pp. 43-53.

A general account of autumnal coloration and its connection with light and gaseous exchange in leaves. A special hypothesis is formulated, viz., that red pigments are oxidation products of chorophyll.

pp. 89,104

1. 1833. *Candolle, A. P. de, Pflanzenphysiologie oder Darstellung der Lebenskräfte und Lebensverrichtungen der Gewächse, Uebersetzt von I. Röper, Stuttgart und Tübingen, 18331835.

Localisation of red pigment and its appearance in different parts of plants. Vegetative pigments classified into two series, xanthic and cyanic.

5. 1835. *Marquart, L. Cl., Die Farben der Blüthen, Eine chemisch-physiologische Abhandlung, Bonn, 1835.

The term anthocyanin is first used for the red, violet and blue pigments of flowers, and the view is brought forward that it is formed by the dehydration of chlorophyll. To the pigment of yellow flowers the name anthoxanthin is given.

pp. 1, 44, 87, 105 
6. 1837. Meyen, F. J. F., Neues System der Pfanzen-Physiologie, Berlin, 1837, Bd I, pp. 181-189, Bd II, pp. 428-464.

One section is devoted to coloured cell-sap, which is noted as the colouring matter of flowers. Another section is concerned with the formation of colour.

7. Mohl, H. von, 'Untersuchungen über die winterliche Färbung der Blätter,' Dissertation, 1837. Vermischte Schriften botanischen Inhalts, Tübingen, 1845, pp. 375-392.

A summary of the views of previous authors on the origin of anthocyanin from chlorophyll; this hypothesis refuted. General account of the winter reddening of leaves.

8. 1838. Mohl, H. von, 'Recherches sur la coloration hibernale des feuilles,' Ann. sci. nat. (Bot.), Paris, 1838, sér. 2, Ix, pp. 212-235.

A translation of the preceding paper.

9. 1853. Martens, 'Recherches sur les couleurs des végétaux,' Bul. Acad. roy., Bruxelles, 1853, xx (1), pp. 197-235.

An erroneous view is held that there are only two fundamental pigments, anthocyanin and anthoxanthin, and that these combine together to give chlorophyll.

10. 1879. Hildebrand, F., Die Farben der Blüthen, Leipzig, 1879, 83 pages.

A very full account is given of the range of colour and colour varieties in various genera and natural orders. Histologicaldistribution and effect of various factors such as light, temperature, soil, etc., on the formation of pigment.

11. 1884. Hansen, A., Die Farbstoffe der Blüthen und Früchte, Würzburg, 1884, 19 pages.

A general account, though mainly chemical, of various plastid and soluble pigments in plants.

12. 1887. Wigand, A.g 'Die rothe und blaue Färbung von Laub und Frucht,' Botanische Hefte, Forschungen aus dem botanischen Garten zu Marburg, Marburg, 1887, Heft 2, pp. 218-243.

Account of the morphological and histological distribution of anthocyanin; the chromogen of anthocyanin and the factors connected with reddening.

13. 1888. Sewell, P., "The Colouring Matters of Leaves and p. 30 Flowers,' Trans. Bot. Soc., Edinburgh, 1888, xvII. (Pt 2), pp. 276-308.

A short general account of plant pigments.

14. 1889. Dennert, E., 'Anatomie und Chemie des Blumenblatts,' Bot. Centralbl., Cassel, 1889, xxxviII, pp. 425-431, 465-471, 513-518, 545-553. 
An important histological account of various pigments found in the petals of a number of species. Also reactions (chemical) of pigments and their connection with tannin.

15. 1896. Newbigin, M. I., 'An Attempt to classify Common Plant Pigments with some Observations on the Meaning of Colour in Plants,' Trans. Bot. Soc., Edinburgh, 1896, $\mathrm{xx}$, pp. $534-549$.

A short account is included of the physiology and functions of anthocyanin, and some original suggestions are made as to the conditions which bring about its formation. As regards the correlation between the presence of anthocyanin and the absence of chlorophyll, it is suggested that the protoplasm of chlorophyll-containing cells has an alkaline reaction, and this is unfavourable to the formation of anthocyanin.

16. 1898. Newbigin, M. I., Colour in Nature, A Study in Biology, London, 1898.

One chapter (chap. III) is concerned with the colours and pigments of plants.

17 1902. Buscalioni, L., e Pollacci, G., Le antocianine e il loro significato biologico nelle piante, Milano, 1902, 379 pages.

A very full account of anthocyanin from every point of view. First part descriptive: second part experimental, giving results of experiments and observations on histological distribution, reactions, etc., of anthocyanin.

pp. $3,32,35,38,91$

18. 1905. Bidgood, J., 'Floral Colours and Pigments,' J. R. Hort. Soc., London, 1905, xxix, pp. 463-480.

Many interesting observations on flower pigments with suggestions as to their chemical nature. General account of anthocyanin.

pp. $10,39,40$

19. 1906. Gertz, 0., Studier öfver Anthocyan, Akademisk Afhandling, Lund, 1906, Ixxxvii +410 pages.

A very important work on anthocyanin dealing with the pigment from every point of view. The first part is a descriptive account of anthocyanin. The second part gives the results of histological examination of species of every natural order, as regards distribution of anthocyanin. pp. $3,17,26,28,29,30,41,52,84,88,89$

20. 1913. Haas, P., and Hill. T. G., An Introduction to the Chemistry of Plant Products, London, 1913.

Short account of anthocyanin from the point of view of chemistry, physiology and genetics. 


\section{DISTRIBUTION OF ANTHOCYANINS}

21. 1675. Malpighi, M., Anatome Plantarum, London, 1675.

First account of the histology of coloured petals.

22. 1827. Guibourt et Robinet, 'Rapport sur Ia coloration des feuilles à diverses époques de la végétation,' Journal de Pharmacie, Paris, 1827, xIII, pp. 26-27.

A short note on winter coloration of leaves. It is suggested that there is a correlation between the colour of autumn leaves and the colour of ripe fruits in the same plant.

23. 1830. Meyen, F. J. F., Phytotomie, Berlin, 1830, pp. 141-143.

One of the first accounts of the histological distribution of anthocyanin. The red, purple and blue colours of stems, leaves, hairs and petals are stated to be due to coloured cell-sap, and some cases of localisation of pigment are mentioned.

24. 185.7. Chevreul, 'Note sur la couleur d'un assez grand nombre

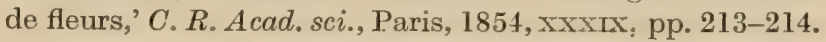

Remarks on composite colour in flowers and leaves.

25. 1857. Chevreul, 'Explication de la zone brune des feuilles du Geranium zonale,' C. R. Acad. sci., Paris, 1857, xLV, pp. 397-398.

Statement that brown colour in the leaf zone is due to the mixture of the complementary colours of green and red (anthocyanin) pigments. The two pigments can be extracted separately and also detected microscopically. The phenomenon can also be reproduced by an artificial blending of the same colours.

26. 1858. *Morren, E., Dissertation sur les fevilles vertes et colorées, envisagées spécialement au point de vue des rapports de la chlorophylle et de l'érythrophylle, Gand, 1858.

Distribution of anthocyanin in variegated leaves.

27. 1860. Irmisch, Th., 'Ueber einige Crassulaceen,' Bot. Ztg., Leipzig, 1860, xvirI, pp. 85-90 (p. 87).

Violet and blue pigments in root tips of species of Sedum, Umbilicus, Sempervivum and Saxifraga.

28. 1861. Chatin, Ad., "Sur la structure anatomique des pétales
comparée à celle des feuilles; une conséquence physiologique des faits observés,' Bull. soc. bot., Paris, 1861, VIII, pp. 22-23.

Pigment of flowers usually present in epidermal cells which are prolonged into papillae. In thicker petals pigment more deep-seated. 
29.

Lowe, E. J., and Howard, W., Beautiful Leaved Plants, London, 1861, 144 pages, 60 figs.

Good illustrations of pigmented (anthocyanin) leaves of tropical species used as ornamental plants.

30. 1863. Hildebrand, F., 'Anatomische Untersuchungen über die p. 19 Farben der Blüthen,' Jahrb. wiss. Bot., Berlin, 1863, IIt, pp. 59-75.

An important account of the pigments in flowers; the form and distribution of pigments in blue, purple, red, orange, yellow and green parts of flowers. pp. 30, 31, 32, 38, 39

31. 1865. Jaennicke, F., 'Ueber gefleckte Blätter,' Bot. Ztg.. Leipzig, 1865, xxiII, pp. 269-271.

Reference to classes of plants with red, green and white leaves.

32. 1866. Kny, L., 'Ueber Bau und Entwickelung der Riccien,' Jahrb. wiss. Bot., Leipzig, 1866-1867, v, pp. 364-386.

Record of the presence of violet pigment in Riccia.

33. Tieghem, $\mathbf{P h}$. van, 'Recherches sur la structure des Aroidées,' Ann. sci. nat. (Bot.), Paris, 1866, sér. 5, vr, pp. 72-200.

Anthocyanin in roots of Aroids.

34. 1870. *Chatin, A., De l'anthère, Recherches sur le développement, la structure et les fonctions de ses tissus, Paris, 1870, pp. $17,22,34,35$.

Occurrence of anthocyanin in anthers.

35. 1874. *Chatin, A., Der Naturforscher, 1874, No. 11 (Biedermanns Centralbl. Agrik. Chem., Leipzig, 1874, vi, p. 111).

Varying localisation of anthocyanin in the leaf at. different ages.

36. *Sempolowski, A., Beiträge zur Kenntniss des Baues der Samenschale, Inaugural-Dissertation, Leipzig, 1874, pp. 16, 23,38 .

Record of red pigments in testa of Lupinus and Vicia seeds.

37. 1877. Fraustadt, A., 'Anatomie der vegetativen Organe von

Dionaea muscipula Ell.,'Beitr. Biol. Pfanzen, Breslau, 1877, II, pp. 27-64 (pp. 57, 60).

Anthocyanin in cells of root-cap of Dionaea.

38. 1880. *Borbás, V., 'Adatok a leveses (húsos) gyümölesök szövettani szerkezetéhez (Beiträge zur histologischen Structur der saftigen (fleischigen) Früchte),' Földmivelési Érdekeink., 1880, No. 37-45.

Localisation of anthocyanin and other pigments in tissues of fruits, such as Berberis, Rivina, Phytolacca, Hedera, Ribes, etc. 
39. *Klein, G., 'A virágok szinéröl (Ueber die Farbe der

Blüten),' Népszerü természettudományi elö-adások gyiujteménye (Sammlung populär naturwissenschaftlicher Vorträge), 1880, Heft 21.

A publication which treats of flower pigments and their distribution: colour-varieties and the significance of flower-colours.

40. 1882. *Koschewnikow, D., 'Zur Anatomie der corollinischen Blüthenhüllen,' Schriften der neurussischen Gesellschaft der Naturforscher, Odessa, 1882, viII (1), pp. 1-199.

Some account of the distribution of anthocyanin in the corolla, petaloid calyx and perianth.

41. Meehan, T., 'Autumn Color of the Bartram Oak,' Bot. Gaz., Indianapolis, 1882, vII, p. 10.

Anthocyanin in Quercus heterophylla.

42. Pirotta, R., 'Intorno alla produzione di radici avventizie nell' Echeveria metallica Lndl.,' Atti Soc. nat. mat., Modena, 1882, ser. 3, I, pp. 73-75.

Adventitious aerial roots, developed from the leaf bases, are coloured red with anthocyanin.

p. 28

43. 1883. Ascherson, P., 'Bemerkungen über das Vorkommen gefärbter Wurzeln bei den Pontederiaceen, Haemodoraceen und einigen Cyperaceen,' Ber. D. bot. Ges., Berlin, 1883, I, pp. 498-502.

List and description of genera and species in which pigmented red and blue roots occur, but no evidence to show that pigment is anthocyanin.

44. Hildebrand, F., 'Ueber einige merkwïrdige Färbungen ron Pflanzentheilen,' Ber. D. bot. Ges., Berlin, 1883, I, pp. xxvii-xxix.

Pigment in roots of Pontederia, Wachendorfia and fruits of Rivina; also in bracts of Euphorbia fulgens.

45. 1884. Johow, Fr., 'Zur Biologie der floralen und extrafloralen Schau-Apparate,' Jahrbuch des Königlichen botanischen Gartens und des botanischen Museums zu Berlin, Berlin, 1884, III, pp. 47-68.

Descriptions of perianths, coloured calyces, bracts, spathes, involucres, floral axes, etc. List of ten different classes of 'Schau-Apparate.'

46. Strasburger, E.., Das botanische Practicum, Jena, 1884, pp. 61-66.

Histological distribution of anthocyanin in various flower petals.

47. 1885. Schimper, A. F. W., 'Untersuchungen über die Chloro- 
phyllkörper und die ihnen homölogen Gebilde,' Jahrb.

wiss. Bot., Berlin, 1885, xvi, pp. 1-247.

Almost entirely an account of plastid pigments. References to soluble pigment in Strelitzia, Billbergia, Delphinium and Glaucium.

48. 1886. Zopf, W., 'Ueber die Gerbstoff- und AnthocyanBehälter der Fumariaceen und einiger anderen Pflanzen,' Bibl. bot., Cassel, 1886, I (2), 40 pages.

An important histological account of anthocyanin. containing sacs in Fumariaceae. In tissues of certain representatives of the family, i.e. spp. of Corydalis, Diclytra, Fumaria and Adlumia, there are isolated cells which contain tannin, together with either anthocyanin or a yellow pigment. Underground organs contain yellow pigment, the organs exposed to sunlight, red. Light brings about the change from yellow to red. Yellow pigment is also converted into red by acids. It is suggested that the process is not one of oxidation.

pp. 27,35

49. 1887. Fintelmann, H., 'Betrachtungen über die Herbstfärbung der Belaubung unsrer Wald-und im freien Lande ausdauernden Schmuck-Gehölze,' Gartenflora, Berlin, 1887, xxxvi, pp. 635-637, 651-656.

List of plants showing various autumnal colorations.

50. Heinricher, E., 'Vorläufige Mittheilung ïber die Schlauchzellen der Fumariaceen,' Ber. D. bot. Ges., Berlin, 1887, v, pp. 233-239.

The author fails to detect tannin in the anthocyanincontaining cells of the Fumariaceae (see No. 48).

51. *Lierau, M., Beiträge zur Kenntniss der Wurzeln der Aracéen, Inaugural-Dissertation der Universität Breslau, Leipzig, 1887.

Anthocyanin formation in roots of Aroids.

52. 1888. *Levi-Morenos, D., 'Contribuzione alla conoscenza dell' antocianina studiata in alcuni peli vegetali,' Atti Ist. ven., Venezia, 1888, vi, ser. 6.

Note on the distribution of anthocyanin in hairs on radical leaves of Scabiosa arvensis and Hieracium Pilosella.

53. 1889. Aitchison, J. E. T., 'The Source of Badsha or Royal Salep,' Trans. Bot. Soc., Edinburgh, 1889, xvII, pp. 434440.

(?) Anthocyanin in roots of Allium giganteum.

54. Claudel, L., 'Sur les matières colorantes du spermoderme dans les Angiospermes,' C. R. Acad. sci., Paris, 1889, ctx, pp. 238-241.

Colouring matter of the testa occurs either in the cell- 
wall or in the cell-cavity. Account of pigmentation in is made

55. several species.

Kny, L., 'Ueber Laubfärbungen,' Sonder-Abdruck aus der Naturwissenschaftlichen Wochenschrift, Berlin, 1889, 28 pages.

Distribution of anthocyanin in leaves.

56. *Potonié, H., 'Die Verbreitung der Samen insbesondere der Paternoster-Erbse,' Natw. Wochenschr., Berlin, 1889, IV, p. 207.

Anthocyanin in testa of seeds.

57. 1890. Fischer, H., 'Beiträge zur vergleichenden Morphologie der Pollenkörner,' Jahresber. Ges. vaterl. Cultur, Breslau, 1890, LxviI, pp. 72-73.

Statement that pollen grains may be coloured with anthocyanin.

58. Levi-Morenos, D., 'Sulla distribuzione peristomatica dell' antocianina in alcuni Sedum,' Nuovo Giorn. bot. ital., Firenze, 1890, xxII, pp. 79-80.

Occurrence of groups, round stomata, of specially shaped epidermal cells (two, three and four in number), containing anthocyanin.

59. 1892. Kronfeld, M., 'Ueber Anthokyanblïten von Daucus Carota,' Bot. Centralbl., Cassel, 1892, xurx, pp. 11-12.

The central purple flower of the inflorescence contains anthocyanin in all its parts.

60. 1893. Haberlandt, G., Eine botanische Tropenreise, Leipzig, 1893, pp. 117-119.

Description of the pendent position and red colour (anthocyanin) of young leaves of certain tropical trees.

61. Müller, L., 'Grundzüge einer vergleichenden Anatomie der Blumenblätter,' Nova Acta der Kaiserlichen Leopoldinisch-Carolinischen Deutschen Akademie der Naturforscher, Halle, 1893, $\operatorname{LIx}(1), 356$ pages.

A very full account of the structure of floral leaves, including the distribution of anthocyanin in the tissues. Also the investigation of the tannin present in petals and the connection between tannins and anthocyanin.

62. Stahl, E., 'Regenfall und Blattgestalt,' Ann. Jard. bot., Buitenzorg, 1893, XI, pp. 98-179.

Examples are mentioned of the development of anthocyanin in young pendent shoots-Hängezweige-in the tropies.

63. Veitch, H. J., 'Autumnal Tints," J. R. Hort. Soc., London, 1893, xv, pp. 46-57.

List of trees and shrubs showing autumnal coloration. 
64. 1898. Berthold, G., Untersuchungen zur Physiologie der pflanzlichen Organisation, Leipzig, Pt 1, 1898, pp. 199-242.

Morphological and histological distribution of anthocyanin in leaves and stems in representatives of a number of natural orders; also in leaves reddened by decortication.

pp. $35,38,82$

65. Diels, L., 'Stoffwechsel und Structur der Halophyten,' Jahrb. wiss. Bot., Berlin, 1898, xxxrr, pp. 309-322.

Appearance of anthocyanin in halophytes.

66. 1899. *Preyer, A., Ueber die Farbenvariationen der Samen einiger Trifolium-Arten, Doktor-Dissertation, Berlin, 1899.

Anthocyanin in testa of seeds of species of Trifolium.

67. Schmidt, F., 'Die Farben der Bliithen,' Die Natur, Halle a. S., 1899, XLVIr, pp. 223-225.

Short account (popular) of the pigments of flowers.

68. 1900. Möbius, M., 'Die Farben in der Pflanzenwelt,' Sonder-

Abdruck aus der Naturwissenschaftliche Wochenschrift, Berlin, 1900, 24 pages.

A general account of pigments, including anthocyanin, found in all classes of the vegetable kingdom. Examples of the occurrence of anthocyanin in leaves, flowers, fruits and seeds.

pp. $27,28,30$

69. *Rodrigue, A., 'Les feuilles panachées et les feuilles colorées,' Mémoire de l'Herbier Boissier, No. 17 B, Genève et Bâle, 1900.

Anthocyanin in variegated leaves.

70. 1902. *Massart, J., 'Comment les jeunes feuilles se protègent contre les intempéries,' Bulletin du Jardin Botanique de l'État à Bruxelles, 1902-1905, I, p. 181.

Localisation of anthocyanin in hairs.

71. *Wulff, Th., Ueher das Vorkommen von Anthocyan bei arktischen Gewächsen, Botanische Beobachtungen aus Spitzbergen, Akademische Abhandlung, Lund, 1902, II.

Arctic vegetation is characterised by abundant production of anthocyanin. Hence periodicity between spring and autumn coloration is less marked.

72. 1903. Burbidge, F. W., "The Leaf-marking of Arum maculatum,' Irish Nat., Dublin, 1903, xuI, p. 137.

The author states that the black spotted form is in general distribution in England, whereas in Ireland the unspotted form is more common.

73. Colgan, N., 'The Leaf-Marking of Arum maculatum,' Irish Nat., Dublin, 1903, xI, pp. 78-81.

The author states that the prevalent plant in Ireland 
is unspotted, and is inclined to believe that the same is

true for Great Britain, though the spotted form may be more abundant in this country than in Treland. Description given of form of spots.

74. Garjeanne, A. J. M., 'Buntblätteriglseit bei Polygonum,' Beihefte zum Bot. Centralbl., Jena, 1903, xıIr, pp. 203-210.

A description of varieties of several species of Polygonum in which chlorophyll is absent from portions of the leaves. Hence the usual dark leaf-blotch of anthocyanin shows bright red.

75. Gunn, W. F., 'Arum maculatum again,' Irish Nat., Dublin, 1903, xII, p. 219.

.Suggestion that black spotted form is a variety.

76. Lindinger, L., 'Anatomische und biologische Untersuchungen der Podalyrieensamen,' Beihefte zum Bot. Centralbl., Jena, 1903, xIv, pp. 20-61.

Mention is made of the histological distribution of anthocyanin in the seed-coats of several genera.

77. Parkin, J., 'On the Localisation of Anthocyan (red cell-sap) in Foliage Leaves,' Rep. Brit. Ass., London, 1903, p. 862 .

Investigation of the seat of anthocyanin in leaves reddened through various causes. See text.

78. Pethybridge, G. H., 'The Leaf-spots of Arum maculatum,' Irish Nat., Dublin, 1903, xII, pp. 145-151.

From data collected, the author finds that the form with spotted (anthocyanin) leaves is less widely distributed in Great Britain than the unspotted. Remarks on the structure and significance of the spot.

79. 1906. Wittmack, L., 'Violette Weizenkörner,' SitzBer. Ges. natf. Freunde, Berlin, 1906, pp. 105-108.

Anthocyanin in outer layers of wheat grain.

80. 1910. Exner, F. und S., 'Die physikalischen Grundlagen der Blütenfärbungen,' Anz. Ak. Wiss., Wien, 1910, xLvII, pp. 11-12.

The authors maintain that, apart from differences in pigmentation, the colours of flowers may be modified by physical phenomena arising from structural features of the petal. Examples are the heightening of epidermal colour by a sub-epidermal air-containing layer; the deadening of tints when pigments of complementary colours are mixed; the raising of colour saturation by reflexion caused by the epidermal papillae.

81. *Paasche, E., Beiträge zur Kenntnis der Färbungen und Zeichnungen der Blüten und der Verteilung von Anthocyan 
und Gerbstoff in ihnen, Dissertation, Göttingen, 1910, 113 pages.

Observations upon the development of anthocyanin in perianth leaves of Tulipa, Anthericum and Asphodelus. Also upon the histological distribution of anthocyanin and tannin.

82. 1911. Coupin, H., 'Sur la localisation des pigments dans le tégument des graines de Haricots,' $C$. R. Acad. sci., Paris, 1911, CLII, pp. 1489-1492.

Account of histological structure of testa of species and varieties of Phaseolus and Dolichos, and distribution of pigments (including anthocyanin) in the testa.

\section{NATURAL OCCURRENCE OF SOLID AND CRYSTALLINE ANTHOCYANINS}

83. 1844. Hartig, Th., Das Leben der Pflanzenzelle, Berlin, 1841. Mention of solid anthocyanin in Solanum nigrum.

84. 1851. Mohl, H. von, Grundzüge der Anatomie und Physiologie der vegetabilischen Zelle, Braunschweig, 1851, p. 47.

Cases of occurrence of solid anthocyanin in Strelitzia Reginae and Salvia splendens.

85. 1855. Nägeli, C., und Cramer, C., Pflanzenphysiologische Unterpp. 31,32 suchungen, Zürich, 1855, Heft 1, pp. 5, 6-7, 31, 41-42, Taf. 2, figs. 1-8.

Plasmolysis of anthocyanin-containing cells and formation of anthocyanin bodies.

86. Unger, F., Anatomie und Physiologie der Pflanzen, Pest, Wien und Leipzig, 1855, pp. 110-111.

Anthocyanin bodies in berries of Passiflora species.

87. 1856. Hartig, Th., 'Weitere Mittheilungen, das Klebermehl pp. 31,32 (Aleuron) betreffend,' Bot. Ztg., Leipzig, 1856, xIv, pp. 257268, 273-281, 297-305, 313-319, 329-335 (pp. 266, 267).

Pigmented aleurone grains.

88. 1857. Böhm, J. A., 'Physiologische Untersuchungen über blaue Passiflorabeeren,' SitzBer. Ak. Wiss., Wien, 1857, xxIII, pp. 19-37.

Crystalline anthocyanin in berries of Passiflora.

89. 1858. Trécul, A., 'Des formations vésiculaires dans les cellules végétales,' Ann. sci. nat. (Bot.), Paris, 1858, sér. 4, x, pp. 20-74, 127-163, 205-376 (pp. 375, 376).

Anthocyanin bodies in Rubus and other species.

90. 1862. Nägeli, C., 'Farberystalloide bei den Pflanzen,' SitzBer. Ak. Wiss., München, 1862 (2), pp. 147-154.

References to crystalline anthocyanin in Solanum. 
91. 1864. Weiss, A., 'Untersuchungen über die Entwickelungs-

geschichte des Farbstoffes in Pflanzenzellen,' SitzBer. Ak. Wiss., Wien, 1864, I (1), pp. 6-35, 1866, LIV (1), pp. 157217.

Appearance of solid blue colouring matter in fruits of Solanum.

pp. $30,31,32$

92. 1870. Rosanoff, S., 'Zur Morphologie der Pflanzenfarbstoffe,' Bot. Ztg., Leipzig, 1870, xxviı, pp. 720-723.

Record of anthocyanin bodies in Neptunia oleracea.

93. 1883. Schimper, A. F. W., 'Ueber dio Entwickelung der Chlorophyllkörner und Farbkörper,' Bot. Ztg., Leipzig, 1883, XLI; pp. 105-112, 121-131, 137-146, 153-160.

Mention of blue colour-bodies in Glaucium.

94. 1884. Fritsch, P., 'Ueber farbige körnige Stoffe des Zellinhalts,' Jahrb. wiss. Bot., Berlin, 1884, xIV, pp. 185-231.

Chiefly concerned with plastid pigment. Solid anthocyanin noted in Delphinium.

95. Pim, G., 'Cell-sap Crystals,' J. Bot., London, 1884, xxiI, p. 124.

Formation of crystals in cells of Justicia speciosa by placing sections of stamen in glycerine gelatine.

96. 1887. *Hanausek, T. F., und Bernowitz, V., 'Ueber die Farbstoffkörper des Pimentsamens,' Zs. Allg. Oest. A pothVer., Wien, 1887, No. 16, pp. 253-256.

Colour of seeds of Pimenia is due to the presence, in the cells, of large dark red masses which give the reactions of anthocyanin.

97. 1888. Courchet, L., 'Recherches sur les chromoleucites,' Ann. sci. nat. (Bot.), Paris, 1888, sér. 7, vil, pp. 263-370.

Summary of cases of occurrence of anthocyanin in the form of globules and deposits.

98. *Hansen, A., 'Ueber Sphärokrystalle,' Arbeiten des botanischen Instituts in Würzburg, Leipzig, 1888, III, p. 92 .

Formation of anthocyanin sphaerites similar to those of inulin.

99. 1889. Bokorny, Th., 'Ueber Aggregation,' Jahrb. wiss. Bot., Berlin, 1889, xx, pp. 427-473.

Anthocyanin bodies in Primula sinensis.

p. 32

100. 1898. *Tschirch, A., 'Violette Chromatophoren in der Frucht-
schale des Kaffees,' Schweiz. Wochenschr. Chem., Zürich,

p. 32 1898, xxxvi.

Solid anthocyanin in fruit of Coffea arabica. Deep violet, or blue-black, globules and crystals in the epidermal and sub-epidermal layers.

p. 32 
101. 1899. *Wallin, G., 'Om egendomliga innehållskroppar hos Bromeliaceerna,' Kongl. Fysiografiska Sällskapets i Lund Handlingar, $1899, \mathrm{x}(2)$.

Occurrence of deposits, coloured with anthocyanin, in cells.

102. 1900. Kroemer, K., 'Ueber das angebliche Vorkommen von p. 35 violetten Chromatophoren,' Bot. Centralbl., Cassel, 1900. Lxxxiv, pp. 33-35.

Pigment of pericarp of Coffea fruits shown to consist of violet crystals of anthocyanin.

103. 1904. Spiess, K. von, 'Ueber die Farbstoffe des Aleuron,' Oest. Bot. Zs., Wien, 1904, LIV, pp.' 440-446.

Blue colour, in aleurone grains of Maize, due to anthocyanin.

104. 1905. Molisch, H., 'Ueber amorphes und kristallisiertes Anthokyan,' Bot. Ztq., Leipzig, 1905, LxIII, pp. 145-162.

Important account of a number of cases of crystalline and amorphous anthocyanin in tissues of living plants. Also of preparation of crystalline anthocyanin outside the cell. Summary of chief researches and other work on anthocyanin.

pp. $31,32,34,45,46,66$

105. 1906. Gertz, O., 'Ett nytt fall af kristalliseradt anthocyan,' Bot. Not., Lund, 1906, pp. 295-301.

Perianth leaves of Laportea moroides (Urticaceae) become red and fleshy after flowering. The author observed crystals of anthocyanin in the tissues; crystals dimorphous.

106. 1914. Gertz, O. 'Nya iakttagelser öfver anthocyankroppar,' Sv. Bot. Tidskr., Stockholm, 1914, viII, pp. 405-435.

Further observations on anthocyanin bodies and crystals.

\section{CHEMISTRY OF ANTHOCYANINS}

107. 1664. Boyle, R., Experiments and Considerations touching Colours, London, 1664.

An account is included of the colour changes which take place on adding acids and alkalies to extracts from flowers and other parts of plants; also the effect of sulphur dioxide on flower pigments.

pp. $2,8,49,55,57$

108. 1670. Wray, J., "Extract of a Letter written to the Publisher,' Phil. Trans. R. Soc., London, 1670, v, pp. 2063-2066.

The following observation on Chicory flowers is recorded: 'Bare an Ant-hill with a stick, and then cast 
the flowers upon it, and you shall see the Ants creep very thick over them. Now as they creep, they let fall a drop of liquor from them, and where that chanceth to light, there you shall have in a moment a large red stain.' 'The author was able to show eventually that the same colora tion could be obtained by treating the petals with various acids.

109. 1671. Lister, M., 'Some Observations, touching Colours, in order to the Increase of Dyes, and the Fixation of Colours,' Phil. Trans, R. Soc., London, 1671, vi, pp. 2132-2136.

Among other reactions, it is noted that the green parts of plants give a yellow colour with alkalies.

110. 1807. Braconnot, H., 'Observations sur le phytolncca, vulg. raisin d'amérique,' Annales de Chimie, Paris, 1807, LxנI, pp. 71-90.

An extract is made of the berries, and the effect of various reagents is tried, such as acids, alkalies, salts of metals. It is noted that the behaviour of the pigment towards reagents is different from that of other fruits.

111. 1808. Melandri, G., 'Extrait d'une lettre de M. G. Melandri, docteur en médecine, à Milan, à M. Bouillon-Lagrange," Annales de Chimie, Paris, 1808, Lxv, p. 223.

Use of pigment of fruits of Atropa Belladonna as an indicator.

112. 1818. Smithson, J., 'A few facts relative to the colouring matters of some vegetables,' Phil. Trans. R. Soc., London, 1818 (1), pp. 110-117.

Reactions of pigments of Violet, Black Mulberry and Corn Poppy towards acids, alkalies, etc. The view is held that probably all these pigments are the same substance.

113. 1820. Chevallier, A., 'Sur la manière dont se comporte avec les acides et les alcalis la matière colorante des baies de sureau (sambucus nigra) appliquée sur le papier,' Journal de Pharmacie, Paris, 1820, vi, pp. 177-178.

Action of acids and alkalies on pigment. Different acids are said to give characteristic reactions with paper soaked with the pigment.

114. 1822. Payen, A., et Chevallier, A., "Sur la fleur de la mauve p. 44 sauvage (malva sylvestris), et particulièrement sur la matière colorante de ses pétales, employée comme réactif, soit en teinture, soit étendue sur le papier pour démontrer la présence des alcalis,' Journal de Pharmacie, Paris, 1822, viII, pp. 483-488.

The pigment is said to be very sensitive to alkalies, and hence is of value as an indicator. 
115. Payen, A., et Chevallier, A., 'Sur la matière colorante des fruits du bois de Sainte-Lucie, cerasus mahaleb,' Journal de Pharmacie, Paris, 1822, vIII, pp. 489-490.

Action of acids and alkalies on the pigment.

116. 1825. Roux, J., 'D'analyse chimique de la fleur de tilleul ('Tilia europaea, L.), et de celle de la belle-de-nuit,' Journal de Pharmacie, Paris, 1825, xi, pp. 507-512.

Method for extracting pigment from flowers is described. Also solubilities and reactions with acids and alkalies.

117. Schübler, G., und Franck, C. A., Untersuchungen über die Farben der Blüthen, Inaugural-Dissertation, Tübingen, 1825, 38 pages.

A number of observations on the action of acids, alkalies and other reagents on flower pigment extracts. Hypothesis of two series of pigments-oxidised and deoxidised.

p. 8

118. 1834. Kuhlmann, F., 'Betrachtungen iiber den Einfluss des Sauerstoffs auf die Färbung der organischen Produkte und über die Wirkung der schweflichten Säure als Entfärbungsmittel,' Annalen der Pharmacie, Heidelberg, 1834, Ix, pp. 275-291.

Remarks on the bleaching of flower-pigments with sulphurous acid.

119. 1836. Hünefeld, 'Beiträge zur Chemie der Metamorphose der Pflanzenfarben,' J. prałt. Chem., Leipzig, 1836, Ix, pp. 217238.

Experiments to test the effect on flower-pigments of a number of reagents, such as oxygen, carbon dioxide. water, acids, alkalies, alcohol, metallic salts, etc.

120. Hünefeld, 'Das mit schwefeliger Säure gesảuerte Wasser als Mittel zur Erleichterung der mikroskopischen Untersuchung von Pflanzentheilen,' J. prakt. Chem., Leipzig, 1836, Ix, pp. 338-241.

Bleaching of pigments with sulphurous acid. 
Cyanus by extracting flowers, and analyses are made of product. Pigment also prepared from Scilla nutans, but more unstable.

pp. $8,47,58,59$

123. 1851. Schönbein, C. F., 'Ueber das Verhalten organischer Farbstoffe zur schweflichten Säure,' J. prakt. Chem., Leipzig, 1851, LIII, pp. 321-331.

Pigment of both blue and red flowers bleached by sulphurous acid.

124. Schönbein, C. F., 'Ueber die Einwirkung der schweflichten Säure auf Blumenfarbstoffe,' J. prakt. Chem., Leipzig, 1851, LIV, pp. 76-78.

Further observations on the bleaching of pigments of flowers and autumnal leaves.

125. 1854. Filhol, E., 'Observations sur les matières colorantes des fleurs,' C. R. Acad. sci., Paris, 1854, xxxIx, pp. 194-198.

Observation that white flowers turn yellow with alkalies. Yellow colour destroyed again by acids. Substance which is thus affected is in solution in the cell-sap, is soluble in water and alcohol, and less so in ether. Red flowers turn blue or green with alkalies, the green being due to a mixture of blue and yellow.

126. Fremy, E., und Cloëz, 'Ueber die Farbstoffe der Blumen," J. prakt. Chem., Leipzig, 1854, LXII, pp. 269-275.

An account of the properties of soluble blue (cyanin), red and yellow (xantheïn) plant pigments.

pp. $8,44,47$

127. 1855. Martens, 'Nouvelles recherches sur la coloration des plantes,' Bul. Acad. roy., Bruxelles, 1855, xxII (1), pp. $157-179$.

Observations upon substances in plants which turn yellow with alkalies (now known to be flavones). Erroneous suggestion that they form pigment of yellow plastids.

128. 1856. *Mulder, G. J., Chemie des Weines, Leipzig, 1856.

129. 1858. Glénard, A., 'Recherches sur la matière colorante du vin,' Ann. chim. phys., Paris, 1858, sér. 3, LIV, pp. 366-376.

Preparation and analysis of pigment of wine. See text.

130. Glénard, A., 'Ueber den Farbstoff des Weines,' J. prakt.

pp. $8,58,59$ Chem., Leipzig, 1858, Lxxv, pp. 317-318.

Same as previous paper.

131. 1859. Nicklès, J., "Sur la matière colorante du troëne et son application à la recherche des eaux potables,' J. pharm. chim., Paris, 1859, xxxv, pp. 328-334.

An account of the properties and extraction of the pigment of Privet (Ligustrum) berries. Preparation by precipitation with lead acetate, decomposition with 
sulphuretted hydrogen and subsequent purification. Found to contain carbon, hydrogen and oxygen only, but no constant analysis results. Reactions with acids, alkalies, salts of metals and various natural waters. Pigment termed liguline.

132. 1860. Filhol, E., "Note sur quelques matières colorantes végétales,' C. R. Acad. sci., Paris, 1860, L, pp. 545-547.

Further account of the properties of the substance which gives a yellow colour in white flowers on treatment with alkali. It was found to occur also in green parts of plants and to be analogous to luteolin; absent from some flowers, Pelargonium and Papaver, which become blue or violet with alkalies.

pp. $8,49,50$

133. Filhol, E., 'Nouvelles recherches sur les matières colorantes végétales,' C. R. Acad. sci., Paris, 1860, I, pp. 1182-1185.

Author is of the opinion that there is only one kind of red or blue soluble pigment (cyanine). Differences in colour due to other substances in the cell-sap.

134. 1862. Chevreul, 'Observations sur la propriété décolorante' de l'eau oxygénée mêlée avec plusieurs matières colorées d'origine organique,' C. R. Acad. sci., Paris, 1862, LV, pp. $737-738$.

Action of hydrogen peroxide on soluble flower pigments. Bleaching takes place.

135. Wiesner, J., 'Einige Beobachtungen über Gerb- und Farbstoffe der Blumenblätter,' Bot. Ztg., Leipzig, 1862, xx, pp. 389-392.

Researches on reactions given by tissues with iron salts and alkalies. If a colourless cell-sap contains a tannin which gives a green colour reaction with iron salts, it also gives a yellow reaction with allkalies: if a blue reaction with iron salts, no colour with alkalies. Anthocyanin itself gives a blue colour with alkalies, never green. Hence, when the former kind of tannin is present with anthocyanin, the cell-sap gives a green, i.e. blue plus yellow, reaction with alkalies; when the latter, a blue reaction only.

136. Wigand, A., 'Einige Sätze über die physiologische Bedeutung des Gerbstoffes und der Pflanzenfarbe,' Bot. Ztg., Leipzig, 1862, xx, pp. 121-125.

Distribution of tannin and pigments in leaves, stems and flowers. It is stated that anthocyanin has no relation to chlorophyll, but arises from a colourless chromogen, which is a tannin, and gives a yellow colour with alkalies. 
The chromogen, on oxidation, gives rise to anthocyanin.

is made

With alkalies, blue anthocyanin turns green, then yellow; red anthocyanin turns first blue, then green, and finally yellow.

pp. $8,44,50,58,91,106$

137. 1866. Gmelin, L., Fortsetzung des Handbuchs der organischen Chemie, Heidelberg, 1866, Bd Iv (2), pp. 1421-1430.

Important summary of chemical work on anthocyanin up to this period.

138. 1867. Nägeli, C., und Schwendener, S., Das Mitrostiop, p. 105 Leipzig, 1867, II, pp. 500-509.

An account of the reactions of anthocyanin including a discussion on the significance of its reaction with alkalies.

139. Sorby, H. C., 'On a definite Method of Qualitative Analysis of Animal and Vegetable Colouring-Matters by means of the Spectrum Microscope,' Proc. R. Soc., London, 1867, xv, pp. 433-455.

The spectrum microscope can be applied to the examination of pigments of flowers and fruits. Methods de. scribed for use and preparation of pigments to be examined. Numerous reagents are used for developing spectra, and a classification of the latter is outlined.

140. 1870. Schönn, 'Ueber Blattgrün und Blumenblau,' Zs. anal. Chem., Wiesbaden, 1870, Ix, pp. 327-328.

Note on spectroscopic examination of pigments.

141. 1871. Vries, H. de, 'Sur la perméabilité du protoplasma des betteraves rouges,' Arch. Néerl. Sci. Soc. Holl., Haarlem, 1871, vi, pp. 117-126.

Relative permeability of living and dead protoplasm to coloured cell-sap.

142. 1872. Wiesner, J., 'Untersuchungen über die Farbstoffe einiger für chlorophyllfrei gehaltenen Phanerogamen,' Jahrb. wiss. Bot., Leipzig, 1872, viI, pp. 575-594.

Pigment bodies in Neottia Nidus-avis and Orobanche spp. Red pigment of Orobanche. Discussion as to the nature of the-anthocyanin reaction with alkalies.

p. 50

p. 50

p. 29

143. 1873. Kraus, C., 'Ueber die Ursache der Färbung der Epidermis vegetativer Organe der Pflanzen,' Flora, Regensburg, 1873, xxxI, pp. 316-317.

Suggestions as to chemical substances from which anthoeyanin is derived.

144. Sorby, H. C., 'On Comparative Vegetable Chroma. tology,' Proc. R. Soc., London, 1873, xxт, pp. 442-483.

Method of separation of plastid pigments from others by means of carbon bisulphide as a solvent. Spectro. scopical examination of all kinds of pigments. Suggestion 
that red pigment in leaves is produced by the action of light on chlorophyll under circumstances not yet reproduced. Presence or absence of pigment due to equilibrium, or ahsence of the same, between constructive and destruc. tive agencies. Colour of flowers due to erythrophyll, and frequently exactly the same as in the leaves.

145. 1875. Bořšcow, El., 'Notiz uiber den Polychroïsmus einer alkoholischen Cyaninlösung,' Bot. Ztg., Leipzig, 1875, xxxirr, pp. 351-352.

A hot alcoholic extract was made from flowers of $A j u g a$ reptans and $A$. pyramidalis, and it was found that the pigment showed continuous changes in fluorescence as the solutions cooled.

146. 1876. Pellagri, G., 'Sull' uso della fllocianina come reattivo,' Gazz. chim. ital., Palermo, 1876, vi, pp. 35-38.

Anthocyanin in dilute solution can be used as a very sensitive reagent for alkalies.

147. 1877. Church, A. H., 'Coleïn,'Ber. D. chem. Ges., Berlin, 1877, $\mathrm{x}(1)$, p. 296.

Preparation and analysis of red pigment from leaves and stem of Coleus Verschaffelii. See text.

148. Senier, H., 'The Colouring Matter of the Petals of Rosa gallica,' Pharm. J., London, 1877, ser. 3, viI, pp. 650-652.

Extraction and analysis of red pigment. Chief point of interest is the preparation of crystalline salts of the pigment with alkali metals. See text.

149. 1878. Gautier, A., 'Sur les matières colorantes des vins,' C. R. Acad. sci., Paris, 1878, Lxxxvi, pp. 1507-1510.

View that plant pigments are formed from colourless tannic acids which redden on oxidation. Preparation and analyses of pigments from wines. It has been shown by later investigators that products were mixtures. See text.

pp. $9,58,60,106$

150. 1879. Hilger, A., 'Ueber den Farbstoff der Familie der Caryophyllinen,' Landw. Versuchstat., Berlin, 1879, xхпI, pp. $456-461$.

Investigation of pigments of representatives of orders included under Centrospermae, i.e. Beta, Phytolacca, Chenopodium and Amaranthus. Pigments found to be similar, both as regards spectra and chemical reactions, but to differ from other red and violet pigments. Preparation of pigment from Phytolacca, but no analyses.

151. 1880. Lepel, F. von, 'Pflanzenfarbstoffe als Reagentien auf Magnesiumsalze,' Ber. D. chem. Ges., Berlin, 1880, xIII (1), pp. $766-768$. 
Spectroscopic examination of a number of red and blue anthocyanin pigments. Development of spectra after addition of magnesium salts.

152. Schnetzler, J. B., 'Ueber Veränderungen des rothen p. 56 Farbstoffes von Paeonia officinalis unter dem Einfluss chemischer Reagentien,' Bot. Centralbl., Cassel, 1880, I, p. 682 .

Short note on the action of acids, alkalies, iron salts, etc., on anthocyanin.

153. Schnetzler, J. B., 'Observations sur les matières colorantes des fleurs,' Bul. Soc. Sci. Nat., Lausanne, 1880, XVII, pp. 96-98. flowers.

Note on reactions of colouring matter of Paeonia

154. Schnetzler, J. B., 'Ueber den rothen Farbstoff der - Blätter von Ampelopsis hederacea,'Bot. Centralbl., Cassel. 1880, I, pp. 247-248.

Slight note on anthocyanin of Ampelopsis. Reactions with alkalies, etc.

155. *Schnetzler, J. B., 'De la couleur des fleurs,' Les Mondes, 1880 , LIII, p. 158.

Author contradicts the supposition that various flower colours are due to different chemical substances, on the ground that Paeonia anthocyanin gives different colours with various reagents. Statement is made that reddening of leaves in autumn is due to the action of tannin on chlorophyll, and that chlorophyll is at the basis of all flower pigments.

156. 1882. Husemann, A., Hilger, A., und Husemann, Th., Die Pflanzenstoffe in chemischer, physiologischer, pharmakologischer und toxikologischer Hinsicht, Berlin, 1882, Bd 1, pp. 259-260.

Short account of anthocyanin from the chemical point of view:

157. Maumené, E. J., 'Sur l'œnocyanine,' C. R. Acad. sci., Paris, 1882, xcv, p. 924.

Green grapes dried in vacuo over sulphuric acid do not redden, but, on exposure to air, pigment is rapidly formed. Hence conclusion that colouring matter (oenocyanin) is - formed from a colourless chromogen by oxidation and possibly hydration.

158. 1883. Gardiner, W., 'On the general occurrence of Tamnins in the vegetable cell and a possible view of their physio. logical significance,' Proc. Phil. Soc., Cambridge, 1883, Iv, pp. 388-395. 
Slight reference to connection of anthocyanin with tannins.

159. 1884. Flesch. M., 'Notiz ïber die Anwendung des Farbstoffes des Rothkohls in der Histologie,' Zs. wiss. Mikrosk., Braunschweig, 1884, I, pp. 253-254.

Anthocyanin as a stain.

160. Lavdowsky, M., 'Myrtillus, ein neues Tinctionsmittel für thierische und pflanzliche Gewebe,' Arch. mikr. Anat., Bonn, 1884, XXIII, pp. 506-508.

Anthocyanin from berries of Vaccinium Myrtillus used as a stain for plant and animal tissues.

161. *Marquis, E., 'Ueber den Farbstoff des kaukasischen Rothweines, seine Isolirung, quantitative Bestimmung und chemische Reaktion,' Pharmaceutische Zeitschrift für Russland, 1884, xхıI, pp. 7, 20.

162. *Marquis, E., 'Ueber die Zersetzung des isolirten Pig. ments des kaukasischen Rothweines durch Wärme,' Pharmaceutische Zeitschrift für Russland, 1884, xxıI, p. 186.

163. 1885. Lindt, 0 ., 'Ueber den Nachweis von Phloroglucin,' $Z s$. wiss. Mikrosk., Braunschweig, 1885, II, pp. 495-499.

Connection between phloroglucin and anthocyanin formation.

164. Terreil, 'Faits pour servir à l'histoire de la matière colorante du vin et des matières colorantes rouges des végétaux,' Bul. soc. chim., Paris, 1885, xuIv, pp. 2-6.

Exposition of Terreil's reaction for anthocyanins.

165. 1886. Vries, H. de, 'Ueber die Aggregation im Protoplasma von Drosera rotundifolia,' Bot. Ztg., Leipzig, 1886, xLIV, pp. 1-11, 17-26, 33-43, 57-62.

Some microchemical reactions in anthocyanin-containing cells.

166. 1887. *Jonas, V., Photometrische Bestimmung der Absorptionsspektra roter und blauer Blütenfarbstoffe, Inaugural-Dissertation, Kiel, 1887.

167. 1889. Heise, R., Zur Kenntniss des Rothueinfarhstoffes, Berlin, 1889.

Account of preparation and properties of two pigments obtained from grapes. See text.

pp. $9,58,60$

168. Molisch, H., 'Ueber den Farbenwechsel anthokyan. hältiger Blätter bei rasch eintretendem Tode,' Bot. Ztg., Leipzig, 1889, xLVII, pp. 17-23.

Red leaves of Coleus and Perilla, when boiled with water, lose red colour and give yellowish or greenish solution, to which red colour returns on acidification. 
Author maintains that loss of colour is due to alkalinity of dead tissues, and that acidity of cell-sap is essential for preservation of red colour.

169.

Müller, N. J. C., 'Spectralanalyse der Blüthenfarben;' Jahrb. wiss. Bot., Berlin, 1889, xx, pp. 78-101.

Observations on spectra and fluorescence of various anthocyanins in solution in both sulphuric acid and potash.

170. 1890. Lacour, E., 'Note sur le suc et la matière colorante du phytolacca,' J. pharm. chim., Paris, 1890, xxI, pp. 243-245.

Note on the pigment of Phytolacca which is used for colouring wines. Action of acids, alkalies, salts of metals; solubilities of pigment, etc.

171. Macchiati, L., 'Ricerche preliminari sulle sostanze coloranti delle gemme foglifere del castagno indiano,' Nuovo Giorn. bot. ital., Firenze, 1890, xxII, pp. 76-78.

Slight note on extraction of red pigment from budscales of Horse Chestnut.

172. Waage, Th., 'Ueber das Vorkommen und die Rolle des Phloroglueins in der Pflanze,' Ber. D. bot. Ges., Berlin, 1890, vIII, pp. 250-292.

Connection of phloroglucin with anthocyanin.

173. * *Zopf, W., Die Pilze in morphologischer, physiologischer, biologischer und systematischer Beziehung, Breslau, 1890.

Decomposition of anthocyanin by Moulds.

174. 1891. *Lidforss, B., 'Ueber die Wirkungssphäre der Glycoseund Gerbstoffreagentien,' Kongl. Fysiografiska Sällskapets $i$ Lund Handlingar, Ny Följd., Bd 3, Lund, 1891-1892, IX.

Reduction of Fehling's solution by anthocyanin in its capacity of a glucoside.

175. 1892. Gautier, A., 'Sur l'origine des matières colorantes de la vigne; sur les acides ampélochroïques et la coloration automnale des végétaux,' C. R. Acad. sci., Paris, 1892, CxIV, pl. 623-629.

Account of isolation, purification and properties of three pigments from Vine leaves. See text.

pp. $9,24,46,58,61,82,84,106$

176. Glan, R., Ueber den Farbstoff des schwarzen Malve (Althaea rosea), Inaugural-Dissertation, Erlangen, 1892.

Full account of preparation, properties and analysis of pigment. See text.

177. *Haverland, Fr., Beiträge zur Kenntniss der in den Früchten von Phytolacea decandra (Kermesbeeren) enthaltenen Bestandtheile, Inaugural-Dissertation, Erlangen, 1892. 
178. 1894. Heise, R., 'Zur Kenntniss des Heidelbeerfarbstoffes,' Arb. Gesundhtsamt, Berlin, 1894, Ix, pp. 478-491.

Preparation, purification and analysis of pigments from Bilberry fruits. See text.

179. 1895. Weigert, L., 'Beiträge zur Chemie der rothen Pfianzenfarbstoffe,' Jahresbericht und Programm der k. k. önologischen und pomologischen Lehranstalt in Klosterneuburg, Wien, 1895, pp. i-xxxi.

Scheme for differentiation of anthocyanin pigments by means of qualitative tests into two groups, 'Weinroth' and 'Rübenroth.'

180. 1897. Beilstein, F., Handbuch der organischen Chemie, 1897, Bd III, pp. 651-652.

Short account of anthocyanin from chemical point of view.

181. Carles, P., et Nivière, G., 'Influence des matières colorantes sur la fermentation des vins rouges très colorés,' C. R. Acad. sci., Paris, 1897, cxxv, pp. 452-453.

Explanation offered is that tannin nature of colouring matters acts as an antiseptic and inhibits the fermentation.

182. Sostegni, L., 'Sulle materie coloranti delle uve rosse,' Gazz. chim. ital., Roma, 1897, xxvII (2), pp. 475-485.

Extraction and analysis of pigments from grapes.

183. 1898. Dippel, L., Das Mikroskop und séine Anwendung, Braunschweig, 1898, Th. 2, pp. 65-66, 105-106, 108-109.

Solubilities and other properties of anthocyanin.

184. 1899. Claudius, M., 'Ueber die Anwendung einiger gewöhnlicher Pflanzenfarbstoffe in der mikroskopischen Färbungs. technik,' Centralbl. Bakt., Jena, 1899, v, pp. 579-582.

Use of anthocyanin for histological staining.

185. Keegan, P. Q., 'Experiments on the Floral Colours,' Nature, London, 1899, LXT, pP. 105-106.

Reactions of anthocyanin with alkalies, salts, etc.

186. 1900. Formánek, J., 'Der Farbstoff der rothen Rübe und sein Absorptionsspectrum,' J. prakt. Chem., Leipzig, Neue Folge, 1900, LxiI, pp. 310-314.

Account of normal spectrum and of those developed with acid and alkali respectively.

187. Miyoshi, M., 'Ueber die kiinstliche Aenderung der p. 56 Bliitenfarben,' Bot. Centralbl., Cassel, 1900, Lxxxm, pp. $345-346$.

Reactions of alum salts, acids and alkalies on various anthocyanins. Bearing on Molisch's results with Hydrangea (see No. 467). 
188. 1901. Goppelsroeder, Fr., Capillaranalyse beruhend auf Capillaritäts- und Adsorptionserscheinungen mit dem Schlusskapitel: Das Emporsteigen der Farbstoffe in den Pflanzen, Basel, 1901.

Method which can be adapted to the separation of mixtures of pigments in solution. Strips of specially prepared filter paper are allowed to dip slightly into the solutions, and the various pigments rise by capillarity to different heights. By cutting off zones of paper, and by repetition of the process, a certain amount of pure pigment can be obtained.

189. 1902. Bouffard, A., 'Action de l'acide sulfureux sur l'oxydase et sur la matière colorante du vin rouge,' $C$. R. Acad. sci., Paris, 1902, cxxxiv, pp. 1380-1383.

Action of acid considered to be twofold: first, preservation of the colour of the wine, and secondly, a destructive action on the oxidising enzyme.

190. Sostegni, L., 'Sulle materie coloranti delle uve rosse,' Gazz. chim. ital., Roma, 1902, xxxı (2), pp. 17-19.

Continuation of analysis of pigment from grapes.

191. 1903. Griffiths, A. B., 'Die Pigmente des Geraniums und anderer Pflanzen,' Ber. D. chem. Ges., Berlin, 1903, xxxvi (4), pp. 3959-3961.

Account of analyses and properties of pigment. pp. 46, 58, 63

192. Ichimura, T., 'On the Formation of Anthocyan in the Petaloid Calyx of the Red Japanese Hortense,' J. Coll. Sci., Tokyo, 1903-1904, xviII, art. 3, pp. 1-18.

Stages of development of anthocyanin in the calyx. View that pigment arises from a tannin-like substance, protanthocyan, which gives a yellow colour with alkalies, and is probably identical with Wigand's cyanogen (see No. 136). In final stages, violet crystals of pigment were observed.

193. 1904. Kraemer, H., 'The Origin and Nature of Color in Plants,' Proc. Amer. Phil. Soc., Philadelphia, Pa., 1904, XLIII, pp. 257-277.

Method for extraction and separation of plastid and soluble pigments. Reactions with acids, alkalies, and other reagents are represented in tables.

194. Naylor, W. A. H., and Chappel, E. J., "Note on the Colouring Matters of Rosa Gallica,' Pharm. J., London, 1904, ser. 4, xIx, pp. 231-233.

Preparation of the pigment.

195. 1905. Czapek, Fr., Biochemie der Pfanzen, Jena, 1905, Bd r, pp. $471-477$. 
Good general account of anthocyanin, chiefly from the chemical point of view.

196. Kastle, J. H., 'A Method for the Determination of the Affinities of Acids Colorimetrically, by Means of Certain Vegetable Coloring Matters,' Amer. Chem. J., Baltimore, Md., 1905, xxxII, pp. 46-59.

Solutions of anthocyanin from purple grapes, red Pelargonium and purple Petunia flowers were bleached with sulphur dioxide, and then used colorimetrically to test the 'strength' of a number of acids by amount of return of colour. The resulting order corresponds closely to that given by Ostwald's methods:

197. 1906. Grafe, V., 'Studien über das Anthokyan (I. Mitteilung),' SitzBer. Ak, Wiss., Wien, 1906, CxV (Abt. 1), pp. $975-993$.

Important paper on preparation and analyses of pigments from flowers of Althaea rosea. See text.

pp. $9,46,47,50,55,58,63$

198. 1907. Toni, J.-B. de, 'Observations sur l'anthocyane d'Ajuga et de Strobilanthes,' C.R. ass. franc. avanc. sci., Paris, 1907 ( $2^{\mathrm{e}}$ partie), pp. 415-418.

Repetition of Bořšcow's experiment on fluorescence (see No. 145). Phenomenon explained by Molisch's view of alkalinity of dying tissues (see No. 168). Solution of Strobilanthes pigment heated to $90^{\circ}$ loses properties of anthocyanin.

199. 1908. Laborde, J., 'Sur l'origine de la matière colorante des raisins rouges et autres organes végétaux,' $C . R . A c a d$. sci., Paris, 1908, cxlvr, pp. 1411-1413.

Author obtains tannin-like chromogens from unripe grapes of both green and red varieties. Chromogens become red on heating with dilute hydrochloric acid at $120^{\circ}$. Investigation of these substances should explain reddening of leaves and fruits, and also why white grapes do not develop pigment, although containing chromogen.

200. Laborde, J., 'Sur les transformations de la matière chromogène des raisins pendant la maturation,' C.R. Acad. sci., Paris, 1908, cxlvII, pp. 753-755.

Chromogen of pigment, which is in insoluble form in green fruit, becomes more and more soluble as fruits mature. Change probably brought about by a diastase.

201. Laborde, J., 'Sur le mécanisme physiologique de la coloration des raisins rouges et de la coloration automnale des feuilles,' C.R. Acad. sci., Paris, 1908, cxuvir, pp. 993-995.

Conclusion that anthocyanin is formed from tannin- 
like substances. Red products are obtained by the action is made

202. of various reagents on tannins.

p. 106

Malvezin, $\mathbf{P h}$., 'Sur l'origine de la couleur des raisins rouges,' C. $R$. Acad. sci., Paris, 1908, CxLviI, pp. 384-386.

Water extracts of unripe red (or white) grapes, heated for 24 hours at $85^{\circ}$, give red pigment, but not in absence of air. Absence of pigment in white grapes in nature is due to lack of diastase, but high temperature will cause oxidation (artificially).

203. Palladin, W., 'Ueber die Bildung der Atmungschromogene in den Pflanzen,' Ber. D. bot. Ges., Berlin, 1908, xxvi $a$, pp. $389-394$.

Suggestion that anthocyanin is a respiration pigment. pp. $11,58,91,99,101,107$

204. Portheim, L. von, und Scholl, E., 'Untersuchungen über die Bildung und den Chemismus von Anthokyanen,'Ber. D. bot. Ges., Berlin, 1908, xxvi $a$; pp. 480-483.

Method described for purification of anthocyanin by dialysis. Anthocyanin is also prepared from testas of seeds of Phaseolus multiflorus by extraction with alcohol. By fractional crystallisation, yellow and red crystalline products are obtained.

205. Russo, Ph., 'Des pigments floraux,' C. R. soc. biol., p. 46 Paris, 1908, cxv, pp. 579-581.

Examination of pigments of many flowers with tournesol paper leads to the conclusion that, in the cyanic series, flower colour varies in tint according to the greater or less acidity of the cell-sap.

206. Sorby, H. C., 'On the Colouring Matters of Flowers,' Nature, London, 1908, LxxvI, pp. 260-261.

Note on the solubilities of various flower pigments; also observations as regards spectra.

207. 1909. Combes, R., 'Rapports entre les composés hydrocarbonés et la formation de l'anthocyane,' $A n n$. sci. nat. (Bot.), Paris, 1909, sér. 9, Lx, pp. 275-303.

View held that an increase in amount of sugars and glucosides in tissues leads to increase in formation of anthocyanin. Estimation is made of glucosides and sugars in various green and red leaves. Found that red leaves contain considerably greater quantities of these substances than green control leaves.

208. Combes, R., 'Recherches biochimiques sur le développement de l'anthocyane chez les végétaux,' C. R. Acar. sci., Paris, 1909, cxlviII, pp. 790-792.

Same results as in preceding paper. 
Grafe, V., 'Studien über das Anthokvan (II. Mitteilung),' SitzBer. Ak. Wiss., Wien, 1909, cxvIII (Abt. 1), pp. 1033-1044.

Further researches on anthocyanin from flowers of Althaea. See text.

pp. $45,58,63$

210. Palladin, W., 'Ueber das Wesen der Pflanzenatmung,' Biochem. Zs., Berlin, 1909, xviII, pp. 151-206.

Full account of the significance of anthocyanin as a respiration pigment.

pp. 11,107

211. Wheldale, M., 'The Colours and Pigments of Flowers, with Special Reference to Genetics,' Proc. R. Soc., London, 1909, Lxxxi B, pp. 44-60.

Attempt to show that there is some correlation between the chemical reactions of pigments and their behaviour in genetics. Recognition of a certain number of types which give rise to a definite series of colour varieties. pp. 39, 51, 56, 91

212. Wheldale, M., 'On the nature of anthocyanin,' Proc. Phil. Soc., Cambridge, 1909, xv, pp. 137-161.

Suggestion, made for the first time, that anthocyanins are formed from chromogens, which are glucosides of flavones, or possibly, xanthones, by the action of oxidase. Successive oxidation stages may give rise to the series, red, purplish-red and purple pigments. pp. 11, 56, 91, 109, 224

213. Wheldale, M., "Note on the Physiological Interpretation of the Mendelian Factors for Colour in Plants,' Rep. Evol. Com. Roy. Sor., London, 1909, Rpt. 5, pp. 26-31.

Expression of colour-factors in terms of oxidases and reductases.

214. 1910. *Dezani, S., 'Le sostanze cromogene dell' uva bianca,' Staz. sper. agr. ital., Modena, 1910, XLIII, pp. 428-436.

Substance found in white grapes which gives oenocyanin-like products on treatment with hydrochloric acid.

215. *Sacher, J. F., 'Der Farbstoff der roten Radieschen,' Chem. Ztg., Cöthen, 1910, xxxrv, p. 1333.

Properties of colouring matter of radish as indicator.

216. *Schwertschlager, J., 'Der Farbstoff der roten Radieschen,' Chem. Ztg., Cöthen, 1910, xxxıv, p. 1257.

Properties of colouring matter of the radish.

217. Wheldale, M., 'Plant Oxidases and the Chemical Interrelationships of Colour-Varieties,' Progr. rei bot., Jena, 1910, IIJ, pp. 457-473.

Chiefly a résumé of papers published by author in 1909. pp. 11, 224

218. 1911. Abderhalden, E., Biochemisches Handlexikon, Berlin, 1911, Bd vi, pp. 182-183.

Short account, chiefly chemical, of anthocyanin. 
Combes, R., 'Recherches sur la formation des pigments anthocyaniques,' C. R. Acad. sci., Paris, 1911, cuIII, pp. $886-889$.

Microchemical tests for anthocyanin and its chromogen in tissues of Ampelopsis.

220. Combes, R., 'Recherches microchimiques sur les pigments anthocyaniques,' $C$. $R$. ass. franç. avanc. sci., Paris, 1911, pp. 464-471.

Same as preceding paper.

221. Gautier, A., 'Sur les mécanismes de la variation des races et les transformations moléculaires qui accompagnent ces variations,' C. R. Acad. sci., Paris, 1911, clIII, pp. 531539.

Connection between variation and chemical constitution. Analyses of pigments from different varieties of grapes.

222. Grafe, V., 'Studien über das Anthokyan (III. Mitteilung),' SitzBer. Ak. Wiss., Wien, 1911, Cxx (Abt. 1), pp. 765-807.

Important paper on the red pigment of Pelargonium flowers. See text.

pp. $9,46,55,56,58,66$

223. Kastle, J. H., and Haden, R. L., 'On the Color Changes occurring in the Blue Flowers of the Wild Chicory, Cichorium Intybus,' Amer. Chem. J., Baltimore, Md., 1911, xLVI, pp. 315-325.

Author shows that changes in colour exhibited by flowers on withering are due, in part, to variations in amount of acid in the pigmented cells, and, in part, to the action of an oxidase which oxidises and destroys the plant pigment.

224. Nierenstein, M., und Wheldale, M., 'Beitrag zur Kenntnis der Anthocyanine. 1. Ueber ein anthocyaninartiges Oxydationsprodukt des Quercetins,' Ber. D. chem. Ges., Berlin, 1911, xuIv (3), pp. 3487-3491.

Description of a red pigment formed on oxidation of quercetin with chromic acid. Properties of oxidised pro. duct resemble anthocyanin in some respects.

225. Politis, I., 'Sopra speciali corpi cellulari che formano Antocianine,' Rend. Acc. Lincei, Roma, 1911, xx, pp. 828834.

Hypothesis, supported by microscopical and microchemical observations, that anthocyanin is produced by special bodies termed cyanoplasts, which contain tannin substances capable of forming anthocyanin. On disintegration of cyanoplast, anthocyanin colours the cell-sap. 
226. Wheldale, M., 'On the Formation of An
J. Genetics, Cambridge, 1911, I, pp. 133-157.

226. Wheldale, M., 'On the Formation of Anthocyanin,
J. Genetics, Cambridge, 1911, I, pp. 133-157.

It is suggested that anthocyanin is formed from glucosides of xanthones and flavones, and that the reaction takes place in two stages. First, the hydrolysis of glucosides by an enzyme, and then the oxidation of the free flavone by oxidase. Summary of evidence in favour of the hypothesis.

pp. 11, 101, 112

227.

*Wissemann, E., Beiträge zur Kenntnis des Auftretens und der topographischen Verteilung von Anthocyan und Gerbstoff in vegetativen Organen, Dissertation, Göttingen, 1911,110 pages.

Respective distributions of anthocyanin and tannin and connection between the same.

228. 1912. *Chodat, R., 'Les pigments végétaux,' Verhandl. schweiz. Naturforsch. Ges., 95 Jahresversamml., Altdorf, 1912, pp. 79-95.

Action of tyrosinase on gallic acid produces a series of pigments resembling anthocyanin in their reactions. Suggestion made that anthocyanin is derived from tannins.

229. Keeble, F., and Armstrong, E. F., 'The Oxydases of Cytisus Adami,' Proc. R. Soc., London, 1912, Lxxxv B, pp. $460-465$.

Oxidase reactions of flowers of $C$.purpureus, C. Adami and $C$. Laburnum support view of Baur that Adami is a periclinal chimera, composed externally of purpureus and internally of Laburnum.

230. Keeble, F., and Armstrong, E. F., 'The Distribution of Oxydases in Plants and their Rôle in the Formation of Pigments,' Proc. R. Soc., London, 1912, Lxxxv B, pp. 214218.

Oxidase tests upon tissues of plants of all varieties of $P$. sinensis support view that anthocyanin is the product of activity of an oxidase, and that albinism in Primula is due to loss of chromogen.

231. Keeble, F., and Armstrong, E. F., 'The Rôle of Oxydases in the Formation of the Anthocyan Pigments of Plants,' J. Genetics, Cambridge, 1912, II, pp. 277-309.

Previous paper in greater detail.

232. Nierenstein, M., 'Beitrag zur Kenntnis der Anthocyanine. II. Ueber ein anthocyanin-artiges Oxydationsprodukt des Chrysins,' Ber. D. chem. Ges., Berlin, 1912, xLV (1), pp. 499-501.

Description of a red pigment, formed on oxidation of chrysin by chromic acid, and similar to that prepared by 
the same method from quercetin (see No. 224). Product

resembles anthocyanin in some of its properties, since it gives a blue colour with alkalies, and red with concentrated sulphuric acid.

233. 1913. Atkins, W. R. G., 'Oxidases and their Inhibitors in Plant Tissues,' Sci. Proc. R. Soc., Dublin, 1913, xrv (N. S.), pp. 144-156.

Account of oxidase tests with tissues of various plants. Special attention given to comparison of distribution of oxidases and pigment in the genus Iris.

234.

Combes, R.. 'Production expérimentale d'une anthocyane identique à celle qui se forme dans les feuilles rouges en automne, en partant d'un composé extrait des feuilles vertes,' $C . R$. Acad. sci., Paris, 1913, clvir, pp. 1002-1005.

By treating yellow pigment (flavone) occurring in Ampelopsis with nascent hydrogen, the author obtains a purple substance which he maintains to be identical with natural anthocyanin. Hence, contrary to previous views, anthocyanin formation from a flavone is brought about by reduction, not oxidation. See text.

pp. 14, 121

235. Combes, R., 'Passage d'un pigment anthocyanique extrait des feuilles rouges d'automne au pigment jaune contenu dans les feuilles vertes de la même plante,' $C . R$. Acad. sci., Paris, 1913, cLvII, pp. 1454-1457.

Crystalline anthocyanin from Ampelopsis is converted into a flavone by oxidation with hydrogen peroxide. See text.

pp. 14, 121

236. Combes, R., 'Untersuchungen iiber den chemischen Prozess der Bildung der Anthokyanpigmente,' Ber. D. bot. Ges., Berlin, 1913, xxxi, pp. 570-578.

Repetition of last two papers.

237. Jones, W. N., 'The Formation of Anthocyan Pigments of Plants. Part 5. 'The Chromogens of White Flowers,' Proc. R. Soc., London, 1913, Lxxxvi B, pp. 318-323.

Investigations on presence of chromogens and oxidases in white flowers. See text.

238. Jones, W. N., 'Some Investigations in Anthocyan Formation,' Ren. Brit. Ass., London, 1913, p. 713.

Anthocyanin formation considered to be the result of an oxidase system. Summary of previous papers.

239. Keeble, F., Armstrong. E. F., and Jones, W. N., 'The Formation of the Anthocyan Pigments of Plants. Part 4. The Chromogens,' Proc. R. Soc., London, 1913, Lxxxvi B, pp. $308+317$.

Hypothesis, that anthocyanin is formed by oxidation W. P. 
of ehromogen by an oxidase, is further supported by phenomena connected with the behaviour of pigment in alcohol and water solutions. See text.

pp. 47,119

240. Keeble, F., Armstrong, E. F., and Jones, W. N., 'The Formation of the Anthocyan Pigments of Plants. Part 6.' Proc. R. Soc., London, 1913, LxxxvII B, pp. 113-131.

Purple pigments are obtained by treatment of flower extracts with nascent hydrogen, and subsequent oxidation. Suggestion that preliminary reduction plays a part in pigment formation.

pp. 13, 122, 123

241. Molisch, H., Mikrochemie der Pfanze, Jena, 1913, pp. 236-241.

Microchemical reactions of anthocyanin; occurrence as crystals, etc.

242. Peche, K., "Ueber eine neue Gerbstoffreaktion und ihre Beziehung zu den Antholyyanen,' Ber. D. bot. Ges., Berlin, 1913, xxxI, pp. 462-471.

A new microchemical reaction for tannins which gives a colour resembling anthocyanin. Cells containing irongreening tannins give, with potash solution and formol, a blue-green pigment which becomes red with acids, and is similar to anthocyanin except in its solubilities.

243. Tswett, M., 'Beiträge zur Kenntnis der Anthocyane. Ueber künstliches Anthocyan,' Biochem. Zs., Berlin, 1913, IVIII, pp. 225-235.

Artificial anthocyanin-like substances can be obtained from alcoholic extracts of many colourless parts of plants by treatment with aldehyde and hydrochloric acid. See text.

244. Wheldale, M., 'The Flower Pigments of Antirrhinum majus. 1. Method of Preparation,' Biochemicai Journal, Cambridge, 1913, vII, pp. 87-91.

Preparation and purification of anthocyanin pigments from varieties of Antirrhinum majus. See text.

pp. $12,58,69,113$

245. Willstätter, R., und Everest, A. E., 'Ueber den Farbstoff der Kornblume,' Liebigs Ann. Chem., Leipzig, 1913, сCCCI, pp. 189-232.

Method of extraction and preparation of blue pigment from Cornflower. Suggestions as to constitutional formulae for red, purple and blue anthocyanins. See text.

pp. $13,45,46,47,50,52,56,58,72,112$

246. 1914. Atkins, W. R. G., 'Oxidases and their Inhibitors in Plant Tissues. Part 2. The Flowers and Leaves of Iris,' Sci. Proc. R. Soc., Dublin, 1914, xIv (N. S.), pp. 157-168. 
Correlation between distribution of anthocyanin and that of oxidases and inhibitors.

247. Atkins, W. R. G., 'Some Recent Work on Plant Oxidases,' Sci. Progr., London, 1914, Ix, pp. 112-126.

Summary of situation as regards connection between pigment formation and oxidase reactions.

248. Everest, A. E., 'The Production of Anthocyanins and Anthocyanidins,' Proc. R. Soc., London, 1914, Lxxxviı B, pp. 444-452.

Account of the production of pigments, which are claimed to be true anthocyanins, by reduction of flavones with nascent hydrogen. See text.

249. Everest, A. E., 'The Production of Anthocyanins and Anthocyanidins. Part 2.' Proc. R. Soc., London, 1914, LxxxviI B, pp. 326-332.

Further evidence to prove identity of artificial and natural anthocyanins which has been questioned by Willstätter and also by Wheldale and Bassett.

250. Everest, A. E., 'A Note on Wheldale and Bassett's p. 123 Paper "On a supposed Synthesis of Anthocyanin,", J. Genetics, Cambridge, 1914, IV, pp. 191-192.

Further remarks on the identity of artificial and natural anthocyanins.

251. Hall, A. D., Armstrong, E. F. and H. E., Keeble, F., and Russell, E. J., "The Study of Plant Enzymes, particularly with relation to Oxidation,' Rep. Brit. Ass., London, 1914, pp. 108-109.

It is pointed out that every oxidation involves also a reduction. Hence the concurrence in distribution between oxidases and pigments need not necessarily prove the pigments to be formed by oxidation. Some such view becomes necessary if the reduction hypothesis of anthocyanin formation be retained.

252. Tswett, M., "Zur Kenntnis des "vegetabilischen Chamaeleons," "Ber. D. bot. Ges., Berlin, 1914, xxxiI, pp. 61-68.

Discussion of the acid and alkali reactions of anthocyanin, and Willstätter's hypothesis as regards them. Also Keeble and Armstrong's explanation of losis of colour of anthoeyanin in alcohol which is disbelieved by author ('Tswett). Further remarks on author's artificial anthocyanin.

253. Wheldale, M., 'Our Present Knowledge of the Chemistry of the Mendelian Factors for Flower-Colour,' J. Genetics, Cambridge, 1914, IV, pp. 109-129.

Summary of work on subject. 
254. Wheldale, M., and Bassett, H. Ll., 'The Flower Pig. ments of Antirhinum majus. . 3. The Red and Magenta Pigments,' Biochemical Journal, Cambridge, 1914, vIII, pp. 204-208.

Purification and analyses of anthocyanins. See text.

pp. $12,46,50,58,69,122$

255. Wheldale, M., and Bassett, H. Ll., 'On a supposed Synthesis of Anthocyanin,' J. Genetics, Cambridge, 1914, IV, pp. 103-107.

Criticism of a paper by Everest who maintains that natural anthocyanins can be obtained by reduction of the flavones. See text.

256. Willstätter, R., 'Ueber die Farbstoffe der Bliiten und Früchte,' SitzBer. Ak. Wiss., Berlin, 1914, pp. 402-411.

Preparation and analyses of anthocyanins from $\mathrm{Del}$ phinium and other flowers, and fruits of Grape Vine, Bilberry and Cranberry. Suggestions for the constitution of anthocyanin. See text.

pp. $13,45,58,76$

257. Willstätter, R., und Mallison, H., 'Ueber die Verwandtschaft der Anthocyane und Flavone,' SitzBer. Ak. Wiss., Berlin, 1914, pp. 769-777.

Constitution for anthocyanins suggested. Anthocyanins regarded as forming a reduced series from flavones. Production of anthocyanin experimentally by reduction of a flavone. See text.

pp. $13,15,45,58,76,124$

258. 1915. Atkins, W. R. G., 'Oxidases and Inhibitors in Plant 'Tissues. Part 4. The Flowers of Iris,' Sci. Proc. R. Soc., Dublin, 1915, xIV (N. S.), pp. 317-327.

Further observations on the distribution of oxidases in Iris flowers; it is found that the distribution does not coincide with that of anthocyanin. Difference possibly due to inhibitors of oxidases.

259. Cockerell, T. D. A., 'Characters of Helianthus,' Torreya, Lancaster, Pa., 1915, xv, pp. 11-16.

Some reactions of Helianthus anthocyanin are described.

260. Everest, A. E., 'Recent Chemical Investigations of the Anthocyan Pigments and their Bearing upon the Production of these Pigments in Plants,' J. Genetics, Cambridge, 1915 , IV, pp. 361-367.

Chiefly a summary of Willstätter's work.

261. Everest, A. E., 'The Anthocyan Pigments,' Sci. Progr., London, 1915, Ix, pp. 597-612.

General review of work on the subject.

262. Schiemann, E., 'Neuere Arbeiten über Bildung der Blütenfarbstoffe. Sammelreferat vom Standpunkte der 
Mendelspaltung,' Zs. indukt. Abstammungslehre, Leipzig,

1915, xIV, pp. 80-96.

Résumé of work on the subject.

263.

Wheldale, M., 'Our Present Knowledge of the Chemistry of the Mendelian Factors for Flower-Colour, Part 2,'

J. Genetics, Cambridge, 1915, IV, pp. 369-376.

Summary of work on anthocyanin continued.

\section{FACTORS AND CONDITIONS INFLUENCING THE FORMATION OF ANTHOCYANINS}

264. 1816. *Voigt, F. S., Die Farben der organischen Körper, Jena, 1816, p. 19.

Reference to the effect of light on the formation of soluble pigments.

265. 1848. Middendorff, A. Th. von, Reise in den üussersten Norden und Osten Sibiriens, St Petersburg, 1848-1875, Bd IV (1), p. 674.

Appearance of anthocyanin in plants in Arctic regions.

265. 1860. Duchartre, P., 'Note sur le Lilas blanchi par la culture forcée,' Bul. soc. bot., Paris, 1860, vil, pp. 152-155.

Purple lilaes, cultivated at $35^{\circ}$ and in darkness, produce white flowers, but any lowering of temperature, or exposure to light, causes development of colour.

267. Treviranus, L. C., 'Ueber den Wechsel des Grünen und Rothen in den Lebenssäften belebter Körver,' Bot. Ztg., Leipzig, 1860, xvII, pp. 281-288.

Discussion as to factors and causes bringing about reddening of leaves.

268. 1863. Corenwinder, B., 'Expiration nocturne et diurne des feuilles. Feuilles colorées,' C. R. Acad. sci., Paris, 1863 , LVII, pp. 266-268.

Red leaves behave in exactly the same way as green leaves with respect to assimilation of carbon dioxide.

269. Sachs, J., 'Ueber den Einfluss des 'Tageslichts auf Neubildung und Entfaltung verschiedener Pflanzenorgane,' Beilage zu Bot. Ztg., Leipzig, 1863, xxт, 30 pages.

Author, by experiment, detects two classes of flowers, of which one develops normal coloration without the buds being previously exposed to light; the other only develops normally coloured flowers when the buds have been exposed to light up to the time of unfolding. Experiments conducted in total darkness.

pp. 5, 88, 89

270.

Wied, Prinz Maximilian zu, 'Eine Frage an die Herren 
Botaniker ïber die Ursachen der schönen Herbstfärbung der Baumvegetation im nördlichen Amerika,' Arch. Natg., Berlin, 1863, xxıx, pp. 261-266.

Relation between geographical position and intensity of autumnal coloration.

271. 1865. Sachs, J., "Wirkung des Lichts auf die Bliithenbildung unter Vermittlung der Laubblätter,' Bot. Ztg., Leipzig, 1865, xхII, pp. 117-121, 125-131, 133-139.

Experiments on the effect on development and coloration of flowers of darkening certain shoots only, the remainder of the plant being in the light.

272. 1868. *Hallier, E., Phytopathologie, Die Krankheiten der Culturgewächse, Leipzig, 1868, p. 101.

Anthocyanin in roots of Salix.

273. 1870. *Weretennikow, J., Arbeiten der St. Petersburger Gesellschaft der Naturforscher, 1870, I (1), p. 57.

Reddening of seedlings of Polygonum and other plants is entirely absent in the dark.

274. 1871. Colladon, D., 'Effets de la foudre sur les arbres et les plantes ligneuses,' Mém. Soc. Phys., Genève, 1871-1872, XxI, pp. 501-584.

Injury brought about by lightning may act like artificial ringing, and cause leaves above point of injury to turn red.

275. Wiesner, J., 'Untersuchungen über die herbstliche Entlaubung der Holzgewächse,' SitzBer. Ak. Wiss., Wien, 1871, LXIV (1), pp. 465-510.

Paper includes a short account of autumnal coloration and various causes and conditions connected with it. Greater acidity noted in autumnal leaves.

276. 1872. Kraus, C., "Weitere Mittheilungen über die winterliche Färbung immergrüner Gewächse,' SitzBer. physik. Soc, Erlangen, 1872, Heft 4, pp. 62-65.

$\mathrm{L}$ ow temperature is the most important factor in anthocyanin production.

277. 187.3. *Kraus, C., 'Studien über die Herbstfärbung der Blätter und über Bildungsweise der Pflanzensäuren,' Buchner's Neues Repertorium für Pharmacie. München, 1873, xxII, p. 273.

View that production of anthocyanin is augmented by acidity of cell-sap

278. Rafarin, 'Coloration des feuilles à l'automne,' Rev. hortic., Paris, 1873, pp. 50-51.

Red and yellow autumn pigments exist in a latent state in the green leaves. 
279. 1874. Chargueraud, A., 'Observations sur la coloration des

feuilles à l'automne,' Rev. hortic., Paris, 1874, pp. 34-36.

Remarks on causes of autumnal coloration.

280. Chargueraud, A., 'Influence du froid sur la coloration des feuilles du Phalaris picta,' Rev. hortic., Paris, 1874, pp. 248-249.

Formation of anthocyanin in white portions of varie. gated leaves of $P$. arundinacea picta when exposed to frost.

281. 1875. Kraus, C., 'Pflanzenphysiologische Untersuchungen.

7. Ueber die Einwirkung von Pflanzensäuren auf Chlorophyll innerhalb der Pflanzen,' Flora, Marburg, 1875, xхxuI, pp. 365-368.

Acidity of cell-sap augments the formation of anthoeyanin.

282. 1876. Askenasy, E., 'Ueber den Einfluss des Lichtes auf die Farbe der Blüthen,' Bot. Ztg., Leipzig, 1876, xxxIv, pp. 1-7, 27-31.

Investigations on various plants as to whether they require light for the production of normal colour in flowers.

283. Haberlandt, G., 'Untersuchungen über die Winterpp. $5,85,88$ färbung ausdauernder Blätter,'SitzBer. Ak. Wiss., Wien,

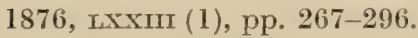

Account of winter reddening of leaves. Reddening due to low temperature at night and bright light by day.

284. Mer, E., 'Des phénomènes végétatifs qui précèdent ou accompagnent le dépérissement et la chute des feuilles,' Bul. soc. bot., Paris, 1876, xxiII, pp. 176-191.

Observations on the reddening of leaves of Cissus quinquefolia.

285. Schell, J., "Wirkung einiger Einflïsse auf die Färbung der Pflanzen,' Beilage zu dem Protocolle der 75. Sitzung der Naturforscher-Gesellschaft an der Universität zu Kazan, Kazan, 1876. Reference in Justs bot. Jahresber., Berlin, 1876 , IV, p. 717 .

Effect of light and temperature on reddening of scedlings of Polygonum, Rumex, ete.

286. 1877. Mer, E., 'Recherches sur les causes des colorations diverses qui apparaissent dans les fetulles en automne et en hiver,' Bul. soc. bot., Paris, 1877, xxıv, pp. 105-114.

Anthocyanin no connection with chlorophyll. Formation of pigment as a result of injury caused by animal and vegetable parasites. Oxygen necessary for the appearance of pigment. 
287. Schell, J., 'Ueber die Pigmentbildung in den Wurzeln einiger Salix-Arten,' Beilage zu dem Protocolle der 95. Sitzung der Naturforscher-Gesellschaft an der Universitüt zu Kazan, Kazan. Reference in Justs bot. Jahresber., Berlin, 1877 , v, p. 562.

Light causes formation of colour in adventitious roots of Salix sp. grown in water in glasses.

288. 1878. Bonnier, G., et Flahault, Ch., 'Sur les variations qui se produisent avec la latitude dans une même espèce végétale,' Bul. soc. bot., Paris, 1878, xxv, pp. 300-306.

Colours of flowers more intense in Norway than those of the same species in France. Discussion of the subject.

289. Bonnier, G., et Flahault, $\mathbf{C h}_{\text {., 'Observations sur les }}$ modifications des végétaux,' Ann. sci. nat. (Bot.), Paris, 1878, sér. 6, vII, pp. 93-125.

Intensity of flower colour increases in Northern latitudes.

290. Flahault, Ch., 'Nouvelles observations sur les modifications des végétaux,' Ann. sci. nat. (Bot.), Paris, 1878, sér. 6 , Ix, pp. 159-207.

Effect of latitude on formation of pigment. Of a number of species grown bot!n in Upsala and Paris, individuals in the former district produced the more vividly coloured flowers.

p. 6

p. 6

291. Pellat, A., 'Sur quelques variations que prísentent les végétaux avec l'altitude,' Bul. soc. bot., Paris, 1878, xxv, pp. 307-308.

Greater intensity of colour at high altitudes.

292. 1878. Flahault, Ch., 'Sur la formation des matières colorantes dans les végétaux,' Bul. soc. bol., Paris, 1879, xxvi, pp. 268-273.

Connection between pigment formation and both light and reserves of nutritive substances.

293. 1880. Batalin, A., 'Die Einwirkung des' Lichtes auf die Bildung des rothen Pigmentes,' Acta horti Petr., St Petersburg, 1880, vi (Fas. 2), pp. 279-286.

Effect of light on pigment production in seedlings.

294. Bonnier, G., 'De la variation avec l'altitude des matières colorées des fleurs chez une même espèce végétale,' Bul. soc. bot., Paris, 1880, xxvi, pp. 103-105.

Colours of flowers of various species increase in intensity with altitude.

295. *Pynaert, E., 'De l'influence de la lumière sur la coloration des feuilles,' Congrès de Botanique et d'Horticulture de 1880 tenu à Bruxelles, Partie 2, p. 53. 
296. 1881. Meehan, Th., 'Color in Autumn Leaves,' Proc. Acarl. Nat. Sci., Philadelphia, Pa., 1881, pp. 454-456.

Description of plants producing anthocyanin in salt marshes of New Jersey. Discussion as to the greater production of anthocyanin in American as compared with European species of the same genus. No definite conclusion as to causes.

297. 1882. Costerus, J. C., 'Seasonal Order in Colours of Flowers,' Nature, London, 1882, xxv, pp. 481-482.

Observations on the development of colour in flowers and fruits in the dark. Conclusion that formation of pigment largely depends upon the supply of chromogen at the time of darkening. For production of chromogen, light is necessary.

298. *Müller-Thurgau, H., 'Ueber den Einfluss der Belaubung auf das Reifen der Trauben,' Weinbaucongress zu Dürkheim a.d. H., 1882.

Coloration of fruits of Vitis takes place in the dark.

299. Schunck, E., 'Remarks on the Terms used to denote p. 88 Colour, and on the Colours of Faded Leaves,' Chem. News, London, 1882, xLV, pp. 17-20.

Short, somewhat popular, account of colour in autumnal leaves.

300. 1883. Heckel, E.g 'Sur l'intensité du coloris et les dimensions considérables des fleurs aux hautes altitudes,' Bul. soc. bot., Paris, 1883, xxx, pp. 144-154.

High mountain plants owe intense colour to strong insolation rather than to insect visitation.

301. Kraus, C., 'Beiträge zur Kenntniss des Verhaltens der leicht oxydablen Substanzen des Pflanzensaftes,' Ber. $D$. bot. Ges., Berlin, 1883, I, pp. 211-216.

Development of pigment in Dahlia tubers as a result of oxidation.

302. 1884. Sorby, H., 'On the Autumnal Tints of Foliage,' Nature, Jondon, 1884, xxxi, pp. 105-106.

Slight note on autumnal coloration.

303. 1885. Beyerinck, M. W., 'Die Galle von Cecidomyia Poae an Poa nemoralis. Entstehung normaler Wurzeln in Folge der Wirkung eines Gallenthieres,' Bot. Ztg., Leipzig, 1885, XIIII, pp. 305-315, 321-331.

Coloured roots formed in the region of an injury caused by gall insect.

304. 1886. Sorauer, P., Handbuch der Pflanzenkrankheiten, Berlin, p. 28 $1886, \mathrm{Bd}$ T, p. 324. 
Connection of anthocyanin formation with infection by parasites.

pp. 31,83

305. 1887. Dufour, L., 'Influence de la lumière sur la forme et la structure des feuilles,' Ann. sci. nat. (Bot.), Paris, 1887, sér. 7, v, pp. 311-413 (pp. 331, 352, 353, 405).

Observations made on various plants indicate that anthocyanin is only developed in parts of organs exposed to the sun. Anthocyanin noted in roots of Maize exposed to the light.

306. Martin, W. K., and Thomas, S. B., 'The Autumnal Changes in Maple leaves,' Bot. Gaz,, Crawfordsville, Indiana, 1887, xII, pp. 78-81.

Slight note on autumnal coloration and its effect on cell-contents, etc.

307. 1888. Bonnier, G., 'Étude expérimentale de l'influence dı climat alpin sur la végétation et les fonctions des plantes,' Bul. soc. bot., Paris, 1888, xxxv, pp. 436-439.

Of individuals of the same species grown both in the High Alps and in a lowland station, the former had more highly coloured flowers.

308. Devaux, 'De l'action de la lumière sur les racines croissant dans l'eau,' Bul. soc. bot., Paris, 1888, xxxv, pp. 305-308.

Reddening of roots of Maize growing in water and exposed to light.

309. 1889. Emery, 'Sur les variations de l'eau dans les périanthes,' Bul. soc. bot., Paris, 1839, xxxvi, pp. 322-333.

Anthocyanin is not found in flowers kept under water although exposed to sunlight.

310. Goiran, A., 'Di una singolare esperienza praticata sopra le corolle di Cyclamen persicum,' Nuovo Giorn. bot. ital., Firenze, 1889, XxI, p. 415.

Petals, with purplish-red base, of a white variety of Cyclamen persicum giganteum were partially cut across. After a time, the cut edge developed anthocyanin of the same colour as that at the base of the petals.

311... Kraus, G., Grundlinien zu einer Physiologie des Gerbstoffs, Leipzig, 1389.

Artificial ringing of the stem and consequent production of anthocyanin in the leaves above.

312. 1890. *Benecke, Fr., 'Over de bordeaux-roode kleur der p. 101 suikerrietwortels,' Mededeelingen van het Proefstation 'Midden-Java' te Semarang, 1890, 77 pages.

Question as to whether 'Bordeaux-red' colour (antho. cyanin) of sugar cane is normal or pathological. Author 
finds development of pigment is dependent on light, and is made

313. concludes, from experiments, that colour is not caused by disease, but is a normal development and protects root-tip from too intense light.

Curtel, G., 'Recherches physiologiques sur les enveloppes florales,' C. R. Acad. sci., Paris, 1890, cxI, pp. 539-541.

Greater respiratory activity in coloured than in white flowers. This energetic oxidation leads, among other things, to formation of anthocyanin pigments from tannins.

314. *Hieronymus, G., 'Beiträge zur Kenntniss der europäischen. Zoocecidien und der Verbreitung derselben,' Jahresher. Ges. vaterl. Cultur, Breslau. 1890, p. 49.

Work on galls and connection of anthocyanin development with these structures.

315. *Laurent, E., 'Influence de la radiation sur la coloration des raisins,' Comptes rendus des séances de la Société Royale de Botanique de Belgique, Bruxelles, 1890, xxix (2), p. 71 .

Colour of grapes develops in the dark.

316. *Molisch, H., 'Blattgrün und Blumenblau,' Vorträge des Vereines zur Verbreitung naturwissenschaftlicher Kenntnisse in Wien, Wien, 1890, $\mathrm{xxx}(3)$.

General account of anthocyanin is included, in which author emphasises fact that drought favours development of the pigment.

317. 1891. Cockereil, T. D. A., 'The Alpine Flora: with a Suggestion as to the Origin of Blue in Flowers,' Nature, London, 1891, XLIII, p. 207.

Preponderance of blue in high mountain flowers. Suggestion that blue is metabolically the most complex of the colours, and that great concentration of metabolism, correlated with dwarf structure, may lead to the formation of the most complex pigments in the inflorescence.

318. *Heim, F., 'Influence de la lumière sur la coloration du périanthe de l'Himantophyllum variegatum,' Bulletin mensuel de la Société Linnéenne de Paris, 1891, ı, p. 932.

Intensity of coloration of flower is directly proportional to the amount of light received. This is contrary to Sachs' view that light does not influence colour so long as leaves can assimilate.

319. Massalongo, C., 'Sull' alterazione di colore dei fiori dell' Amarantus retroflexus infetti dalle oospore di Cystopus Bliti,' Nuovo Giorn. bot. ital., Firenze, 1891, xxm, pp. 165167.

Anthocyanin is developed in the inflorescence when 
infected with Cystopus. Suggestion that inflorescence thereby becomes attractive, and possibly spores may be disseminated by insects in consequence.

320. Noll, F., 'Einfluss des Lichtes auf die herbstliche Verfärbung des Laubes,' Verh. nathist. Ver., Bonn, 1891, XLVII, p. 80 .

Autumnal coloration dependent on exposure to light. Natural photographs, in green on a red ground, obtained by the shading of one leaf by another.

321. . Ráthay, E., 'Ueber eine merkwürdige, durch den Blitz an Vitis vinifera hervorgerufene Erscheinung,' Denkschr. $A k$. Wiss., Wien, LVIII, 1891, pp. 585-610.

Action of lightning in bringing about formation of anthocyanin is due to the same effect as 'ringing' of stem.

322. 1893. Gain, E., 'Sur la matière colorante des tubercules et des organes souterrains,' Bul. soc. bot., Paris, 1893, xL, pp. 95-102.

Author measured the amount of pigment in tubers of Solanum tuberosum (red-tubered variety) and Helianthus tuberosus grown both in wet and dry ground. More pigment developed in dry ground when conditions otherwise the same.

323. Landel, G., 'Influence des radiations solaires sur' les végétaux,' C. R. Acad. sci., Paris, 1893, cxvir, pp. 314-316.

Effect of sun and shade on development of anthocyanin.

324. *Nienhaus, C., 'Die Bildung der violetten Pflanzenfarbstoffe,' Schweiz. Wochenschr. Chem., Zürich, 1893, No. 39.

Author investigates the formation of anthocyanin in fruits of Solanum niyrum, and notes that coloration begins at places where air penetrates, i.e. wounds, stomata. Concludes, however, that oxidation is not essential to formation of all blue and violet pigments.

325. Vöchting, H., 'Ueber den Einfluss des Lichtes auf die Gestaltung und Anlage der Blüthen,' Jahrb. wiss. Bot., Berlin, 1893, xxv, pp. 149-208.

When leaves of certain plants were deprived of light, and were thus unable to assimilate, it was found that flowers did not develop anthocyanin.

326. 1894. Küstenmacher, M., 'Beiträge zur Kenntniss der Gallenp. 85 bildungen mit Berücksichtigung des Gerbstoffes,' Jahrb. wiss. Bot., Berlin, 1894, xxvi, pp. 82-185.

Work on galls, and hence connection of anthocyanin with the same. 
*Warming, E., 'Exkursionen til Fanø og Blaavand i Juli 1893,' Bot. Tids., Kjøbenhavn, 1894-1895, xTx, p. 52 .

Formation of anthocyanin may vary in the same species according to whether individuals are growing in water or not.

328. 1895. Bonnier, G., 'Recherches expérimentales sur l'adaptation des plantes au climat alpin,' Ann. sci. nat. (Bot.), Paris, 1895, sér. 7, xx, pp. 217-358.

Comparative cultures of plants in Alps and in lowlands. Among other differences, flowers of the former are more intensely coloured.

pp. $6,84,102$

329. Tubeuf, K. Freiherr von, Diseases of Plants induced by Cryptogamic Parasites, English edition by W. G. Smith, London, 1897. (Pflanzenkrankheiten durch kryptogame Parasiten verursacht, Berlin, 1895.)

Anthocyanin in connection with pathological conditions caused by Fungi.

330. 1897. Curtel, G., 'Recherches physiologiques sur la fleur,' Ann. sci.nat. (Bot.), Paris, 1897, sér. 8, vi, pp. 221-306.

Connection between flower pigmentation and various physiological processes, i.e. respiration, transpiration, etc.

331. 1899. Griffon, E., 'L'assimilation chlorophyllienne et la coloration des plantes,' Ann. sci. nat. (Bot.), Paris, 1899 , sér. 8, x, pp. 1-123.

Comparison of assimilation in red (anthocyanin) leaves with that in green.

332. Mirande, M., Recherches physiologiques et anatomiques sur les Cuscutacées, Paris, 1899.

Variation in the amount of anthocyanin developed in these parasites when growing on different hosts. See text.

pp. $4,28,85,89$

333. Overton, E., 'Beobachtungen und Versuche über das Auftreten von rothem Zellsaft bei Pflanzen,' Jahrb. wiss. Bot. Leipzig, 1899, xxxiII, pp. 171-231.

Important series of experiments connected with effect of light and temperature on anthocyanin formation. Also effect of many and various nutrient solutions, i.e. sugars, alcohol, glycerine, etc., on its development. See text,

$$
\text { pp. } 4,6,23,30,45,50,58,86,93,106
$$

334. Overton, E., 'Experiments on the Autumn .Colouring of Plants,' Nature, London, 1899, LIx, p. 296.

Same as previous paper.

335. Rathbone, MI., 'Colouring of Plants,' Nature, London, p. 4 1899 , LIx, p. 342. 
Red and green leaves of different plants of Sempervivum were tested, and red leaves found to contain more starch than green. Contrary to Overton's results (see No. 333).

Schenkling-Prévôt, 'Die herbstliche Färbung des Laubes,' Die Natur, Halle a. S., 1899, xLVII, pp. 584-585.

Slight note on autumnal coloration and its causes.

337. 1900. Daniel, L., 'L'Incision annulaire du Chou,' Bul. soc. sci. méd., Rennes, 1900, Ix, pp. 135-140.

In Brassica, anthocyanin is formed in leaves after decortication of the stem.

338. *Timpe, H., Beiträge zur Kenntnis der Panachierung, Inaugural-Dissertation, Göttingen, 1900.

Author shows that red-brown (anthocyanin) zone in leaf of Pelargonium zonale is increased by culture of the leaf in sugar solution.

339. 1901. Beulaygue, L., 'Influence de l'obscurité sur le développement des fleurs,' C. R. Acad. sci., Paris, 190 ], cxxsis, pp. $720-722$.

Experiments on development of anthocyanin in flowers in the dark. In some cases slightly less colour, in others considerably less: in yet other cases, no colour produced at all.

340. Genau, K., 'Physiologisches über die Entwicklung von Sauromatum guttatum, Schott,' Oest. Bot. Zeitschr., Wien, 1901, LI, pp. 321-325.

Anthocyanin develops in spathe and leaves of Sauromatum even when kept in the dark.

341. Linsbauer, L., 'Einige Bemerkungen über Anthokyanbildung;' Oest. Bot. Zeitschr., Wien, 1901, Lx, pp. 1-10.

Discussion of influence of outside factors on anthocyanin formation.

342. *Lüdi, R., 'Beiträge zur Kenntniss der Chytridiaceen,' Hedwigia, Dresden, 1901, xL, pp. 1-44.

Appearance of anthocyanin as a result of infection.

*Warming, E., und Johannsen, W., Den almindelige

No colour formed in blue Lilacs when cultivated above optimum temperature for anthocyanin formation.

344. 1902. *Daniel, L., La théorie des capacités fonctionnelles et ses conséquences en agriculture, Rennes, 1902.

Views as to the effect of water-supply on anthocyanin formation.

345. *Rostrup, E., Plantepatologi, Kjøbenhavn, 1902.

Formation of anthocyanin under pathological conditions. 
*Warming; E., 'Exkursionen til Fang og Blaavand i Tuli 1899,' Bot. Tids., Kjøbenhavn, 1902, xxv, p. 53.

Reddening varies in the same species according to whether it is growing in or out of water.

347. 1903. Eberhardt, $\mathbf{P h}$., 'Influence de l'air sec et de l'air humide sur la forme et sur la structure des végétaux,' Ann. sci. nat. (Bot.), Paris, 1903, sér. 8, xviII, pp. 61-153.

Dry atmosphere increases formation of anthocyanin in Coleus Blumei and Achyranthes angustifolia.

348. Keegan, P. Q., 'Leaf Decay and Autumn Tints,' Nature, London, 1903, Lxix, p. 30.

Note on autumnal coloration.

349. Klebs, G., Willkürliche Entwickelungsänderungen bei Pflanzen, Jena, 1903.

Effect of water vapour in atmosphere on development of colour in flowers.

350. *Küster, E., Pathologische Pflanzenanatomie, Jena, 1903.

References to anthocyanin in connection with these conditions.

351. Sorauer, P., 'Ueber Frostbeschädigungen am Getreide und damit in Verbindung stehende Pilzkrankheiten,' Landw. Jahrb., Berlin, 1903, xxxir, pp. 1-66. light.

In Secale seedlings, anthocyanin formed in diffuse

352. 1904. Burgerstein, A., Die Transpiration der Pflanzen, Eine physiologische Monographie, Jena, 1904.

Connection between transpiration and anthocyanin formation.

353. 1905. *Guttenberg, H. von, Beiträge zur physiologischen Anatomie der Pilzgallen, Leipzig, 1905, p. 6.

Production of anthocyanin in galls.

354. Katic, D. L., Beitrag zur Kenntnis der Bildung des roten Farbstoffs (Anthocyan) in vegetativen Organen der Phanero. gamen, Inaugural-Dissertation, Halle a. S., 1905, 83 pages.

Important account of anthocyanin and the conditions governing its formation. Observations on results obtained by growing certain plants in sugar and other nutritive solutions.

355. Ravaz, L., et Roos, L., 'Sur le rougeot de la vigne,' C. R. Acad. sci., Paris, 1905, cxur, pp. 366-367.

Discussion as to cause of reddening. Analyses of red leaves.

356.

Sorauer, P., Handbuch der Pflanzenkrankheiten, Berlin, 1905.

References to production of anthocyanin in galls. 
*Zacharewicz, 'La maladie rouge de la Vigne et son traitement,' Revue de Viticulture, 1905, xxrv, pp. 447-448.

Leaves turn red when attacked by Tetranychus telarius.

358. 1906. Gautier, A., "Sur la coloration rouge éventuelle de certaines feuilles et sur la couleur des feuilles d'automne,' C. R. Acad. sci., Paris, 1906, cximr, pp. 490-491.

Note to the effect that the author had previously stated anthocyanin to be formed on injury to tissues, etc.

359. Karzel, R., 'Beiträge zur Kenntnis des Anthokyans in Blïten,' Oest. Bot. Zeitschr., Wien, 1906, Lvi, pp. 348-354, $377-379$.

Histological account of distribution of anthocyanin in various flowers, and effect of absence of light on anthocyanin formation.

360. Klebs, G., 'Ueber Variationen der Bliiten,' Jahrb. wiss. Bot., Leipzig, 1906, XII, pp. 155-320.

Effect of temperature, nutrition, differently coloured light and other conditions on colour and development of flowers.

pp. $6,85,87$

361. Klebs, G., 'Ueber kiinstliche Metamorphosen,' Abh. natf. Ges., Halle, 1906, xxv, 162 pages.

Some effects of artificial conditions on flower-colour are included.

362. Mirande, M., 'Sur un cas de formation d'anthocyanine sous l'influence d'une morsure d'Insecte,' C. R. Acad. sci., Paris, 1906, cxliII, pp. 413-416.

Ravages of a certain caterpillar.in leaves of Galeopsis Tetrahit are followed by development of anthocyanin. Suggestions as to cause of appearance of pigment.

363. *Suzuki, S., 'On the Formation of Anthokyan in the Stalks of Barley,' Bull. Coll.: Agric., Tokyo, 1906, vII, pp. 29-37.

Results of water and soil cultures show that insufficient supply of phosphorus and nitrogen leads to formation of anthocyanin.

364. 1907. *Granier, L., et Brun, G., Rev. hortic., Paris, 1907, 1908.

Formation of anthocyanin in vegetative parts correlated with lack of flowering.

365. Mirande, M., 'Sur l'origine de l'anthocyanine déduite de l'observation de quelques Insectes parasites des feuilles,' C. R. Acad. sci., Paris, 1907, CXLv, pp. 1300-1302.

Production of anthocyanin under such circumstances is due to formation of excess of tannins and glucose, accompanied by presence of oxidases.

pp. 83, 91, 101, 106 
Molliard, M., 'Action morphogénique de quelques substances organiques sur les végétaux supérieurs,' Rev. gén. bot., Paris, 1907, xix, pp. 241-291, 329-349, 357-391.

Formation of anthocyanin in plants cultivated in sugar solutions.

367. *Richter, 0., 'Ueber Antokyanbildung in ihrer Abhängigkeit von ä usseren Faktoren,' Med. Klinik, Berlin, 1907, xxxiv, 15 pages.

368. 1908. *Cordemoy, J. de, 'A propos de la coloration rouge des feuilles,' Rev. hortic., Paris, 1908, p. 31.

Anthocyanin formed in vegetative parts when plants do not flower. Considered to be due to accumulation of sugars which would otherwise have passed into flowers and fruit.

369. Fischer, H., 'Belichtung und Blütenfarbe,' Flora, Jena, 1908, xCVIII, pp. 380-385.

Author found that, when developing inflorescences were darkened, both blue and red flowers mostly developed little colour. Since plants were not prevented to any great extent from assimilating, it would appear that assimilation is not the only factor upon which the development of colour depends.

370. $\quad$ *Jumelle, H., 'A propos de la coloration automnale des feuilles,' Rev. hortic., Paris, 1908, p. 20.

Same observations and conclusions as previous author (Cordemoy, No. 368).

371. *Linsbauer, L., 'Ueber photochemische Indulktion bei der Anthokyanbildung,' Wiesner-Festschrift, Wien, 1908, pp. $42 \mathrm{I}-436$.

Anthocyanin formation regarded as a reaction following on a stimulus. Experiments are conducted on the connection between stimulus and response, using Fagopyrum seedlings and artificial light.

372. 1909. Abbott, G., 'The Colours of Leaves (Faqus sylvatica purpurea),' Nature, London, 1909, Lxxx, p. 429.

Young tree of Copper Beech, when partially covered with sacking, developed no anthocyanin in covered leaves. After exposure to light for two days, red colour formed.

373. Colin, H., 'Sur le rougissement des rameaux de Salicornia fruticosa,' C. R. Acad. sci., Paris, 1909, cxLviII, pp. 1531-1533.

Red branches contain more soluble carbohydrates than green. Accumulation in cells of inorganic chlorides does not prevent formation of anthocyanin.

374. Combes, R., 'Production d'anthocyane sous l'influence 
de la décortication annulaire,' Bul. soc. bol., Paris, 1909, LVI, pp. 227-231.

Production of anthocyanin noted on decortication of branches of Spiraea prunifolia and S. paniculata. pp. 4, 24, 82

375. Miyoshi, M., 'Ueber die Herbst- und Trockenröte der Laubblätter,' J. Coll. Sci., Tokyo, 1909, xxvII, 5 pages.

It is noted that, during the dry period in East Indies and Ceylon, a reddening of the leaves of certain trees is produced. Also classification of conditions under which anthocyanin appears.

376. Molliard, M., 'Production expérimentale de tubercules blanes et de tubercules noirs à partir de graines de Radis rose,' C. R. Acad. sci., Paris, 1909, cxlvirr, pp. 573-575.

Oxygen shown to be necessary for formation of pigment by totally submerging radishes in sugar solution, with the result that no pigment was formed.

377. 1910. Combes, R., 'Du rôle de l'oxygène dans la formation et la destruction des pigments rouges anthocyaniques chez les végétaux,' C. R. Acad. sci., Paris, 1910, CL, pp. 1186-1189.

As anthocyanin develops, there is greater absorption of oxygen; the reverso is the case as plants lose the pigment.

378. Combes, $R$.g 'Sur le dégagement simultané d'oxygène et d'anhydride carbonique au cours de la disparition des pigments anthocyaniques chez les végétaux,' $C . R$. Acad. sci., Paris, 1910, cL, pp. 1532-1534.

Experiments made on gaseous exchange in red and green leaves of Ailanthus. It is shown that respiration in red leaves is much more active than in green.

379. Combes, R., 'Les échanges gazeux des feuilles pendant la formation et la destruction des pigments anthocyaniques,' Rev. gén. bot., Paris, 1910, xxir, pp. 177-212.

An account is given of numerous experiments on autumnal leaves, young red leaves, leaves reddened by decortication of branches, by attacks of insects and by exposure to strong light. Results go to show that the appearance of anthocyanin in the tissues is correlated with accumulation of oxygen in the tissues. The disappearance of pigment from the tissues is accompanied by a loss of oxygen. pp. 91, 101, 117

380. Ravaz, L., 'Recherches, sur l'influence spécifique réciproque du sujet et du greffon chez la Vigne,' C.R. Acad. sci., Paris, 1910, CL, p. 712.

From relationship between colour in leaves and fruits in certain vines, author concludes that pigment is synthesised in fruits, and not in leaves. 
381. 1911. Chartier, H., et Colin, H., 'Sur l'anthocyane des plan-

tules de Crassulacées,' Rev. gén. bot., Paris, 1911, xxiI, pp. 264-266.

Properties of anthocyanin developed in roots of species of Crassulaceae, and factors influencing its formation.

382.

*Czartkowski, A., 'Einfluss des Phloroglucins auf die Entstehung des Anthokyans bei Tradescantia viridis,' Sitzber. d. Warschauer Ges. Wiss., 1911, IV, pp. 23-30.

Author finds that, in addition to sugar, phloroglucin solution favours the production of anthocyanin.

383. Friedel, J., 'De l'action exercée sur la végétation par une obscurité plus complète que l'obscurité courante des laboratoires,' C. R. Acad. sci., Paris, 1911, cLII, pp. 825826 .

It is shown by experiment that anthocyanin can be produced in complete darkness.

384. Gertz, 0., 'Om anthocyan hos alpina växter. Ett bidrag till Schneebergflorans ökologi,' Bot. Not., Lund, 1911, pp. 101-132, 149-164, 209-229.

385. 1912. Combes, R., 'Formation de pigments anthocyaniques déterminée dans les feuilles par la décortication annulaire des tiges,' Ann. sci. nat. (Bot.), Paris, 1912, sér. 9, XVI, pp. 1-53.

Decortication experiments on a number of species, most of which showed reddening of leaves above decortication point, though some did not. Estimation of dry weight, water, ash and hydrocarbon content of red and green leaves respectively; also gaseous exchange.

pp. 4, 24, 82

386. Gertz, 0., 'Nagra iakttagelser öfver anthocyanbildning i blad vid sockerkultur,' Ark. Bot., Stockholm, 1912, xI, No. 6,45 pages.

Important contribution to the subject of anthocyanin formation and sugar-feeding. See text.

387. 1914. Gertz, O., 'Om anthocyan hos alpina växter, II,'Bot. Not., Lund, 1914, pp. 1-16, 49-64, 97-126.

\section{PHYSIOLOGICAL SIGNIFICANCE OF ANTHOCYANINS}

388. 1879. Comes, O., 'Ricerche sperimentali intorno all' azione della Luce sulla Traspirazione delle Piante,' Rend. Acc. sc., Napoli, 1879, xvIII, Fasc. 12, pp. 267-282.

The author gives an account of experiments on the effect of light on transpiration. The results are also published later in other papers (see Nos. 389,390 below). Of special 
interest in the present paper are his experiments on the transpiration of differently coloured petals, of which he also examined the spectra. He found that transpiration was greatest in those of which the pigment had absorption bands in the greatest number, width and intensity. $\mathrm{He}$ found, in addition, that yellow petals of Hunnemannia fumariaefolia and Eschscholtzia sp. transpire more in bluẻ light than in yellow, other conditions being equal. The contrary was the case with blue petals of species of Plumbago, Commelina and Tradescantia.

389. 1880. Comes, 0., 'La luce e la traspirazione nelle piante,' Mem. Acc. Lincei, Roma, 1880, vII, pp. 55-88.

An investigation of the effect of light, of various intensities and of different colours, on transpiration. See text.

390. Comes, O., 'Influence de la lumière sur la transpiration des plantes,' C. R. Acad. sci., Paris, 1880, xcr, p. 335.

A short summary of work published in previous papers (Nos. 388, 389).

391. 1883. Pick, H., 'Ueber die Bedeutung des rothen Farbstoffes bei den Phanerogamen und die Beziehungen desselben
zur Stärkewanderung,' Bot. Centralbl., Cassel, 1883, xvI, pp. 281-284, 314-318, 343-347, 375-382.

The author agrees with Wigand that there is a connection between the occurrence of red pigment and the presence of tannins. A theory is formulated that the protection from white light, afforded by anthocyanin pigment, facilitates the hydrolysis and transportation of starch, and various evidence is given in support.

392. 1884. Johow, Fr., 'Ueber die Beziehungen einiger Eigen. schaften der Laubblätter zu den Standortsverhältnissen,' Jahrb. wiss. Bot., Berlin, 1884, xv, pp. 282-310.

Anthocyanin is regarded as a protection for leaves, especially the conducting system, against too intense light.

393. 1886. Hassack, C., 'Untersuchungen über den anatomischen

Bau bunter Laubblätter, nebst einigen Bemerkungen, betreffend die physiologische Bedeutung der Buntfärbung derselben,' Bot. Centralbl., Cassel, 1886, xxvıI, pp. 84-85, $116-121,150-154,181-186,211-215,243-246,276-279$, $308-312,337-341,373-375,385-387$.

An important histological account of the distribution of anthocyanin in red leaves. Favourable reference is made to the screen theory of anthocyanin, and Kerner's observations are quoted as evidence.

pp. $19,20,30,35,129$ 
394. 1887. Engelmann, Th. W., 'Dic Farben bunter Laubblätter

und ihre Bedeutung für die Zerlegung der Kohlensäure im Lichte,' Bot. Zig., Leipzig, 1887, xLv, pp. 393-398, 409-419, 425-436, 441-450, 457-463.

Investigations on the spectra of various pigments of coloured leaves. That of anthocyanin is found on the whole to be complementary to that of chlorophyll. See text.

395. 1889. Roze, E., 'Contribution à l'étude de l'action de la chaleur solaire sur les enveloppes florales,' Bul. soc. bot., Paris, 1889, xxxvi, pp. cexii-cexiv.

The author attempts to arrive at a reason for the great variety of coloration of corollas, perianths, etc. He takes temperature of flowers (differently coloured) which have been exposed to the sun, and finds that some colours absorb more heat than others. He believes this to have a great physiological importance as regards fertilisation, dehiscence of anthers, etc.

396. 1890. Jumelle, H., 'Sur l'assimilation chlorophyllienne des arbres à feuilles rouges,' C.R. Acad. sci., Paris, 1890, cxI, pp. 380-382.

Less assimilation in red leaves than in green.

397. 1892. Kny, L., 'Zur physiologischen Bedeutung des Antho. cyans,' Estratto dagli Atti del Congresso Botanico Inter. nazionale, 1892.

Account of experiments performed in support of the function of anthocyanin as a screen and as a medium for transforming light rays into heat.

398. 1894. Kerner von Marila um, A., and Oliver, F. W., The Natural pp. 130,133 History of Plants, London, 1894.

Many references to anthocyanin:

Morphological distribution in leaves, etc.

Development in Alpine plants.

Various physiological functions suggested.

Description of autumnal coloration.

pp. 25, 102

Development of pigment in rhizomes.

399. Wehrli, L., 'Ueber die Bedeutung der Färbung bei den Pflanzen,' Ber. Schweiz. Bot. Ges., Bern, 1894, Iv, pp. xxiiixxviii.

Scheme for classification of anthocyanin and other pigments according to uses. Physiological uses of chief importance. These are classified as (1) protection of chlorophyll, (2) conversion of light into warmth.

400. Wiesner, J., 'Pflanzenphysiologische Mittheilungen aus Buitenzorg. 2. Beobachtungen über Einrichtungen zum 
Schutze des Chlorophylls tropischer Gewächse,' SitzBer. $A k$. Wiss., Wien, 1894, CIII (1), pp. 8-36.

Sereen theory of anthocyanin is supported.

01. 1895. Ewart, A. J., 'On Assimilatory Inhibition in Plants,'

J. Linn. Soc. Bot., London, 1895-1897, xxxi, pp. 364461.

Author states that, in addition to its protective function against too intense light and heat, the main function of anthocyanin is to protect the assimilating cells against those rays of light which tend to induce in the protoplasm, more especially in the chlorophyll grain, a condition of light rigor, and thereby to diminish or inhibit their power of assimilation. See text.

402. Filarszky, F., 'Ueber Anthocyan und einen interes. santen Fall der Nichtausbildung dieses Farbstoffes,' Bot. Centralbl., Cassel, 1895, uxrv, p. 157.

Protective function of anthocyanin by changing light into heat.

403. Keeble, F. W., 'The Hanging Foliage of certain Tropical Trees,' Ann. Bot., Oxford, 1895, Ix, pp. 59-93.

A suggestion is made that, in addition to its value as a screen, anthocyanin in young leaves in the tropics protects the leaf against the too great heating effects of the sun's rays. Experimental evidence is given in favour of this view. See text.

pp. 21, 22, 130, 136

404. 1896. MacDougal, D. T., 'The Physiology of Color in Plants,' Science, New York, 1896, IV, pp. 350-351.

Short note on Stahl's hypothesis.

405. Stahl, E., 'Ueber bunte Laubblätter,' Ann. Jard. bot., Buitenzorg, 1896, xII, pp. 137-216.

Important paper on the physiological significance of anthocyanin. The author favours the view that the chief function of the pigment is to convert light rays into heat. By virtue of this property, it has the power of accelerating transpiration under difficult circumstances, and hence its distribution in many shade-loving plants in damp tropical regions. See text.

pp. $7,20,21,22,35,131,133,134$

406. 1897. Ewart, A. J., 'The Effects of 'Tropical Insolation,' Ann. Bot., Oxford, 1897, xI, pp. 439-480.

The author maintains that anthocyanin is highly important in its protective action against rigor pro. duced in the assimilating cell by too strong insolation. Stahl's views are adversely criticised. See text. 
Keeble, F. W., 'The Red Pigment of Flowering Plants,' Sci. Progr., London, 1897, vI (N. S. I), pp. 406-421.

General account of the physiological significance of anthocyanin.

408. 1898. Montemartini, L., 'Sopra la struttura del sistema assimilatore nel fusto del Polygonum Sieboldii,' Malpighia, Genova, 1898, XII, pp. 78-80.

Red spots on the stem are found to correspond to an area of epidermal anthocyanin-containing cells round the stomata. Beneath this area is assimilating tissue. The suggestion is made that anthocyanin protects chlorophyll from too intense light.

409. 1899. Macchiati, L., 'Ufficio dei peli, dell' antocianina e dei nettarii estranuziali dell' Ailanthus glandulosa,' Boll. Soc. bot. ital., Firenze, 1899, pp. 103-112.

Suggestion that anthocyanin acts as a screen against too bright light and excessive transpiration.

410. 1900. Hansgirg, A., 'Zur Biologie der Laubblätter,' SitzBer. Böhm.Ges. Wiss., Prag, 1900, No. 20, 142 pages.

Classification of leaves into physiological types.

411. 1901. Linsbauer, L., 'Untersuchungen über die Durchleuchtung von Laubblättern,' Beiheft z. Bot. Centralbl., Cassel, 1901, x, pp. 53-89.

Slight reference to the significance of anthocyanin as a light screen.

412. Smith, F. G., 'On the Distribution of red Color in vegetative Parts in the New England Flora,' Bot. Gaz., Chicago, Ill., 1901, xxxII, pp. 332-342.

Distribution of anthocyanin in plants growing in various situations, wet and dry, shady and sunny. Short discussion on significance of anthocyanin; no conclusion reached.

413. Thomas, Fr., 'Anpassung der Winterblätter von Galeobdolon luteum an die Wärmestrahlung des Erdbodens,' Ber. D. bot. Ges., Berlin, 1901, xix, pp. 398-403.

A suggestion that anthocyanin in the under surface of the leaf increases the capacity of the leaf for absorbing warmth from the ground.

414. 1902. Casares, Gil A., 'Algunas observaciones sobre la coloración rojiza de ciertas hepáticas,' Boletín de la 'Sociedad Española de Historia Natural, 1902, II, pp. 207-211.

Pigment (? anthocyanin) in certain species of Liverworts. It is developed on under surfaces, which roll over. and protects thallus from undue exposure to the more refrangible rays of sunlight. 
415. *Thomas, Fr., 'Ueber die Winterblätter von Galeobdolon luteum,' Mittheilung des Thüringischen botanischen Vereins, N. F., 1902, xvI, p. 13.

Probably as in paper above (No. 413).

416. 1903. Koning, C. J., en Heinsius, H.W., 'De beteekenis en het ontstaan van het anthocyaan in bladeren,' Ned. Kruidk. Arch., Nijmegen, 1903 (ser. 3), II, pp. 1011-1018.

Results support view that anthocyanin favours translocation of starch by protection of diastase.

417. 1905. *Hryniewiecki, B., 'Antocyan a wytrzymatość roślin na zimno (Anthocyan und Winterhärte der Pflanzen),' Wszechświat, Warszawa, 1905, xxIv, p. 687.

Red-leaved beech more readily acclimatised than greenleaved.

418. Tischler, G., 'Ueber die Beziehungen der Anthocyanbildung zur Winterhärte der Pflanzen,' Beihefte z. Bot. Centralbl., Cassel, 1905, xvir, pp. 452-471.

Greater endurance of red-leaved varieties to low temperatures. Reasons suggested.

419. 1908. *Schilberszky, K., 'Az anthoczián elöfordulásáról és élettani szerepéröl (Ueber das Vorkommen und über die physiologische Rolle des Anthocyans),' Pótf. Termt. Közl., Budapest, 1908, xL, pp. 153-155.

420. 1909. Smith, A. M., 'On the Internal Temperature of Leaves in Tropical Insolation with special Reference to the Effect of their Colour on the Temperature,' Ann. R. Bot. Gard., Ceylon, 1909, IV, pp. 229-298.

Author has shown experimentally that red leaves have a higher temperature than green.

pp. $7,22,131,139$

421. 1910. Weevers, Th., 'Kurze Notizen in Bezug auf die Anthocyanbildung in jungen Schösslingen der tropischen Pflanzen,' Ann. Jard. bot., Buitenzorg, 1910, 3ième sup., $1^{\text {e }}$ partie, pp. 313-318.

T.ist of plants inhabiting damp tropical forests and developing anthocyanin in young shoots.

\section{BIOLOGICAL SIGNIFICANCE OF ANTHOCYANINS}

422. 1877. *Kuntze, O., 'Die Schutzmittel der Pflanzen gegen Thiere und Wetterungunst,' Bot. Ztg., Leipzig, 1877, Supplementheft.

Suggestion that red colour in plants may resemble blood to animals, and thereby be protective. 
423. 1888. Focke, W. O., 'Die Verbreitung beerentragender

Pflanzen durch die Vögel,' Abh. natw. Ver., Bremen, 1888, $\mathrm{x}, \mathrm{p} .140$.

Examples of cases of distribution of fruits.

424. 1889. *Ludwig, F., 'Extranuptiale Saftmale bei Ameisenpflanzen,' Humboldt, 1889, viIr, pp. 294-297.

Red pigmented cushions and lines denote the path to extra-floral nectaries (cp. honey-guides) in Impatiens, Viburnum and Sambucus.

425. 1891. Lúdwig, F., 'Die Beziehungen zwischen Pflanzen und Schnecken,' Beihefte z. Bot. Centralbl., Cassel, 1891, I, pp. 35-39.

Red colour as a warning signal to animals.

426. 1898. Knuth, P., Handbuch der Blüthenbiologie, Leipzig, 1898. (Handbook of Flower Pollination, Translated by J. R. Ainsworth Davis, 3 vols., Oxford, 1906, vol. I, pp. 212-380.)

Full bibliography relating to biological significance of anthocyanin.

427. 1899. Macchiati, L., 'Osservazioni sui nettarii estranuziali del pp. 7, 126 Prunus Laurocerasus,' Boll. Soc. bot. ital., Firenze, 1899, pp. 144-147.

Anthocyanin as guide for insects to extra-floral nectaries.

\section{ANTHOCYANINS AND GENETICS}

428. 1817. Hopkirk, T., Flora Anomoia. A General Tiew of the Anomalies in the Vegetable Kingdom, London, 1817, 187 pages.

An interesting account of variation in plants. A section is devoted to variation in flower-colour, and lists of species are given in which the colour varies from blue, purple, or red, to white: red to blue, red to yellow, etc. Also variation in colour of fruits. The causes of variation are discussed.

429. 1834. Schübler, G., und Lachenmeyer, C., 'Untersuchungen über die Farbenveränderungen der Blüthen,' J. prakt. Chem., Leipzig, 1834, I, pp. 46-58.

An account of the effect of different soils on the flowercolour of Hortensia speciosa. Cases of change in colour with varying age of flowers are mentioned (ex. Boraginaceae).

430. 1849. Gärtner, C. F. von, Versuche und Beobachtungen über die Bastarderzeugung im Pfanzenreich, Stuttgart, 1849.

Inheritance of flower-colour in hybrids. 
431. 1872. Hoffmann, H., 'Ueber Variation,' Bot. Ztg., Leipzig, 1872, xxx, pp. 529-539.

The causes of variation in flower-colour are dealt with. The effects of chemical substances, temperature, light, water and cross-fertilisation on variation are discussed. Also the fixing of varieties.

432. 1874. Hoffmann, H., 'Ueber Papaver Rhoeas, L.,' Bot. Ztg., Leipzig, 1874, xxxII, pp. 257-269.

An account of the variations noted in cultures of Papaver.

433. Hoffmann, H., 'Zur Kenntniss der Gartenbohnen,' Bot. Ztg., Leipzig, 1874, xxxп, pp. 273-283, 289-302.

Variation in flower- and seed-colour in cultures of beans.

434. 1875. Hoffmann, H., 'Culturversuche,' Bot. Ztg., Leipzig, 1875, ххх1н, pp. 601-605, 617-628.

Variation in flower-colour in cultures of species of Clarkia, Collinsia, Datura, Gilia, Godetia, Gypsophylla: Hydrangea, Myosotis and others.

435. 1876. Hoffmann, H., 'Culturversuche,' Bot. Ztg.y Leipzig, 1876, xxxiv, pp. 545-552, 561-572.

Variation in flower-culture colour in cultures of Althaea rosea, Cheiranthus Cheiri, and species of Linum, Lychnis and Primula.

436. 1877. Hoffmann, H., 'Culturversuche,' Bot. Ztg., Leipzig, 1877, xxxv, pp. 265-279, 281-295, 297-305.

Experiments on the effect of darkness, mechanical bending, temperature, chemical substances, etc., on variation in Papaver.

437. 1878. Hoffmann, H., 'Culturversuche,' Bot. Ztg., Leipzig, 1878, xxxvI, pp. 273-286, 289-299.

Variation in flower-colour in cultures of Atropa Belladonna and fruits of Prunus Avium.

438. 1879. Hoffmann, H., 'Culturversuche,' Bot. Ztg., Leipzig, 1879, XxxvII, pp. $177-187,193-207,569-576,585-595$, 601-604.

Variations in flower-colour in cultures of Anagallis coerulea, Papaver and others.

439. 1881. Focke, W. O., Die Pflanzen-mischlinge, Berlin, 1881.

Very complete account of hybridisation among Phanerogams.

440. Hoffmann, H., 'Culturversuche über Variationen,' Bot. Ztg., Leipzig, 1881, xxxıx, pp. 105-110, 121-125, 137-143.

Variation in flower-colour in cultures of Anthyllis Yulneraria and Glaucium luteum. 
441. Hoffmann, H., 'Rïckblick auf meine VariationsVersuche,' Bot. Ztg., Leipzig, 1881, xxxrx, pp. 345-351, $361-368,377-383,393-399,409-415,425-432$.

Résumé of previous experiments.

442. 1882. Hoffmann, H., 'Culturversuche über Variation,' Bot. Ztg., Leipzig, 1882, xL, pp. 483-489, 499-514.

Variation in flower-colour in cultures of Papaver alpinum, $P$. somniferum, Dianthus superbus and others.

443. 1883. Hoffmann, H., 'Culturversuche über Variation,' Bot. Ztg., Leipzig, 1883, xLr, pp. 276-281, 289-299, 305-314, 321-330, 337-347.

Variation in flower-colour in cultures of Anemone nemorosa, Phyteuma spicatum, and others.

444. 1884. Goff, E. S., 'The Relation of Color to Flavor in Fruits and Vegetables,' Amer. Nat., Philadelphia, 1884, xviII, pp. 1203-1210.

Many cases are quoted in which there is a distinctoften strong and unpleasant-flavour when colour is present in fruits and vegetables. See text.

445. Hoffmann, H., 'Culturversuche über Variation,' Bot. Ztg., Leipzig, 1884, xLII, pp. 209-219, 225-237, 241-250, 257-266, 275-279.

Variation in flower-colour in cultures of species of Papaver and Raphanus.

446. 1887. Focke, W. O., 'Die Culturvarietäten der Pflanzen,' Abh. natw. Ver., Bremen, 1887, Ix, pp. 447-468.

General discussion on variation. Examples are given of variation in colour of flowers, fruits, roots, etc., under cultivation.

447. Hoffmann, H., 'Culturversuche über Variation,' Bot. Ztg., Leipzig, 1887, xLv, pp. 24-28, 40-45, 55-57, 72-76, $86-90,169-174,233-239,255-260,288-291,729-746,753-$ 761, 769-779.

Variation in flower-colour in cultures of Anagallis arvensis, Anthyllis Vulneraria, Atropa Belladonna, Dictamnus Fraxinella, Digitalis purpurea and others.

448. Jäger, H., 'Zur Färbung der Blutbuche,' Gartenflora, Berlin, 1887, xxxvi, pp. 40-41.

Suggested correlation between young wood colour and leaf colour.

449. Webster, A. D., 'Change of Colour in the Flowers of Anemone nemorosa,' J. Bot., London, 1887, xxv, p. 84 .

Colour of flowers is said to depend on nature of soil in which plants were growing. 
450. 1888. Pammel, L. H., 'Color Variation in Flowers of Del-

phinium,' Bot. Gaz., Crawfordsville, Indiana, 1888, xıI, p. 216 .

Record of colour varieties of $D$. tricorne occurring naturally.

451. 1889. *Focke, W. O., 'Der Farbenwechsel der Rosskastanienblumen,' Verh. bot. Ver., Berlin, 1889, xxxi, pp. 108-112.

Changes in colour in flowers after fertilisation.

452.

Kerner von Marilaum, A., 'Ueber das Wechseln der Blüthenfarbe an einer und derselben Art in verschiedenen Gegenden,' Oest. Bot. Zs., Wien, 1889, xxxIx, pp. 77-78.

The distribution of different colour varieties of any species may be determined by colour contrast (and consequent attraction for insects) with flowers of other species amongst which it grows.

453. 1890. Jacobasch, E., "Verschiedene Blütezeit der rot-, blauund weissblütigen Form von Hepatica triloba Gil. und Umwandlung der Normalform in die Rote,' Verh. bot. Ver., Berlin, 1890, xxxı, pp. 253-254.

Observations on the time of flowering of different colour-varieties. Author suggests that cold may cause variation in colour.

454. *Körnicke, 'Varietätenbildung im Pflanzenreiche,' Sitzungsberichte der niederrheinischen Gesellschaft für Naturkunde, Bonn, 1890, pp. 14-20.

Mention is made of the influence of soil on the colour of plants. A case is quoted where development of red and violet colour in Maize-cobs, due to effect of soil, is said to have taken place.

455. 1891. Eckert, J. P., "Some Peculiar Changes in the Colour of the Flower of Swainsonia procumbens,' Nature, London, 1891-1892, xLV, p. 185.

The corolla is at first lilac, but changes later to crimson in places and blue. Petals may assume original colour and go through the gradations once more.

456. 1892. Guinier, E., 'Sur la coloration accidentelle de la fleur du Fraisier commun,' Bul. soc. bot., Paris, 1892, xxxıx, pp. 64-66.

An account of the occurrence of a variety of strawberry with reddish-purple flowers.

457. 1893. Gillot, $\mathbf{X}$., 'Observations sur la coloration rosée ou érythrisme des fleurs normalement blanches,' Bul. soc. bot., Paris, 1893, xL, pp. clxxxix-cxciv.

List of species in which flowers of the types are without anthocyanin, and which give rise to varieties 
with anthocyanin, or to coloration with anthocyanin is made under certain conditions.

p. 155

458.

Hildebrand, F., 'Ueber einige Variationen an Bliithen,' Ber. D. bot. Ges., Berlin, 1893, xr, pp. 476-480.

The author notes the occurrence, among the pale blue flowers of Iris florentina, of a sudden 'sport' (in some individual flowers) which had a large portion of the perianth dark violet. Also a hybrid Dahlia (from red $\times$ white) was found to produce both red and white flowers and pure red flowers at different times.

459. Newell, J. H., 'The Flowers of the Horse Chestnut,' Bot. Gaz., Bloomington, Indiana, 1893, xvıII, pp. 107-109.

Change of colour in flowers with age.

460. Praeger, R. L., 'Colour-variation in Wild Flowers,' Irish Nat., Dublin, 1893, II, pp. 174-175.

The author gives a list of colour-variations he has noted in British wild flowers: ex. Scabiosa succisa (white, pink), Orchis mascula (white, flesh-colour), Jasione montana (pink): white of Scilla verna, Vicia sepium, Trifolium pratense, Epilobium montanum and many others.

461. 1894. Chabert, A., 'Les variations à fleurs rouges de certains Galium,' Bul. soc. bot., Paris, 1894, xLI, pp. 302-305.

In connection with a red-flowered variety of Galium silvestre found by Gillot (see No. 457), the author objects to its being called a new variety; he believes 'erythrism' on the contrary to be merely due to chemical nature of the soil, etc. He quotes cases of occurrence of redflowered individuals of other species of Galium.

462. Gillot, X., "Variations parallèles à fleurs rouges des espèces du genre Galium,' Bul. soc. bot., Paris, 1894, XLI, pp. 28-30.

Record of red-flowered varieties of Galium spp., the types being normally white-flowered.

463. Meehan, T., 'Contributions to Life Histories of Plants. On Purple-leaved Plants, No. 11,' Proc. Acad. Nat. sci., Philadelphia, Pa., 1894, pp. 162-171.

Note on grafting of blood-variety of Betula on type.

464.

Pillsbury, J. H., 'On the Color Description of Flowers,' Bot. Gaz., Madison, Wisconsin, 1894, xıx, pp. 15-18.

Attempt to classify and define terms used for colour by means of a mechanical device.

465. 1895. Prehn, J., 'Ueber das Vorkommen zuweilen weissblühender Pflanzen,' Schr. natw. Ver., Kiel, 1895, x, pp. 259-261.

Author gives a list of white-flowered varieties he has 
found among wild plants. Includes white varieties of Carduus crispus, Centaurea Cyanus, Aster Tripolium, Cichorium Intybus, Campanula Trachelium, Echium vulgare and many others.

466. 1896. Hildebrand, F., 'Einige biologische Beobachtungen,' Ber. D. bot. Ges., Berlin, 1896, xтv, pp. 324-331.

Further observations on a hybrid Dahlia (see No. 458). It was found that the production of completely red flowers, or of red and white flowers, was influenced more or less by nutrition. Same kind of phenomenon observed with purple and white Petunia.

467. 1897. Molisch, H., 'Der Einfluss des Bodens auf die Bliithenfarbe der Hortensien,' Bot. Ztg., Leipzig, 1897, Lv, pp. 49-61.

Effect on flower-colour of adding salts of iron and aluminium, and many other substances, to the soil. See text.

468. Zopf, W., 'Ueber den Einfluss des Bodens auf die Farbe der Hortensiablüten,' Die Natur, Halle a. S., 1897, xLvi, pp. 318-319.

Blue colour produced in flowers by artificial use of aluminium salts in soil. See text.

469. 1898. Hasslinger, J. von, 'Beobachtungen über Variationen in den Blüten von Papaver Rhoeas, L.,' Oest. Bot. Zs., Wien, 1898, XLVII, pp. 139-141.

Record of variation in blotches (purple anthocyanin) at the base of the petals.

470. 1899. Buchenau, F., 'Zwei interessante Beobachtungen an Topf-Pelargonien,' Abh. natw. Ver., Bremen, 1899, xvI, pp. 274-277.

Authpr describes a scarlet-flowered Pelargonium plant with a branch bearing rose-coloured flowers.

471. Jackson, B. D., 'A Review of the Latin Terms used in Botany to denote Colour,' J. Bot., London, 1899, xxxvII, pp. 97-106.

Classification of Latin terms used for various colours.

472. 1900. Correns, C., 'Ueber Levkojenbastarde,' Bot. Centralbl., Cassel, 1900, Lxxxiv, pp. 97-113.

Preliminary experiments on inheritance of flowercolour in Stocks are included (violet, red and white). Relation of flower- to seed-colour.

473. Hildebrand, F., 'Ueber Bastardirungsexperimente p. 156 zwischen einigen Hepatica-Arten,' Bot. Centralbl., Cassel, 1900, LxxxIv, pp. 65-73.

Inheritance of flower-colour and other characters in crosses between different species of Hepatica.

.


474. Vries, H. de, 'Der Spaltungsgesetz der Bastarde,'Ber. D. bot. Ges., Berlin, 1900, xvıI, pp. 83-90.

Early record of cases of Mendelian dominance and segregation. Certain instances of colour-variation are included, i.e. in Papaver, Antirhinum, Polemonium, Lychnis, Datura, Clarkia, Trifolium and others.

pp. 156, 157, 164, 172, 184

475. 1901. Bateson, W., and Saunders, E. R., 'Experimental Studies in the Physiology of Heredity,' Rep. Evol. Com. Roy. Soc., London, 1901 , Rpt. I, 160 pages.

Experiments on inheritance of colour in flowers of Lychnis: in flowers and fruits of Atropa and Datura: in flowers of Matthiola. See text.

pp. $9,151,156,161,164,168,169,180,181,183,184$

476.

477 .

Correns, C., 'Bastarde zwischen Maisrassen,' Bibl. bot., Stuttgart, $1901, \mathrm{x}, \mathrm{pp} . \mathrm{xii}+161$.

Important account of inheritance of colour (anthocyanin) and other characters. See text.

pp. 157,179

Coupin, H., 'La couleur des fleurs de la flore française,' C. $R$. ass. franç. avanc. sci., Paris, $1901,2^{\mathrm{e}}$ partie, pp. 500 520 .

Statistical study of the flora of France showing percentages of different flower-colours in various natural orders. Also percentage of colours in various habitats, viz., forests, mountains, dry and wet regions, sea-shore, etc.

478 .

Taliew, W., 'Ueber den Polychroismus der Frühlings. pflanzen,' Beihefte z. Bot. Centralbl., Cassel, 1901, x, pp. $562-564$.

The author maintains that there is greater variation in flower-colour in species of spring plants than others. $\mathrm{He}$ suggests it may be due to the conditions to which they are exposed at this season. Many examples are quoted including Anemone, Tulipa, Iris, Myosotis and Primula species.

479. Tschermak, E. von, "Weitere Beiträge über Vcrschiedenwerthigkeit der Merkmale bei Kreuzung von Erbsen und Bohnen,' Ber. D. bot. Ges., Berlin, 1901, xix, pp. 35-51.

A preliminary account of some cross-breeding in Phaseolus and Pisum. Among the characters observed are flower-and seed-colour.

pp. $156,157,189$

480. 1902. Bateson, W., "Note on the Resolution of Compound Characters by Cross-breeding,' Proc. Phil. Soc., Cambridge, 1902-1904, XII, pp. 50-54.

Suggestion as to the factors for inheritance of flowercolour in Antirrhinum.

pp. 156,158 
481.

Bateson, W., Mendel's Principles of Heredity. $A$ Defence, Cambridge, 1902.

References to inheritance of colour.

482 .

Correns, C., 'Ueber Bastardirungsversuche mit MirabilisSippen,' Ber. D. bot. Ges., Berlin, 1902, xx, pp. 594-608.

Experiments on inheritance of colour in flowers of Mirabilis Jalapa. Also crosses between M. longiflora and M. Jalapa. Scheme of factors suggested.

483. Emerson, R. A., 'Preliminary Account of Variation in Bean Hybrids,' Annual Report Nebraska Agricultural Experiment Station, Nebraska, 1902, xv, pp. 30-43.

Pigmentation in testa of seeds of Phaseolus.

484. Tschermak, E. von, 'Ueber die gesetzmässige Gestaltungsweise der Mischlinge. Fortgesetzte Studien an Erbsen und Bohnen,' Zs. Landw. 'VersWes., Wien, 1902, 81 pages.

485. 1903. Correns, C., 'Ueber die dominierenden Merkmale der Bastarde,' Ber. D. bot. Ges., Berlin, 1903, xxi, pp. 133-147. Definition of dominance. Partial and total dominance. Illustrations among flower-colour cases.

486. Correns, C., 'Weitere Beiträge zur Kenntnis der dominierenden Merkmale und der, Mosaikbildung der Bastarde,' Ber. D. bot. Ges., Berlin, 1903, xxı, pp. 195-201.

Four types of dominance in $\mathbf{F}_{1}$. Illustrations among flower-colour cases.

pp. $156,157,174$

487. 1904. Bateson, W., Saunders, E. R., and Punnett, R. C., 'Experimental Studies in the Physiology of Heredity,' Rep. Evol. Com. Roy. Soc., London, 1904, Rpt. II, 154 pages.

Accounts of inheritance of flower-colour in Matthiola, Salvia, Pisum and Lathyrus. See text.

pp. $9,147,152,156,157,167,167,169,174,178,181,182$

488. Bidgood, J., 'Albinism, with special Reference to Shirley Poppies,' J. R. Hort. Soc., London, 1904, xxvıII, pp. 477-482.

The author discusses albinism in general, and in particular the loss of colour and of the black basal patch in Papaver. The black pigment at the base of the petal gives different chemical reactions from that in the rest of the petal.

489. *Bitter, G., 'Dichroismus und Pleochroismus als Rassencharaktere,' Festschrift für P. Ascherson, Berlin, 1904, pp. 158-167.

From a number of observations, the author makes the suggestion that within the species there may be races having either different colouring in all the organs, or in one organ only, viz. in stem, leaf, flower, fruit or seed. 
Correns, C., 'Ein typisch spaltender Bastard zwischen einer einjährigen und einer zweijährigen Sippe des Hyoscyamus niger,' Ber. D. bot. Ges., Berlin, 1904, xxı, pp. 517524.

Crosses are made between $H$. niger and $H$. pallidus, the former having anthocyanin, the latter none. $F_{1}$ is intermediate in colour. Mendelian segregation in $\mathrm{F}_{2}$.

491. Coutagne, G., 'De la polychromie polytaxique florale des végétaux spontanés,' C. R. Acad. sci., Paris, 1904, Cxxxix, pp. 77-79.

Discussion as to existence, side by side in nature, of differently coloured varieties of the same species.

492. Emerson, R. A., 'Heredity in Bean Hybrids,' Annual Report Nebraska Agricultural Experiment Station, Nebraska, 1904, xVII, pp. 33-68.

Appearance of anthocyanin in testa of $F_{1}$ from two varieties without pigment.

493. Lock, R. H., 'Studies in Plant Breeding in the Tropics,' Ann. R. Bot. Gard., Ceylon, 1904, II, pp. 299-356.

Some observations on colour inheritance in peas and maize are included.

494. *Tschermak, E. von, 'Weitere Kreuzungsstudien an pp. 157,179 Erbsen, Leukojen und Bohnen,' Zs. Landw. VersWes., Wien, 1904, vII, pp. 533-638.

Same observation as in No. 492 .

495. Wittmack, L., 'Daucus Carota, L. var. Boissieri Schweinfurth,' Gartenflora, Berlin, 1904, LIII, pp. 281-284.

Description of a variety of Carrot of which the root contains anthocyanin.

p. 155

496. 1905. Bateson, W., Saunders, E. R., and Punnett, R. C., 'Further Experiments on Inheritance in Sweet Peas and Stocks,' Proc. R. Soc., London, 1905, LxxviI B, pp. 236238.

Reference to inheritance of colour. Expression of $\mathrm{C}$ and $\mathrm{R}$ factors. See text. pp. $9,156,167,169$

497. Correns, C., 'Zur Kenntnis der scheinbar neuen Merkmale der Bastarde,' Ber. D. bot. Ges., Berlin, 1905, xxiII, pp. 70-85.

Further experiments on inheritance of flower-colour in Mirabilis Jalapa. Chiefly second and third generations. Also striped varieties.

498. Vries, H. de, Species and Varieties. Their Origin by Mutation, Chicago and London, 1905.

Various references to inheritance of colour. pp. $153,154,156,157,161,165,179,189,197$ 
499. 1906. Bateson, W., 'Coloured Tendrils of Sweet Peas,' Gard.

Chron., London (Ser. 3), 1906, xxxix, p. 333.

Association with coloured leaf-axils.

pp. 156,181

500. Bateson, W., Saunders, E. R., and Punnett, R. C., 'Experimental Studies in the Physiology of Heredity,' Rep. Evol. Com. Roy. Soc., London, 1906, Rpt. III, 53 pages.

References to inheritance of flower-colour in Sweet Peas and Stocks.

pp. 152, 156, 167, 169

501. Biffen, R. H., 'Experiments on Hybridisation of Barleys,' Proc. Phil. Soc., Cambridge, 1906, xIII, pp. 304308.

Purple colour in paleae and grains of Barley.

pp. 156,167

502.

Hurst, C. C., 'Mendelian Characters in Plants and Animals,' Rep. Conf. Genet. R. Hort. Soc., London, 1906, pp. 114-128.

Inheritance of flower-colour in Antirrhinum, Sweet Peas, Poppies, and Orchids. pp. 156, 163, 164, 172, 188

503. Kraemer, H., 'Studies on Color in Plants,' Bull. Torrey Bot. Cl., New York, N. Y., 1906, xxxiI, pp. 77-92.

Chiefly an account of the effect on flower-colour of various salts added to the soil.

504. Lock, R. H., 'Studies in Plant Breeding in the Tropics,' Ann. R. Bot. Gard., Ceylon, 1906, III, pp. 95-184.

Inheritance of colour in Zea Mays. See text.

pp. $156,157,163,172,179$

505. Ostenfeld, C. H., 'Experimental and Cytological Studies in the Hieracia. 1. Castration and Hybridisation Experiments with some Species of Hieracia,'Bot. Tids., Kjøbenhavn, 1906, xxvII, pp. 225-248.

Inheritance of anthocyanin in some of the hybrids concerned.

506. Saunders, E. R., 'Certain Complications arising in the p. 156 Cross-breeding of Stocks,' Rep. Conf. Genet. R. Hort. Soc., London, 1906, pp. 143-147.

Relationship between factors for hoariness and factors for colour.

pp. 156,169

507. 1907. Bateson, W., 'The progress of Genetics since the rediscovery of Mendel's Papers,' Progr. rei bot., Jena, 1907, I, pp. 368-418.

References to the inheritance of colour in plants.

508. Fletcher, F., 'Mendelian Heredity in Cotton,' J. Agric. Sci., Cambridge, 1907-1908, II, pp. 281-282.

Inheritance of anthocyanin in flower is mentioned, and is noted as not being a simple Mendelian case. 
Focke, W. O., 'Betrachtungen und Erfahrungen über Variation und Artenbildung,' Abh. natw. Ver., Bremen, 1907, xIx, pp. 68-87.

Some observations on colour variation are included.

510.

Gregory, R. P., 'On the Inheritance of certain Characters in Primula sinensis,' Rep. Brit. Ass., London, 1907, pp. 691-693.

Remarks on inheritance of colour in flower and stem.

511.

*Lindman, C. A. M., 'Amphichromie bei Calluna vulgaris,'Bot. Not., Lund, 1907, pp. 201-207.

Variation in colour in flowers of an individual of Calluna vulgaris.

512. Lock, R. H., 'On the Inheritance of Certain Invisible Characters in Peas,' Proc. $R$. Soc., London, 1907, Lxxix B, pp. 28-34.

Mention is made of the purple spots (due to anthocyanin) on the testa as a Mendelian character. pp. 157, 174

513. Shull, G. H., 'Some Latent Characters of a White Bean,' Science, N. S., New York, N. Y., 1907, xxv, pp. 828-832.

Inheritance of colour (anthocyanin) in the testa. See text.

pp. $156,173,189$

514. Wheldale, M., 'The Inheritance of Flower-colour in Antirrhinum majus,' Proc. R. Soc., London, 1907, Lxxm B, pp. 288-305.

Preliminary account of the colour varieties and the Mendelian factors for flower-colour. See text. pp. 10, 156, 158

515. 1908. Balls, W. L., 'Mendelian Studies of Egyptian Cotton,' J. Agric. Sci., Cambridge, 1908, II, pp. 346-379.

Inheritance of anthocyanin in spot on leaf and petals.

pp. $156,165,184,188$

516. Bateson, W., Saunders, E. R., and Punnett, R. C., 'Experimental Studies in the Physiology of Heredity,' Rep. Evol. Com. Roy. Soc., London, 1908, Rpt. Iv, 60 pages.

Gametic coupling in the Sweet Pea. Colour factors involved.

pp. 156,167

517. Baur, E., 'Einige Ergebnisse der experimentellen Vererbungslehre,' Med. Klinik, Berlin, 1908, Iv, Beiheft 10, pp. 265-292.

Colour inheritance in flowers of Antirrhinum and Mirabilis. pp. $156,159,170$

518. Lock, R. H., 'The Present State of Knowledge of Heredity in Pisum,' Ann. R. Bot. Gard., Ceylon, 1908, Iv, pp. 93-111.

Inheritance of anthocyanin in flowers, leaf-axils, testa, etc. of Pisum. See text.

pp. $147,157,174,182,189$ 
519.

Rawson, H. E., 'Colour Changes in Flowers produced by controlling Insolation,' Rep. Brit. Ass., London, 1908, pp. 902-903.

Account of variations of flower-colour produced in Tropaeolum by shading plants at certain times of the day. See text.

520. Shull, G. H., 'Some new Cases of Mendelian Inheritance,' Bot. Gaz., Chicago, I11., 1908, xLV, pp. 103-116.

Among other cases an account is given of a cross between white- and purple-flowered Lychnis dioica. Inheritance of the purple (anthocyanin) disk in Sunflower.

pp. 156, 166, 169, 181

521. Shull, G. H., 'A new Mendelian Ratio and several Types of Latency,' Amer. Nat., New York, 1908, xLII, pp. 433-451.

Factors controlling inheritance of mottling (anthocyanin) in Beans.

pp. $156,173,185,189$

522. Vouk, V., 'Einige Versuche über den Einfluss von Aluminium-salzen auf die Blütenfärbung,' Oest. Bot. Zs., Wien, 1908, LVIII, pp. 236-243.

An account of experiments on treating plants of Hydran. gea hortensis with solutions of aluminium salts. See text.

523. 1909. Balls, W. L., 'Studies of Egyptian Cotton,' Yrbk. Khed. p. 202 Agric. Soc., Cairo, 1909, 158 pages.

Spot on leaf due to anthocyanin. Inheritance of spot. See text.

pp. $156,165,184,188$

524. Bateson, W., Mendel's Principles of Heredity, Cambridge, 1909. (3rd ed. 1913.)

Full reference to inheritance of colour in plants.

pp. $147,151,156,163,181,190,198,206$

525. Bunyard, E. A., 'The Effect of Salts upon Pigments,' Gard. Chron., London, 1909, XLVI, pp. 97-98.

Note on effect of various salts in the soil upon flowercolour in Hydrangea and Roses. Lead acetate said to intensify red colour.

526 Chodat, R., 'Sur des grappes de raisins panachées,' Bul. Soc. Bot., Genève, 1909, I (sér. 2), pp. 359-363.

Description of cases among vines in which white grapes appear among coloured branches. Also individual berries which are partly purple and partly white.

527 East, E. M., "The Transmission of Variations in the Potato in Asexual Reproduction,' Report Connecticut Experiment Station, 1909-1910, pp. 119-160.

A record of the production asexually of white tubers as a variety which breeds true. 
Emerson, R. A., 'Tnheritance of Color in the Seeds of the Common Bean, Phaseolus vulgaris,' Annual Peport Nebraska Agricultural Experiment Station, 1909, xxIr, pp. 67-101.

Full account of inheritance of pigmentation and mottling.

pp. $156,174,189$

529. Emerson, R. A., 'Factors for Mottling in Beans,' Amer. Breed. Ass. Rep., Washington, D. C., 1909, v, pp. 368-376.

Suggestion is made that two factors are concerned in the production of mottling in beans.

pp. $156,174,189$

530.

*Hildebrand, F., 'Die Veränderung der Blumenfarben durch die Kultur,' Umschau, Frankfurt a. M., 1909, XIII, pp. 612-615.

Author remarks on the appearance of different colourvarieties under cultivation. He contrasts some cases (Primula acaulis, $P$. sinensis) where blue varieties have arisen, with other cases (Althaea, Antirrhinum, Calceolaria, among others) where no blue variety has appeared. Sometimes variation only gives rise to different shades of the original colour.

531. Hurst, C. C., 'Inheritance of Albinism in Orchids,' Gard. Chron., London, 1909, xLV, pp. 81-82.

Production of colour (anthocyanin) by crossing albinos.

pp. 156, 163, 164

532. Lock, R. H., 'A Preliminary Survey of Species Crosses in the Genus Nicotiana from the Mendelian Standpoint,' Ann. R. Bot. Gard., Ceylon, 1909, Iv, pp. 195-227.

Dominance of blue colour in pollen grains.

pp. 156, 171

533. Marryat, D. C. E., 'Hybridisation Experiments with Mirabitis Jalapa,' Rep. Evol. Com. Roy. Soc., London, 1909, Rpt. $\nabla$, pp. $32-50$.

Inheritance of flower-colour in Mirabilis and Mendelian factors concerned. See text.

pp. $149,156,170,185,192$

534. Weiss, F. E., 'Note on the Variability in the Colour of the Flowers of a Tropaeolum Hybrid,' Mem. Lit. Phil. Soc., Manchester, 1909, LIV, No. 18, 5 pages.

Description of a Tropaeolum plant which bore both yellow and red flowers. The offspring, from selfing, consisted of red-flowered and yellow-flowered individuals, and of these, one varied like the original parent. This variation to redness appeared to be affected by weather conditions.

535. Wheldale, M., 'Further Observations upon the Inherip. 157 tance of Flower-colour in Antirrhinum majus,' Rep. Evol. Com. Roy. Soc., London, 1909, Rpt. v, pp. 1-26.

Full account of the inheritance of flower-colour in Antirrinum. See text.

pp. $10,148,152,156,159,185,188$ 
536. 1910. Baur, E., 'Vererbungs- und Bastardierungsversuche mit is made

Antirrhinum,' Zs. indukt. Abstammungslehre, Berlin, 1910, III, pp. 34-98.

Full account of inheritance of flower-colour in Antirrhinum. See text. pp. $10,156,160$

537. Correns, C., 'Der Uebergang aus dem homozygotischen in einen heterozygotischen Zustand im selben Individuum bei buntblättrigen und gestreiftblïhenden Mirabilis-Sippen,' Ber. D. bot. Ges., Berlin, 1910, xxvir, pp. 418-434.

Connection between striped and whole-coloured flowers in inheritance is included.

pp. $156,170,197$

538.

East, E. M., 'Inheritance in Potatoes,' Amer. Nat., New York, 1910, Xurv, pp. 424-430.

Inheritance of anthocyanin in potatoes. See text.

pp. 157,178

539. Gates, R. R., 'The Material Basis of Mendelian Phenomena,' Amer. Nat., New York, 1910, xıIv, pp. 203-213.

Suggestion of a quantitative inheritance of pigment in Oenothera.

pp. 156,171

540. Hurst, C. C., 'Mendel's Law of Heredity and its Application to Horticulture,' J. R. Hort. Soc., London, 1910, xxxvi, pp. 22-52.

Mendel's work, cases of Sweet Pea and Antirrhinum given in detail. Instances of coloured $F_{1}$ produced by mating of two albino Orchids.

pp. 156, 163, 164

541. Keeble, F., and Pellew, C., 'White Flowered Varieties of Primula sinensis,' J. Genetics, Cambridge, 1910, I, pp. 1-5.

A record of the existence of a recessive white-flowered Primula with coloured (anthocyanin) stems. pp. 157, 176, 177, 182

542. Keeble, F., Pellew, C., and Jones, W. N., 'The Inheritance of Peloria and Flower-colour in Foxgloves (Digitalis purpurea),' N. Phytol., London, 1910, IX, pp. 68-77.

Inheritance of flower-colour (anthocyanin). See text. pp. $156,165,181,188$

543. Ostenfeld, C. H., 'Further Studies on the Apogamy and Hybridization of the Hieracia,' Zs. indukt. Abstammungslehre, Berlin, 1910, III, pp. 241-285.

Inheritance of anthocyanin in some of the hybrids concerned.

544. Salaman, R. N., 'The Inheritance of Colour and other Characters in the Potato,' J. Genetics, Cambridge, 1910, I, pp. 7-46.

Inheritance of colour (anthocyanin) in the Potato. See text.

pp. $27,154,157,178$ 
545. Shull, G. H., 'Germinal Analysis through Hybridizais made

546. tion,' Proc. Amer. Phil. Soc., Philadelphia, Pa., 1910, xLIx, pp. 281-290.

Consideration of nature, chemical and otherwise, of unit characters.

Shull, G. H., 'Color Inheritance in Lychnis dioica,' Amer. Nat., New York, 1910, xuIV, pp. 83-91.

Inheritance of colour in Lychnis flowers. See text. pp. 156, 169

547.

Thoday (Sykes), M. G., and Thoday, D., 'On the Inheritance of the Yellow Tinge in Sweet Pea Colouring,' Proc. Phil. Soc., Cambridge, 1910, xvI, pp. 71-84.

Some cases of inheritance of anthocyanin are included. See text.

pp. $151,156,168$

548. Wheldale, M., 'Die Vererbung der Blütenfarbe bei Antirrhinum majus,' Zs. indukt. Abstammungslehre, Berlin, 1910, III, pp. 321-333.

Comparison of results obtained by the author with those of Baur (see Nos. 535 and 536). pp. 148, 152, 156, 160

549. 1911. Bateson, W., and Punnett, R. C., 'On the Inter-relations of Genetic Factors,' Proc. R. Soc., London, 1911, Lxxxıv B, pp. 3-8.

Account of certain 'couplings' which involve some colour factors. See text.

550. Bateson, W., and Punnett, R. C., 'On Gametic Series involving Reduplication of Certain Terms,' J. Genetics, Cambridge, 1911, I, pp. 293-302.

On the so-called 'coupling' between colour and other factors.

551. Baur, E., Einführung in die experimentelle Vererbungs. p. 185 lehre, Berlin, 1911.

General work on Genetics. Contains details of experiments on inheritance of flower-colour, especially in Antirrhinum.

552. Colgan, N., 'On the Inheritance of pitted Leaf-blotchings in Arum maculatum,' Irish Nat., Dublin, 1911, xx, pp. 210 217.

Segregation among offspring of a blotched plant. See text.

pp. $156, \mathbf{1 6 1}, 188$

553. East, E. M., and Hayes, H. K., 'Inheritance in Maize,' Bulletin Connecticut Agricultural Station, 1911, No. 167, 142 pages.

General account of an inheritance of anthocyanin in Maize. See text.

554. Emerson, R. A., 'Genetic Correlation and Spurious
Allelomorphism in Maize,' Annual Report Nebraska 
Agricultural Experiment Station, Nebraska, 1911, xxiv, pp. 59-90.

Inheritance of anthocyanin in separate parts of Maize inflorescence, both independently and otherwise. Discussion of the same.

pp. 157, 180, 182

555. Gates, R. R., 'Studies on the Variability and Heritability of Pigmentation in Oenothera,' Zs. indukt. Abstammungslehre, Berlin, 1911, Iv, pp. 337-371.

Experiments and discussion upon the quantitative inheritance of anthocyanin in Oenothera rubrinervis and Oenothera rubricalyx.

pp. 156, 171, 181

556. *Gawalowsky, A., 'Künstliche Blatt- und Blütenfärbungen,' Wiener landw. Zeit., 1911, LXI, p. 616.

Author finds that treatment of soil with sodium orthophosphate gives a deep red or blue-violet colour to petals of Rosa centifolia; also to Malva tinctoria a deep brown-red. Potassium carbonate causes development of anthocyanin in Lactuca sativa.

557. Gregory, R. P., 'Experiments with Primula sinensis,' J. Genetics, Cambridge, 1911, I, pp. 73-132.

Full account of inheritance of anthocyanin in Primula. See text. $\quad$ pp. 149, 152, 153, 154, 157, 175, 182, 184, 189, 197

558. Gregory, R. P., 'On Gametic Coupling and Repulsion in Primula sinensis,' Proc. R. Soc., London, 1911, Lxxxiv B, pp. 12-15.

'Coupling' in Primula involving colour-factors.

559. Kajanus, B., 'Genetische Studien an Beta,' Zs. indukt. Abstammungslehre, Berlin, 1911, vi, pp. 137-179.

Inheritance of anthocyanin in root and leaves of Beta. See text.

pp. $156,162,181$

560. *Kajanus, B., 'Ueber die Farben der Blüten und Samen von Trifolium pratense,' Fühlings landw. Ztg., Stuttgart, 1911, pp. 763-776.

Inheritance of flower and seed colour (anthocyanin).

561. Leake, H. M., 'Studies in Indian Cotton,' J. Genetics, Cambridge, 1911, I, pp. 205-271.

Inheritance of colour (anthocyanin) in the leaf and flower. See text.

pp. $156,166,181,184,185,188$

562. Saunders, E. R., 'Further Experiments on the Inheritance of "Doubleness" and other Characters in Stocks, J. Genetics, Cambridge, 1911, I, pp. 303-376.

Notes on inheritance of flower-colour are included. pp. 156, 169

563. Saunders, E. R., 'On Inheritance of a Mutation in the Common Foxglove (Digitalis purpurea), N. Phytol., London, $1911, \mathrm{x}$, pp. 47-63. 
Remarks on inheritance of spots (anthocyanin) on corolla.

pp. $156,165,181$

564. Tammes, T., 'Das Verhalten fluktuierend variierender Merkmale bei der Bastardierung,' Rec. Trav. Bot. Néerl., Nijmegen, 1911, vIII, pp. 201-286.

References to inheritance of colour of flowers in varieties of Linum.

pp. $156,168,184$

565.

Vries, H. de, The Mutation Theory, Translated by J. B. Farmer and A. D. Darbishire, 1911. (Die Mutationstheorie, Leipzig, 1901.)

References to inheritance of pigmentation.

pp. $154,156,157,188,189,191,192,197$

566. Weiss, F. E., 'Researches on Heredity in Plants,' Mem. Lit. Phil. Soc., Manchester, 1911-1912, LVI, pp. 1-12.

Inheritance of colour in Anagallis. See text.

pp. 156,157

567. 1912. Baur, E., 'Vererbungs- und Bastardierungsversuche mit Antirrhinum. 2. Faktorenkoppelung,' Zs. indukt. Abstammungslehre, Berlin, 1912, IV, pp. 201-216.

Reduplication in Antirrhinum involving factors for flower-colour.

568. Burtt-Davy, J., 'Observations on the Inheritance of Characters in Zea Mays,' Trans. R. Soc. S. Africa, Cape Town, 1912, II, pp. 261-270.

Red pigment in pericarp and in aleurone layer.

569. Compton, R. H., 'Preliminary Note on the Inheritance of Self-sterility in Reseda odorata,' Proc. Phil. Soc., Cambridge, 1912-1914, XVII, p. 7.

Anthocyanin in pollen (orange) dominant to its absence (yellow).

East, E. M., 'Inheritance of Color in the Aleurone Cells of Maize,' Amer. Nat., New York, 1912, xLvi, pp. 363-365.

Production of purple colour in aleurone layer is due to presence of factor, $\mathrm{P}$, in addition to $\mathrm{C}$ and $\mathrm{R}$.

571. Emerson, R. A., 'The Unexpected Occurrence of Aleurone Colors in $\mathrm{F}_{2}$ of a Cross between Non-colored Varieties of Maize,' Amer. Nat., New York, 1912, xLvi, pp. 612-615.

$\mathrm{F}_{2}$, from mating of two whites, contained both red and purple grains. Two factors are necessary for red colour, and a third for purple: colour is also inhibited by a fourth factor. Hence it is possible to show how the present result is obtained.

572. Finlow, R. S., and Burkill, I. H., 'The Inheritance of p. 157 Red Colour, and the Regularity of Self-fertilisation, in Corchorus capsularis, Linn.,- - the Common Jute Plant,' 
Mem. Depart. Agric. India, Bot., London and Calcutta,

1912, IV, pp. 73-92.

Inheritance of anthocyanin in stem and leaf. See text.

pp. $156,163,181,184$

573. Gates, R. R., 'Mutations in Plants,' The Botanical Journal, 1912.

Descriptions of the mutant, Oenothera rubrinervis. pp. 156, 171

574. Hedrick, U. P., and Wellington, R., 'An Experiment in Breeding Apples,' New York Agricultural Experiment Station, Geneva, N. Y., 1912, Bull. 350, pp. 141-186.

Pigmentation in apples.

575. Heribert-Nilsson, N., 'Die Variabilität der Oenothera Lamarckiana und das Problem der Mutation,' Zs. indukt. Abstammungslehre, Berlin, 1912, viu, pp. 89-231.

References to inheritance of anthocyanin.

576. Heribert-Nilsson, N., 'Ärftlighetsförsök med blomfärgen hos Anagallis arvensis,' Bot. Not., Lund, 1912, pp. 229-235.

Inheritance of flower-colour in Anagallis. See text. pp. 156, 157

577. Hill, A. W., 'The History of Primula obconica, Hance, under Cultivation, with some Remarks on the History of Primula sinensis, Sab.' J. Genetics, Cambridge, 1912, II, pp. 1-20.

History of variation in flower-colour is involved. pp. 148, 151

578. Jones, W. N., 'Species Hybrids of Digitalis,' J. Genetics, Cambridge, 1912, Ir, pp. 71-88.

Inheritance of anthocyanin in hybrids $D$. purpurea and D. arandiflora.

579. Kajanus, B., 'Ueber die Farben der Blüten und Samen von Trifolium pratense,' Fühlings landw. Ztg., Stuttgart, 1912, IV, pp. 763-776.

Anthocyanin in flowers and seeds.

pp. $151,157,179$

580. Kajanus, B., 'Mendelistische Studien an Rüben,' Fühlings landw. Ztg., Stuttgart, 1912, IV, pp. 142-149.

Inheritance of anthocyanin in root of Beta and Brassica spp. See text.

pp. $156,162,163$

581. Kajanus, B., 'Genetische Studien an Brassica,' Zs. indukt. Abstammungslehre, 1912, vI, pp. 217-237.

Inheritance of anthocyanin in root. See text.

582. Keeble, F., 'Gigantism in Primula sinensis,' J. Genetics, Cambridge, 1912, Ir, pp. 163-188.

Various results in colour inheritance are included.

p. 157

583.

Lock, R. H., 'Notes on Colour Inheritance in Maize,' Ann. R. Bot. Gard., Ceylon, 1912, v, pp. 257-264.

Reply to East and Hayes' criticism of Lock's previous results. 
584. Punnett, R. C., Mendelism, London, 1912.

References to inheritance of colour in plants.

Salaman, R. N., 'A Lecture on the Hereditary Characters in the Potato,' J. R. Hort. Soc., London, 1912, xxxviII, pp. 34-39.

Inheritance of anthocyanin in flower and tuber.

586.

Saunders, E. R., 'On the Relation of Linaria alpina Type to its Varieties concolor and rosea,' N. Phytol., London, 1912, xI, pp. 167-169.

Inheritance of anthocyanin in the flower. See text.

587.

pp. $147,156,168$

Saunders, E. R., 'Further Contribution to the Study of the Inheritance of Hoariness in Stocks (Matthiola), 'Proc. R. Soc., London, 1912, Lxxxv B, pp. 540-545.

Further observations on the connection between hoariness and sap-colour (anthocyanin). It is shown that two factors are essential for hoariness, and that a certain relation exists between these and the factors for colour. See text.

588. Shull, G. H., 'The Primary Color-factors of Lychnis and p. 206 Color-inhibitors of Papaver Rhoeas,' Bot. Gaz., Chicago, II1., 1912, LIV, pp. 120-135.

An account of the inheritance of anthocyanin in both genera. See text.

pp. $156,169,172,189$

589. Trow, A. H., 'On the Inheritance of Certain Characters in the Common Groundsel-Senecio vulgaris, Linn.-and its Segregates,' J. Genetics, Cambridge, 1912, II, pp. 239276.

Inheritance of anthocyanin in stem. See text.

Tschermak, E. von, 'Bastardierungsversuche an Levko-

590. jen, Erbsen und Bohnen mit Rücksicht auf die Faktorenlehre,' Zs. indukt. Abstammungslehre, Berlin, "1912, vrr, pp. 81-234.

Inheritance of anthocyanin in flowers and seeds of the above plants.

pp. $156,157,170,189$

591. 1913. Bateson, W., Problems of Genetics, New Haven, London and Oxford, 1913.

Includes references to inheritance of pigmentation.

592.

Davis, B. M., 'Genetical Studies on Oenothera. 4. The Behaviour of Hybrids between Oenothera biennis and $O$. grandiflora in the Second and Third Generations,' Amer. Nat., New York, 1913, XLVII, pp. 449-476, 547571.

Inheritance of anthocyanin in stem papillae in cross O. grandiflora $\times$ biennis is included.

pp. 156, 172 

Somatic Cells,' Amer. Nat., New York, 1913, xuvII, pp. $375-377$.

Reference to striping of anthocyanin in Maize in con. nection with origin of mutations in somatic cells.

Haig Thomas, R., 'Nicotiana Crosses,' Comples Rendus et Rapports, Conférence Internationale de Génétique, Paris, 1911, Paris, 1913, pp. 450-461.

Inheritance of anthocyanin in Nicotiana species. pp. 156, 171

595.

*Holdefleiss, P., 'Ueber Züichtungs- und Vererbungsfragen bei Rotklee,' Kühn Arch., Berlin, 1913, pp. 81115.

Inheritance of colour in flower and seed of Trifolium pratense.

596. Hurst, C. C., 'The Application of Genetics to Orchid Breeding,' J. R. Hort. Soc., London, 1913, xxxvII, pp. 412 429.

Albinism in Orchids. Production of coloured $\mathrm{F}_{1}$ by mating of two albinos, and other results connected with colour.

597. *Kajanus, B., 'Ueber die kontinuierlich violetten Samen von Pisum arvense,' Fühlings landw. Ztg., Stuttgart, 1913, pp. 153-160.

Observations upon varieties with purple pigment in the testa.

598. Kajanus, B., 'Ueber die Vererbungsweise gewisser Merkmale der Beta- und Brassica-Rüben,' Zeitschrift für Pflanzenzüchtung, 1913, I, pp. 125-463.

Inheritance of anthocyanin is included.

599. Punnett, R. C., 'Reduplication Series in Sweet Peas,' J. Genetics, Cambridge, 1913, III, pp. 77-103.

Reduplications involving colour-factors.

600. Rawson, H. E., 'Variation of Structure and Colour of Flowers under Insolation,' Rep. Brit. Ass., London, 1913, pp. 711-713.

Further observations on the variations in flower-colour produced by screening Tropaeolum flowers from the sun's rays at different times of the day.

601. Saunders, E. R., 'On the mode of Inheritance of Certain Characters in Double-throwing Stocks, A Reply,' Zs. indukt. Abstammungslehre, Berlin, 1913, x, pp. 297310.

Paper includes case of reduplication in factors for flowercolour involving full and pale colour (anthocyanin) and white and cream plastid colour. 
602. 1914. Cockerell, T. D. A., 'Suppression and Loss of Characters is made

in Sunflowers,' Science, N. S., New York, N. Y., 1914, xx, pp. 283-285.

Variation in occurrence and dominance of red pigment over yellow.

pp. $150,153,156,166$

603. Cockerell, T. D. A., 'Sunflower Problems,' Science, N. S., New York, N. Y., 1914, XL, pp. 708-709.

Discussion as to nature of variation which produces red Sunflower. pp. $150,153,156,166$

604. Davis, B. M., 'Genetical Studies on Oenothera. 5. Some Reciprocal Crosses of Oenothera,' Zs. indukt. Abstammungslehre, Berlin, 1914, xIr, pp. 169-205.

Inheritance of anthocyanin in stem papillae and in sepals in crosses, $O$. franciscana $\times$ biennis and reciprocal, and $O$. biennis $\times$ grandiflora and reciprocal, is included. pp. 156, 172

605. Emerson, R. A., 'The Inheritance of a Recurring Somatic Variation in Variegated Ears of Maize,' Amer. Nat., New York, 1914, xLvIII, pp. 87-115.

Inheritance of variegation of red colour in the pericarp. See text.

pp. $157,193,194$

606. Gates, R. R., 'Breeding Experiments which show that Hybridisation and Mutation are independent Phenomena,' Zs. indukt. Abstammungslehre, Berlin, 1914, xI, pp. 209279.

Inheritance of anthocyanin in calyx in cross, $O$. grandi. flora $\times 0$. rubricaly $x$ and reciprocal, is included.

pp. 156,171

607. Gregory, R. P., 'On the Genetics of Tetraploid Plants in Primula sinensis,' Proc. $R$. Soc., London, 1914, LxxxvII B, pp. $484-492$.

References to inheritance of anthocyanin are included.

608. Honing, J. A., 'Experiments on Hybridisation with p. 157 Canna indica,' Proc. Sci. K. Akad. Wet., Amsterdam, 1914, XVI, pp. 835-841.

Inheritance of anthocyanin in stems, leaves, fruits, etc. of Canna.

pp. 156,163

609. Shull, G. H., 'A Peculiar Negative Correlation in Oenothera Hybrids,' J. Genetics, Cambridge, 1914, IV, pp. 83-102.

Inheritance of anthocyanin in stems, leaves, calyx, etc. among offspring of selfed plants of $O$. rubricalyx, and from reciprocal crosses between $O$. rubricalyx and $O$. Lamarckiana and $O$. rubrinervis.

pp. 156, 171, 182

610. Tammes, T., 'The Explanation of an apparent Exception to Mendel's Law of Segregation,' Proc. Sci. $K$. Akad. Wet., Amsterdam, 1914, xvI, pp. 1021-1031. 
Explanation of a deficiency of white-flowered plants in $\mathrm{F}_{2}$ from a cross between blue- and white-flowered varieties of Linum.

pp. 156,168

611. 1915. Cockerell, T. D. A., 'An Early Observation on the Red Sunflower,' Science, N. S., New York, N. Y., 1915, XLI, pp. 33-34.

Origin of the red Sunflower as a 'sport' in wild state. Connection between pigmentation of inflorescence and stem. See text.

pp. $150,153,156,166,181$

\section{UNCLASSIFIED REFERENCES}

612. 1902. *Ichimura, T., 'On the Anthocyan Formation in the Leaf Organ of Saxifraga sarmentosa (Japanese),' Bot. Mag., Tokyo, 1902, pp. 171-183.

613. *Schulz, H., 'Das Anthokyan und seine Bedeutung für den Pflanzenkörper, Phyto-physiologische Betrachtung, Nerthus, Altona, 1902, Iv, pp. 517-519, 523-525, 548-549. $553-555,574-576$.

614. 1903. *Buscalioni, L., e Pollacci, G., 'Ricerche anatomofisiologiche intorno alle antocianine,' Rendiconti del Congresso botanico nazionale tenutosi a Palermo nel maggio, 1902, Palermo, 1903, pp. 84-91.

615. 1904. *Heinsius, H. W., 'L'anthocyane chez les plantes (Dutch),' Werk. Gen. Nat. Genees. Heelk., Amsterdam (ser. 2), 1904, V, pp. 5-9.

616. 1912. *Nicolas, G., 'Formation d'anthocyane à l'obscurité à la suite du non-développement de la radicule chez le Galactites tomentosa,' Bull. Soc. Hist. nat. Afrique Nord, v, pp. 37-40.

617. *Viski, J., 'Zur Kenntnis des Anthozyans und der Färbung des Aleurons,' Bot. Közl., xII, pp. 169-172.

Papers accidentally omitted from the previous classes.

618. 1878. Erdmann, J., 'Ueber die Veränderlichkeit des Rothweinfarbstoffes,' Ber. D. chem. Ges., Berlin, 1878, XI (2), pp. 1870-1876.

Chemical test for wine pigment. See text.

619. 1884. Wortmann, 'Criticism of Pick's paper: "Ueber die p. 52

Bedeutung des rothen Farbstoffes bei den Phanerogamen und die Beziehungen desselben zur. Stärkewanderung" (Bot: Centralbl., Cassel, 1883, xvi, p. 281),'Bot. Ztg., Leipzig, 1884, xLII, p. 237.

Criticism of Pick's hypothesis as to the function of anthocyanin. See text. 
620. 1914. Combes, R., 'Sur la présence, dans des feuilles et dans

des fleurs ne formant pas d'anthocyane, de pigments jaunes pouvant être transformés en anthocyane,' C. R. Acad. sci., Paris, 1914, cuviII, pp. 272-274.

Preparation of artificial anthocyanin. See text.

621. Wheldale, M., and Bassett, H. L1., 'The Chemical Interpretation of some Mendelian Factors for Flower-Colour,' Proc. R. Soc., London, 1914, LxxxviI B, pp. 300-311.

Discussion on loss of colour of anthocyanin in alcohol is included.

Papers received too late for inclusion in bibliography.

622. 1913. Czartkowski, A., 'Einfluss der. Konzentration der Minerallösung auf die Anthocyanbildung aus dem Zucker bei Tradescantia viridis,' Sitzber. Warschau. Ges. Wiss., 1913, pp. 959-979.

623. Guilliermond, A., 'Sur la formation de l'anthocyane au sein des mitochondries,' C. R. Acad. sci., Paris, 1913, CLvi, pp. $1924-1926$.

624. Guilliermond, A., 'Nouvelles recherches cytologiques sur la formation des pigments anthocyaniques,' C. R. Acad. sci., Paris, 1913, clvir, pp. 1000-1002.

625. 1914. Kajanus, B., 'Ueber die Vererbung der Blütenfarbe von Lupinus Swt. mutabilis,' Zs. indukt. Abstammungslehre, Berlin, 1914, xII, pp. 57-58.

626. Löwschin, A. M., 'Zur Frage über die Bildung des Anthocyans in Blättern der Rose,' Ber. d. Bot. Ges., Berlin, 1914, хxxir, pp. 386-393.

627. Rosé, E., 'Étude des échanges gazeux et de la variation des sucres et des glucosides au cours de la formation des pigments anthocyaniques dans les fieurs de Cobaea scandens,' Rev. gén. bot., Paris, 1914, xxvi, pp. 257-270.

628. Willstätter, R., und Zechmeister, L., 'Synthese des Pelargonidins,' SitzBer. Ak. Wiss., Berlin, 1914, pp. $886-$ 893.

629. 1915. Emerson, R. A., 'Anomalous Endosperm Development in Maize and the Problem of Bud sports,' $Z s$. indukt. Abstammungslehre, Berlin, 1915, xIv, pp. 241-259.

630. Guilliermond, A., 'Quelques observations cytologiques sur la mode de formation des pigments anthocyaniques dans les fleurs,' C. R. Acad. sci., Paris, 1915, clxi, pp. $494-$ 497.

631. Hallqvist, C., 'Brassicakreuzungen,' Bot. Not., Lund, 1915, pp. 97-112. 
632. Heribert-Nilsson, N., 'Die Spaltungserscheinungen der Oenothera Lamarckiana,' Univ. Arsskr., N. F., Lund, 1915, Avd. 2, Bd 12, 131 pages.

633. Honing, J. A., 'Kreuzungsversuche mit CannaVarietäten,' Rec. Trav. Bot. Néerl., Groningen, 1915, xir, 26 pages.

634. Nagai, I., 'Ueber roten Pigmentbildung bei einigen Marchantia-Arten,' Bot. Mag., Tokyo, 1915, xxix, pp. 90 98.

635. Nohara, S., 'Genetical Studies on Oxalis,' J. Coll. Agric., Tolkyo, 1915, vI, pp. 165-181.

636. Rawson, H. E., 'Changes of Colour and Structure of Flowers,' J. R. Hort. Soc., London, 1915, xuI, pp. 42-46.

637. Willstätter, R., und Bolton, E. K., 'Ueber den Farbstoff der Scharlachpelargonie,' Liebigs Ann. Chem., Leipzig, 1915, cCccviII, pp. 42-61.

638. Willstätter, R., und Mallison, H., 'Ueber den Farbstoff der Preiselbeere,' Liebigs Ann. Chem., Leipzig, 1915, CCCCVIII, pp. 15-41.

639. Willstätter, R., und Mallison, H., 'Ueber Variationen der Blütenfarben,' Liebigs .Ann. Chem., Leipzig, 1915 , CCCCVIIr, pp. 147-162.

640. Willstätter, R., und Martin, K., 'Ueber den Farbstoff der Althaea rosea,' Liebigs Ann. Chem., Leipzig, 1915, CCCCviI, pp. 110-121.

641. Willstätter, R., und Mieg, W., 'Ueber ein Anthocyan des Rittersporns,' Liebigs Ann. Chem., Leipzig, 1915, CCCCVIII, pp. 61-82.

642. Willstätter, R., und Mieg, W., 'Ueber den Farbstoff der wilden Malve,' Liebigs Ann. Chem., Leipzig, 1915, ccccvir, pp. 122-135.

643. Willstätter, R., und Nolan, T. J., 'Ueber den Farbstoff der Rose,' Liebigs Ann. Chem., Leipzig, 1915, Cccoviı, pp. 1-14.

p. 222

p. 219

p. 219

p. 219

p. 218

644. Willstätter, R., und Nolan, T. J., 'Ueber den Farbstoff der Päonie,' Liebigs Ann. Chem., Leipzig, 1915, Coccvir, pp. 136-146.

645. Willstätter, R., und Zollinger, E. H., 'Ueber die Farbstoffe der Weintraube und der Heidelbeere,' Liebigs Ann. Chem., Leipzig, 1915, ccccvir, pp. 83-109. 


\section{INDEX}

Abbott, 372

Abderhalden, 109, 218

Abrus, 27; A. precatorius, 30

Abutilon, 147

Acacia, 42

Acalypha, 19

Acanthaceae, 19, 43, 135

Acantholimon, 32

Acer, $21,22,36,42,84,135$; A. campestris,

21; A. pseudoplatanus, 21, 84

Aceraceae, 42

Achillea, 43; A. Millefolium, 25, 153

Achyranthes angustifolia, 92; A. Verschaffeltii, 52

Acids, anthocyanin and, 2, 8, 48, 56

Aconitum, 26

Adenanthera, 27

Adiantum, 17;'A. macrophyllum, 33

Adonis, 39

Aechmea, 30

Aerua, 36

Aeschynanthus, 19; A. atropurpureus, 36

Aesculus, 21

Agrostemma, 25, 156, 157

Ailanthus, 110, 274; A. glandulosa, 33, 91

Aira, 41; A. caespitosa, 25

Aitchison, 53

Aizoaceae, 41, 52

Ajuga, 36; A. pyramidalis, $246 ;$ A. reptans 155,246

Albinism, 147 ; partial, 153

Albinos, 10, 111, 209

Alcohol, loss of colour of anthocyanin in, 47,120

Aleurone, anthocyanin and, 35

Algae, 127

Alisma, 41

Alkalies, anthocyanin and, 2, 8, 48, 50, 51, 53

Alkanet, 2

Allium, 41, 100; A. Cepa, 97; A. giganteum, 234; A. Schoenoprasum, 30

Allocyanidin, 124

Alloplectus speciosus, 33; A. vittatus, 33

Alnus, 24, 26, 28, 135; A. glutinosa, 23

Alocasia, 19

Aloe, 17

Alopecurus, 27, 41

Alpine plants, anthocyanin in, 6, 25, 84, 102

Alsinaceae, 38
Alsinoideae, 42

Alternanthera, 19

Althaea, 9, 46, 47, 50, 55, 58, 282, 293; analysis of pigment, $62,63,78,80,219$, 224 ; colour-varieties, 148, 149, 152, 191, 210,215

Althaeĩn, 219

Alyssum, 42

Amarantaceae, 9, 19, 41, 47, 51, 52

Amaranthus, 52, 89, 246; A. caudatus, 156,157

Amaryllidaceae, 17, 41

Amelanchier, 42

Amentales, 24, 26

Amherstia, 21, 130, 131, 139, 140

Amorpha, 31

Ampelochroïc acids, 61

Ampelopsis, 14, 22, 36, 247, 255; $A$. hederacea, 91, 95, 121, 122; A. humulifolia, 32; A. muralis, 32; quinquefolia, 31,52

Amsonia latifolia, 33; A. salicifolia, 32

Anacardiaceae, 42

Anagallis, 215; A. arvensis, 32, 156, 157, 283 ; var. ciliata, 32 ; var. coerulea, 32 , 151,282

Androsace, 43, 128; A. lactiflora, 33

Anemone, 26, 100, 154, 217, 287; 4 . fulgens, 46; A. Hepatica, 42; A.japonica, $42,96,101,120,152$; A. nemorosa, 283; A. Pulsatilla, 42 ; var. rubra, 147

Angiosperms, 18

Angraecum, 30

Anthemis, 28

Anthericum, 238

Anthocyanin, analysis of, 8, 9, 12, 13, 58 et seq.; and decortication, 4, 82; and drought, 24, 92 ; and injury, 4, 24, 82; and light, 5, 87; and oxidases, 11, 91, 117; and sugar-feeding, 93 et seq.; and sugars, $4,85,101,116$; and tannins, 34 $50,60,106$; and temperature, $5,6,24$; and translocation, $5,6,83,86,102,131$; and transpiration, 133, 135; artificial, $13,14,15,121,122,123,124,125$; as glucoside, 46 ; as indicator, 8,54 ; as stain, 29; autumnal, 4, 6, 22, 86, 89, 90 ; biological function of, 7,126 ; bodies, 30 et seq.; chromogen of, 4,5 , $8,11,84,102,117$; constitution of, 75 ; crystalline, 30 et seq., 45 ; in alcohol, 47 ,

Numbers in heavy type denote papers in Bibliography

W. P. 
120 ; in Alpine plants, 6, 25, 84, 102; in Arctic plants, 26; in cell-wall, 29, 30; in corolla, 26, 38 et seq.; in fruit, 27 ; in Gymnosperms, 17; in halophytes, 26, 92 ; in leaves, 18 et seq., 35,37 ; in parasites, 28, 85; in Pteridophyta, 17; in roots, 27 ; in tropics, 19 et seq.; isomer of, $47,53,72,76$; periodic, 36 ; permanent, 36: physiological function of, 7 ; and assimilatory inhibition, 131, 136, 137 ; as light screen, 127, 129; as protection for translocation, 128, 131, 132; for conversion of light into heat, 128 $129,130,133-136$; hypotheses as to, 126 ; in tropics, 130,131 : plants lacking in, 17; reactions in formation of, 112 , $113,114,115,121,122,123,124,125$; reactions of acids with, $2,8,48$; of alkalies with, 2, 8, 48 et seq.; solubilities of, 2,46 ; spectrum of, 7,56

Anthriscus, 95

Anthyllis, 34, 282, 283

Antirrhinum, 5, 10, 11, 12, 15, 32, 40, 58, $88,111,122,124,125,156,198,204$, $205,207,293,295,297$; colour-variation, 148, 149, 152, 154, 180, 182, 183, $184,185,188,190,215$; inheritance of colour, 157; isolation of pigment, 69,80 ; properties of pigment, $46,50,51$; reactions in pigment formation, 114, 115, $119,205,207,209,210,211,212,214$; striping, 191, 192, 193, 194, 197, 199, $216 ;$ A. majus luteum rubrostriatum, 193 Apigenin, 12, 110, 114, 160, 207, 208 Apium, 110; A. Petroselinum, 12 Apocynaceae, 43

Aquilegia atrata, 31; A. vulgaris, 95, 147

Arabis, 18

Araceae, 19, 20, 26, 135

Arctic plants, anthocyanin in, 26

Arctostaphylos, 110

Arisarum, 36

Aristolochiaceae, 41

Armeria, 89; A. vulgaris, 155

Armstrong, 11, 12, 13, 14, 16, 47, 123, 125, $212,229,230,231,239,240,251$; artificial anthocyanin, 122 ; oxidases, $117-120$

Aroideae, 27, 41

Artemisia, 28

Arum 19, 36, 135, 156, 161, 188, 190

Ascherson, 27, 43

Asclepiadaceae, 43

Asclepias, 39

Askenasy, 5, 85, 88, 282

Asphodelus, 238

Assimilatory inhibition, anthocyanin as protection against, 131, 136, 137

Aster, 38, 56; A. Tripolium, 156, 161, 286 Atkins, 119, 233, 246, 247, 258

Atriplex, 26, 56; A. hortensis, 36, 52, 154 ; A. litoralis, 52

Atropa, 27, 182; A. Belladonna, 32, 154,
$156,161,180,183,241,282,283 ; A$. Belladonna lutea, 147, 161

Autumnal coloration, 4, 6, 22 et seq., 86, 89,90 ; in Alps 23; on Danube, 22

Avena, 41

Azalea, 194, 198; A. indica, 38; $A$. Verve. ana 198

Azolla, 17

\section{Baldingera, 41}

Balfour, 127

Ballota, 43

Balls, 156, 165, 184, 188, 515, 523

Banana, 153, 154

Baptisia australis, 31 ; B. minor, 33

Barley, 123; crown variety of, 153

Bartlett, 116

Bartsia, 25

Basella, 52

Basellaceae, 52

Bassett, 12, 46, 50, 56, 114, 120, 124, 160 , 254, 255, 621

Batalin, 89, 293

Bateson, 9, 156, 157, 190, 209, 475, 480 $481,487,496,499,500,507,516,524,549$, 550, 591; Antirrhinum, 158; bud-variation, 198, 199; Clarkia, 147, 163; Lathyrus, 151, 152, 167, 181, 198, 206; Phaseolus, 173; Pisum, 174; Primula, 175; reduplication, 185

Bauhinia, 21

Baur, 10, 156, 159, 160, 170, 517, 536, 551 , 567

Beech, 21, see Fagus; red-leaved, 41, 136, $141,198,280$

Beet-root, 56, 130, see Beta

Begonia, 19, 26, 30, 101, 137; B. acanthostigma, $34 ; B$. discolor, 32 ; $B$. flori. bunda, $38 ; B$. heracleifolia var. nigricans, 134; B. maculata, $30,32,34 ; B$. semperflorens, 153

Begoniaceae, 20, 42, 135

Beilstein, 180

Bellis, 98, 101, 152

Benecke, 28, 312

Bentham, 155

Berberidaceae, 42

Berberis, 26; B. vulgaris, 22, 154; $B$. vulgaris atropurpurea, 36

Bergenia, 26

Bernowitz, 96

Berthold, 35, 38, 82, 84, 64

Berzelius, 121

Beta, 5, 52, 89, 100, 156, 162, 181, 246; B. vulgaris, $27,36,99,154$

Betonica, 43

Betula, 24, 26; B. alba, 23; red-leaved, 154,285

Betulaceae, 41

Beulaygue, 88, 339

Beyerinck, 28, 303

Bidgood, 10, 39, 40, 18, 488

Biffen, 156, 167, 501 
Bignoniaceae, 43

Bilberry, 9, 13, 46, 53, 56, 58, 62, see Vaccinium

Billbergia, 234; B. gigantea, 19

Biological function of anthocyanin, 7, 126

Bitter, 489

Blackman, 87, 139

Blechnum, 17

Blitum, 52

Böhm, 32, 88

Bokorny, 32, 99

Bolton, 76, 218, 637

Bommer, 116

Bonnier, Gaston, 6, 25, 84, 102, 288, 289 , 294, 307, 328

Boraginaceae, 43

Borbás, 41, 38

Bořšcow, 145

Bouffard, 189

Bougainvillaea, 26

Boyle, 2, 8, 49, 55, 57, 107

Braconnot 8, 110

Bracts, anthocyanin in, 26

Brandza, 41

Brassica, 26, 34, 35, 88, 156; B. napus, $163 ; B$. oleracea, 31,$154 ;$ B. rapa, 163 Braya, 42

Briza, 41 ; B. media, 25

Bromeliaceae, 19, 35, 41

Bromus, 41

Brown, 132

Brownea grandiceps, 22; B. hybrida, 22

Brun, 364

Buchenau, 470

Bud-scales, anthocyanin in, 21

Bud-variation, 197-199

Bunyard, 525

Burbidge, 72

Burgerstein, 352

Burkill, 156, 163, 181, 184, 572

Burtt-Davy, 157, 568

Buscalioni, 3, 32, 35, 36, 38, 91, 17, 614

Butomus, 41

Buxus, 17

Cabbage, 29, 34, 123, see Brassica

Caesalpineae, 21

Caladium, 19, 140

Calamagrostis, 41

Calathea, 19

Calceolaria, 293

Callistephus, 202

Calluna, 36, 110; C. vulgaris, 155, 291

Calystegia, 33

Camelina, 42

Camellia, 38, 194; C. japonica, 191

Campanula, 6, 27,36, 215; C. alliariaefolia, 202; C. latifolia, 155; C. medium, 147; C. persicifolia, 18; C. pusilla, 25; C. rotundifolia, $155 ; C$. Trachelium, 87, 286

Campanulaceae, 43

Canavalia, 156, 163
Candolle, de, 4

Canna, 36; C. indica, 97, 154, 156, 163

Caprifoliaceae, 43

Cardamine, 28; C. amara, 25; C.trifolia, 18

Carduus crispus, 286; C. nutans, $155 ; C$. palustris, 155

Carex aterrima, 25; $C$. atrata, 25; C. nigra, 25

Carles, 181

Carlina, 25

Carnation, 198, 217, see Dianthus

Carpels, anthocyanin in, 26

Carpinus, 24, 26, 135; C. Betulus, 23

Carrot, 123

Carya, 33

Caryophyllaceae, 17, 42, 52

Casares, 414

Castanea, 24; C. vesca, 33, 36

Catabrosa, 41

Catalpa, 83

Cattleya, 41, 156, 163; C. quadricolor, 31 Ceanothus, 33, 83

Celosia, 89; C. variegata cristata, 191, 194

Centaurea, 13, 43, 58, 80, 191, 286 ; colour varieties, $147,214,215,222,223,224$, 225,226 ; pigment, constitution of, 75 , 76 ; preparation of, 59,72 ; properties of, $46,47,51,52,53,56$

Centradenia, 32

Centranthus, 155

Centrospermae, 9, 52

Cerastium, 36

Ceratophyllum, 94

Cercis, 42

Cerefolium, 100

Chabert, 155, 461

Chaerophyllum Cicutaria, 25; $C$. sylvestre, $22 ; C$. temulum, 21, 22, 42

Chamaenerium, 42

Chappel, 194

Characeae, 127

Chargueraud, 279, 280

Chartier, 381

Chatin $38,39,28,34,35$

Cheiranthus, 40, 110, 122, 148, 150; C. annuus, $35 ; C$. Cheiri, 39, 149, 153, $154,191,192,282$

Chenopodiaceae, 47. 52

Chenopodium, 246;C. album, 36

Chevallier, 8, 113, 114, 115

Chevreul, 24, 25, 134

Chionanthus, 43

Chlorophyll, bleaching of, by light, 127 : origin of anthocyanin from, 101; by oxidation, 104; by dehydration, 105: protection of, by anthocyanin, 127, 129, $131,136,137$

Chodat, 228, 526

Chromogen, of anthocyanin, $4,5,8,11$, $14,15,84,85,101,102,103,117$; and photosynthesis, 116; flavone as, 112, 114 Chrysanthemum, 120, 150

Chrysin, 110

Numbers in heavy type denote papers in Bibliography 
Chrysosplenium, 17

Church, 58, 59, 80, 147

Cichorium, 286

Cineraria, 38, 151, 215

Cinnamomum, 21

Circaea, 42

Cissus, 35, 91; C. discolor, 20

Citrus, 27

Clarkia elegans, 147, 156, 163, 282; $C$. pulchella, 191, 194

Claudel, 54

Claudius, 29, 184

Clerodendron, 38

Cloëz, 8, 44, 47, 126

Cobaea, 33

Cockerell, 150, 153, 156, 166, 181, 259, $317,602,603,611$

Codiaeum, 19

Coffea, 32

Colein, 59

Coleus, 36, 43, 58, 59, 80, 248; C. Blumei, 92; C. Verschaffeltii, 19

Colgan, 19, 156, 161, 188, 73, 552

Colin, 373, 381

Colladon, 274

Collinsia, 282

Collomia, 33

Colour-factors, 9, 10, 145; chemical interpretation of, 114, 207 et seq. ; in vegetative organs, 180-183; kinds of, 211-213

Colour-varieties, 40, 145; albino, 147 ; and flavones, 207; and hoariness, 206; and vigour, 204; blue, 151, 214; cream, 151 ; deep, 152, 213 : effect of salts on. 200,202 ; of insolation on, 203-204: in fruits and seeds, 154; in nature, 155 ; pigments in, 222-225; plastid-yellow, 149; red, 147, 148, 214; soluble-yellow, 148,215 ; tinged, 152, 213

Columnea picta, 33 ; C. Schiedeana, 32

Combes, 58, 101, 106, 207, 208, 219, 220, $234,235,236,374,377,378,379,385$, 620 ; artificial anthocyanin, 14, 15, 121, 122; carbohydrates in leaves, 117; decortication experiments, 4, 24, 82, 83 ; gaseous exchange in leaves, 91

Combinations of pigments, 39, 40, 148-150, 215

Comes, 126, 133, 388, 389, 390

Commelinaceae, 19, 41

Compositae, 43, 107, 155

Compton, 157, 178, 569

Conium, 21, 42

Constitution of anthocyanin, 75

Convallaria, 30

Convolvulaceae, 38,43

Convolvulus, 191

Corchorus, 156, 163, 180, 181, 184

Cordemoy, de, 368

Corenwinder, 268

Coreopsis tinctoria, 156, 164, 184; C. var. brunnea, 164, 184

Corispermum, 52
Cornaceae, 43

Cornflower, 15, 50, 57, 214, 215, see Centaurea

Cornus, 22, 36; C. florida, 99, 100; $C$. mas, 22; C. sanguinea, 22, 52, 89; $C$. sibirica, 89

Corolla, anthocyanin in, 26, 38, 39, 40

Correns, 156, 157, 170, 174, 179, 197, $472,476,482,485,486,490,497,537$

Corydalis, 38

Corylus, 24, 26, 36, 135; C. Avellana, 21 ; red-leaved, $154 ; C$. tubulosa, 33

Costerus, 297

Costus, 20

Cotoneaster, 42

Coupin, 41, 82, 477

Courchet, $30,32,97$

Coutagne, 491

Cramer, 85

Cranberry, 13, 58, 76, 77, 214, 218, see Vaccinium

Crassulaceae, 27, 42, 107, 275

Crataegus, 21, 22, 23, 88, 89, 110, 154; C. Oxyacantha, 153

Crepis, 89

Crocus, 5, 13, 88, 122; C. aureus, $40 ; C$. sativus, 87 ; C. vernus, 32

Croton, 19, 36, 42

Cruciferae, 18, 42, 107

Crystalline anthocyanin, 34, 45, 46

Crystalloids, anthocyanin and, 35

Cucurbita, 27, 88

Cucurbitaceae, 17

Curtel, 313, 330

Cuscuta, 4, 28, 43, 85, 89

Cyanidin, 79, 220; in colour varieties, 223

Cyanin, 79, 220; from Centaurea, 13, 72, 76 ; from Cranberry, 77, 218; from Rosa, 77, 218

Cyclamen, 43, 123, 152, 194; C. europaeum, 18; $C$. hederifolium, 18; $C$. persicum, 153,$191 ; C$. persicum giganteum, 101; C. repandum, 18

Cydonia, 36, 42; C. japonica, 38

Cynometra, 22

Cynosurus, 27

Cyperaceae, 17, 27

Cypripedium, 38, 39, 41, 156, 164, 188, 190

Cystopus, 268

Cytisus Adami, 256; C. Alschingeri, 31; C. Laburnum, 31, 256; C. purpureus, $256 ; C$. scoparius, 31

Czapek, 195

Czartkowski, 382, 622

Dactylis, 27

Daffodil, 13, 122

Dahlia, 146, 149, 223, 224, 225, 265; D. variabilis, $40,148,152,191,210,215,226$

Dalechampia, 38

Daniel, 82, 337, 344

Daphne, 154

D'Arbaumont, 35 
Datura, 180, 282 ; D. Stramonium, 147 , 156, 164, 181, 184; D. Tatula, 164, 181, 184

Daucus Carota var. Boissieri Schweinfurth, 155

Davallia, 17

Davis, $156,172,592,604$

Decortication and anthocyanin, 4, 82

Delphinidin, 219, 221 ; in colour varieties, 224

Delphinin, 78, 79, 219, 220

Delphinium, 13, 26, 31, 40, 56, 58, 76, 80, 110,234 ; colour varieties, 223,224 ; constitution of pigment, 78 ; preparation of pigment, $219 ; \quad D$. Ajacis, 147, 155, 191, 192; D. Consolida, 191, 192; D. Consolida striatum plenum, 192; D. elatum, 31; D. formosum, 31; D. tricolor, $31 ; D$. tricorne, 284

Dendrobium, 41, 156, 165; D. chrysanthum, $32 ;$ D. tirsiflorum, 38

Dennert, 30, 32, 39, 40, 14

Dentaria, 28

Deutzia, 36 ; D. gracilis, 101

Devaux, 28, 89, 308

Dezani, 214

Dianthus, 33, 38, 42, 119; D. barbatus, $118,120,147,149,152,191,194,215$; D. Caryophyllus, $31,120,148,152,191$, 215; D. inodorus (sylvestris), 25; $D$. superbus, 283

Dicentra, 35

Dicotyledons, 30,95

Dictamnus, 147, 283

Diels, 65

Dielytra, 38

Digitalis, 43, 110, 190; D. purpurea, 2:, $84,155,156,165,180,181,283$

Dionaea, 232

Dippel, 183

Dipsaceae, 43

Dircaea, 33

Doodia, 17

Draba, 42

Dracaena, 19, 36; D. Jonghi, 30, 32

Dracocephalum, 26

Drosera, 33

Drought and anthocyanin, 24, 92

Dryobalanops, 21

Duchatre, 266

Dufour, 28, 89, 305

East, 157, 178, 179, 182, 527, 538, 553, 570

Eberhardt, 92, 347

Echeveria grandiflora, 38; E. metallica, 28

Echium, 286

Eckert, 455

Egyptian Cotton, 165

Elatine, 92

Eleocharis, 17

Elodea, 98, 127, 128; $E$. canadensis, 93, 97

Emerson, 156, 157, 483, 492, 528, 529, 554, $571,593,605,629$; beans, 174, 185, 189 ; maize, 180,182 ; striping, 193, 194, 195 , 197, 199

Emery, 91, 309

Empetrum, 36; E. nigrum, 154

Engelmann, 7, 30, 35, 56, 129, 141, 394

Epacridaceae, 43

Epacris, 38

Epidendrum, 31

Epilobium, 42; E. angustifolium, 147 ; E. montanum, $19,30,285$; $E$. parviflorum, 95, 100

Eximedium, 33

Epipactis, 41

Expiscia, 19; E. cupreata, 33

Erdmann, 51, 52, 53, 54, 618

Erica, 38; E. cinerea, 155

Ericaceae, 43, 107

Eriophorum, 28, 30

Erodium, 190; $E$. cicutarium, 188; $E$. Manescari, 31

Eryngium, 42

Erythrina, 27, 30

Erythronium, 36

Eucalyptus, 110

Eucomis, 36

Euonymus, 22; E. Europaeus, 22, 36; $E$. radicans, 99,$100 ; E$. verrucosus, 22

Eupatorium atrorubens, 43; E. Cannabinum, 95

Euphorbia, 26, 35, 42; $E$. amygdaloides, 18 ; E. Cyparissias, 100

Euphorbiaceae, 19, 42

Euphrasia, 43

Everest, 112, 113, 114, 122, 123, 245, 248, $249,250,260,261$

Ewart, 22, 107, 126, 131, 132, 136, 137, 138, $139,401,406$

Exner, 80

Fagaceae, 41

Fagopyrum, 89; F. esculentum, 90

Fagus, 24, 26, 36, 198; red-leaved, 15t; F. sylvatica, 21, 23, 154

Farsetia, 42

Festuca, 25

Ficus, $41 ; F$. indica, 27

Filarszky, 402

Filhol, 8, 10, 47, 49, 50, 58, 125, 132, 133

Filices, 127

Finlow, 156, 163, 181, 184, 572

Fintelmann, 49

Fischer, 57, 369

Fisetin, 79, 110

Fittonia, 19; F. Pearcei, 34

Flahault, 6, 288, 289, 290, 292

Flavones, $10,12,13,14,49,51,208$; colour-variation and, 207 ; constitution, 109 ; distribution, 110,111 : origin of anthocyanin from, by oxidation, 112, 114,115 ; by reduction, 121, 122, 123, 124,125 : properties of, 111 ; synthesis of, 111,208

Flax, 141, see Linum 
Flesch, 29, 159

Fletcher, 156, 508

Focke, 126, 423, 446, 451, 509

Formánek, 56, 186

Forsythia, 43; F. viridissima, 85

Fragaria, 27, 89, $155 ; F$. vesca, 154

Franck, 104, 117

Fraustadt, 37

Fraxinus, 26, 135; $F$. excelsior, 21

Freesia, 153

Fremy, 8, 44, 47, 126

Friedel, 383

Fritillaria, 95, 147

Fritsch, 31, 32, 94

Fruit, anthocyanin in, 27

Fuchsia, 42, 92; F. triphylla, 33

Fumariaceae, 234

Fungi, 24, 35, 83

Gain, 322

Galanthus, 17

Galeopsis, 83

Galium, 155, 285; G. Aparine, 22; $G$. silvestre, 285

Garcinia, 33

Gardiner, 158

Garjeanne, 19, 74

Gärtner, 430

Gates, 156, 171, 181, 539, 555, 573, 606

Gaucher, 35

Gaura, 36, 42

Gautier, 9, 24, 46, 58, 60, 61, 80, 82, 84, $106,149,175,221,358$

Gawalowsky, 556

Genau, 340

Genista, 110

Gentiana, 38; G. acaulis, 33; G. alba, 34; G. Oliveri, 33; G. punctata, 188

Gentianaceae, 43

Geraniaceae, 42

Geranium molle, 28; G. pratense, 191, 194: G. Robertianum, $18,30,153$; $G$. sanguineum, $33,118,119,147$

Gertz, 3, 17, 84, 19, 105, 106, 384, 386, 387 ; anthocyanin, and sugar-feeding, 4, 98, 100,101 ; effect of light on, 88,89 ; in Arctic plants, 26; in cell, 29, 34; in cell-wall, 30 ; in leaves, 36 ; in Natural Orders, 41; in roots, 28; 'Rübenroth' group of, 52 ; solid, $32,33,35$

Gesneria, 27; G. caracasana, 32 ; G. cinaberina, 19, 20; G. Donkelaari, 36; G. fulgens, 33

Gesneriaceae, 43, 135

Geum, 31, 156, 165; G. coccineum, 39; G. rivale, 84

Gierke, 29

Gilia, 282; G. tricolor, 32

Gillot, 155, 457, 462

Glan, 58, 62, 80, 176

Glaucium, 234; G. fulvum, 31; G. luteum, 282

Gleditschia, 42
Glénard, 8, 58, 59, 80, 129, 130

Glucosides, $4,5,46,83,85,101$; anthocyanin formation and, 112, 113, 114, 116, 117; in pigment formation, 115; of flavones, 112; of respiration pigments, 109

Glycyrrhiza, 42

Gmelin, 105, 137

Godetia, 42, 282

Goff, 205, 444

Goiran, 101, 310

Goodia, 30

Goodyera, 41

Goppelsroeder, 188

Gossypium, 156, 165, 180, 181, 183, 184, 188,190

Grafe, 9, 45, 46, 47, 50, 56, 58, 80, 197 , 209, 222; Althaea pigment, 63; Pelar. gonium pigment, 55,66

Graminaceae, 26, 98

Gramineae, 41

Granier, 364

Grape, $13,53,54,56,58,84,88,247,250$, $251,253,254,255$; isolation of pigment, $60,77,219$

Gregory, 149, 152, 153, 154, 157, 175, 182 , $184,187,189,197,510,557,558$, 607

Grew, 2, 47, 104, 203, 1

Griffiths, 46, 58, 63, 80, 191

Griffon, 35, 331

Guibourt, 22

Guilliermond, 623, 624, 630

Guinier, 155, 456

Gunn, 75

Gunnera, 28

Guttenburg, 83, 353

Gymnocladus, 42

Gymnosperms, 17, 24

Gynura, 43

Gypsophylla, 25, 282

Haas, 20

Haberlandt, 60, 283

Haden, 223

Haemaria, 41

Haematoxylon, 21, 110

Haemodoraceae, 27

Haig-Thomas, 156, 171, 594

Hall, 251

Hallier, 89, 272

Hallquist, 156,631

Halophytes, anthocyanin in, 26, 92

Hanzusek, 96

Hansen, 44, 47, 11, 98

Hansgirg, 410

Hartig, 29, 32, 35, 83, 87

Hassack, 19, 20, 30, 35, 129, 393

Hasslinger, 469

Haverland, $\mathbf{1 7 7}$

Hayes, 157, 179, 182, 553

Hazel, red-leaved, 136, 141, 198

Hebeclinium, 43 
Heckel, 84, 300

Hedera, 6, 36, 86; H. Helix, 95

Hedrick, 574

Hedysarum, 31

Heim, 318

Heinricher, 50

Heinsius, 126, 132, 416, 615

Heise, 9, 46, 58, 60, 62, 80, 167, 178

Helianthemum, 150, 153

Helianthus, 89, 153, 156, 167, 180, 183, $260 ; H$. annuus, 150, 166, 181; $H$. tuberosus, 268

Helichrysum, 191

Helleborus multifidus, 33; H. niger, 38

Helobiae, 41

Hepatica, 156, 194; H. triloba, 18

Heribert-Nilsson, $156,157,575,576,632$

Hering, 30

Herniaria, 17

Hesperis, 191, 194

Heterozygous forms, anthocyanin in, 183185,209

Hibbert, 71

Hibiscus, 38, 110

Hieracium, 89, 156 ; H. tenuifolium, 18

Hieronymus, 83,314

Higginsia, 36

Hildebrand, 27, 30, 31, 32, 38, 39, 156, 191, $10,30,44,458,466,473,530$

Hilger, 150, 156

Hill, A. W., 148, 151, 577

Hill, T. G., 20

Hoffmann, $200,431,432,433,434,435,436$, $437,438,440,441,442,443,445,447$

Holcus, 41

Holdefleiss, 595

Hollyhock, 13, 219, see Althaea

Homalomena, 30

Honing, 156, 163, 608, 633

Hooker, 155

Hopkirk, 204, 217, 428

Hordeum, 156, 167

Horse Chestnut, 249, see Aesculus

Hortensia, 200, 202

Howard, 19, 29

Hoya, 32, 33

Hryniewiecki, $\mathbf{4 1 7}$

Hünefeld, 55, 119, 120

Hurst, 156, 163, 164, 165, 172, 188, 502, $531,540,596$

Husemann, 156

Hutchinsia, 128

Hyacinthus, 5, 88, 148, 194, 217; $H$. orientalis, $32,38,151,152$

Hydrangea, 31, 200, 202, 203, 217, 282, 292

Hydrilla, 97, 100; $H$. verticillata, 96

Hydrocharis, 4, 6, 19, 41, 86, 87, 93, 94, 97, 100

Hydrocharitaceae, 96

Hyoscyamus, 156; H. niger, 32

Hypericaceae, 42

Hypericum, 27
Hypochaeris, 135

Ichimura, 31, 192, 612

Ilex, 95

Impatiens, 127, 281; I. Balsamina, 191; I. glanduligera, 33

Indian Cotton, 166, 181, 184, 188, see Gossypium

Indican, 115

Indigofera, 42, 110

Indimulsin, 115

Inhibiting factor, 152, 153, 154; chemical interpretation of, 216

Injury, anthocyanin as result of, $4,17,24$, 82,83

Insolation, effect of, on colour, 203-204

Iresine, 19; I. Herbstii, 36; I. Lindeni, 52

Iris, $5,88,89,119,287 ; \quad$. foetidissima, 155 ; I. hybrida, 32; I. pumila, 30, 88; I. xiphioides, 192

Irmisch, 27, 27

Iron salts, reaction of anthocyanin with, 54

Isoloma, 33

Isomer, of anthocyanin, 47, 53, 72, 76

Jackson, 471

Jacobasch, 453

Jacquinia, 30

Jaennicke, 31

Jäger, 448

Jasione, 153, 285

Jasminum, 43

Johannsen, 343

Johow, 22, 45, 392

Jonas, 166

Jones, 117, 119, 120, 121, 122, 123, 156 , $165,181,188,237,238,239,240,542$, 578

Jonesia, 22

Juglans, 24, 35; J. macrocarpa, 33; J. regia, 21,33

Jumelle, 370,396

Juncaceae, 41

Juncus castaneus, 25; J. Jacquinii, 25; J. trifidus, 25

Juniperus, 22

Jussieua, 42

Justicia formosa, $34 ; J$. speciosa, 32

Kajanus, $151,156,157,162,163,179,181$, $559,560,579,580,581,597,598,625$ Kampherol, 79, 110

Karzel, 359

Kastle, 55, 196, 223

Katić, 4, 58,91, 96, 97, 98, 100, 117, 354

Keeble, 11, 12, 13, 14, 16, 21, 22, 125, 156, $157,229,230,231,239,240,251,403$, $407,541,542,582$; anthocyanin and oxidases, $117,118,119,120,125,212$; anthocyanin in alcohol, 47, 120; artificial anthocyanin, 122, 123; Digitalis, 165, 181, 188; physiological significance 
of anthocyanin, 126, 130, 131, 136; Primula, 176, 177, 178, 182, 212

Keegan, 185, 348

Kerner, 28, 398, 452; anthocyanin, autumnal, 22; in Alpine plants, 25, 102 ; in leaves, 18; physiological function of, $126,128,129,133,134,141$

Killby, 174, 209

Klebs, 6, 85, 87, 349, 360, 361

Klein, 39

Kniphofia, 17

Knuth, 7, 126, 426

Kny, 126, 130, 133, 32, 55, 397

Kohlrabi, 123

Koning, 126, 132, 416

Körnicke, 454

Koschewnikow, 38, 40

Kostanecki, 15, 109

Kraemer, 202, 193, 503

Kraus, 30

Kraus, C., 143, 276, 277, 281, 301

Kraus, G., 82, 311

Kroemer, 32, 102

Kronfeld, 59

Kuhlmann, 55, 118

Kuntze, 422

Küstenmacher, 83, 326

Küster, $82,83,350$

Labiatae, 19, 38, 43, 107

Laborde, 106, 107, 199, 200, 201

Lachenmeyer, 200, 429

Lacour, 170

Lactuca muralis, 19; L. sativa, 154, 296

Laelia, 41; L. Perrinii, 31, 32

Lamium, 36; L. purpureum, 38, 155

Landel, 323

Laportea, 240

Larix, 17

Larkspur, 192, see Delphinium

Laserpitium, 25

Lathraea, 28; L. squamaria, 28

Lathyrus, 9, 10, 12, 56, 161, 171, 182, 184; $L$. heterophyllus, $31 ; L$. odoratus, 156 , 180, 181, 183, 198; colour-inheritance, 167; colour-varieties, 151,152 ; interpretation of colour-factors, 207, 211, 212, 217; oxidases, 118, 119; reduplication, 186 ; L. silvestris, 31

Laurent, 88, 315

Laurus, 35

Lavatera, 147

Lavdowsky, 29, 160

Lead acetate, reaction of anthocyanin with, $48,51,69$

Leake, 156, 166, 181, 184, 185, 188, 561

Leaves, anthocyanin in, 18 et seq. ; localisa. tion of, 36,37

Leguminosae, 21, 27, 42, 163

Leitgeb, 27

Lemna, 135; L. minor, 94 ; L. polyrrhiza, 19; L. trisulca, 94

Lemnaceae, 41
Lengerken, 32

Lentibulariaceae, 43

Leontodon, 43

Lepeirosia, 27

Lepel, von, 56, 151

Leucanthemum, 26

Leucojum, 17

Levi-Morenos, 52, 58

Libanotis, 25, 26

Lidforss, 86, 174

Lierau, 27, 51

Light, as stimulus reaction, 90: effect of, on colour, in flowers, 88 ; in fruits, 88 ; in leaves, 89 ; in roots, 89

Ligustrum, 6, 27, 86; L. vulgare, 24, 95, 121

Lilac, 261, 270

Liliaceae, 19, 41

Litium candidum, 22; L. Martagon, 30, 94

Lily of Valley, 123

Limodorum, 41

Limosella, 43

Linaceae, 42

Linaria, 43; L. alpina, 147, 156, 168; L. Cymbalaria, 147

Lindinger, 27, 41, 76

Lindman, 511

Lindt, 163

Linsbauer, 82, 90, 341, 371, 411

Linum, 134, 135, 141, 282; L. usitatissi. mum, 129, 156, 168, 184

Lister, 109

Liverworts, 279

Lobelia, 147

Localisation of anthocyanin, in leaves, 35, 36,37 ; in Natural Orders, 41 et seq.; in stems, 38

Lock, 156, 157, 172, 173, 493, 504, 512, 518, 532, 583; Canavalia, 163; Nico. tiana, 171; Pisum, 147, 174, 182, 189; Zea, 179

Lonicera, 27; L. brachypoda, 99, 100

Lotus, 25

Lourea, 42

Lowe, 19, 29

Löwschin, 626

Lüdi, 83,342

Ludwig, 424, 425

Lupinus, 42; L. grandiflorus, $34 ; L$. perennis, 34 ; L. polyphyllus, 34

Luteolin, 50, 79, 160, 207

Lychnis, 282; L. coronaria, $120 ; L$. dioica, 156,168 ; L. Flos-cuculi, 155; L. vesper. tina, 168; L. Viscaria, 26

Lycopersicum, 27

Lycopus, 43

Lycoris, 202

Lythraceae, 42

Macaire-Princep, 89, 104, 106, 3

Macchiati, 171, 409, 427

Mac-Dougal, 404

Maclurin, 79 
Macroplectrum, 30

Magnolia, 38; M. acuminata, 101

Mahonia, 6, 24, 86; M. aquifolium, 82, 91 95

Maize, 179, 180, 194, 284, 300, see Zea

Malcomia, 42

Mallison, 76, 218, 257, 638, 639

Mallotus, 36

Mallow, 13, 58, 219, see Malva

Malope, 147

Malpighi, 21

Mlalte, 31

Malva, 36, 76, 78, 80; M. moschata, 147, 155; M. rotundifolia, $33 ; M$. sylvestris, $219,224,225 ;$ M. tinctoria, $296^{\circ}$

Malvaceae, 42

Malvezin, 202

Malvidin, 79, 219, 220

Malvin, 78, 219, 220

MLaranta, 19, 36

Marantaceae, 19, 20, 135

Marquart, $1,44,87,105,106,5$

Marquis, 161, 162

Marryat, 149, 156, 170, 185, 192, 533

Martens, 9, 127

Martin, 76, 218, 219, 306, 640

Massalongo, 319

Massart, 36, 70

Matricaria, 43

Matthaei, 139

Matthiola, 9, 10, 12, 156, 161, 171, 184, 191; colour-inheritance, 169 ; colour-varieties, 147, 151, 152; hoariness, 206; interpretation of colour-factors, 211, 212; oxidases, 120

Maumené, 157

Maxillaria Henchmanni, 32; M. tenuifolia, 32

Medicago, 42; M. maculata, 19; M. sativa, 31

Meehan, 41, 296, 463

Melampyrum, 43

Melandri, 111

Melandrium album, 169; M. rubrum, 169

Melastomaceae, 20, 135

Melica, 41 ; M. nutans, 32

Menyanthes, 43

Mer, 31, 91, 284, 286

Mesembryanthemum, 52

Mesua, 139

Meyen, 6, 23

Microstylis, 41

Middendorff, 265

Mieg, 76, 218, 219, 641, 642

Milium, 25

Mimosa, 42; M. pudica, 137

Mimulus, 190; M. quinquevulnerus, 188

Mirabilis, 197, 209, 217; M. Jalapa, 40, $149,156,170,185,191,192$

Mirande, $4,28,58,83,85,89,91,101,106$, $332,362,365$

Miyoshi, 25, 92, 202, 187, 375

Möbius, 27, 28, 30, 39, 68
Hogiphanes, 52

Mohl, von, 31, 32, 104, 105, 7, 8, 84

Molecular weight of anthocyanin, 71

Molinia, 26

Molisch, 29, 31, 32, 45, 66, 92, 115, 104, $168,241,316,467$; colour in Hydrangea, 200, 201, 202, 203; crystalline antho cyanin, $34,35,46$

Molliard, 117, 366, 376

Monocotyledons, 30, 95

Montemartini, 408

Moraceae, 41

Morot, 8, 47, 58, 59, 80, 122

Morren, 35, 89, 26

Morris, 132

Morus, 24; MI. tinctoria, 79

Mulder, 128

Müller, L., 32, 38, 61

Müller, N. J. C., 45, 56, 169

Müller-Thurgau, 86, 88, 116, 298

Multiplicity of anthocyanin pigments, 44, 45

Musa, 137; M. zebrina van Houtle, 20

Muscari, 38

Musci, 127

Myosotis, 215, 282, 287; M. sylvatica, 147

Myrica, 26, 110; M. Gale, 33

Myricetin, 79, 110

Myrtaceae, 42

Myrtillidin, 79, 221

Myrtillin, from Bilberry, 77, 219; from Hollyhock, 78, 219

Myrtillus, 29

Nagai, 634

Nägeli, 30, 31, 32, 35, 50, 85, 90, 138

Najus major, 94; N. minor, 94

Narcissus, 17; N. incomparabilis, 121

Naylor, 194

Nemesia, 43

Nemophila, 32; N. insignis, 191

Nepenthes, 135; N. Hookeriana, 33

Neptunia, 31

Newbigin, 15, 16

Newell, 459

Nicklès, 131

Nicolas, 616

Nicotiana, 156, 171

Nidularium, 19; N. Cervantesi, 33

Nienhaus, 324

Nierènstein, 224, 232

Nivière, 181

Nohara, 156, 172, 635

Nolan, 76, 218, 222, 643, 644

Noll, 320

Nyctaginaceae, 41, 52

Nymphaea, 135; N.Lotus, $19 ; N$.thermalis, 19

Oats, 'Crown' variety of, 153

Odontites, 36,43

Oenidin, 79, 219, 220

Oenin, 77, 221 
Oenoline, 59

Oenothera, 24, 36, 42, 82, 156, 180, 181, 183 ; O.biennis, $172 ; 0$. franciscana, 172; O. grandiflora, 171,$172 ; 0$. Lamarckiana, $91,171,182 ;$ O. rubricalyx, 171, 181 ; O. rubrinervis, 171

Oenotheraceae, 36, 42

Oleaceae, 43

Oliver, 398

Oncidium, 32, 41; O. sphacelatum, 31, 33 Onobrychis, 42

Ononis arvensis, 155 ; 0 . natrix, 31

Oplismenus, 41, O. imbecillis, 98, 100

Opuntia, 102; O. leucotricha, 89; $O$. robusta, 89

Orange, 27, 123, 153

Orchidaceae, 20, 27, 41, 135

Orchis, 36, 41; O. latifolia, 89, 135; 0 . maculata, 19, 135; O. mascula, 31, 285

Ornithogalum, 17

Orobanchaceae, 43

Orobanche, 28

Osmunda, 17

Ostenfeld, 156, 505, 543

Ostrya, 135

Overton, 4, 6, 23, 30, 45, 50, 58, 106, 333 , 334; anthocyanin and temperature, 86 , 87 ; sugar-feeding, $93,94,95,96,98$, 100,101

Oxalis, 156; O. corniculata, 172; O. Ortgiesii, 30

Oxidases, and anthocyanin, 11, 91, 117; relative distribution of, 118, 119: colour-factors and, 212; direct and indirect, 107, 108; distribution of, 107

Oxonium salts of anthocyanin, $13,53,75,76$

Oxybaphus, 52

Oxybenzoic acids, 78, 111, 208, 226

Oxygen and anthocyanin, in gascous exchange, 91, 117

Paasche, 81

Paeonia, 222, 223, 225, 247; $P$. coriacea, 42

Paconidin, 221, 222

Paconin, 221, 222

Palladin, 11, 58, 91, 99, 101, 107, 108, $109,116,121,203,210$

Pammel, 450

Panicum, 41; $P$. variegatum, 92

Pansy, 150, see Viola

Papaver, 31, 39, 49, 50, 56, 88, 127, 190, $191,282,283,288 ; P$. alpinum, 283; $P$. nudicaule, 191; $P$. orientale, 189 ; $P$. Rhoeas, $156,172,189 ; P$. somniferum, $156,172,189,283$

Papaveraceae, 42

Paphiopedilum, 156, 164, 188

Papilionaceae, 38

Parasites, anthocyanin in, 28, 85

Parietaria, 27

Parkin, 3, 37, 89, 116, 77
Parsley; 12

Passiflora acerifolia, 32; $P$. alata, 32; $P$. laciniata, $32 ; P$. limbata, $32 ; P$. suberosa, 32

Pattern in colour variation, 188-190

Paulownia, 33

Payen, 8, 114, 115

Pea, Sweet, 9, 188, 206, see Lathyrus

Peach, 205

Peche, 242

Pedicularis, 43; $P$. incarnata, 25; $P$. recutita, $25 ; P$. rostrata, $25 ; P$. sylvatica, 155

Peireskia, 92

Pelargonidin, 78, 79, 219, 221 ; in colourvarieties, 223 ; synthesis of, 222

Pelargonin, 78, 219, 221

Pelargonium, 9, 13, 24, 46, 49, 50, 58, 80, $82,92,100,123,222,286$; colour varieties, 223, 224; preparation of pigment, $63,66,76,218$; properties of pigment, $55,56,78 ; P$. altum, 198; $P$. 'Don Juan,' 198; P. Odier hortorum, 31 ; $P$. peltatum, 134, 223, 224, 225; $P$.zonale, $31,33,45,96,223,225,270$

Pellaea, 17

Pellagri, 54, 146

Pellat, 291

Pellew, 156, 157, 165, 176, 177, 178, 181, 182, 188, 541, 542

Pellionia, 36

Peltaria, 18

Pennisetum, 41

Pentstemon, 43

Peplis, 92

Perilla, 154, 248

Perkin, 10, 109

Pethybridge, 19, 78

Petioles, anthocyanin in, 21

Petunia, 191

Pfeffer, 29, 107

Phajus, 116

Phalaenopsis, 41

Phalaris, 89, 100; P. arundinacea picta, 263

Phanerogams, 127

Pharus, 41

Phaseolus, 27, 39, 153, 154, 185, 189, 190 ; $P$. multiflorus, $46,156,172 ; P$.vulgaris, 156

Philadelphus, 36; P. coronarius, 49

Phleum, 26, 41

Phloroglucin, 78, 110, 111, 208

Phlox decussata, 203; P. Drummondii, 111 , $119,148,149,151,152,209$

Phormium, 30

Photinia, 42

Photosynthesis and anthocyanin, 81, 86, 116

Phragmites, 28

Phrynium, 33

Physiological function of anthocyanin, 7, 126 et ser. 
Phyteuma, 156; P. Halleri, 174; $P$. spicatum, 135, 174, 283

Phytolacca, 52, 100, 246, 249

Phytolaccaceae, 9, 47, 51, 52

Picea, 17

Pick, 21, 35, 126, 128, 131, 132, 134, 391

Pillsbury, 464

Pilosella, 89

Pim, 32, 95

Pimenta, 239

Pimpinella, 25

Pinguicula, 43

Pink, 56, 123, 217, see Dianthus

Pinus, 17; P. excelsa, 83

Piperaceae, 20, 41

Pirotta, 28, 42

Pistacia, 42

Pistia, 94

$P$ isum, 27, 153, 154, 183, 189, 190; $P$. sativum, 101, 157, 180, 182; colourinheritance in, 174; colour-varieties of, 147; oxidases in, 118, 119

Pitlosporum, 97

Plantaginaceae, 43

Plantago, 82; P. major, 28, 99, 100, 154

Platanus, 135

Plumbago, 120

Poa annua, 25; P. nemoralis, 25, 28

Podalyrieae, 27

Pogonia, 41; P. crispa, 20

Poinseltia, 26

Polemonium, 157; $P$. caeruleum, 147, 174; $P$. flavum, 174

Politis, 225

Pollacci, 3, 32, 35, 36, 35, 91, 17, 614

Pollen, anthocyanin in, 27

Polyanthus, 13, 122

Polygala, 153, 155

Polygalaceae, 42

Polygonaceae, 41, 52

Polygonum, 89, 110; P. Persicaria, 19, 33,$135 ; P$. tartaricum, 89

Pontederia, 30

Pontederiaceae, 27

Populus, 24, 26, 36, 84, 110, 135; $P$. alba, 23; $P$. nigra, 23; $P$. tremula, 23

Portheim, 46, 204

Portulaca, 40, 52, 191

Portulacaceae, 9, 41, 52

Potamogeton, 17; $P$. pectinatus, $94 ; P$. perfoliatus, 94; $P$. pusillus, 94

Potato, 123, see Solanum

Potentilla anserina, 28; $P$. thuringiaca, 33 ; P. Tiroliensis, 26

Poterium, 135

Potonié, 27, 56

Praeger, 460

Prehn, 465

Prenanthes, 95

Preyer, 27, 30, 41, 66

Prillieux, 116

Primula, 6, 11, 12, 119, 282, 287; P.acaulis, 153,$293 ; P$. sinensis, 32, 33, 87, 122,
157, 293; colour in vegetative parts, $180,182,183$; colour-varieties, 148, 149 , $151,152,153,154,184,215$; inheritance of colour, 175; oxidases, 118, 212; pattern, 189, 190; reduplication, 187; striping, 191, 192, 197; $P$. veris, 153, 154 Primulaceae, 43

Pringsheim, 7, 127, 130

Prunella, 5, 88; $P$. vulgaris, 43

Prunus, 23, 26, 27, 36, 110;P. Avium, 282 ; P. Chamaecerasus, 22; P. Padus, 23, 89; P. Pissardi, 82; P. spinosa, 22

Puccinia, 24, 83

Pulmonaria, 5, 88

Punnett, 9, 152, 156, 167, 185, 188, 487, $496,500,516,549,550,584,599$

Pynaert, 295

Pyrus, 23, 27, 42; P. communis, 31

Quercetin, 79, 110

Quercus, 24, 35, 36, 41, 110; Q. coccinea, 24; Q. heterophylla, 233; Q. macrocarpa, 33,$36 ; Q$. palustris, 30; Q. Robur, 21,23 ; Q. rubra, 24, 33, 36, 132

Radish, 56, 194, 254

Rafarin, 278

Ranunculaceae, 42, 155

Ranunculus, 217; R. acris, 135

Raphanus, 283; R. sativus, 27

Ráthay, 321

Rathborie, 335

Ravaz, 84, 355, 380

Rawson, 203, 204, 519, 600, 636

Red-leaved varieties, 26, 154

Reduction of anthoeyanin, 55

Reduplication series, colour in, 185-188

Reinke, 7, 127, 129, 136

Reseda, 110, 157; R. lutea, 17; R. odorata, 17,178

Respiration pigments, 11, 107, 108, 121; and anthocyanin, 109

Restrepia, 32, 41

Reversible reactions, 210 ; colour-factors and, 211

Reversion, to type-colour, 9

Rhamnus, 110

Rheum, 24, 82, 89; rugosum, 33

Rhinanthus, 43

Rhododendron, 38

Rhodotypos, 83

Rhus, 22, 36, 42, 110; R. Coriaria, 89; R. typhina, 33,52

Ribes, $27,35,42,198$; $R$. grossularia, 153 ; R. petraeum, 33 ; R. rubrum, $154 ; R$. sanguineum, 197

Riccia, 232

Rice, 'Crown' variety of, 153

Richter, 367

Ricinus, 26, 42, 131, 132

Robinet, 22

Robinia, 110; R. Pseudacacia, 83, 153; R. viscosa, 33 


\section{Rodrigue, 69}

Roos, 355

Roots, anthocyanin in, 27

Rosa $, 21,88,89,123,127,151,226$. autumnal coloration, 23; galls, 24 ; localisation of anthocyanin, 36 ; pigment, 56 ; solid pigment, 31 ; $R$. centifolia, 296; $R$. gallica, 58, 214, 223, 225; preparation of pigment, $59,76,77,80$, 218; $R$. 'Maréchal Niel,' 97

Rosaceae, 23, 42

Rosanoff, 31, 92

Rosé, 627

Rostrup, 83, 345

Roux, 8. 116

Roze, 395

'Rübenroth' group of anthocyanins, 9, 52 Rubiaceae, 43

Rubus, 21, 27, 35, 36, 89, 95; $R$. caesius, 31 ; R. corylifolius, 31 ; R. fruticosus, 91 ; $R$. glandulosus, 31 ; R. Idaeus, 33, 154; $R$. laciniatus, 31 ; R. lasiocarpus, 31

Rumex, 24, 26, 82, 89; R. Acetosella, 28,$30 ; R$. crispus, 33,$91 ; R$. domesticus, $33,99,100 ; R$.Patentia, $99 ; R$. scutatus, 135

Russell, 251

Russo, 205

Saccharum, 28

Sacher, 54, 215

Sachs, 5, 85, 88, 89, 269, 271

Sagittaria, 97

Salaman, 27, 154, 157, 178, 189, 544, 585

Salicaceae, 41

Salicornia, 26, 92

Salix, 24, 26, 28, 36, 89, 135

Salpiglossis, 150

Salvia, 26, 36; S. Horminum, 147, 157 , $178,180,182,183$; S. splendens, 32, 49, 50

Sambucus, 27, 88, 281; S. Ebulus, 43; S. nigra, $85 ;$ S. racemosa, 33,43

Saponaria, 42; S. ocymoides, 25

Saraca, 139, 140

Sarcanthus, 134

Satureja, 128, 134, 135, 141; S. hortensis, 25,26

Saunders, 9, 156, 157, 475, 487, 496, 500, $506,516,562,563,586,587,601$; Atropa, 161, 180, 183; Datura, 164, 181, 184; Digitalis, 165, 181; Linaria, 147, 168; Lychnis, 168; Matthiola, 147, 151, $152,169,206$; Salvia, 147, 178, 182

Sauromatum, 270

Savory, 129

Saxifraga, 42, 101, 128; S. cordifolia, 97; S. crassifolia, $95 ;$ S. cuneifolia, 18 ;

S. Geum, 18; S. granulata, 33; S. tridactylites, 33; S. umbrosa, 24

Saxifragaceae, $17,27,42$

Scabiosa arvensis, 234; S. succisa, 285

Schell, 28, 89, 285, 287

Schenckia, 115
Schenkling-Prévôt, 336

Schiemann, 216, 262

Schilberszky, 419

Schimper, 31, 47, 93

Schlockow, 31, 39

Schmidt, 67

Schnetzler, 152, 153, 154, 155

Scholl, 46, 204

Schönbein, 55, 123, 124

Schönn, 140

Schübler, 104, 200, 117, 429

Schulz, 613

Schunck, 299

Schwendener, 30, 50, 138

Schwertschlager, 216

Sciadocalyx, 33, 34

Scilla amoena, 38 ; S. nutans, 155, S. verna, 285

Scitamineae, 41

Scopolia, 33, 34

Scorzonera, 43

Screen-theory, 7, 127, 129, 130

Scrophularia, 33

Scrophulariaceae, 43

Secale, 36, 41, 89, 271

Sedum, $27 ; S$. acre, $26 ;$ S. album, 26 ; S. atratum, $25 ;$ S. sexangulare, 26

Seeds, anthocyanin in, 27

Sempervivum, 270; S. dichotomum, 33; S. tectorum, 134

Sempolowski, 41, 36

Senebier, 87, 88, 2

Senecio nebrodensis, 19; S. nemorensis, 19 ; S. vulgaris, 157,178

Senier, 58, 59, 80, 148

Serjania, 33

Setaria, 41

Sewell, 13

Shull, 156, 166, 169, 171, 172, 173, 174, 181 , $182,185,189,513,520,521,545,546$, 588,609

Silene, $36,88,89 ;$ S. acaulis, 42 ; $S$. Armeria, 157, 178; S. tunetana, 33

Silenoideae, 42

Sinningia atropurpurea, 19; S. purpurea, 36

Sium, 99, 100

Smith, A. M., 7, 22, 131, 139, 140, 420

Smith, F. G., 20, 412

Smithson, 44, 112

Snapdragon, 204, see Antirrhinum

Sodium bisulphite, bleaching of anthocyanin by, 55 ; compounds with anthocyanin, 65,67

Soil, effect of, on colour variation, 200 ; in Hydrangea, 200-203

Solanaceae, 43

Solanum, 27; S. americanum, 32, 35; S. Dulcamara, 33; S. etuberosum, 178; S. guincense, 32; S. Melongena, 32 ; S. nigrum, $32,154,157,268$; S. tubero. sum, $27,89,154,157,178,179,189,268$; S. verrucosum, 179 
Soldanella, 18

Solid anthocyanin, 30; obtained in cell by reagents, 33,34

Solidago, 38,43

Sorauer, 31, 83, 304, 351, 356

Sorby, 56, 88, 139, 144, 206, 302

Sorghum, 30

Sostegni, 182, 190

Spectrum of anthocyanin, 7, 56; and protection of chlorophyll, 129

Spiess, 35, 103

Spillman, 174

Spiraea, 24, 36, 82, 117; S. prunifolia, 91

Spots of anthocyanin, on flowers, 39 ; on leaves, 19 ; on seeds, 39

Stachys, 28

Stahl, 7, 20, 21, 22, 35, 126, 131, 132, 133, $134-136,137,138,139,140,141,62,405$

Staining with anthocyanin, 29 ; of cellwall, 30 ; of protoplasm, 29

Stellaria, 36

Stems, anthocyanin in, 38

Stock, 194, 206, see Matthiola

Strasburger, 46

Strelitzia, 31, 234

Striping, 190; bud-variation and, 197; chemical interpretation of, 216 ; inheritance of, 192-197

Strobilanthes, 252; S. Dürianus, 34; S. Sabinianus, 34

Suaeda, 26, 92

Sudborough, 71

Sugar, anthocyanin and, 4, 85, 86, 101, 116, 117; flavones and, 111

Sugar-feeding, and anthocyanin, 4; Gertz on, 98; in flowers, 101; Katić on, 96 ; localisation of pigment in, 100 ; Overton on, 93

Sunflower, 184

Suzuki, 363

Swainsonia, 120

Sweet William, 120, see Dianthus

Swertia, 32

Symphytum, 43; S. officinale, 155

Synthetic products, anthocyanin and, 82, 83,84 ; lack of, 85

Syringa, 43

Tagetes, 191, 192; T. signata, 39

Tait, 29

Taliew, 478

Tammes, 116, 156, 168, 184, 564, 610

Tannin, anthocyanin and, $34,35,50,60$; origin of anthocyanin from, 106

Taraxacum, 36, 43; T. officinale, 25, 95

Tassi, 30

Temperature, anthocyanin and, 5, 6, 24, 86,87 ; in leaves, $7,134,139-140$

Terminalia, 92

Terreil, 164

Tetragonia crystallina, 52; T. expansa, 154

Tetranychus, 272

Theaceae, 42
Theobroma, 140

Thoday, 15l, 156, 168, 547

Thomas, Fr., 413, 415

Thomas, S. B., 306

Thunbergia, 32

Tieghem, van, 27, 33

Tilia, 84, 89; T. europaea, 21

Tiliaceae, 42

Tillaea, 92

Tillandsia, 19; T. amoena, 30; T. diantoidea, 30

Timpe, 338

Toni, de, 198

Tischler, 418

Tradescantia, 92, 100; T. discolor, 19, 32 , 33; T. Loekensis, 99; T. virginica, 204; T. zebrina, 20,28

Tragopogon, 43

Translocation, and anthocyanin, 5, 6, 83 , 102,103 ; protection of, by anthocyanin, $128,131,132$

Transpiration, accelerated by anthocyanin, 133; in tropics, 135

Trapa bicornis, 33; T. natans, 33

Trécul, 31, 32, 89

Treviranus, 267

Trifolium, 42, 151, 154, 157, 179; $T$. pratense, $27,30,285$

Triticum, 41

Tropaeolaceae, 42

Tropaeolum, 38, 88, 146, 157, 190, 203 ; T. majus, $39,40,101,150,189$

Trow, 157, 178, 187, 589

Tschermak, 156, 157, 170, 173, 174, 189 ; $479,484,494,590$

Tschirch, $30,32,100$

Tswett, 120, 122, 123, 243, 252

Tubeuf, von, 83,329

Tulipa, 5, 38, 87, 88, 89, 103, 191, 192, $217,238,287 ; \quad T$. Gesneriana, 88; T. Greigi, 134

Turritis, 18

Tussilago, 83; Farfara, 24, 100

Ullon, 39

Ulmus, 135; U. campestris, 21; $U$ montana, 33

Umbelliferae, 21, 25, 27, 42, 107

Uncaria, 137

Unger, 32, 86

Utricularia Bremii, 94 ; U. minor, 94; $U$. vulgaris, 94

Vaccinium, 27; V. Myrtillus, 76, 77, 80; 219,$224 ; \quad V . V i t i s-i d a e a, 80,218,223$

Valeriana montata, 19; V. tripterie, 19

Valerianaceae, 43

Vallisneria, 41; V. spiralis, 93, 98

Vanda, 38

Variation, loss of factors and, 209

Veitch, 63

Verbascum, 43

Verbena, 191 
Veronica, 36, 43, 179, 198; V. Beccabunga, 155 ; V.Chamaedrys, 97, 155; V. longifolia, 157, 197, 198; V. officinalis, 155; V. spicata, 155

Vervain, 49

Vesque, 30

Viburnum, 22, 27, 36, 281; $V$. Lantana, 24,$89 ; \quad V$. Opulus, 24, 49, 89, 101 ; V. Tinus, 32,33

Vicia, 36; V. Cracca, 25; V. Faba, 39; $V$. sepium, 25, 285

Victoria, 19

Vigour, colour variation and, 204

Villarsia, 135; V. nymphoides, 19

Vilmorin, 191

Vinca, 147, 153, 194

Vine, 9, 24, 46, 58, 60, 6], 84, 121

Viola, 28, 110; V. cornuta, 157, 179 ; V. lutea, 200; V. odorata, 147; V. tri. color. 32,150

Violaceae, 42

Viscaria, 89; V. viscosa, 33

Viski, 617

Vitaceae, 20, 42

Vitis, 22, 27, 31, 36, 52; V. alexandrina, 36 ; V. Labrusca, $36 ; \quad V$. vinifera, 76,80 , 154,224

Vöchting, 85, 325

Voight, 89, 264

Vouk, 202, 203, 522

Vries, de, 29, 153, 154, 156, 157, 161, 165, $169,178,179,141,165,474,498,565$; Antirrlinum, 157, 159; bud-variation, 197; Coreopsis, 164, 184; Papaver, 172; pattern, 188, 189; red varieties, 153; striping, 191, 192, 193, 194, 197

Vriesia, 19

Waage, 172

Wachendorfia, 27

Wallflower, 13, sec Cheiranthus

Wallin, 35, 101

Warming, 92, 327, 343, 346

Webster, 449

Weevers, 22, 421

Wehrli, 399

Weigert, 9, 45, 51, 52, 54, 179

Weingaertneria, 41

"Weinroth" group of anthocyanins, 9, 51

Weiss, 30, 31, 32, 156, 157, 91, 534, 566
Wellington, 574

Weretennikow, 89, 273

Wheat, 24

Wheldale, $10,11,12,15,16,58,80,122$ $156,211,212,213,217,224,226,244,253$. $254,255,263,514,535,548,621$; anthocyanin, alkali reactions, 51; artificial, 124; formation of, 101, 109, 112, 113, 114,224 ; in alcohol, 56, 120; oxidases and, 91, 212: Antirrhinum, colourvarieties, 148, 152, 180, 185, 188; inheritance of colour, 158, 159, 160; preparation of pigments, 69 ; properties of pigments, $46,50,122$; striping, 197 : flower-pigments, 39, 56: oxidases, 108, 212

Wied, 270

Wiesner, 8, 45, 50, 126, 130, 135, 142, 275, 400

Wigand, 8, 30, 44, 50, 58, 91, 106, 12, 136

Willis, 21

Willstätter, $13,16,57,58,80112,211$, $212,215,245,256,257,628,637,638,639$, $640,641,642,643,644,645$; allocyanidin, 124; anthocyanin, alkali reaction, 51, $52,53,54$; artificial, 15, 124; constitution, $45,75,78,79$; groups of, 56 ; preparation, $72,76,218,219,222$; properties, $46,47,50,56$; synthesis, 222 : colour-varieties, $214,215,216,224,225$

Wine, $8,9,52,58,59,60$

Wissemann, 227

Witt, 111, 112

Wittmack, 155, 79, 495

Wortmann, 132, 619

Wray, 108

Wulff, 26, 30, 42, 71

Xanthogène, 49, 50

Xanthosoma, 19

Zacharewicz, 357

Zea, 28, 35, 89, 157, 179, 180, 182, 183, 194-197, 199

Zechmeister, 218, 222, 628

Zerewitinoff, 71

Zimmermann, 31

Zinnia, 39, 40; Z. elegans, 150, 191

Zollinger, 76, 218, 219, 645

Zopf, 27, 35, 48, 173, 468

Numbers in heavy type denote papers in Bibliography 
Mendel's Principles of Heredity. By W. Bateson, M.A., F.R.S., V.M.H., Director of the John Innes Horticultural Institution. Third impression, with additions With 3 portraits, 6 coloured plates, and 38 figures. Royal $8 v o$. $12 \mathrm{~s}$ net.

The Methods and Scope of Genetics. An Inaugural Lecture delivered 23 October 1908 by W. Bateson, M.A., F.R.S. Crown 8vo. 1s 6d net.

The Elements of Botany. By Sir Francis Darwin, Sc.D., M.B., F.R.S., Fellow of Christ's College. Second edition. With 94 illustrations. Crown 8vo. $4 \mathrm{~s} 6 \mathrm{~d}$.

Practical Physiology of Plants. By Sir Francis Darwin, Sc.D., F.R.S., and E. Hamilton ACtoN, M.A. Third edition. With 45 illustrations. Crown 8vo. 4s $6 \mathrm{~d}$.

Botany. A Text-Book for Senior Students. By D. Thoday, M.A., Lecturer in Physiological Botany and Assistant Director of the Botanical Laboratories in the University of Manchester. With 205 figures. Large crown 8vo. 5s 6 d net.

Grasses: a Handbook for use in the Field and Laboratory. By H. Marshall Ward, Sc.D., F.R.S. With 81 figures. Crown 8vo. 6s. Cambridge Biological Series.

Trees: a Handbook of Forest Botany for the Woodlands and the Laboratory. By H. Marshall Ward, Sc.D., F.R.S. Vol. I. Buds and Twigs. Vol. II. Leaves. [Out of print.] Vol. III. Flowers and Inflorescences. Vol. IV. Fruits. Vol. V. Form and Habit, with an appendix on Seedlings. With numerous illustrations. Crown 8vo. 4s 6 d net each. Cambridge Biological Series.

A Manual and Dictionary of the Flowering Plants and Ferns. By J. C. Wrulis, M.A., Sc.D. Third edition. Crown 8 vo. 10s 6 d net.

The Classification of Flowering Plants. By AlERed BartoN Rendle, M.A., D.Sc., F.L.S. Vol. I. Gymnosperms and Monocotyledons. With 187 illustrations. Demy 8vo. 10s 6 d net.

Genera of British Plants. Arranged according to Engler's Syllabus Der Pflanzcnfamilien (Seventh edition 1912), with the addition of the Characters of the Genera. By H. G. Carter, M.B., Ch.B. Crown 8vo. 4s net.

Types of British Vegetation. By members of the Central Committee for the Survey and Study of British Vegetation. Edited by A. G. TANSLEY, M.A., F.L.S. With 36 plates and 21 figures. Crown 8 vo. 6s net.

The Vegetation of the Peak District. By C. E. Moss, B.A., D.Sc., F.R.G.S., F.L.S. With 36 illustrations and 2 coloured maps. Demy 8 vo. 12s net.

The Genus Iris. By William Rickatson Dykes. With 47 coloured drawings by F. H. Round. 1 coloured plate of seeds by Miss R. M. CARDEW, and 30 line drawings by C. W. Johnson. Demy folio. $£ 6.6 \mathrm{~s}$ net.

The Ferns of South Africa containing Descriptions and Figures of the Ferns and Fern Allies of South Africa. By Thomas R. Sim. Second edition. With 186 plates. Demy 8vo. 25s net.

Fossil Plants. A Text-Book for Students of Botany and Geology. By A. C. Seward, M.A. F.R.S., Professor of Botany in the University of Cambridge. In 3 vols. Demy 8vo. Vol. I. With a frontispiece and 111 illustrations. 10s net. Vol. II. With a frontispiece and 265 illustrations. 15s net. [Vol. III. In the press 
The Cambridge British Flora. By C. E. Moss, D.Sc., F.L.S., assisted by specialists in certain genera. Illustrated from drawings by E. W. HUNNYBUN. The work will be completed in about ten volumes. Volume II is now ready.

The styles of binding and the prices will be as follows:-

Paper boards, with canvas back and paper label, each volume in two parts, the first containing the text and the second the plates .

Quarter morocco, in two parts divided as above:

Paper boards, with canvas back and paper label, in one volume, the plates mounted on guards and bound interspersed with the text

Quarter morocco, in one volume, the plates mounted on guards and bound interspersed with the text .

$\begin{array}{ll}\begin{array}{l}\text { Published Price } \\ \text { per volume }\end{array} & \begin{array}{c}\text { Price per volume } \\ \text { to subscribers to } \\ \text { the whole work }\end{array} \\ \begin{array}{l}£ 2 \text { 10s net } \\ £ 6 \text { net }\end{array} & £ 2 \text { 5s net } \\ & £ 5 \text { s net } \\ £ 3 \text { net } & £ 215 \text { s net } \\ £ 6 \text { net } & £ 5 \text { s net }\end{array}$

Cambridge Manuals Series. Editors: P. GILES, Litt.D. and A. C. Seward, M.A., F.R.S. Royal 16mo. Cloth, 1s 3 d net each; leather, $2 \mathrm{~s} 6 \mathrm{~d}$ net each. Links with the Past in the Plant World. By A. C. SEwArd, M.A., F.R.S. With frontispiece and 20 figures.

Plant-Life on Land considered in some of its biological aspects. By F. O. Bower. With 27 figures.

Plant-Animals. By F. W. Keeble, Sc.D. With 23 figures.

Heredity in the light of recent research. By L. Doncaster, Sc.D. With 12 figures.

Journal of Genetics. A periodical for the publication of records of original research in Heredity, Variation, and allied subjects. Edited by W. BATESON, M.A., F.R.S., Director of the John Innes Horticultural Institution, and R. C. Punnetr, M.A., F.R.S., Arthur Balfour Professor of Geneties in the University of Cambridge. Issued in parts as material accumulates, a volume, consisting of 4 parts, appearing, so far as possible, annually. The subscription price, payable in advance, is 30 s net per volume (post free); separate parts $10 \mathrm{~s}$ net each.

The Journal of Ecology. Edited for the British Ecological Society by Frank Cavers. An International quarterly review of Plant and Animal Ecology and Geography, Soil Investigation, Planktonology, and Nature Protection. Published in March, June, September, and Decmber. Members of the British Ecological Society should send their annual subseription of One Guinea (which includes the supply of one copy of each of the four issues of the Journal) to the Secretary, Dr F. Cavers, Goldsmiths' College, New Cross, London, S.E. The annual subseription for non-members of the Society is 1 is net per volume (post free); single numbers, 5s net (post free).

The Annals of the Bolus Herbarium. Edited by H. H. W. PEarson, Sc.D., F.L.S., Harry Bolus Professor of Botany in the South African College, Capetown. Each volume consists of four parts, of which two will probably appear each year. The subscription price. payable in advance, is 15 s net per volume; single numbers, 5s net.

Makers of British Botany. A collection of Bingraphies by living botanists, edited by F. W. OLIVER. With frontispiece and 26 illustrations. Demy 8vo. 9s net.

Herbals. Their Origin and Evolution. A Chapter in the History of Botany, 1470-1760. By AGNes ArBer, D.Sc., F.L.S. With frontispiece, 21 plates and 113 illustrations in the text. Royal 8vo. 10s $6 \mathrm{~d}$ net.

\section{Cambridge University Press}

Fetter Lane, London: C. F. Clay, Manager 



